Thomas Fischer

Staat, Recht und

Verfassung im Denken

von Walter Eucken

$\mathrm{Zu}$ den staats- und

rechtstheoretischen Grundlagen einer wirtschaftsordnungspolitischen Konzeption 


\section{Thomas Fischer}

\section{Staat, Recht und Verfassung im Denken von Walter Eucken}

Die Soziale Marktwirtschaft in der Bundesrepublik Deutschland ist entscheidend durch die sogenannte "Freiburger Schule" initiiert und geprägt, deren geistiger Mentor und Wegbereiter unbestritten Walter Eucken war. Der Erfolg seiner wirtschaftsordnungspolitischen Konzeption ließ das Interesse an deren staatsund rechtstheoretischen Grundlagen und in diesem Zusammenhang insbesondere die Frage nach Umfang und Intensität staatlicher Mitwirkung bei der Realisierung verkehrswirtschaftlicher Prinzipien in den Hintergrund treten. Eine nach und nach aufkeimende Diskussion blieb rudimentär. Die von Walter Eucken selbst geforderte Interdependenz der Ordnungen von Wirtschaft und Staat wurde nur in singulären Aspekten thematisiert. Die vorliegende Arbeit will diese Ansätze erweitern und in einer interdisziplinären Analyse die Bedeutung von Staat, Recht und Verfassung als integrale Bestandteile der epistemologisch und ökonomisch fundierten Gesamtkonzeption Walter Euckens nachweisen.

Thomas Fischer wurde 1951 in Reutlingen geboren. Nach dem Studium der Rechtswissenschaft in Tübingen und dem juristischen Vorbereitungsdienst war er von 1979 bis 1984 als wissenschaftlicher Mitarbeiter am Institut für Rechtswissenschaft - Lehrstuhl für Öffentliches Recht - an der Universität Hohenheim beschäftigt. Seit 1985 ist er als selbständiger Rechtsanwalt niedergelassen. 
Staat, Recht und Verfassung im Denken von Walter Eucken $\mathrm{Zu}$ den staats- und rechtstheoretischen Grundlagen einer wirtschaftsordnungspolitischen Konzeption 


\section{Hohenheimer Volkswirtschaftliche Schriften}

Herausgegeben von

Prof. Dr. Cay Folkers, Prof. Dr. Joachim Genosko, Prof. Dr. Harald Hagemann, Prof. Dr. Klaus Herdzina,

Prof. Dr. Franz Mehler t, Prof. Dr. Renate Ohr, Prof. Dr. Walter Piesch, Prof. Dr. Ingo schmidt, Prof. Dr. Helmut Walter, Prof. Dr. Josua Werner

Band 16

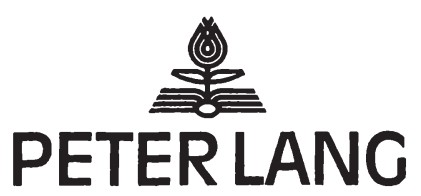

Frankfurt am Main · Berlin · Bern · New York · Parls · Wien 


\section{Thomas Fischer}

\section{Staat, Recht und Verfassung im Denken von Walter Eucken \\ Zu den staats- und rechtstheoretischen Grundlagen einer wirtschaftsordnungspolitischen Konzeption}

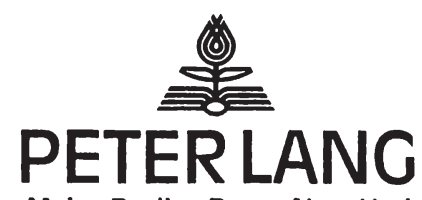

Frankfurt am Main - Berlin - Bern - New York · Paris - Wien 
Die Deutsche Bibliothek - CIP-Einheitsaufnahme

Fischer, Thomas:

Staat, Recht und Verfassung im Denken von Walter Eucken : zu den staats- und rechtstheoretischen Grundlagen einer wirtschaftspolitischen Konzeption / Thomas Fischer. -

Frankfurt am Main ; Berlin ; Bern ; New York ; Paris ; Wien : Lang, 1993

(Hohenheimer volkswirtschaftliche Schriften ; Bd. 16)

Zugl.: Hohenheim, Univ., Diss., 1990

ISBN 3-631-43911-3

Open Access: The online version of this publication is published on www.peterlang.com and www.econstor.eu under the international Creative Commons License CC-BY 4.0. Learn more on how you can use and share this work: http://creativecommons. org/licenses/by/4.0.

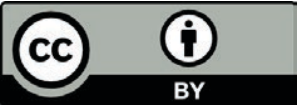

This book is available Open Access thanks to the kind support of ZBW - Leibniz-Informationszentrum Wirtschaft.

NE: GT

\author{
D 100 \\ ISSN 0721-3985 \\ ISBN 3-631-43911-3 \\ ISBN 978-3-631-75526-6 (eBook) \\ cc Verlag Peter Lang GmbH, Frankfurt am Main 1993 \\ Alle Rechte vorbehalten.
}

Das Werk einschlie Blich aller seiner Teile ist urheberrechtlich geschützt. Jede Verwertung außerhalb der engen Grenzen des

Urheberrechtsgesetzes ist ohne Zustimmung des Verlages unzulāssig und strafbar. Das gilt insbesondere fūr

Vervielfältigungen, Übersetzungen, Mikroverfilmungen und die Einspeicherung und Verarbeitung in elektronischen Systemen.

Printed in Germany 1234567 


\section{INHHALTSVERZEICHNIS}

Seite

Einleitung

1. Kapitel

Der ordnungstheoretische und ordnungspolitische Hintergrund des Staatsdenkens von Walter Eucken

1. Abschnitt

Die wissenschaftstheoretische Exposition

A. Das wissenschaftstheoretische Kernproblem

B. Die Problembewältigung

I. Die Negation einer apriorischen Begriffsordnung

II. Die Wissenschaft im Stile Walter Euckens als paradigmatisches Unternehmen

III. Das Wissenschaftsprogramm Walter Euckens

1. Das Wissenschaftsziel: Die Erkenntnis der nicht-relativen Wahrheit

2. Der Wissenschaftsbegriff: Die Einheit des theoretischen systems

3. Die wissenschaftliche Methode:

Das korrigierte rationalistische Verfahren

2. Abschnitt

Die wirtschaftstheoretische Grundlegung

A. Die Reflexion auf das erste Hauptproblem der Nationalökonomie 
Seite

B. Das Ordnungsgefüge der Wirtschaft

I. Die Untauglichkeit der tradierten Lehren

zur Überwindung der "großen Antinomie"

II. Die heuristische Idee der Wirtschaftsordnung

- Das zweite Problem der Nationalökonomie 20

III. Die Genese des morphologischen Systems 22

1. Lenkung und ordnung - zum tatsächlichen

Verhältnis von erstem und zweitem Hauptproblem der Nationalökonomie

2. Vom skelett der Methode zur ordnungsgestalt der Wirtschaft 25

a) Die Euckensche Lehre vom Idealtypus 26

aa) Das Wirtschaftssystem der zentralgeleiteten wirtschaft

bb) Das Wirtschaftssystem der Verkehrswirtschaft - Die Lehre von den Marktformen 30

cc) Die Hauptformen der Geldwirtschaft

IV. Die doppelte Funktion des morphologischen Systems

1. Die typologische Charakterisierung geschichtlicher ordnungen

2. Der morphologische Apparat als axiomatisches system

v. Zur Kritik der Idealtypenbildung

1. Die phänomenologische Methode Edmund Husserls

2. Die "klassische" Variationsproblematik und die Frage der selektiven Einklammerung

3. Die paradigmatische Wahrnehmungsverschiebung bei Walter Eucken

4. Das Ergebnis der Kritik der Idealtypenbildung 
VI. Die nationalökonomische Theorie

1. Der logische Charakter der theoretischen Sätze

2. Der Erkenntniswert der nationalökonomischen Theorie

3. Der Schritt zur Wirklichkeit - Wahrheit und Aktualität der nationalökonomischen Theorie

3. Abschnitt

Die wirtschaftspolitischen Grundsätze

A. Das Verhältnis von theoretischer Erkenntnis und wirtschaftspolitischer Entscheidung

I. Das duale Wissenschaftsverständnis

Walter Euckens

1. Zur grundsätzlichen Unterscheidung von theoretischem Idealtypus und politischem Ideal nach Max Weber

2. Die Notwendigkeit einer praktisch brauchbaren wissenschaft nach Walter Eucken

B. Die Grundlagen des wirtschaftspolitischen Denkens von Walter Eucken

I. Die Notwendigkeit des Ordnens 65

II. Der Ordogedanke als Maßstab des ordnens 68

1. Der Primat der Freiheit 69

2. Das Erfordernis eines funktionsfähigen Lenkungssystems

III. Die Wettbewerbsordnung als maßstabsgerechte ordnung

1. Die Wettbewerbsordnung als Programm der Freiheit

2. Die Maximierung volkswirtschaftlicher Produktivität durch die Wettbewerbsordnung 76 
VI. Die Identifikation von maßstabsgerechter ordnung der Wirtschaft und Wirtschaftspolitik

1. Die instrumentale Betrachtungsweise der maßstabsgerechten ordnung
a) Die Wettbewerbsordnung als naturge- gebene ordnung - Der theoretische Idealtypus als werthaftes politisches Ideal
b) Die doppelte Instrumentalisierung des korrigierten rationalistischen Ver- fahrens
c) Die praktische Verwirklichung wissenschaftlicher Erkenntnis

2. Kapitel

Der staat im Denken von walter Eucken

1. Abschnitt

Einführung

2. Abschnitt

Der Staat als "Hüter der Wettbewerbsordnung"

A. Das Desiderat: Der staat als "ordnende Potenz"

B. Die Fakten: Die Pathogenese des neuzeitlichen staates

I. Die erste Epoche: Der absolute staat 92

II. Die zweite Epoche: Der liberale Rechtsstaat 94

1. Das Rechtsstaatsprinzip in der Interpretation walter Euckens

2. Der liberale Rechtsstaat und sein Verhältnis zur wirtschaft

a) Die "wirtschaftsverfassungsrechtliche Revolution" 
b) Staatsverfassung und wirtschaftsverfassung 98

c) Zur Frage der Interdependenz von liberalem Rechtsstaat und Wettbewerbsordnung

III. Die dritte Epoche: Der totale Wirtschaftsstaat 105

1. Der Wirtschaftsstaat als Produkt der Säkularisation

a) Der ökonomismus 108

b) Der Politismus 108

2. Die Zerstörung des altkapitalistischen $\begin{array}{ll}\text { Systems } & 109\end{array}$

3. Die identitäre Demokratie als Staatsform der säkularisierung

C. Die neue Staatsbildung Walter Euckens

I. Die Folgerungen aus dem staatsbildungsproze $\beta$ der Neuzeit

II. Die Natur des wirtschaftsordnenden staates

III. Die Grenzen der Wirksamkeit des wirtschaftsordnenden staates

IV. Exkurs: Zur Unvereinbarkeit von Rechtsstaat und wirtschaftspolitik zentraler Leitung

v. Die staatstheoretischen Implikationen der neuen Staatsbildung walter Euckens

1. Der staat als wertverwirklichende Institution

2. Die unabhängige staatsgewalt als Topos antidemokratischen Denkens

3. Der autoritäre staat als "Hüter der Wettbewerbsordnung"

4. Die Grenzen der Wirksamkeit des autoritären staates

a) Das ordoindizierte Schrankensystem staatlicher Macht 
b) Die Realität des "leistungsfähigen Rechtsstaates" 138

a) Die horizontale Gewaltenteilung 138

- Die Gesetzgebung 139

- Die Rechtsprechung 139

- Die Verwaltung 141

bb) Die vertikale Gewaltenteilung 142

3. Abschnitt

Wissenschaft als potesta constituens für die

ordnungen von staat und Wirtschaft

3. Kapitel

Die praktische Verwirklichung der Wettbewerbsordnung

- Zugleich ein Beitrag zum Rechts- und Verfassungsverständnis Walter Euckens

1. Abschnitt

Die Entscheidung

A. Das Denken in "Wirtschaftsverfassungen"

B. Der "positive Verfassungsbegriff" Carl Schmitts

c. Der positive Wirtschaftsverfassungsbegriff Walter Euckens

2. Abschnitt

Die Verwirklichung der Entscheidung

A. Die konstituierenden Prinzipien der Wettbewerbsordnung

B. Natur und Struktur der konstituierenden Prinzipien 
Seite

3. Abschnitt

Ansätze einer Rechts- und Verfassungstheorie bei Walter Eucken

Schlußbetrachtung

Anmerkungen

178

Literaturverzeichnis 



\section{Einleitung}

Walter Eucken hat ein durch gedankliche Kraft, sprachliche Klarheit und äußeren Umfang imponierendes Werk geschaffen. Er wird, bei aller Divergenz der Meinungen zu diesem Werk und seinen Folgen, von der Nationalökonomie zu ihren Großen gerechnet. 1

E. Welter hat den Beitrag Euckens zur wirtschaftswissenschaftlichen Forschung in ein prägnantes Beispiel gefaßt. "Euckens Grundstrukturen sind als Grundlage für die Erfassung der wirtschaftlichen wirklichkeit kaum von geringerer Bedeutung als Max Plancks ungleich verwickeltere Quantentheorie für die Physik".2 Die Wirtschaftswissenschaften, "auf einem Holzweg nach dem anderen festgefahren" ${ }^{3}$, erfuhren durch Eucken ihre Neuerung.

Seine Fähigkeit, einerseits vom stoff her zu denken und in phänomenologischer Betrachtungsweise Erscheinungen des täglichen Lebens als "individuell-historische Probleme" zu begreifen, andererseits jedoch mit Hilfe eines durch methodische Raffinesse und Akkuratesse geprägten wissenschaftstheoretischen Verfahrens aus der Fülle des historischen Materials $z u$ uberzeitlichen, allgemein-theoretischen Erkenntnissen vorzustoßen, haben diese Wertschätzung maßgeblich begründet. ${ }^{4}$ Euckens historische Analysen und seine Ableitungen aus den geschichtlichen Erfahrungen sind schlüssig vorgetragen, die Reduktion der untersuchten wirtschaftlichen Phänomene auf formalisierte Gesetzmäßigkeiten gelingt bruchlos.

Wie kaum ein anderer Wissenschaftler vor ihm war Eucken darüber hinaus fähig, die Ergebnisse seines Denkens in eingängige, konzise Begrifflichkeiten $z u$ fassen. In seiner dem "Freunde und Mitherausgeber zum Gedächtnis" gewidmeten würdigung des Lebenswerkes Euckens hat F. Böhm diese Leistungen zu kennzeichnen gesucht. "Eucken hat seine zeit instandgesetzt, sich von dem Alpdruck geschichtlichen Entwicklungsdenkens in Zwangsabläufen und anderer spielarten von pseudo- 
wissenschaftlichen Prädestinationslehren $z u$ befreien, und hat ihr statt dessen eine schlichte, vollständige, übersichtliche und kristallklare Musterkarte von Gestaltungsund ordnungsmöglichkeiten dargeboten. Indem uns Eucken lehrte, in einem Nebeneinander von ordnungsmöglichkeiten, anstatt in einem Nacheinander von geschichtlichen, psychologischen oder soziologischen Zwangsläufigkeiten oder Wahrscheinlichkeiten zu denken, hat er eine wahrhaft befreiende Tat vollbracht. Es ist wie ein Durchbruch aus lähmender Enge und unentrinnbarer Verhaftung in Schicksal oder Pseudowerte in eine welt der freien und verantwortlichen Wahl."5

Eucken begrenzte seine wissenschaftliche Arbeit jedoch nicht auf die theoretische Erfassung wirtschaftlicher Problemstellungen. Die nationalökonomische Theorie war ihm Grundlage und Ausgangspunkt für die Entwicklung seiner "Grundsätze der Wirtschaftspolitik", einer Monographie, die der praktischen Durchsetzung bestimmter ordnungsvorstellungen $\mathrm{zu}$ dienen bestimmt war. E. Salin sprach in einem Nachwort zu diesem Werk folgerichtig davon, daß Eucken "die erste geschlossene Theorie der wirtschaftspolitik, gewachsen auf dem Boden einer eigenständigen Theorie und einer selbstgeschaffenen Begriffsbildung" entworfen habe, die unter Zuhilfenahme bisheriger theoretischer und geschichtlicher Erkenntnisse sowie "unter Auswertung des illustrativen Anschauungsmaterials der allerjüngsten deutschen Vergangenheit" zustande gekommen sei.6

Das wissenschaftliche Schaffen Euckens ist auch damit indes keineswegs abschließend beschrieben. Er beließ es nicht bei der wirtschaftstheoretischen und wirtschaftspolitischen Arbeit, sondern er überwand die Enge des eigenen Fachgebietes und überschritt die Vorsichtsgrenze zu den Nachbarwissenschaften. Dieser Grenzüberschreitung lag die Einsicht zugrunde, daß die ordnung der wirtschaft nicht isoliert betrachtet werden kann, sondern daß sie auf das engste mit den ordnungen von staat, Recht und Gesellschaft verknüpft ist. 
Auch im Hinblick auf die Frage der Interdependenz der verschiedenen Lebensordnungen gebührt Eucken das Verdienst der ersten Erkenntnis, auch insoweit wird ihm deshalb "eine jener im großen stil zusammenfassenden Leistungen" bescheinigt, "wie sie in der Geschichte der Einzelwissenschaften immer nur wenigen Denkern gelungen sind. Er hat die Probleme seiner Wissenschaft in ihrer ganzen interdependenten Verflechtung übersehbar gemacht".?

Eucken, dies mag die kurze zusammenfassende Schilderung seines Werkes ausreichend belegen, hat wissenschaftsgeschichte geschrieben. Als Kopf der ordoliberalen hat er schulbildend gewirkt" , wenngleich er selbst keine "neue Richtung oder neue Sekte begründen, sondern (...) der einen wissenschaft dienen" wollte. " Veröffentlichungen und Lehrtätigkeit haben ihm auch nach seinem Tode im Jahre 1950 einen nachhaltigen und entscheidenden EinfluB bewahrt. ${ }^{10}$

Eine Arbeit, die sich mit einem Wissenschaftler vom Range Euckens befaBt und die damit Interesse an der durch dessen Denken geprägten Entwicklung der wissenschaften bekundet, vermag sich mehrere Aufgaben zu stellen. Zum einen kann sie der Frage nach dem Verhältnis von werk und Person nachgehen. obgleich wissenschaftliche Erkenntnisse insoweit bislang kaum vorhanden sind und insbesondere die Prägung des Werkes Euckens durch sein "Elternhaus und insbesondere den vater Rudolf Eucken, Professor der Philosophie und Nobelpreisträger für Literatur 1908, einer Klärung bedarf"11, ist dieses Verhältnis nicht Gegenstand dieser Arbeit. Es muß einer gesonderten Untersuchung vorbehalten bleiben.

Die vorliegende Arbeit will, angeregt durch die breitgefächerten Forschungsinteressen Euckens, dessen Staats- und Rechtsverständnis aufzeigen und in den Gesamtzusammenhang seiner wissenschafts- und wirtschaftstheoretisch fundierten wirtschaftsordnungspolitischen Konzeption stellen. Da der 
Gesamtentwurf seines Werkes "natürlich nicht von Beginn seiner wissenschaftlichen Laufbahn an" feststand ${ }^{12}$, sondern von Eucken, wenngleich "mit erstaunlicher innerer Konsequenz"13 in stufenweise vordringender Erkenntnis gewonnen wurde, erschließen sich die auch für die vorliegende Arbeit maßgeblichen Zusammenhänge des Euckenschen Werkes nur als integrierende Bestandteile seiner Gesamtkonzeption.

Die Gliederung der Arbeit hat dem Rechnung zu tragen. Sie folgt Eucken über seine - bislang fast unbeachtet gebliebene - wissenschaftstheoretische Exposition hin zu den "Grundlagen der Nationalökonomie"14 und den "Grundsätzen der Wirtschaftspolitik"15 und versucht auf diesem Unterbau sein Staats- und Rechtsverständnis $z u$ bestimmen. Mit dieser Arbeitsweise soll ein im Zusammenhang mit Stellungnahmen zu Euckens Werk nicht nur vereinzelt zu registrierender Fehler vermieden werden, der darin besteht, dessen Ideen als Ideologien abzutun, um sich der Mühe einer tiefergehenden Analyse zu entziehen und die Einordnung der Euckenschen Erkenntnisse unter die alten, bequemen Schemata nicht zu gefährden. Die pauschalierende Erledigung neuer Ideen mag in den Diskussionen eines arbeitsteiligen und aufgesplitteten wissenschaftsbetriebes häufig und kaum $z u$ vermeiden sein. Sie erleichtert dessen Abwicklung und bringt Entlastung insbesondere in Fällen, in denen wie bei Eucken die Interdependenz wissenschaftlicher Erkenntnisse aus verschiedenen Fachgebieten und damit eine zeitaufwendige Auseinandersetzung mit wissenschaftsbereichen in Frage steht, die dem analysierenden, rezensierenden oder kritisierenden Bearbeiter von Haus aus in ihrem gesamten spektrum nicht ohne weiteres zugänglich sind.

Unbeschadet und in Ansehung dieser Gefahren soll in der vorliegenden Arbeit der Versuch unternommen werden, die vielfältigen Erkenntnisse Euckens unter Vermeidung einer vorschnellen Etikettierung in der stufenfolge ihrer theoretisch objektivierten zusammenhänge darzustellen, die systematische Einheit der wissenschaft im stile Euckens kenntlich zu ma- 
chen, um dergestalt sein festgefügtes Weltbild "aus einem Guß"16 in seinen wesentlichen Teilen offenzulegen. 


\section{Rapitel}

Der ordnungstheoretische und ordnungspolitische Hintergrund des staatsdenkens von walter Eucken

\section{Abschnitt \\ Die wissenschaftstheoretische Exposition}

\section{A. Das wissenschaftstheoretische Kernproblem}

"Alle Erfahrungswissenschaften beginnen ihre Untersuchung mit der Feststellung von Tatsachen" durch "volle, unmittelbare Anschauung" der Wirklichkeit" ${ }^{17}$. Aus der alltäglichen Erfahrung erwachsen die Probleme und Fragestellungen, aber auch die Möglichkeiten der Erforschung des Phänomens wirtschaftliche wirklichkeit, dem das Erkenntnisinteresse Eukkens gilt. Alle Erkenntnis beginnt daher mit der Erfahrung. ${ }^{18}$ Allerdings sind "Charakter und Aufgabe wissenschaftlicher Erkenntnis" von der "naiven Erfassung der wirklichkeit" durch den Laien streng zu trennen. Die vorwissenschaftliche Meinung des "naiven Menschen" stellt sich sogar als Hindernis für die Beantwortung der Fragen dar, die der wirtschaftliche Alltag aufwirft. 19 "Wenige Menschen denken, aber alle wollen Meinungen haben."20 Solche Meinungen im Hinblick auf gesamtwirtschaftliche zusammenhänge sind gefährlich, da sie von einer "vulgären Subjektivität" geprägt und daher außerstande sind, in einer vernünftigen Gesamtschau die wirtschaftlichen Sachverhalte zu beurteilen.

Neben dieser "bunten Mannigfaltigkeit" subjektiver Ansichten sind die religiösen, philosophischen und politischen "Ideologien geschlossener Gruppen" der zweite Hemmschuh für die wissenschaftliche Erkenntnis der wirtschaftlichen Wirklichkeit.

Wie kann dieses alltägliche, von Vorurteilen, Naivität, Beschränktheit und willkür gekennzeichnete Gerede der Laien und Interessenten überwunden werden, um den Anforderungen gerecht $z u$ werden, die an wissenschaftliche Aussagen $z u$ 
stellen sind. Das ist das "Kernproblem der Wissenschaftslehre" 21 .

\section{B. Die Problembewältigung}

\section{Die Negation einer apriorischen Begriffsordnung}

Seine Bewältigung ist nach Auffassung Euckens eine Frage der richtigen wissenschaftlichen Einstellung. Nicht die kontemplative Betrachtung der realen wirtschaftlichen Vorgänge in laienhafter "unbekümmerter Selbstverständlichkeit"22, sondern radikales Fragen und Infragestellen ist notwendig, um von vorwissenschaftlicher, alltäglicher Erfahrung zu von Ideologien und subjektivismen befreiten wissenschaftlichen Problemstellungen zu gelangen. Diesen Ansatz verfehlt ein wissenschaftsverständnis, das die radikale, erfahrungsbedingte und damit wirklichkeitsnahe Reflexion auf die suche nach "Begriffsinhalten" reduziert; hier löst die Untersuchung von Begriffen die Analyse der Sachverhalte ab. ${ }^{23}$ Anstatt in die Sachprobleme einzudringen, beschränkt sich das "begriffsnationalökonomische Verfahren" darauf, die Ergebnisse der Begriffsanalysen in Definitionen zu fassen, die als festgefugtes System von "Pseudoaxiomen" am Beginn der Untersuchung der wirtschaftlichen Realitäten stehen. ${ }^{24}$

Die in einem solchen, ausschließlich von subjektivismen geprägten Verfahren gewonnene Begriffsordnung ${ }^{25}$ dient dann als Prämissensystem, aus dem im Hinblick auf Einzelfragen deduziert wird. Dabei übersieht man, daß die Schlußfolgerungen aus diesen willkürlich gesetzten "pseudoaxiomatischen Thesen"26 untaugliche Hilfsmittel der Erkenntnis sind, da ihr Inhalt bestimmt wird durch den Umfang dessen, was in die Definition hineingelegt wurde. Deren Fundament kann aber letztlich nur eine, an der Alltagserfahrung ausgerichtete, diffuse Vorstellung des jeweiligen Begriffsinhalts sein. 
Damit bleibt dieses Verfahren der vorwissenschaftlichen Erkenntnis als Ausgangspunkt verhaftet, es erschöpft sich in bloßer "Begriffsspekulation"27, sein Ergebnis sind inhaltsleere Begriffsschemata. Erst nach dem analytischen Eindringen in die Sachfragen wird eine wissenschaftlich fundierte Begriffsbildung möglich. Die "begriffliche Reflexion", die bereits vor der eigentlichen erfahrungswissenschaftlichen Arbeit die Erkenntnis parat hat, ist demnach eine ungeeignete wissenschaftliche Methode, um die Alltagserfahrung zu überwinden, in die Realität einzudringen und das Wesen der Wirtschaft $z u$ erkennen. Andererseits ist eine verwertung der Alltagserfahrung ohne Begriffe nicht denkbar. Die Wissenschaft hat sich deshalb bis zur Bildung wissenschaftlicher Begriffe im Rahmen der theoretischen Analyse mit den umgangssprachlichen Wendungen $z u$ behelfen und sich ihrer als "Krücken" zu bedienen ${ }^{28}$.

II. Die Wissenschaft im Stile Walter Euckens als paradigmatisches Unternehmen

Diese "wissenschaftstheoretischen Überlegungen" um die Verwertbarkeit der begriffsnationalökonomischen Methode und deren Ablehnung sind nur ein konsequenter Aspekt der von "Radikalismus" geprägten Neuorientierung in der wissenschaftlichen Problemstellung, der ganz allgemein der Rekurs auf "früher geäußerte Lehrmeinungen" zum opfer fällt. Jeder Forscher hat Fragen und Probleme seiner Wissenschaft völlig neu zu überdenken und nicht nur tradierte Fragestellungen aufzunehmen und fortzuentwickel $n^{29}$.

Diese wissenschaftstheoretische Einstellung Euckens läßt eine Auffassung erkennen, die wissenschaft nicht nur als Ausnutzung und Weiterführung bekannten wissens, kurz als Wissenserweiterung begreift, sondern der auch die angestammten Grundlagen des Wissens fragwürdig werden und die sich radikal um deren Veränderung und Erneuerung bemüht ${ }^{30}$. 
Indem sich Eucken gezwungen sieht, selbst solche Grundlagenforschung $z u$ treiben und die gesamte "überkommene Wissenschaft" in Frage zu stellen, attestiert er ihr gleichzeitig, die entscheidenden Probleme nicht erkannt zu haben und somit auf einer vagen und im wesentlichen nur scheinbar wissenschaftlichen Grundlage zu stehen.

Die revolutionäre wissenschaftliche Arbeit muß sich von den als Datum wirksamen, traditionellen Angeboten der Problemlösung abwenden und die Nationalökonomie auf völlig neue Beine stellen, indem sie eine entschiedene Wendung "von Lehransichten zu den Sachen vollzieht", um aus der Analyse der wirtschaftlichen wirklichkeit die neuen wissenschaftlichen Grundlagen $z u$ entwickeln ${ }^{31}$. Erst dann wird ein Urteil darüber möglich, ob einer Forschungsrichtung in einzelnen Punkten der Durchbruch $z u$ echter wissenschaftlich-ökonomischer Forschung gelungen ist und welche sich nur als wissenschaftlich geriert und im Grunde nicht mehr ist, als pseudowissenschaftliches, naives, interessenbedingtes Gerede ${ }^{32}$.

In diesem, durch einen tiefen Vertrauensschwund gekennzeichneten Verdrängungsproze $\beta$ von bisher legitimen wissenschaftlichen Fragen und Antworten manifestiert sich die Einsicht in eine krisenhafte Entwicklung der Nationalökonomie, die ohne traditionszerstörende Problemlösungen nicht überwunden werden kann. Der Übergang von den in der Krise erstarrten zu den neuen Grundlagen ist allerdings kein "kumulativer Prozeß"33, sondern im Vergleich zur bloßen Grundlagenpräzisierung und -erweiterung macht er einen Neuaufbau erforderlich, der neben der zwangsläufigen Neubestimmung des Inhalts die Veränderung der elementarsten Methoden und ziele einer wissenschaft zur Folge haben muß. Im Gegensatz zur "normalen Wissenschaft" 34 muß die Wissenschaft, die sich die Grundlagenrevision zur Aufgabe gemacht hat, daher umfassend auf die Bedingungen der Erkenntnisgewinnung zur Erreichung der angestrebten zielsetzungen wissenschaftlicher Betätigung reflektieren, um das neue Lehrgebäude $z u$ fundamentieren und $z u$ rechtfertigen. Eng in diesen Rechtfertigungszusammenhang 
eingebettet, ihm genaugenommen sogar vorgeschaltet, ist die weitere Aufgabe des Grundlagenkritikers, die vorherrschende Meinung in ihrer krisenauslösenden Fehlerhaftigkeit zu lokalisieren, sowohl was Inhalt und ziele als auch Erkenntnismittel und -verfahren anbelangt, um durch ihre Analyse und Kritik die Notwendigkeit der neuen Lehre zur Überwindung der Krise und daraus folgend ihren ausschließlichen Geltungsanspruch $z u$ begründen. Damit rücken die wissenschaftsprogrammatischen Vorstellungen Euckens in den Vordergrund ${ }^{35}$.

\section{Das Wissenschaftsprogramm Walter Euckens}

1. Das Wissenschaftsziel:

Die Erkenntnis der nicht-relativen wahrheit

"Alle echte Erfahrungswissenschaft und Wissenschaftstheorie hat es seit den Griechen als Hauptaufgabe angesehen, vom Alltagsgerede zu wissenschaftlicher Wahrheit zu kommen"36. Mit dieser Sentenz ist der Richtpunkt und das absolute wissenschaftsziel der Euckenschen Grundlegung bezeichnet ${ }^{37}$. Die Negation der Idee der "nicht-relativen Wahrheit" ist identisch mit der Negation der Existenzberechtigung von wissenschaft überhaupt ${ }^{38}$.

Damit sind die Anforderungen an die Problemlösungen, die die wirtschaftliche wirklichkeit als Erkenntnisgegenstand der Nationalökonomie betreffen, deutlich gemacht. "Entweder sind objektive Aussagen über die Verknüpfung der Wirklichkeit möglich" - dann ist das Lebensrecht der Wissenschaft gesichert - "oder nicht - dann ist ihre Möglichkeit geleugnet". Dieses Entweder-Oder in der Wissenschaftslehre wurde im Zuge der allgemeinen Tendenz der Auflösung der Kultur zu Lasten der Idee der Wahrheit entschieden ${ }^{39}$.

Auf der Suche nach der Denkrichtung, die für den damit verbundenen Verfall des Denkens und das Abgleiten in eine ohne Sinnhaftigkeit betriebene Wissenschaft, kurz die Krise ver- 
antwortlich ist, ortete Eucken den "Historismus", eine geistige Bewegung, deren Siegeszug Ende des 19. Jahrhunderts begann und die in den dreißiger Jahren des 20. Jahrhunderts das "gesamte geistige Leben" entscheidend beeinflußte ${ }^{40}$. Die Entwicklung des Historismus ist das Ergebnis der Einsicht in die Individualität geschichtlicher Sachverhalte, die konsequent die Negation eines objektiven überzeitlichen Seins zur Folge haben mußte. Da jede historische Erkenntnis durch den singulären Bedingungsrahmen relativiert wird ${ }^{41}$, stellt auch die Wahrheit keine zeitlose Kategorie mehr dar, sondern sie ist, wie alle anderen Werte, nur noch eine "Funktion der geschichtlich gegebenen Bedingungen des Daseins" 12 .

Mit dieser Relativierung der Wahrheitsidee verlor die Wissenschaft ihre Basis, sie wurde letztlich zum bloßen "Trabanten des Lebens"43. Die Trennung von der empirischen Grundlage auf der suche nach absoluten Wahrheiten war verpönt, der "Durst nach mehr wirklichkeit"44 legitimierte lediglich punktuelle Untersuchungen geschichtlicher Tatbestände.

Die dem "Kultus des Faktischen" erlegene Wissenschaftsidee des Historismus war zwar aus verschiedenen Denkrichtungen zusammengesetzt, allen gemeinsam war jedoch die ihr wesen prägende relativistische, fatalistische und skeptizistische Denkhaltung ${ }^{45}$, die die Möglichkeit einer absoluten Wahrheit und damit den Weg zum "wahren Sein" verneinte ${ }^{46}$.

Diese historisch-relativistische Umwälzung der Wissenschaft machte auch vor der Nationalökonomie nicht halt, wo ihr die jüngere historische schule unter Führung G. Schmollers zum Durchbruch verhalf. Der "Wissenschaft im stile Schmollers"47 war infolge historistischen Mißtrauens jede grundsätzliche Problemstellung suspekt, weshalb sie sich auf die Sammlung, Untersuchung und Darstellung von geschichtlichen Details beschränkte. Das Ergebnis des empiristischen Verfahrens war dem entsprechend eine verbindungslose Aneinanderreihung von historischen Tatbeständen, die aufgrund der relativistisch gefärbten Forschungsmethode und dem daraus resultierenden 
Theorieverständnis keine objektiven Aussagen über die gesamtwirtschaftlichen Zusammenhänge erlaubten. ${ }^{48}$

Dem Empirismus fehlte demgemäß die "strenge Methode" zur Entwicklung einer Theorie, der über die Interpretation von Einzelaspekten hinaus, die Erfassung des "interdependente( $n$ ) Ganze(n)" gelingt ${ }^{49}$ und die in der Lage ist, im Hinblick auf den Gesamtkomplex Wirtschaft die "methodische Kardinalfrage jeder Erfahrungswissenschaft" zu klären, wie "natürliche, verworrene" und damit relativistische Alltagserfahrung $z u$ wahrer, zeitungebundener, wissenschaftlicher Erkenntnis wird $\mathrm{d}^{50}$.

Aus dieser kritischen Auseinandersetzung mit der dominierenden Denkhaltung in der Wissenschaft im allgemeinen und in der Nationalökonomie im besonderen ergibt sich bereits die Richtung, in der sich die eigenen methodologischen überlegungen Euckens weiter $z u$ bewegen haben, um die durch radikales Fragen entstandenen Probleme in einer dem Wissenschaftsziel adäquaten Weise zu bewältigen ${ }^{51}$. Zum Begriff der Wissenschaft gehört demnach nicht nur die Beachtung der Mannigfaltigkeit von Einzelerscheinungen, sondern auch deren Integration in einen Gesamtzusammenhang, weil anders ihre jeweilige Funktion nicht erkennbar wird ${ }^{52}$.

2. Der Wissenschaftsbegriff: Die Einheit des theoretischen systems

Damit rückt das Verständnis der objektiven strukturen dieser Einheit in den Brennpunkt des methodischen Interesses.

Gepaart mit der Aufgabe der Wissenschaft, der Wahrheitsidee zum Durchbruch zu verhelfen, ergibt sich damit das präzise wissenschaftstheoretische Programm: Das Gefüge der strukturen der wirtschaftlichen wirklichkeit ist in toto in seinem objektiven Wahrheitsgehalt zu erfassen ${ }^{53}$. 
Das "Reich der Wahrheit" ist nun, korrelativ der ihm zugrunde liegenden wirklichkeit, "kein ungeordnetes Chaos", sondern ein nach Gesetzmäßigkeiten geordnetes Ganzes ${ }^{54}$. Um der systematik, die "in den Sachen" verborgen ist, $z u$ entsprechen, muß daher auch die Erforschung und Darlegung der Wahrheiten systematisch $\operatorname{sein}^{55}$. Erst die systematische Einheit im theoretischen Sinn macht Wissenschaft zur Wissenschaft, der, befreit von krudem subjektivismus und interessenbedingter Verblendung, die Einsicht in das faktische Beziehungsgeflecht gegeben ist.

3. Die wissenschaftliche Methode: Das korrigierte rationalistische Verfahren

Um die Voraussetzungen der Möglichkeit wahrer Erkenntnis über das Triviale hinaus zu schaffen, bedarf es demnach eines methodisch begründeten Vorgehens, das den systemcharakter der wirklichkeit offenbart und das system bis auf seinen Ausgangspunkt bringt.

Überraschenderweise scheint sich Eucken dieser Einsicht in die Notwendigkeit einer problemangepaßten Methode zu verschließen, wenn er im Vorwort zu den "Grundlagen der Nationalökonomie" jede Methodologie kategorisch verurteilt ${ }^{56}$.

Noch unwägbarer wird seine Haltung zu dieser Frage dadurch, daß er andererseits im "Abschluß" der "Grundsätze der Wirtschaftspolitik" die Methode als ein konstitutives Element jeder wissenschaftlichen Betätigung bezeichnet ${ }^{57}$. Dieses scheinbar gespaltene Verhältnis zur Methodenfrage entpuppt sich allerdings bei näherem Hinsehen nur als der Versuch, Wissenschaftstheorie und Einzelwissenschaft in das richtige Verhältnis zu setzen.

Infolge seines spezifischen Wissenschaftsprogramms sieht Eucken nicht mehr nur die Idealwissenschaften in der Verantwortung für die Lösung der auftretenden methodischen Fragen, sondern auch die jeweils betroffene Realwissen- 
schaft, die geeignete Forschungsmethoden mit Blick auf den intendierten Zweck $z u$ entwickeln hat ${ }^{58}$. Dies bedeutet jedoch nicht, daß einer bloß forschungsimmanenten Wissenschaftstheorie das Wort geredet wird. Für Eucken ist die dem Programm angemessene Methode eine summe aus einem "Allgemeinen Teil" der wissenschaften, dem methodisch reflektierten Denken, das sich mit den allgemeinen Problemen des Aufbaus der Wissenschaften und der logischen struktur wissenschaftlicher Aussagen, kurz der Methode als objekt befaßt und einer in Verbindung damit entwickelten, objektbezogenen Forschungsmethode, die den Eigentümlichkeiten der jeweiligen empirischen Grundlagen Rechnung trägt. Eucken wehrt sich mit seinen Äußerungen im Vorwort der "Grundlagen" damit lediglich gegen isolierte "methodologische Reflexionen" im Sinne von "sachabgewandten Grübeleien"s9 und (real-)wissenschaftsfernem Räsonieren, da die Lösung der anstehenden Probleme nur durch einen, dem beschriebenen zusammenspiel von Einzelwissenschaft und Wissenschaftstheorie gerecht werdenden Entwurf gelingen kann ${ }^{60}$.

Für Eucken lag es nahe, durch eine unter diesem Aspekt erstellte Genesis methodologischer studien anhand der Selbstmitteilung "bewährter Forscher" das eigene methodische Procedere zu suchen. Dabei wurde jedoch offenbar, daß zwischen den konzipierten Methoden und dem tatsächlich geübten Verfahren nur in Ausnahmefällen eine Konkordanz bestand ${ }^{61}$. Damit scheidet die Rezeption einer bereits entworfenen und angewandten Methode aus, weil die Ergebnisse der jeweiligen wissenschaftlichen Leistungen nicht zwingend als Folge der methodisch-programmatischen Äußerung identifizierbar sind, sondern ebenso nur eine Konsequenz des faktisch geübten Verfahrens sein können.

$\mathrm{Da}$ das Produkt einer Wissenschaft immer von der Art und Weise des letztgenannten Verfahrens abhängt, gleich ob mit der "methodologischen Reflexion" deckungsgleich oder nicht, kann nur die Untersuchung der tatsächlichen Forschungsmethode Aufschluß über den wirklich existierenden Kausalnexus 
zwischen Methode und Ergebnis und ziel der Wissenschaft geben.

Auch im Bereich des Methodischen kann sich Eucken damit nicht ohne weiteres auf bereits vorhandenes Material stützen, sondern er ist hier gleichfalls gezwungen, zurück in die Grundlagen $\mathrm{zu}$ gehen, wobei wiederum die "gesamte methodologische Literatur" ignoriert werden muß, um die Voraussetzungen für die richtige, eigene Methode $\mathrm{zu}$ schaffen. ${ }^{62}$ Diese Grundlagenarbeit läßt die Vielfalt der angewandten Methoden auf die "fundamentale Antinomie" zwischen dem empiristischen und dem rationalistischen Verfahren schrumpfen. ${ }^{63}$ Dem Dilemma zwischen der nur auf der Erfahrung gründenden relativistischen Erkenntnis des Empirismus - die bereits als den Problemen inadäquat ausgesondert wurde - und der lediglich auf intellektualistischer Basis ruhenden, aber mit dem Anspruch auf absolute Wahrheit ausgestatteten apriorischen Erkenntnis des Rationalismus sucht Eucken durch ein korrigiertes rationalistisches Verfahren $z u$ entkommen, in dem sich "geschichtliche Erfahrung mit theoretisch-rationaler Analyse verbindet" 64 .

Dabei bleibt der Ausgangspunkt aller Überlegungen die Erfahrung. Um jedoch zwischen der reinen "Anschauung des geschichtlichen Augenblicks" und der "reinen Ratio" eine Brükke schlagen $z u$ können, müssen durch den Einsatz und die Kraft des abstrakten Denkens bestimmte gleichförmige Problemstellungen erkannt werden, die eine "Hebung ins Allgemeine" legitimieren ${ }^{65}$. Diesem ersten Schritt folgt der zweite in Form der Schaffung von Bedingungen durch Reduktion der tatsächlich gegebenen (gleichförmigen) Tatbestände auf "reine Fälle". Die isoliert hervorgehobenen Wahrnehmungsinhalte geben die Bedingungskonstellationen wieder, die den Vollzug des dritten Schrittes erlauben: Die Konstruktion von Theorien, die hypothetische, denknotwendig wahre Urteile über die Bedingungszusammenhänge ermöglichen ${ }^{66}$. Die summe aller Einzeltheorien fügt sich zu einem konsistenten Gesamtsystem. Diese "korrekt erarbeitete" Gesamttheorie setzt die For- 
schung in den Stand, die wahren Zusammenhänge der Wirklichkeit zu erklären. ${ }^{67}$

Von empirischen Phänomenen ausgehend, kehrt die Wissenschaft im stile Euckens mit den durch das richtige rationalistische Verfahren gewonnenen theoretischen Einsichten in einem letzten Schritt zur wirklichkeit zurück, um das "Durcheinander der einzelnen individuellen Erscheinungen, wie es sich dem Auge des Laien darbietet", zu ordnen ${ }^{68}$. Die objektive, allgemeingültige Verknüpfung der Einzelfakten wird offenbar, der "wahrhaften Erkenntnis der Wirklichkeit" steht nichts mehr im Wege ${ }^{69}$. Indem das konstruierte rationalistische Verfahren die "exakte Erklärung der Zusammenhänge" ermöglicht, "rechtfertigt es sich am eindrucksvollsten"70.

Damit ist der Entwurf des "Allgemeinen Teils" der Wissenschaftstheorie als tragendem Unterbau vollendet, Eucken kann sein eigentliches Anliegen, die neue Grundlegung der Nationalökonomie, in Angriff nehmen.

\section{Abschnitt:}

\section{Die wirtschaftstheoretische Grundlegung}

Der in den Prolegomena gewonnene "Allgemeine Teil" einer Methodenlehre dient Eucken als Gerüst zur Entwicklung der für die "Grundlagen der Nationalökonomie" notwendigen Wissenschaftstheorie, die, naturgemäß durch spezifisch wirtschaftliche problemstellungen bestimmt, die prima facie zusammenhanglosen Sachfragen systematisieren und zu einer Einheit verknüpfen soll, um die Bildung einer geschlossenen, nationalökonomischen Lehre zu ermöglichen. 
A. Die Reflexion auf das erste Hauptproblem der Nationalökonomie

Aus dem auf der Grundlage der Alltagserfahrung gewonnenen Wissen um den wirtschaftlichen Alltag entspringt durch radikale und grundsätzliche Reflexion das erste Hauptproblem der Nationalökonomie und damit die Frage nach der Lenkung und den Zusammenhängen des "gesellschaftlichen Gesamtprozesses der Wirtschaft"71, die sich in die weiteren fünf Teilbereiche 1. Lenkung der vorhandenen Böden, der Arbeitskräfte und der vorhandenen halbfertigen Produkte; 2. Verteilung; 3. zeitlicher Aufbau der Produktion; 4. anzuwendende Technik und 5. die räumliche Lenkung der Produktion untergliedert ${ }^{72}$.

Die fünf Seiten des Hauptproblems sind indes nicht unabhängig voneinander, sondern nur als diversifizierende Aspekte des "organischen Ganzen" Wirtschaft ${ }^{73} \mathrm{zu}$ denken, in dem jede ökonomische Handlung darauf ausgerichtet ist, die vorhandene Knappheit an Gütern $\mathrm{zu}$ überwinden ${ }^{74}$. Die universale Frage Euckens nach dem "Zentralphänomen" der Interdependenz aller ökonomischen Erscheinungen ${ }^{75}$ ist eine notwendige Folge des Einheitsgedankens ${ }^{76}$, der wissenschaftliche Erfahrung im Hinblick auf die summe der Teile nur aus dem Verständnis des Ganzen und damit den wirtschaftsablauf in seinen Einzelheiten nur durch die Einsicht in den Gesamtprozeß des wirtschaftslebens als möglich erscheinen läßt. Euckens Losung lautet daher für die Grundlegung der Nationalökonomie: "nur ein Ganzes, ein Problem und eine Lehre" $n$.

In der Durchführung dieses Vorhabens sieht sich Eucken nun mit der "großen Antinomie" konfrontiert, in der sich intuitive unmittelbare Anschauungen der Vielfalt geschichtlichen Lebens und rationales, wissenschaftliches Begreifen wirtschaftlicher wirklichkeit scheinbar unüberbrückbar gegenüberstehen ${ }^{78}$. Einerseits Ausschnitt des jeweiligen "gesamtgeschichtlichen Seins und Werdens"79 und damit nur im Kontext der "jeweiligen geschichtlichen situation" $\mathrm{zu}$ verstehen und in ihren mannigfaltigen Ausprägungen $z u$ erfassen ${ }^{80}$, sind die 
komplexen wirtschaftlichen Zusammenhänge und variierenden wirtschaftlichen Erscheinungen andererseits nur dann in den wissenschaftlichen Griff $z u$ bekommen, wenn das erste Hauptproblem der Nationalökonomie nicht nur als geschichtliches, sondern auch als "allgemein-theoretisches" Problem begriffen wird. ${ }^{81}$

Die für eine wirklichkeitsnahe, realistische Theorie unabdingbare, "individuell-historische" Betrachtungsweise steht, dies zu begreifen ist für Eucken entscheidend, damit in diametralem Gegensatz zu der jenseits aller Alltagserfahrung und unmittelbaren Anschauung angesiedelten "allgemein-theoretischen" und damit ahistorischen Fragestellung, die durch "strenge(n) Gebrauch der Vernunft" und den "Einsatz des Denkens" allein die Gewähr für eine, vom Gewirr der Einzeltatsachen befreite, wissenschaftliche Erkenntnis bietet, die sich durch den Wahrheitsgehalt ihrer Urteile dem "Alltagsgerede" überlegen zeigt. ${ }^{82}$ Diese Antinomie von "Anschauung und Ratio"83, in der sich historische Individualität und "Einheit des theoretischen systems" begegnen ${ }^{84}$, muß überwunden werden, um die Voraussetzungen für eine wissenschaftliche Erkenntnis der wirtschaftlichen wirklichkeit zu schaffen ${ }^{85}$. Basis für jede ernstzunehmende Aussage über den wirtschaftsproze $\beta$ und die Lösung des ersten Hauptproblems der Nationalökonomie ist damit die Vereinigung von Geschichte und Theorie und die Beantwortung der Frage nach dem beiden seiten gerecht werdenden Modus ihrer Kombination.

Eine Überwindung des (Methoden-)Dualismus durch die suche nach der "rechten Mitte" lehnt Eucken $a b^{86}$, seine Synthese ist das bereits dargestellte korrigierte rationalistische Verfahren. Logisch gerechtfertigt wäre die theoretische Fassung des ersten Hauptproblems demnach nur, wenn gleichförmige Erscheinungen im Wirtschaftsprozeß deren "Hebung ins Allgemeine" zulassen würden ${ }^{87}$.

Einen solchen "invarianten Gesamtstil", der der "physikalisch-chemischen Natur" eigen ist ${ }^{88}$, vermißt Eucken in der Geschichte und der Welt der wirtschaft, die nur in einer 
historischen Abfolge wechselnder und vielfältiger Wirtschaftsordnungen $z u$ bestehen scheint, in denen sich der Wirtschaftsprozeß $z u$ verschiedenen zeiten in verschiedener Weise abspielt. Trotz der Ahnung, daß "eine Naturordnung" vorhanden sein $\mathrm{mu}^{89}$, ist die Vereinigung von Anschauung und Ratio angesichts der fehlenden Einheit und Gleichförmigkeit in der wirtschaftlichen Wirklichkeit nach Ansicht Euckens dann zum scheitern verurteilt, wenn der tatsächliche Nachweis nicht gelingt, daß auch hier Naturgesetze herrschen ${ }^{90}$. Die Aufgabe ist damit gestellt, der rote Faden, der sich durch weite Teile der "Grundlagen der Nationalökonomie" zieht, aufgenommen. Es beginnt die Suche nach dem "invarianten Gesamtstil", der "Physik" der Wirtschaft als Grundlage zur Überwindung der "großen Antinomie".

\section{B. Das Ordnungsgefüge der wirtschaft}

I. Die Untauglichkeit der tradierten Lehren zur Überwindung der "großen Antinomie"

Die Analyse einiger ausgewählter nationalökonomischer Lehren, die mit dem Anspruch auftraten, die "große Antinomie" überwunden zu haben, endet mit der Feststellung Euckens, daß sie einschließlich der angewandten Verfahren bereits in ihrer Grundrichtung verfehlt waren. Im Hinblick auf die Begriffsnationalökonomie und den Empirismus hatte Eucken dieses Verdikt im Rahmen seiner wissenschaftstheoretischen Exposition bereits eingehend begründet ${ }^{91}$. Gleiches gilt indes auch für die klassische Nationalökonomie ${ }^{92}$, die Lehre vom Dualismus zwischen theoretischer und historischer Nationalökonomie ${ }^{93}$ sowie die Lehre von den Wirtschaftsstufen und wirtschaftsstilen ${ }^{94}$, die trotz teilweise zutreffender Ansätze die tatsächlichen Probleme verkannten, demzufolge von verfehlten Grundkonzeptionen ausgingen und so die maßgeblichen Fragen nicht zu stellen vermochten. Der Nationalökonomie, so 
das resümierende Fazit Euckens, fehlt, da die überkommenen Lehransichten angesichts der "großen Antinomie" versagten, ein vollständiges und verläßliches Verfahren, um wirtschaftliche Wirklichkeit wissenschaftlich $z u$ erfassen. "Völlige Umkehr und Suchen eines neuen Weges"95 und damit die bereits wissenschaftstheoretisch fundierte Grundlagenrevision sind angezeigt. Der Zugang $z u$ dem Gewirr geschichtlicher Tatsachen, der Fülle historischen Geschehens und damit den Wesensmerkmalen wirtschaftlicher wirklichkeit eröffnet sich nur dann, wenn die richtige Frage nach dem ordnungsgefüge gestellt wird: "(I)m Rahmen welcher ordnung vollzieht sich alles dieses?" 96

Nicht stufen- oder stileinheit und -reinheit sind demnach als Nenner für das Wirtschaften einer zeit das zutreffende Kriterium, sondern nur die Frage nach dem ordnungsgefüge vermag Licht in das Dunkel der geschichtlichen Wirtschaft zu bringen? .

II. Die heuristische Idee der wirtschaftsordnung - Das zweite Hauptproblem der Nationalökonomie

Mit der unvermittelten und kategorischen Einführung der "heuristischen Idee" der Wirtschaftsordnung ${ }^{98}$ ist Eucken am "entscheidenden Punkt" seiner Kritik der überkommenen Lehren und insbesondere der Lehre von den Wirtschaftsstufen und wirtschaftsstilen angelangt. Indem die stufen- und stilbildner nicht die richtige Frage nach dem ordnungsgefüge gestellt haben, geht Eucken davon aus, daß die entworfenen Typen deshalb grundsätzlich keine geeigneten Instrumente sind, um wirtschaftliche wirklichkeit in ihren historischen Wandlungen $z u$ erfassen und "verstehend" $z u \operatorname{schildern}^{100}$. Die geschaffenen Abbilder der geschichtlichen Realität können zudem nicht als "eindeutige und übersehbare Bedingungskonstellationen"101 dienen, die die Erkenntnis der gesuchten 
theoretischen Sätze und damit allgemeine Aussagen über notwendige Bedingungszusammenhänge des Wirtschaftsprozesses möglich machen. Auf diesen schwankenden und wenig präzisen Grundlagen wird die "Vereinigung von geschichtlicher Anschauung und theoretischem Denken"102 für diese Forschungsrichtung $z u$ einem unerreichbaren Ziel, das erste Hauptproblem der Nationalökonomie muß mit Hilfe der Theorie von den Wirtschaftsstufen und -stilen ungelöst bleiben.

Diesen Mangel behebt das "Denken in Ordnungen"103. Indem das vielfältige wirtschaftliche Leben in der jeweiligen geschichtlichen ordnung einen konstanten Rahmen erhält, bietet sich die Möglichkeit, die Frage nach den Wirkungszusammenhängen im wirtschaftlichen Alltag an das jeweilige geschichtliche Leben heranzutragen und einer Untersuchung zugänglich zu machen. Dies setzt allerdings voraus, da $\beta$ sich invariant durchhaltende "Bauelemente"104 der jeweils untersuchten ordnung aufinden lassen.

Damit rückt die "richtig gestellte Frage"105 nach den gleichförmigen, elementaren ordnungsstrukturen, aus denen sich die vielfältige wirtschaftliche wirklichkeit zusammensetzt, in den Vordergrund.

Als conditio sine qua non des Wirtschaftsprozesses ${ }^{106}$ avanciert das "Denken in Ordnungen" zum "zweiten Hauptproblem der Nationalökonomie", dessen Bewältigung, da von Eucken als denknotwendiger Ansatzpunkt für die Lösung des ersten Hauptproblems konzipiert ${ }^{107}$, so scheint es, vorrangig ist. Erst auf diesen ersten Schritt hin sind dann in einem zweiten Denkabschnitt allgemein-theoretische Fragestellungen im Hinblick auf den Wirtschaftsprozeß zulässig und objektive Erkenntnisse der insoweit vorhandenen Bedingungszusammenhänge mög$\operatorname{lich}^{108}$. 
III. Die Genese des morphologischen Systems

Ist die morphologische Analyse der notwendige erste Schritt zur Überwindung der "großen Antinomie", wird die "exakte Feststellung der ordnungsformen... die erste Aufgabe, welche unsere Wissenschaft durchzuführen hat", um eben den Gegensatz von geschichtlicher Betrachtung und theoretischer Forschung zu überwinden ${ }^{109}$.

Entgegen dieser, auf den herausgearbeiteten zusammenhängen von erstem und zweitem Hauptproblem der Nationalökonomie gründenden programmatischen Erklärung, nimmt Eucken jedoch nicht das ordnungsproblem, sondern die Frage nach der zureichenden Lenkung und damit wiederum das erste Hauptproblem zum Ausgangspunkt seiner weiteren theoretischen Arbeit. Diese auf den ersten Blick programmwidrige Umstülpung des Verhältnisses der beiden Hauptprobleme zueinander wird nur einsichtig, wenn die Euckensche ordnungsidee und damit seine Gestaltlehre nicht nur als fertiges Denkprodukt und Grundlage der methodischen Überlegungen zur Überwindung der "großen Antinomie" vorgestellt, sondern in ihrer Genese bis hin zur theoretischen Vollendung in den idealtypischen wirtschaftssystem im einzelnen nachvollzogen wird.

1. Lenkung und ordnung - zum tatsächlichen Verhältnis von erstem und zweitem Hauptproblem der Nationalökonomie

Eine Basis für die Lösung des Lenkungsproblems läßt sich nur dann gewinnen, wenn auf das "zentrale Phänomen"110 allen wirtschaftens abgestellt wird: die Knappheit der Güter des täglichen Bedarfs und die grundsätzliche Konstanz allen menschlichen Tuns bei dem Versuch, diese Knappheit zu überwinden und durch den Einsatz der vorhandenen Arbeitskräfte und sachlichen Produktionsmitteln die Deckung des Bedarfs zu erreichen, kurz: das Handeln nach dem wirtschaftlichen Prin$z i p^{111}$. Ausgehend von diesen ökonomischen Grundgegebenheiten 
und der Einsicht, daß das wirtschaftliche Prinzip eine "Maxime des vernünftigen Handelns überhaupt" ist ${ }^{112}$, wird die Dimension des Lenkungsproblems deutlich und zugleich erfaßbar: Lenkung ist rationales Handeln aufgrund eines Planes, das der Minderung der Knappheit dient. Damit ist zugleich der "archimedische Punkt" erreicht, denn "wer wirtschaftet, handelt nach einem Plan"113.

Und weiter: Sowohl Lenkung als auch Plan sind nur in bezug auf ein "Subjekt" zu denken, "von welchem beide ihren Anfang nehmen" und das deshalb die Rationalität des Gesamtprozesses garantiert ${ }^{114}$. Diese Kompetenz zur rationalen Gestaltung des Wirtschaftsprozesses ist das entscheidende Merkmal und das Kriterium für alle weiteren Überlegungen zur Frage des $\mathrm{Zu}-$ sammenhangs von Lenkung und ordnung.

Um das Lenkungsproblem unter diesem Aspekt entwickeln zu können, greift Eucken aus Gründen der vereinfachten Darstellung auf kleine überschaubare Wirtschaftseinheiten zurück. Diese von inm so genannten "Liliputformen der Robinsonade" und der "geschlossenen Familien- und Eigenwirtschaft" zeichnen sich dadurch aus, daß hier die Planungskompetenz bei "einem Kopf" liegt"15, wodurch die für den Leiter bei der Bedürfnisbefriedigung, der Wahl der optimalen Produktionsfaktoren und der zeitlichen Abstimmung der komplementären Produktionsmittel relevanten Bewertungen und Handlungsmotive ohne weiteres einsichtig sind ${ }^{116}$.

Die Analyse zeigt, daß das in einem Plan geronnene ordnende Denken eines Plansubjekts ausreicht, um diese "Liliputformen" zu lenken und die Rationalität des Wirtschaftsprozesses zu gewährleisten ${ }^{117}$. Die Frage der ordnung wirft insoweit keine Probleme auf. Wechselt man das Untersuchungsobjekt und betrachtet man die Verhältnisse in einem großen industrialisierten Land mit arbeitsteiliger wirtschaft, wird offensichtlich, daß deren Überschaubarkeit für den einzelnen nicht mehr gegeben ist und damit individuelle Planung illusionär wird. Erst hier zeigt das Lenkungsproblem "seinen 
Stachel", denn es erhält in der industrialisierten welt eine neue Dimension und eine "gleichsam andere Qualität"118.

Die Kapazität des individuellen ordnenden Denkens vermag nurmehr segmente, aber nicht mehr den Wirtschaftsprozeß als Ganzes zu erfassen, die Lenkungsaufgabe scheint "ins unabsehbar Große gewachsen" zu sein"19. "Wie aber erfolgt dann die Lenkung des Gesamtprozesses? Nunmehr ist die Wirtschaftsordnung entscheidend"120. Ihre Aufgabe ist es, "das wirtschaftliche Prinzip, das in den Einzelwirtschaften individuell verfolgt wird, allgemein mit dem wirtschaftlichen Prinzip in Übereinstimmung zu bringen"121. Die auf die einzelwirtschaftlichen Vorgänge reduzierte, planende Ratio der einzelnen selbständigen Betriebe und Haushalte ist auch auf gesamtwirtschaftlicher Ebene mit den anderen Einzelwirtschaften und deren Interessen abzustimmen und auszugleichen, um auch insoweit einen rationalen GesamtprozeB zu gewährleisten ${ }^{122}$. "In den wirtschaftsordnungen der industrialisierten welt sollte eine ordnende Ratio zur Geltung kommen, die das bewältigt, was in der kleinen Eigenwirtschaft die Ratio des Leiters tagtäglich vollzieht"123.

Die suche nach der ordnenden Ratio, die die einzelwirtschaftlichen Plansubjekte koordiniert, muß zwangsläufig mit der Frage gekoppelt sein, wie diese gesamtwirtschaftliche Rationalität zu garantieren ist. Dieses Problem des überindividuellen "Lenkungsmechanismus"124 wird bei Eucken zu einem Problem der Wirtschaftsordnung, da nach seiner Auffassung ein Zusammenhang zwischen derjenigen Ratio, die den arbeitsteiligen Gesamtproze $\beta$ zu lenken imstande ist und dem Aufbau der wirtschaftsordnung und damit zugleich den denkmöglichen ordnungsalternativen überhaupt bestehen muß.

Damit ist $z u$ einem bereits bekannten Problemkreis aufgeschlossen: Nur wenn es gelingt, die Mannigfaltigkeit der geschichtlich auffindbaren ordnungen auf ihre invarianten Bestandteile zu reduzieren, kann die Bewältigung der anstehenden wissenschaftlichen Probleme gelingen. Es wird deutlich: $z w i s c h e n$ der Möglichkeit verstehend $z u$ ordnen und der wis- 
senschaftlichen Arbeit, präziser: der morphologischen Analyse besteht ein Junktim.

Ordnung ohne wissenschaftlichen Beistand kann es demnach im Rahmen der Euckenschen überlegungen nicht geben, die Frage nach der Besetzung der Rolle des die rationale Steuerung des gesamtwirtschaftlichen Prozesses (er-)klärenden und sichernden Subjekts ist beantwortet. Es ist die Wissenschaft ${ }^{125}$, genauer: die Wissenschaft im stile Euckens. Da nach dessen Verständnis die Möglichkeit wahrer wissenschaftlicher Erkenntnis, die den systemcharakter der wirklichkeit offenbart, an die Durchführung des korrigierten rationalistischen Verfahrens gebunden ist, sind die Weichen gestellt. Es ist an erster stelle der im Grundsätzlichen entworfene allgemeine Teil einer Methodenlehre den wirtschaftstheoretischen Erfordernissen und Besonderheiten anzupassen und insoweit zu präzisieren.

2. Vom skelett der Methode zur Ordnungsgestalt der Wirtschaft

Einsatz und Kraft wissenschaftlichen Denkens dürfen für Eucken weder in einer unfruchtbaren Distanz zur wirklichkeit stehen noch darf sich dieses Denken bei der notwendigen "Wendung zu den Sachen" in den komplexen realen wirtschaftlichen Tatbeständen verlieren, sondern die radikale "denkende Durchdringung" der wirklichkeit hat vom einzelnen wirtschaftsgebilde ihren Ausgang $z u$ nehmen ${ }^{126}$ und die einzelnen Seiten dieser individuellen Erscheinung durch eine in der Intensität auf die spitze getriebene Beobachtung "aufs schärfste" herauszuarbeiten ${ }^{127}$, um so diejenigen realen gleichförmigen Vorgänge, Tatsachen und zusammenhänge abzusondern, die als Grundlage des Verfahrens von Evidenz sind und die mit Hilfe der "pointierend hervorhebenden" oder "isolierenden Abstraktion" auf wissenschaftliche Begriffe 
gebracht und solchermaßen dem wissenschaftlichen Denken zugänglich gemacht werden können ${ }^{128}$.

Auf der Basis des gewählten Verfahrens gelingt damit einerseits der sprung von historisch-individueller vielfalt zu allgemein-theoretischer Fragestellung oder in der sprache des von Eucken gewählten Verfahrens: die "Reduktion von tatsächlich gegebenen auf reine Fälle"129, die als überschaubare Bedingungskonstellationen Basis der weiteren theoretischen Arbeit sein können ${ }^{130}$; zum anderen garantiert dieses "vollständige und sichere Verfahren" auch die vollkommene wissenschaftliche Erfassung der wirtschaftlichen wirklichkeit ${ }^{131}$.

a) Die Euckensche Lehre vom Idealtypus

Die nach Maßgabe der methodischen Prämissen mit Hilfe strenger Vernunft gesteigerte Anschauung der konkreten Einzelwirtschaft fördert die - nach der Entwicklung des Euckenschen Ordnungsdenkens zwangsläufige - Einsicht zutage, daß stets und überall wirtschaftliches Handeln Handeln nach Plänen ist ${ }^{132}$.

Die damit auch im Rahmen der wissenschaftlichen Erfassung der wirtschaftlichen wirklichkeit maßgebliche Frage nach dem zuständigen Subjekt der Planung beantwortet Eucken durch die Untersuchung einer konkreten Haushaltung, die ihm die "zwei konstituierenden Elemente" allen wirtschaftens aufzeigt ${ }^{133}$. Indem er unter Benutzung der "isolierenden" Abstraktion die "einzelnen Seiten der individuellen Erscheinung" pointierend heraushebt, reduziert er die möglichen Alternativen in der Planungskompetenz auf die beiden reinen "Wirtschaftssysteme" der "Verkehrswirtschaft", in der Planpluralismus besteht viele Subjekte sind planungsbefugt - und der "zentralgeleiteten Wirtschaft", die durch einen Planmonismus gekennzeichnet ist - nur ein subjekt darf planen - und nennt diese nunmehr für ihn auf wissenschaftliche Begriffe gebrachte 
Formen "Idealtypen"134. In diesem Zusammenhang distanziert sich Eucken jedoch umgehend von der bisherigen, insbesondere von $M$. Weber beeinflußten Diskussion um den Begriff des Idealtypus ${ }^{135}$, die er schon für im Grundsatz verfehlt hält ${ }^{136}$. Die Herstellungsart der Typen unterlag in der Vergangenheit - so Eucken - einem Mißverständnis, weil zwischen Realtypus und Idealtypus keine Unterscheidung in ihrer Funktion getroffen wurde. Da sie jedoch in einem jeweils völlig anders strukturierten Verfahren $z u$ einem jeweils verschiedenen Zweck gebildet wurden, mußten sie einen zwangsläufigen anderen logischen charakter haben ${ }^{137}$.

Der Realtypus ist nach Auffassung Euckens als empirischer Typus ein Produkt der in generalisierender Abstraktion vollzogenen "Überschau über viele konkrete Tatbestände"138, um deren Gemeinsamkeiten in realitätsbezogenen, raum- und zeitgebundenen und damit relativen "Gattungsbegriffen" festzuhalten ${ }^{139}$, die demgemäß den Charakter von Allgemeinbegriffen mit inhaltlicher Grundlage in der wirklichkeit haben. Sie bilden wirtschaftliche wirklichkeit ab. Demgegenüber ist für Eucken der durch pointierend-hervorhebende Abstraktion aus der geschichtlichen wirklichkeit gewonnene Idealtypus "im logischen sinne ideal", d.h. ein abstraktes zeitloses und allgemeingültiges Gedankengebilde, das, obwohl aus der genauen Beobachtung der wirklichkeit entstanden, nicht deren Abbild ist ${ }^{140}$.

Die logische Kategorie des Idealtypus verkörpert nach der Beschreibung Euckens damit eine Klasse von Begriffen, die rein in der wirklichkeit nicht auffindbar sind, die jedoch deswegen noch lange keine "Utopien" im Weberschen sinne sein müssen, weil "Utopien" der Wirklichkeit "entgegengesetzt" werden $^{141}$, wohingegen für Eucken die Idealtypen gerade aus der wirklichkeit herauspräpariert sind.

Das Ergebnis der Euckenschen Differenzierung läßt sich dahingehend präzisieren, daß während der Realtypus ein fundamentum in re auf Grund seiner Konstruktion behalten muß, die wirklichkeit im Idealtypus eine Transformation ins bloß 
noch gedanklich Vorhandene erfährt. Dem Idealtypus kommt so ein bewußt eingehaltener "Abstand gegen die Realität" $z u^{142}$. Die für Eucken solchermaßen aus der geschichtlichen wirklichkeit isolierten "rudimentären" Idealtypen ${ }^{143}$ der kontradiktorischen wirtschaftssysteme der "Verkehrswirtschaft" und der "zentralgeleiteten Wirtschaft" sind zugleich die beiden einzig möglichen "reinen konstitutiven Grundformen"144. Andere als die in diesen bipolaren Grundgegebenheiten zum Ausdruck kommenden Formen der ordnung sind nicht auffindbar und auch nicht denkbar ${ }^{145}$.

Die ordnungstheorie muß somit, um den morphologischen "Werkzeugkasten" $z u$ vervollständigen, die möglichen Varianten dieser beiden Grundformen isolieren und systematisieren. Diese idealtypische Kategorientafel der demnach denkbaren Wirtschaftsordnungsformen hat den bekannten und deshalb im folgenden nur noch skizzenartig vorzustellenden Inhalt.

aa) Das Wirtschaftssystem der zentralgeleiteten Wirtschaft

Die "zentralgeleitete Wirtschaft" tritt in der Geschichte in zwei idealtypischen Ausprägungen auf: der "Liliputform" der "Einfach zentralgeleiteten Wirtschaft" oder "Eigenwirtschaft" und auf der Ebene der Koordination der einzelnen wirtschaftssubjekte, die die gesamte volkswirtschaft umfaßt, der "Zentralverwaltungswirtschaft" ${ }^{146}$. Diese beiden Archetypen zentralgeleiteten Wirtschaftens lassen sich wiederum in jeweils drei Unterformen gliedern:

Das Kennzeichen der "total zentralgeleiteten wirtschaft" ist die alleinige Kompetenz des Leiters oder der Zentralstelle der Wirtschaftseinheit zur Gestaltung des Wirtschaftsplanes und zur strikten Durchführung dieses Planes. Der Leiter entscheidet ausschließlich über die Allokation der Produktionsfaktoren, die Güterverteilung und den Konsum, so daß für die selbständige Planung einzelner Wirtschaftsteilnehmer kein 
Raum mehr bleibt. "Der zentrale Befehl regiert... bis in den letzten winkel hinein und über alle wirtschaftlichen Handlungen" ${ }^{147}$.

In der "zentralgeleiteten Wirtschaft mit freiem Konsumtausch" entscheidet die Zentralstelle zwar gleichfalls über die Allokation der Produktivkräfte, den Produktionsprozeß sowie die zuteilung der Konsumgüter. Durch die Freiheit zum Tausch kann das zugeteilte Güterkontingent vom einzelnen in seiner Zusammensetzung indes korrigiert werden. Der Planmonismus wird, wenngleich "in bescheidenem Ausmaß", durch einen Planpluralismus ersetzt, der im Rahmen der nach wie vor zentralgesteuerten Konsumgüterverteilung die Verwirklichung von Einzelplänen und damit individueller Bedürfnisse erlaubt. Bei ständigem Konsumguttausch bilden sich, immer in völliger subordination unter den Wirtschaftsplan der Zentralstelle, "Märkte und Preise unter Gebrauch eines allgemein gültigen Tauschmittels, des Geldes", durch das sich dem einzelnen Wirtschaftsteilnehmer die Möglichkeit eröffnet, "wenigstens die größten Fehler in der Zuweisung von Gütern" auszugleichen und in Abänderung des für die individuellen wirtschaftlichen Notwendigkeiten blinden Gesamtplanes die Verteilung des zugewiesenen Güterkontingents durch Koordination von Einzelplänen den jeweiligen individuellen Bedürfnissen anzupassen ${ }^{148}$.

In der "zentralgeleiteten Wirtschaft mit freier Konsumwahl" verzichtet die Zentralstelle auf die Zuweisung von Gütern, deren Verteilung im Rahmen des durch den Gesamtplan bestimmten Konsumgüterangebotes sie der individuellen Entscheidung der einzelnen Wirtschaftsteilnehmer überläßt. Infolge der statt Gütern zugeteilten "Löhne und Gehälter in allgemeinen Anweisungen auf Konsumgüter" hat der einzelne das "Recht freier Konsumwahl". Über die Nachfrage auf den sich bildenden Märkten sind die Konsumenten in der Lage, ihren individuellen Bedürfnisse gegenüber der Zentralstelle Ausdruck zu verleihen und solchermaßen Menge, Qualität und Preise der 
hergestellten Güter zu beeinflussen. Die Zentralstelle kann den angezeigten Bedürnissen durch die entsprechende Fertigung von Gütern Rechnung tragen und die ihr angezeigten Versorgungslücken schließen. In einem solchen Fall ist der Gesamtplan letztlich in seiner Durchführung abhängig von den Plänen der Einzelwirtschaften. Die Grenze zur Verkehrswirtschaft ist überschritten. Die Zentralstelle kann andererseits, wenn sie, aus welchen Gründen auch immer, nicht willens ist, die angezeigten Bedürfnisse zu befriedigen, in ihrer Eigenschaft als einzige Anbieterin für Waren und Dienstleistungen den Einfluß der einzelnen Pläne auf den wirtschaftsprozeß zurückdrängen, indem sie durch eine entsprechende Preispolitik die nachgefragten Mengen dem Gesamtplan anpaßt und die Konsumenten so zwingt, das zu kaufen, was produziert wird und abgesetzt werden muß ${ }^{149}$.

bb) Das wirtschaftssystem der Verkehrswirtschaft Die Lehre von den Marktformen

Die Verkehrswirtschaft ist im Gegensatz zum Wirtschaftssystem der zentralgeleiteten wirtschaft durch eine Vielzahl von selbständigen wirtschaftsplänen einzelner Betriebe und Haushalte gekennzeichnet. Jeder Einzelplan ist im Hinblick auf den gesamten WirtschaftsprozeB des Gemeinwesens nur ein Teilplan, den im Vergleich zum Gesamtplan in einer zentralgeleiteten wirtschaft das Merkmal der Unvollständigkeit auszeichnet. Jede Wirtschaftseinheit muß bei ihrer Planung auf die Pläne der anderen wirtschaftsteilnehmer Rücksicht nehmen. Alle Einzelwirtschaften stehen deshalb im "Verhältnis gegenseitiger Abhängigkeit" ${ }^{150}$.

Daraus folgt das Koordinationsproblem, d.h. die Frage nach der Einordnung des Teilplans in das Gesamtgefüge der anderen Teilpläne im Wirtschaftsprozeß der Verkehrswirtschaft.

Die idealtypisierende historische Betrachtung Euckens läßt insoweit zwei notwendige Attribute des wirtschaftssystems Verkehrswirtschaft hervortreten. Erstens muß eine Rechnungs- 
skala als "Koordinationsbasis" der einzelwirtschaftlichen Pläne vorhanden sein. Als standardgut der Rechnungsskala legt Eucken seiner weiteren Analyse das Koordinationsmittel Geld zugrunde. Durch isolierende Abstraktion sind auch hier die Hauptformen der Geldwirtschaft und die Geldsysteme zu gewinnen ${ }^{151}$.

Zum zweiten erfolgt die Koordination von Angebot und Nachfrage über den Markt. Die Untersuchung der denkbaren Variationen des Koordinationsprozesses führt zur Lehre von den Marktformen, wobei sich die dominierende Rolle des Planes auch bei der suche nach den reinen, objektiv gegebenen Formen von Angebot und Nachfrage fortsetzt.

Die Betrachtung der konkreten Einzelwirtschaft zeigt, daß sich deren Leiter bei der Erstellung der Wirtschaftspläne an bestimmten, vorgegebenen Tatsachen sowie Verhaltensweisen anderer Wirtschaftsteilnehmer orientiert, die für ihn "Daten" sind. Jeder Plan basiert auf solchen "Plandaten", von denen das Verhalten der Einzelwirtschaft in Angebot und Nachfrage abhängig und deren Kenntnis demnach zur Aufdeckung der Marktformen unerläßlich ist. In "pointierender Hervorhebung" der denkbaren Datenvariationen ergeben sich so die reinen Formen von Angebot und Nachfrage und daraus die Marktformen selbst ${ }^{152}$ :

Der Planträger hat einen eigenen Markt, mit der Folge, daß die nachfragenden (oder anbietenden) Kunden auf ihn als einzigen Anbieter (bzw. Nachfrager) angewiesen sind. Es liegt der Fall des Angebots- bzw. Nachfragemonopols vor. Der Monopolist setzt das $z u$ erwartende Verhalten der anderen wirtschaftsteilnehmer als Datum in seine Wirtschaftspläne ein und bestimmt entweder den preis, "der eben für ihn kein Datum ist", oder "die anzubietende (oder nachzufragende) Menge und läßt den Preis einspielen"153.

Die marktbeteiligte Einzelwirtschaft setzt den Preis als Datum in ihre Wirtschaftspläne ein. Es liegt als eigenstän- 
dige Marktform das Teilmonopol vor, bei dem mehrere kleinere Betriebe "im Schatten" eines großen Unternehmens oder eines Kollektiv-Monopols leben, dessen Preise sie als Daten in ihre Wirtschaftspläne einsetzen, ohne den Wirkungen, die ihr eigenes Verhalten in Angebot und Nachfrage auslöst, Beachtung in Hinblick auf die Preisgestaltung zu schenken. Der beherrschende Betrieb stellt seinerseits, eine für ihn merkliche Zahl kleinerer Konkurrenten unterstellt, deren Reaktionen in seinen Wirtschaftsplan ein. Seine Monopolstellung ist infolgedessen unvollständig und nur zum Teil verwirklicht ${ }^{154}$.

Rechnet die marktbeteiligte Einzelwirtschaft weder mit den $z u$ zahlenden oder den $z u$ erlösenden Preisen noch mit der voraussichtlichen Reaktion der Marktgegenseite als Plandatum, sondern zieht sie in ihre Überlegungen bei Aufstellung des Wirtschaftsplanes auch die Geschäftspolitik der Wettbewerber mit ein, was regelmäßig dann der Fall sein wird, wenn sie als Anbieterin oder Nachfragerin einer begrenzten, überschaubaren Zahl von Wettbewerbern gegenübersteht, liegt die Marktform des oligopols vor ${ }^{155}$.

Eine weitere Marktform ergibt sich aus der Erkenntnis, daß sich mehrere kleinere Betriebe in ihrer Preisbildung an einigen wenigen Großunternehmen ausrichten. Es liegt ein Teiloligopol bzw. eine "teil-oligopolistische Marktstrategie" der "Großen" vor, die nicht nur die gegenseitig zu erwartenden Reaktionen, sondern auch die Reaktionen der in ihrer Preispolitik auf sie bezogenen Kleinunternehmen beachten $^{156}$.

Das Teiloligopol ist ebenso wie das Teilmonopol eine "wirtschaftlich nicht weiter zerlegbare Form von Angebot und Nachfrage" und damit eine selbständige Marktform ${ }^{157}$.

Den letzten und wichtigsten Fall des Aufeinandertreffens von Angebot und Nachfrage kennzeichnet Eucken dadurch, daß der 
einzelne Planträger "den Preis aus dem anonymen Markt" nimmt. Ein solches Verhalten unterstellt Eucken immer dann, wenn der einzelne sein Angebot bzw. seine Nachfrage als einen so minimalen Teil des Gesamtangebotes bzw. der Gesamtnachfrage einschätzt, daß er mit einer Reaktion des Marktes auf seine Teilnahme am Wirtschaftsprozeß nicht rechnet und ihm eine Einflußnahme auf den Preisbildungsproze $\beta$ als zwecklos erscheint. Der Marktpreis gilt ihm demzufolge als unbeeinflußbare Größe, die er als gegeben hinnimmt und die er in seinen Wirtschaftsplan einstellt. Es liegt der tatsächlich in Vergangenheit und Gegenwart am häufigsten verwirklichte Zustand der Konkurrenz vor ${ }^{158}$.

Da der Markt aus dem Zusammentreffen von Angebot und Nachfrage besteht, sind die Marktformen stets entsprechende Kombinationen von Angebot und Nachfrage. Weil neben fünf Formen des Angebots "ebenso viele Formen der Nachfrage auffindbar sind, ergeben sich 25 Marktformen", deren Zahl sich unter Berücksichtigung des Umstandes, daß jede dieser Marktformen in weiteren vier Varianten auftreten kann, auf insgesamt 100 erhöht ${ }^{159}$.

cc) Die Hauptformen der Geldwirtschaft

Die Darstellung der Verkehrswirtschaft komplettiert Eucken ausgehend von der Erkenntnis, daß in diesem wirtschaftssystem stets eine Rechnungsskala vorhanden sein muß und von den marktbeteiligten Einzelwirtschaften sämtliche Umsätze in Geld getätigt werden, das damit allgemein anerkanntes Tauschmittel ist, um die beiden Hauptformen der Geldwirtschaft und die drei Geldsysteme.

Die pointierende Hervorhebung der idealtypischen Hauptformen der auf die Koordination von Angebot und Nachfrage ausgerichteten Geldwirtschaft beginnt mit der grundsätzlichen Feststellung Euckens, daß Geld als dem "allgemein anerkann- 
ten Tauschmittel" nicht stets zugleich die Funktion der verbindlichen Recheneinheit zukommt ${ }^{160}$. Im Rahmen einer Untersuchung der geschichtlich verwirklichten währungsordnungen legt er dar, daß ursprünglich ein bestimmtes standardgut als Recheneinheit diente, daß sich im Laufe der zeit jedoch die Funktion Recheneinheit von dem (körperlichen) Gegenstand löste und $z u$ einer ideellen Größe wurde, die Tauschwerte bestimmbar und vergleichbar machte ${ }^{161}$. Anhand geschichtlich geprägter Beispiele belegt Eucken seine Auffassung, daß Geld diese für den Tausch maßgebliche "Wertmaßfunktion" zwar häufig, aber keineswegs immer besa $\beta^{162}$. Die oftmals chaotische Vielzahl von in ihrem Wert und Bestand ständig schwankenden Geldsorten, die z.B. im Mittelalter oder in hellenistischer Zeit aus mehreren Prägestätten in Umlauf waren, widersprechen stringent der Annahme, daß Geld und Recheneinheit identische Größen sein konnten. Eine Geldart mußte Wertmaßfunktion haben und damit die "einheitliche und feste Rechnungsskala" darstellen, derer die Händler für die Wirtschaftsrechnung, die Preisgestaltung sowie die Aufnahme und Rückzahlung von Krediten bedurften. Mögen die umlaufenden Geldarten durchweg Verwendung gefunden haben, für sie war die Spaltung zwischen Recheneinheit und Tauschmittel vollzogen, denn nur eine allgemein anerkannte Geldsorte konnte als objektivierte Größe "Träger der Recheneinheit" sein ${ }^{163}$. Dem geschichtlich feststellbaren Tatbestand, daß Geld zwar stets Tauschmittelfunktion hatte, die Wertmaßfunktion indes keine sein Wesen konstituierende Eigenschaft war, hat die Nationalökonomie Rechnung zu tragen und die beiden Hauptformen der Geldwirtschaft demzufolge theoretisch wie folgt zu scheiden:

"Die eine Hauptform, in welcher das Geld auch als Recheneinheit benutzt wird, und die zweite Hauptform, in welcher Geld und Recheneinheit getrennte Größen sind"164.

Den geschichtlich feststellbaren "Ordnungen des Geldwesens" 165 wird indes durch die beiden reinen Hauptformen der Geldwirtschaft nur unter dem Gesichtspunkt Rechnung getragen, ob 
Geld neben seiner Tauschmittelfunktion zugleich Recheneinheit und Wertmaßstab war. Die weitergehende Frage, ob und wie die durchaus mannigfaltigen Währungsordnungen auf bestimmte grundlegende "Bauformen"166 zurückgeführt und damit einer geldtheoretischen Analyse zugänglich gemacht werden können, bleibt damit unbeantwortet. Die deshalb weiter aufzufächernde Morphologie des Geldes beginnt mit der für das wissenschaftstheoretische Programm Euckens bezeichnenden Analyse der Einzelwirtschaft und im Zusammenhang mit den Geldsystemen konkret mit der Untersuchung deren Kassenbestandes und dessen Zusammensetzung. Eucken fragt: "Wie ist dieses konkrete Geld entstanden?"167 Durch die richtige Fragestellung werden die drei idealtypischen "Geldsysteme" offenbar, deren kennzeichnende Merkmale wiederum die pointierendhervorhebende Abstraktion zutage fördert.

Geld entsteht im 1. Geldsystem, indem ein sachgut diese Funktion übernimmt. Durch den Gebrauch des Sachgutes als gegebenenfalls in eine bestimmte Form gebrachtes Tauschmittel tritt dessen Warencharakter zurück. Es erlangt Geldqualität. Waren werden demzufolge nicht mehr ihrem bestimmungsgemäßen Ge- bzw. Verbrauch zugeführt, sondern sie dienen der - mittelbaren - Bedarfsdeckung durch Tausch. Eucken nennt in diesem zusammenhang die Sachgüter Getreide, Datteln, Kupfer und Muscheln oder im Deutschland der Nachkriegsjahre Zigaretten, die, in ihrer substanz unverändert und nur in besonderer Weise zusammengefaßt, als Geld benutzt wurden ${ }^{168}$. Am wichtigsten war in diesem Zusammenhang jedoch "die Einführung der Münzprägung durch die Lyder" und damit die Schaffung der "gemünzten Ware Gold"169. Geld verschwindet im 1 . Geldsystem wieder durch den bestimmungsgemäßen Ge- und Verbrauch der Ware.

Im 2. Geldsystem entsteht Geld bei Lieferung einer Ware oder bei Leistung von Arbeit als Gegenleistung. Die "technische Gestalt des Geldes" in diesem Geldsystem ist vielfältig ${ }^{170}$. Es 
kann in Form von Giral- und Papiergeld, als Banknote oder als Schuldverschreibung auftreten. Dementsprechend ist dieses Geldsystem durch diverse Varianten der Geldschöpfung gekennzeichnet. Geld entsteht einmal dadurch, daß eine Zentralbank Gold ankauft und mit Banknoten oder auf Girokonto den Kaufpreis bezahlt. Dieser Art der Geldschöpfung haben sich besonders häufig staaten oder andere Träger öffentlicher Gewalt dergestalt bedient, daß sie Lieferungen mit Schuldscheinen bezahlt haben, die als Geld in Umlauf gegeben wurden oder daß Dienstleistungen von Beamten und soldaten mit Papiergeld oder Scheidemünzen abgegolten wurden. Private schufen Geld durch Hingabe von auf den Inhaber ausgestellten Schuldverschreibungen, die bei entsprechender Bonität als Geld umliefen und vom jeweiligen Gläubiger am Fälligkeitstag zur Einlösung vorgelegt werden konnten ${ }^{171}$.

Im 3. Geldsystem entsteht Geld durch die Gewährung von Krediten. Geldschöpfende Institutionen sind die Banken als Kreditgeber. Kreditgeld verschwindet durch Rückzahlung der gewährten Darlehen. Neben privaten Banken schafft die Zentralnotenbank Kreditgeld durch Erwerb von Staatsschuldverschreibungen oder durch Gewährung von Krediten im Wechseldiskont - oder Lombardgeschäft, das in den umgekehrten Geschäften, d.h. im Verkauf von Schuldverschreibungen, Zahlungen von Wechsel- und Lombardverbindlichkeiten, wieder verschwindet. Kreditgeld tritt in Form von Giral- oder Guthabengeld bei privaten Banken und zusätzlich in Gestalt der durch die zentralbank geschaffenen Banknoten auf ${ }^{172}$. 
IV. Die doppelte Funktion des morphologischen systems

Mit Hilfe des gewählten Verfahrens ergibt sich damit ein morphologischer Apparat von Wirtschaftssystemen nebst deren Ausprägungen, der durch die diversen Geldsysteme ergänzt wird und dem Eucken im weiteren zwei Funktionen zuschreibt ${ }^{173}$.

1. Die typologische Charakterisierung geschichtlicher ordnungen

Anhand des entwickelten systems von Idealtypen besteht die Möglichkeit, jede historisch-reale Wirtschaftsordnung typologisch zu charakterisieren. Dadurch gelingt die Lösung des zweiten Hauptproblems der Nationalökonomie: die konkret verwirklichten ordnungen können in ihrem jeweiligen Gefüge erkannt werden ${ }^{174}$.

2. Der morphologische Apparat als axiomatisches System

Zudem bieten die in ihrer Zahl bekannten reinen ordnungsformen als eindeutige Bedingungskonstellationen eine feste Basis für die weitere wissenschaftliche Arbeit. Indem die Idealtypen als Modelle benutzt werden ${ }^{175}$, gelingt es, aufgrund der nun gleichförmigen, einfachen Verhältnisse die funktionaltheoretischen Bedingungszusammenhänge des Wirtschaftsablaufes $z u$ erfassen und, da Eucken die Idealtypen als Axiome begreift, die die Ableitung theoretischer Sätze erlauben $^{176}$, eine Ablauftheorie zu entwerfen, die das erste Hauptproblem der Nationalökonomie zu lösen imstande ist.

In seiner zweiten Funktion ist der morphologische Apparat ein axiomatisiertes System, bei dem die jeweils als Modelle benutzten Idealtypen nach erfolgter Ableitung zu einem System von theoretischen Sätzen werden. 
Nach alledem ist der morphologische Apparat das Kernstück der Euckenschen Grundlegung, da er eine "feste, auf Erfahrung gestützte Grundlage theoretischer Forschung" bildet ${ }^{17}$ und die reinen ordnungsformen daher im einzelnen haltbare Verbindungsglieder zwischen der Anschauung der geschichtlich individuellen wirklichkeit, aus der sie gewonnen sind, und der allgemein-theoretischen Analyse, die zur Erkenntnis der Zusammenhänge notwendig werden, darstellen ${ }^{178}$.

Diese euphemistische Einschätzung der Leistungsfähigkeit der angelegten "box of tools" im Hinblick auf die Erkenntnis der wirklichkeit wird aufgrund der prinzipiellen Schwächen, die dem morphologischen system bereits infolge seiner Konstruktion immanent sind, den durch sie tatsächlich eröffneten Möglichkeiten realer Erkenntnis allerdings nicht gerecht.

\section{Zur Kritik der Idealtypenbildung}

Der Vielfalt und Verschiedenheit der möglichen Typen der ordnungsgefüge und dem daraus folgenden skeptischen Relativismus im Hinblick auf die Erkenntnis ihrer sich invariant durchhaltenden Grundstrukturen vermochte Eucken wie dargelegt nicht dadurch Herr zu werden, daß er einerseits dem Historisch-Tatsächlichen verhaftet blieb und die wirtschaftsordnung in ihrem Charakter als individuell gegebene Tatsache untersuchte. Andererseits konnte die theoretische Analyse der "wechselnden und unübersehbaren Wirtschaftsordnungen"179 nicht auf Grund der bloß vorwissenschaftlichen Alltagserfahrung geleistet werden, da das methodische Rüstzeug fehlte, um die allgemeingültigen Merkmale der ordnungsgefüge erkennen $\mathrm{zu}$ können. Eine Antwort auf die Frage nach dem Aufbau der ordnung als Determinante des Wirtschaftens in einer bestimmten historischen Umgebung war demnach "nicht unmittelbar", d.h. ohne "ausreichende Denkmethode" möglich ${ }^{180}$. vielmehr war ein "weiter gedanklicher Umweg" erforderlich, 
um den jeweils "vorherrschenden Spielregeln" auf die Spur zu kommen. ${ }^{181}$

Indem Eucken die Wirtschaftsordnung als die "Gesamtheit der jeweils realisierten Formen, in denen der wirtschaftsproze $\beta$ alltäglich abläuft", definiert ${ }^{182}$, kann der Umweg nur über deren Herausarbeitung und "exakte wissenschaftliche Bezeichnung" führen. ${ }^{183}$

Eucken bedient sich damit keineswegs, wie er immer wieder versichert, der "Sprache des Alltags" bei der Beschreibung der zu analysierenden geschichtlichen Wirtschaftsordnungen ${ }^{184}$, sondern er bringt die Sachverhalte bereits vor der vorgeblichen Analyse der Realität auf wissenschaftliche Begriffe. Auch nach seiner Überzeugung bedingt sein Vorgehen zwangsläufig einen Vorgriff auf wesentliche Teile des durch das rationalistische Verfahren gewonnenen morphologischen Systems $^{185}$.

Das aber bedeutet nichts anderes, als daß sich das Problem der Erfassung der wirtschaftlichen wirklichkeit von vorneherein darauf konzentriert, welcher Bestand an Realität den verschiedenen idealtypischen ordnungsformen durch das konzipierte rationalistische Verfahren vermittelt wird. Diese Abhängigkeit (nur) von der empirischen Transformationsleistung des gewählten Verfahrens hat zur Folge, daß die Tauglichkeit der reinen ordnungsformen im Hinblick auf ihre Verwendung als "Grundlagen der Nationalökonomie" aufgrund der erheblichen Schwächen, die sich bei einer Analyse des Verfahrens offenbaren, grundsätzlich in Frage gestellt ist. In diesem Zusammenhang war nicht nur das von Eucken konzipierte korrigierte rationalistische Verfahren als Grundlage der Analyse heranzuziehen, sondern auch dessen bislang in diesem Zusammenhang fast unbemerkt gebliebenes methodisches Vorbild: die phänomenologische Methode E. Husserls, mit deren Hilfe manches von Eucken zu knapp oder gar nicht Ausgeführte erklärbar wird und fehlende Verbindungslinien nachgezeichnet werden können. 
1. Die phänomenologische Methode Edmund Husserls

Der erste Schritt zur Konstruktion der Idealtypen hat in Anwendung der phänomenologischen Methode über eine unreflektierte Wahrnehmung der individuellen Gegenstände und Erlebnisse hinaus hin $z u$ einem "begreifenden Denken" zu erfolgen $^{186}$. Die konkrete, auf reale Gegenstände gerichtete Vorstellung ist um die Gattung der "abstrakten Vorstellung" zu erweitern ${ }^{187}$. Die Parole von der "Wendung $z u$ den Sachen selbst" bedeutet demnach - und das gilt naturgemäß auch für Eucken, der diese Losung aufgenommen hat - zunächst die Überwindung einer blOß natürlichen "Geradehin-Einstellung" zu den Dingen zugunsten eines "Sich-selbst-klar-Werden(s) "188 über eben diese Einstellung und in der Folge einer reinen Erfassung des jeweiligen Gegenstandes oder Erlebnisses und dessen "adäquater Deskription" als der eigentlich phänomenologisch interessanten Sache ${ }^{189}$.

Eucken beschreibt diesen Vorgang mit einem zitat von Christian Morgenstern: "Man sieht oft etwas hundertmal, tausendmal, ehe man es zum allerersten Mal wirklich sieht" ${ }^{190}$.

Die "Einklammerung der (realen) Lebenswelt durch deren bewußt gemachte und gedachte Wahrnehmung"191 im wege eines Akts der Reflexion kann dem phänomenologischen Forscher allerdings nur unter Beachtung einer notwendig dreifachen Ausschaltung gelingen; es ist von allem subjektiv-Emotionalen ebenso abzusehen, wie vom aktuellen stand der wissenschaft und der Tradition. ${ }^{192}$

Da die Methode bei Eucken der Neuformulierung eines Paradigmas dienen soll, muß das bewußt Wahrgenommene in einem weiteren Erkenntnisschritt auf seine verallgemeinerungsfähigen, wesentlichen Inhalte reduziert werden. Daß Eucken gerade in diesem Zusammenhang erklärtermaßen auf die phänomenologische Methode E. Husserls zurückgegriffen hat, war bereits deutlich geworden. ${ }^{193}$

Demzufolge ist, um den abstrakten Inhalt aus seinem konkreten Hintergrund hervorzuheben und das Wesen bzw. die Wesens- 
gesetzlichkeiten des jeweiligen Gegenstandes oder Erlebnisses erfassen zu können, über die Reflexion auf das Gegenständlich-Typische und die Deskription des bewußt Gegebenen hinaus, alles Faktische abzustreifen ${ }^{194}$. Dieser Schritt gelingt mit Hilfe des der Wesensschau eigentümlichen Verfahrens der Abstraktion im positiven oder pointierend-hervorhebenden Sinne ${ }^{195}$ oder - wie E. Husserl es später nennt - der "eidetischen Reduktion"196.

Der durch das Verfahren vollzogene Übergang "vom singulären, individuell erfahrenen, räumlich-zeitlich bestimmten Faktum zum notwendig-allgemeinen Eidos", zur Essenz des Realen ${ }^{197}$, bedeutet zugleich den Übergang in den Bereich der reinen Möglichkeiten und den Bereich der zulässigen Freisetzung der Phantasie. Der Akt der Wesensschau ist daher konsequent ein Akt freier Denktätigkeit, in dem, durch die Entbindung von allem faktisch Vorhandenen, das Wesen in "freier schöpferischer Variation" in der Phantasie des Suchenden erzeugt und geformt wird ${ }^{198}$. Da Ausgangspunkt der Variation allerdings der individuelle Gegenstand oder das tatsächlich gegebene Erlebnis bleibt, besteht der Kreationsakt darin, das "leitende Vorbild"199 auf seine möglichen Erscheinungsformen hin zu durchleuchten. "Es zeigt sich dann, daß durch diese Mannigfaltigkeit von Nachgestaltungen eine Einheit hindurchgeht, daß bei solchen freien Variationen eines Urbildes ..., in Notwendigkeit eine Invariante erhalten bleibt als die notwendige allgemeine Form, ohne die ein derartiges wie dieses Ding, als Exempel seiner Art, überhaupt undenkbar wäre. Sie hebt sich in der Übung willkürlicher Variation, und während uns das Differierende der Varianten gleichgültig ist, als ein absolut identischer Gehalt, ein invariables Was heraus, nach dem sich alle Varianten decken; ein allgemeines Wesen"200. Die Freilegung der invarianten Grundstruktur mit Hilfe der Wesensanalyse, die eo ipso "auf Wesen, auf Essenzen, auf allgemeine Gegenständlichkeiten gerichtete Erkenntnis" ist ${ }^{201}$, läßt damit auch deutlich werden, was dem jeweiligen Untersuchungsgegenstand bloß zufällig und einzelfall- 
bezogen anhaftet und nicht zu seiner Idee gehört und was ihm als identisches, wesentliches Moment in "einer im Prinzip endlosen Serie eingebildeter Veränderungen" immer zukommt ${ }^{202}$. In dieser Weise wird die Vagheit und Relativität des empirisch festgestellten (Individual-) Typus überwunden.

Eine solche "formale ontologie" 203 als Lehre von den grundlegenden Prinzipien der Wissenschaft überhaupt ist als ein den Tatsachenwissenschaften vorgeordnetes, theoretisches Fundament ohne Bezug zu deren jeweiliger Materie zu denken ${ }^{204}$. Erst in einem weiteren schritt ist der vielfältige Bestand von Erkenntnissen für jede empirische Wissenschaft mit Hilfe einer entsprechend konzipierten, materialen oder wie Husserl es auch nennt, regionalen ontologie $e^{205}$ auf seine Essenzen zu untersuchen und systematisch zu erfassen.

In diesem differenzierenden Sinne ist das von Eucken angewandte, wissenschaftstheoretische Verfahren die erkenntnispraktische Umsetzung der formalen ontologie E. Husserls in eine materiale ontologie für die Region wirtschaft.

2. Die "klassische" Variationsproblematik und die Frage der selektiven Einklammerung

Die allgemeine Beschreibung der intellektuellen Bändigung und geistigen Besitzergreifung von den Grundstrukturen einer realen Erscheinung, die bei Euckens "Grundlagen der Nationalökonomie" nur für die Suche nach der "Invarianz des Gesamtstils' der Wirtschaft" Geltung beanspruchen kann, läßt allerdings das unbeantwortet, was man die "klassische" Variationsproblematik nennen kann. Ohne eine spezifische optik, ohne ein Vor-Urteil im Hinblick auf das, was aus der Mannigfaltigkeit der Attribute des jeweiligen Gegenstandes variiert werden soll, ist die Wesensschau ein im Grunde undurchführbares Unterfangen ${ }^{206}$.

Zugleich läßt diese Variationsproblematik im Rahmen der phänomenologischen Methode auch die ganz prinzipielle Frage un- 
beantwortet, nach welchen Gesichtspunkten die "Einklammerung" einer Erscheinung aus den unendlich vielschichtigen realen Zusammenhängen und Fakten erfolgt, die einem "begreifenden Denken" und einer wissenschaftlichen Erörterung letztlich zugeführt werden.

In Ergänzung der Methode wird man hier ganz allgemein davon auszugehen haben, daß es, um die "absolute Unendlichkeit"207 der geschichtlich-realen Erscheinungen zu überwinden, der wahrnehmungsmäßigen Unterteilung der Wirklichkeit bedarf. Die Prinzipien, nach denen diese Teile ausgesondert werden, bestimmen sich, da es keine "unabhängig von speziellen und 'einseitigen' Gesichtspunkten" bestehende, objektive Analyse gibt ${ }^{208}$, nach den von den jeweiligen Wertideen des Forschers bestimmten Erkenntnisinteressen ${ }^{209}$, die jeweils "(n) ur bestimmte seiten der stets unendlich mannigfaltigen Einzelerscheinungen wissenswert" 210 und wissensnotwendig erscheinen lassen"11. Da andererseits das, was der Forscher "sehen" will und als sein Erkenntnisinteresse definiert, durch die von dem jeweils herrschenden Paradigma gelieferten Wahrnehmungskategorien und die individuelle Erfahrung und Zwecksetzung des Forschens bestimmt wird ${ }^{212}$, war Eucken durch seine in den "Grundlagen der Nationalökonomie" entwickelten Problemstellungen ${ }^{213}$ und sein wissenschaftsziel gehalten, nach der von ihm als notwendig erachteten Trennung von den überkommenen, unzutreffenden Lehrmeinungen sein "Neues" zu bringen, um seine "Einklammerungen" zu rechtfertigen und das von ihm Variierte $z u$ bezeichnen.

Die "Grundlagen der Nationalökonomie" bleiben insoweit allerdings ohne eine präzise Aussage. Erst unter Verwendung der durch die wissenschaftstheoretischen und wirtschaftstheoretischen Analysen gewonnenen Ergebnisse gelingt es, die spezifische Sichtweise Euckens richtig einzuordnen. 
3. Die paradigmatische Wahrnehmungsverschiebung bei Walter Eucken

Auf den ersten Blick scheint die paradigmatische wahrnehmungsverschiebung darin $z u$ bestehen, daß nunmehr die Idee der Wirtschaftsordnung als Grundlage der Erkenntnis der wirtschaftlichen wirklichkeit entscheidend wird, die es demgemäß "einzuklammern" und deren Bauelemente es zu variieren gilt ${ }^{214}$.

Schon auf den zweiten Blick ergibt sich jedoch, daß Eucken nicht die invarianten, elementaren ordnungsformen "sieht", sondern nur eine vorwissenschaftliche Ahnung von möglichen (Ideal-) Typen hat ${ }^{215}$. Dem schöpferischen Denkakt dient als "leitendes Vorbild" nicht das geschichtlich vorgegebene, individuelle ordnungsgefüge der Gesamtwirtschaft, sondern die Perspektive Euckens ist eine ganz andere. Unter der Rubrik "Lenkung und ordnung" war auf eine programmidrige Umstülpung im Aufbau der "Grundlagen der Nationalökonomie" hingewiesen worden. Unter Rückgriff auf die dortigen Ausführungen werden die Bahnen deutlich, in denen die "geordnete Wahrnehmung"216 Euckens tatsächlich verläuft.

Die Wahrnehmungskategorie, die Eucken "einklammert" und mit Hilfe "denkender Durchdringung" 217 ins BewuBtsein hebt, ist auch im Hinblick auf die Frage nach der Gesamtordnung nur das einzelne Wirtschaftsgebilde, dessen wesenhafte Elemente in schöpferischer Variation erkannt werden. Es offenbaren sich "diejenigen Gleichförmigkeiten, die für die Nationalökonomie entscheidend sind"218: das rationale Handeln nach Plänen. "Zu allen Zeiten und überall vollzieht sich das menschliche Wirtschaften in Aufstellung und Durchführung von Wirtschaftsplänen. Auf Plänen beruht also alles wirtschaftliche Handeln"219. Nur über eine Untersuchung des Plans und seines Zustandekommens kann deshalb die exakte, "systematische Bestimmung der reinen Formelemente, aus denen alle historischen Wirtschaftsgebilde gebaut sind", gelingen ${ }^{220}$. Indem Eucken so den Plan als originär identifizierte Inva- 
riante heraushebt und als konstitutives Kriterium allen wirtschaftens betrachtet, hat er aus der endlosen Zahl denkbarer ordnungsrelevanter Fakten das "Merkmalschema" isoliert, das ihm als Grundlage der Idealtypenbildung und damit letztlich zur systematisierung der geschichtlich gegebenen ordnungen dient ${ }^{221}$.

Auch dieser Vorgang findet sich bei E. Husserl präzise beschrieben: "Ideen, reine Allgemeinheiten, können selbst wieder als Varianten fungieren; dann ist aus ihnen in höherer Stufe ein Allgemeines herauszuschauen, eine Idee aus Ideen oder von Ideen"222.

Damit wird deutlich, daß der "eidetische Idealtypus ${ }^{223}$ nicht aus dem gedanklich unbearbeiteten Erfahrungsmaterial, sondern nur in der reinen Ratio nach vorheriger selektion und Reduktion des vielfältigen wirtschaftlichen Geschehens auf das nach der subjektiven Einschätzung Euckens und das nach seiner persönlichen Deutung der wirtschaftlichen Grundtatbestände maßgebliche Kriterium des Planes gewonnen wird. Erst mit Hilfe dieses methodischen Kunstgriffes erhält die Idee des Idealtypus sinn und letztlich gleichförmige Konturen ${ }^{224}$. Geleitet durch die richtige nationalökonomische Fragestellung nach der ordnung ${ }^{225}$ wird der Gegenstand der wissenschaftlichen Betrachtung im reinen Intellekt erzeugt ${ }^{226}$ und als Erkenntnisobjekt in die wirtschaftliche wirklichkeit hineingesehen $^{227}$.

Ihre genetische Begründung weist nach, daß die Euckenschen Idealtypen damit in keinem Fall unmittelbar "aus der konkreten Wirklichkeit gewonnen"228, sondern in einem "psychologischen Prozeß"229 ohne den für die Bildung einer wirklichkeitsnahen, realistischen Theorie notwendigen empirischen Bezug konstruiert sind ${ }^{230}$. Auch sie sind demnach nichts anderes, als das, was M. Weber als das Ergebnis jeder fortschreitenden Abstraktion prognostiziert hat: Utopien. 
4. Das Ergebnis der Kritik der Idealtypenbildung

Als Ergebnis der Kritik der Idealtypenbildung bleibt damit festzuhalten, daß aufgrund der besonderen Perspektive Eukkens von vornherein nur ein limitiertes Instrumentarium zur Erkenntnis der wirklichkeit bereitsteht, das sie bereits in wesentlichen zügen präformiert, klassifiziert und ihres geschichtlich-sozialen Kontextes beraubt ${ }^{231}$.

Diese Feststellung soll nicht in Frage stellen, daß die von Eucken konzipierte Lehre vom Dualismus der Wirtschaftssysteme und die darauf aufbauende Theorie die Nationalökonomie gezwungen hat, tradierte Fragestellungen $\mathrm{zu}$ überdenken und im Laufe der durch den neuen Ansatz initiierten Diskussion die tatsächlichen wissenschaftlichen Probleme konkreter und gedrängter zu fassen, Unerhebliches auszusondern und so insgesamt theoretischen Ballast abzuwerfen, der den wissenschaftlichen Fortschritt zur Erkenntnis der wirtschaftlichen wirklichkeit hinderte. Eucken hat die eingefahrenen Gleise der Nationalökonomie verlassen und darin liegt sein eigentliches Verdienst.

Nicht zu leugnen ist indes, daß auf der Grundlage der heuristischen Idee der ordnung und dem monistischen Merkmal der Aufstellung und Koordination von Plänen die vielfalt wirtschaftlichen Tuns in allen Zeiten in der von Eucken angestrebten Gesamtheit nicht $z u$ erklären ist und der Zugriff auf die komplexen wirtschaftlichen zusammenhänge nicht gelingen kann. Bereits die von Eucken selbst exemplarisch durchgeführte Analyse einiger Wirtschaftsordnungen schürt diese Zweifel, denn sie bleibt jeweils rudimentär und erfüllt erkennbar den Anspruch, die Gesamtzusammenhänge wirtschaftlichen Tuns aufzudecken, nicht ${ }^{232}$. Was Eucken gelingt, ist die stringente "Ausbildung einer strengen" Theorie $e^{233}$ auf hoher Abstraktionsebene und mit deren Hilfe die Bestimmung geschichtlicher Wirtschaftsordnungen nach dem systematisierenden Kriterium des Planes sowie dem sich aus einer bestimmten Plankonstellation ergebenden, theoretischen Wirt- 
schaftsablauf. Was Eucken bereits aufgrund des von ihm angewandten, schwerlich objektivierbaren Verfahrens ${ }^{234}$ nicht gelingen kann, ist die Darstellung und Erklärung der jeweiligen Eigenart und Besonderheit individuell-historischer wirtschaftlicher wirklichkeit, die ihm immer nur als "Schnittund Treffpunkt" seiner Idealtypen und niemals als "quantitativ und qualitativ Eigenes" erscheinen kann ${ }^{235}$. Das morphologische system bleibt damit, und daran ändert auch der Versuch seiner Integration in die "natürlich-geistige-politische-soziale Umwelt"236 nichts, ahistorisch und ohne den von Eucken selbst vorausgesetzten Bezug zur jeweiligen geschichtlichen wirtschaft. Der Versuch, mit Hilfe der vielfältigen Kombinationen reiner Formelemente wirklichkeitsnahe und historisch richtige Aussagen $z u$ treffen, muß deshalb scheitern, denn ein. "Baukasten (liefert) noch kein Geschichtsbild und von wenigen Bausteinen läßt sich auch nicht das Leben in einem großen Hause zeigen"237.

VI. Die nationalökonomische Theorie

1. Der logische Charakter der theoretischen Sätze

Den logischen Charakter der auf der Basis der idealtypischen Bedingungskonstellationen erarbeiteten theoretischen Sätze beschreibt Eucken als den hypothetischer Urteile über Beziehungen zwischen verschiedenen Größen, die "unumstößlich, streng notwendig, apodiktisch und keineswegs vorläufig" gelten und die mit allgemeingültigem, objektivem Wahrheitsgehalt ausgestattet sind ${ }^{238}$.

Das Prinzip, das ihm als Ableitungsschema dient, um morphologischen Apparat und Ablauftheorie zur Überwindung der "großen Antinomie" auf einen Nenner $z u$ bringen, ist der "Satz vom zureichenden Grunde", in dem für Eucken in besonderem Maße die Ratio zur Geltung kommt ${ }^{239}$. 
In Folge ihrer logischen Konstruktion sind die theoretischen Sätze zwar ungeeignet, individuell-historische Gegebenheiten $\mathrm{zu}$ erfassen und $\mathrm{zu}$ beschreiben, da sie notwendig nur Vernunftwahrheiten und keine Tatsachenwahrheiten enthalten ${ }^{240}$. Da die (idealtypischen) Bedingungen, aus denen diese Wahrheiten deduziert werden, durch Verwendung des von Eucken konzipierten Verfahrens und logisch fehlerloser Ableitung jedoch keine "willkürlichen Entwürfe der Phantasie", sondern Reduktionen von konkreten Sachverhalten auf wirklichkeitsbezogene, theoretisch reine Fälle sind, besteht die von ihm entworfene nationalökonomische Theorie für Eucken denknotwendig aus Aussagen, denen nicht nur ein hypothetischer wert im Sinne einer vorläufigen und unverbindlichen Annahme "über einen Erklärungsgrund zur Ausfüllung einer Lücke des Wissens zukommt"241, sondern diese Aussagen sind sowohl mit hypothetisch-notwendigem als auch mit wirklichkeitsnahem, absolutem Wahrheitsgehalt ausgestattet.

Die Theorie ist in ihrer Gesamtheit ein Kasten voller Denkinstrumente, mit dessen Hilfe und unter dessen Benutzung die wahren, notwendigen Zusammenhänge des Wirtschaftsablaufes, frei von "allen Modemeinungen und dem Tagesgeschwätz der Interessenten, Laien und Literaten" ${ }^{242}$ begriffen und verständlich gemacht werden können. Damit ist für Eucken das "Kernproblem der Wissenschaftslehre" gelöst ${ }^{243}$.

2. Der Erkenntniswert der nationalökonomischen Theorie

Die Theoriebildung und vor allen Dingen der von Eucken hervorgehobene Erkenntniswert der Theorie selbst ist problembehaftet. Letzten Endes können, wie im einzelnen nachzuweisen sein wird, die theoretischen Sätze den mit ihrer Schaffung angestrebten Zweck der umfassenden Überwindung der "großen Antinomie" und damit des Theorie-Geschichte-Problems nicht erfüllen. 
Der von Eucken zitierte und von Leibniz formulierte "Satz vom zureichenden Grund" ist nach H. Albert ${ }^{244}$ eine Ausformung der Idee der positiven Rechtfertigung, die als allgemeines Postulat die klassische Methodologie des Denkens beherrschte. Nach dieser Idee bedarf jede Aussage einer zureichenden Begründung durch die Reduktion auf letzte, mit unantastbarer Autorität ausgestattete Quellen, die im Wege des logischen Ableitungsverfahrens diese Eigenschaft auf das zu Begründende transferieren ${ }^{245}$.

Das auf diesem Prinzip basierende hypothetische Urteil Euckens, das dieser im strengen Sinne der Logik als: "Wenn A ist, ist C" definiert ${ }^{246}$, ist demnach eine Aussage, die als Dann-Komponente das logische Implikat einer gesetzten WennKomponente ist ${ }^{247}$. Diese Kopula charakterisiert die Theorie Euckens als ein axiomatisch-deduktives System von Aussagen, in dem nach den Regeln der tautologischen Transformation aus Axiomen (als Vorderglieder) auf die theoretischen Sätze (als Hinterglieder) geschlossen wird ${ }^{248}$. Besteht die Theoriebildung demnach in der Formung neuer bzw. zusätzlicher Aussagen aus den vorgegebenen Axiomen, kann der theoretische Gehalt der deduzierten Aussagen selbst nur mit dem der Axiome identisch sein ${ }^{249}$, das heiBt, sie sind nichtssagend im Hinblick auf nicht bereits axiomatisch gesicherte Informationen.

Damit offenbart sich ohne weiteres die tatsächliche logische struktur der "korrekt gewonnenen Theorie"250. Sie besteht, da ohne Beachtung empirischer Tatsachen allein nach den Regeln der Logik gewonnen, zwangsläufig aus analytischen Urteilen, deren sinn sich in einer bloß formalen Beziehung erschöpft ${ }^{251}$ und deren Wahrheitsgehalt sich allein nach der Übereinstimmung mit den gesetzten Bedingungen und den angewandten Regeln der Logik bemiBt. Nur dies sind die "Kontrollinstanzen", anhand derer solche analytisch-konditionalen Aussagen überprüft werden können ${ }^{252}$. Ihr Anspruch auf objektives, überzeitlich gültiges Wissen um den Ablauf der wirtschaft gründet mithin nicht in der Konkordanz mit der wirtschaftlichen 
Wirklichkeit, sondern ausschließlich in logisch stringenter Normgemäßheit und inhaltlicher Identität.

Der denkbare Erkenntnisbeitrag der von Eucken gebildeten theoretischen Sätze ist damit nur analytischer Natur, das heißt, der durch sie vermittelte Sachverhalt ist nur logisch wahr ${ }^{253}$. Sie gelten, da eben nur den logischen Prinzipien der Identität und des Widerspruchs gehorchend ${ }^{254}$, bei fehlerloser Ableitung unabänderlich, überzeitlich und allgemein, wobei die Frage, wie die Realzusammenhänge im einzelnen tatsächlich beschaffen sind, nicht in den Blick kommt, da keine empirische Erfahrung diese Urteile zu widerlegen in der Lage ist $^{255}$.

Ist die Euckensche Theorie somit aufgrund ihrer logischen Konstruktion ein durch Idealgesetzlichkeiten ausgezeichnetes System ${ }^{256}$, das einen lediglich analytisch-apriorischen Erkenntnisbeitrag zu leisten vermag, muß es erstaunen, daß ihr Eucken in klarer Einsicht in diesen Charakter als (nur) formale Vernunftwahrheit einen scheinbar unbeschränkten empirischen Geltungsanspruch bescheinigt. Diese Einschätzung ist eine Folge des Vertrauens in die Leistungsfähigkeit des korrigierten rationalistischen Verfahrens, das nach Ansicht Euckens inhaltlich wahre Aussagen über die wirtschaftliche wirklichkeit aufgrund methodischen Kalküls verbürgt. Dabei haben die wahren, idealtypischen ordnungsformen unabhängig von allen erfahrbaren Sachverhalten und ohne jede empirische Kontrolle Bestand.

Erinnert man sich an die kritische würdigung der Idealtypenbildung und die bereits dort angesprochenen Bedenken im Hinblick auf die Eignung des gewonnenen morphologischen Apparats als Prämisse eines axiomatischen systems, wird deutlich, wo Euckens Irrtum liegt. Die Schwierigkeiten auch seines korrigierten Rationalismus liegen in der Frage begründet, wie in ein gegen Erfahrung immunisiertes system Informationen über tatsächliche, wirtschaftliche Vorgänge aufgenommen bzw. weitergegeben werden können, wie also, 
prinzipieller formuliert, im Schutze der Logik und methodischer sicherheit empirisches Wissen erworben werden $\mathrm{kann}^{257}$.

Im Rahmen der Methodologie der mittelbaren, weil nur deduzierten Erkenntnis, bei der der aus den Axiomen transformierte (Schluß-) Satz nur das enthalten kann, was sich in den Axiomen an Informationen findet, ist jede deduzierte Erkenntnis nur in ihrer funktionalen Abhängigkeit von der jeweiligen Ausstattung der Prämissen zu begreifen. Damit ist der Ansatzpunkt für die Transformation von Informationen im axiomatisch-deduktiven system offengelegt.

Nur die Bildung empirischer, informationsgesättigter Prämissen als Vorderglieder der logischen Implikation erlaubt es, Aussagen auch mit empirischem Erklärungswert abzuleiten. Hier liegt "die Quelle der Fruchtbarkeit der Deduktion"258. Diese Quelle ist bei Eucken versiegt bzw. sie konnte im Hinblick auf die angestrebten wirklichkeitsnahen und doch denknotwendigen Theorien der Nationalökonomie nie sprudeln, denn die gewonnenen Vernunftwahrheiten haben keine Aussicht, zu Erkenntnissen zu führen, die für die Erklärung realer Zusammenhänge brauchbar sind. Um dieses ziel zu erreichen, hätte Eucken von der nur intellektuellen, der "reinen Ratio" verpflichteten Konstruktion seiner in die Form des zweiten Hauptproblems der Nationalökonomie gegossenen idealtypischen Ordnungsformen der Wirtschaft Abstand nehmen müssen, um sie als für den angestrebten Zweck geeignete Axiome einsetzen zu können. In der durch das pointierend-hervorhebende Abstraktionsverfahren geprägten Form sind sie, entgegen seiner Ansicht, daß gerade die Verwendung dieser Methode die Gewinnung von Modellen mit empirischen Aussagen gewährleistet ${ }^{259}$, im Hinblick auf die Übertragung von wissen über die wirtschaftliche Wirklichkeit Leerstellen ${ }^{260}$. Schon der Anspruch Euckens, Aussagen mit objektivem Wahrheitsgehalt über die Struktur wirtschaftlicher Realität machen $z u$ können, indiziert dieses Ergebnis. 
Axiomatische systeme mit tatsächlichem Erklärungswert bestehen aus allgemeinen, empirisch gehaltvollen Aussagen mit Gesetzescharakter, die weder apodiktisch noch logisch notwendig oder wahr, sondern lediglich hypothetischer Natur sind ${ }^{261}$. Diese für eine realwissenschaftliche Theorie charakteristischen, informativen, wie sie H. Albert ${ }^{262}$ nennt, "nomologischen Hypothesen" bestehen aus einer empirisch nachprüfbaren Verbindung von Wenn-Komponente und Dann-Komponente, die sich als bestätigungsbedürftige Behauptung über das Vorhandensein bestimmter empirischer Regelmäßigkeiten bei einer Überprüfung bewahrheiten oder wegen inneren widerspruchs des Systems selbst oder schlicht an der Erfahrung scheitern ${ }^{263}$.

Eine solche Theorie ist damit niemals objektiv wahr, sondern sie bleibt stets im Versuchsstadium, das heißt im stadium eines permanenten Wechselspiels von Vermutung und Widerlegung, das mit der methodischen und logischen sicherheit eines nur bei sich selbst verbleibenden, unumstößlichen, streng notwendigen, apodiktischen und allgemeingültigen Denkens nichts gemein hat. ${ }^{264}$

Das bedeutet nun keineswegs, daß die theoretischen sätze Euckens das Werk eines esoterischen Forschers sind, denn trotz ihres bloß analytischen Erkenntnisbeitrages kommt ihnen eine wesentliche Bedeutung $\mathrm{zu}$, die man als rationale Heuristik bezeichnen kann. Sind die Bedingungskonstellationen so konstruiert, daß ihr grundsätzlicher Realitätsbezug nicht in Frage steht, so können mit ihrer Hilfe alle denkbaren logischen Konsequenzen, genauer: alle "logisch möglichen Handlungen und Ergebnisse des Wirtschaftsprozesses" abgeleitet werden ${ }^{265}$. Nur: über die Sachen selbst und deren tatsächliche Beschaffenheit sagen diese theoretischen Sätze nichts aus. 
3. Der Schritt zur Wirklichkeit - Wahrheit und Aktualität der nationalökonomischen Theorie

Der vorstehenden Kritik scheint die von Eucken in Aussicht gestellte Anwendung des morphologischen Apparates und der theoretischen Sätze zur wissenschaftlichen Erkenntnis der Wirtschaftsordnung und des Wirtschaftsablaufes an einem konkreten ort $z u$ einer bestimmten Zeit entgegenzustehen. Diese Wendung von den ohne Bezug $z u$ "einem bestimmten historischen Milieu"266 durch pointierend-hervorhebende Abstraktion gewonnenen, theoretischen Typen ${ }^{267}$ und Theorien hin zu den Sachen, d.h. zu den konkreten geschichtlichen ordnungsgefügen soll nach Auffassung Euckens mit Hilfe einer von ihm so genannten "doppelten Synthese" und der Unterscheidung von Wahrheit und Aktualität des theoretischen Apparates ${ }^{268}$ gelingen. Dem "historistischen Vorurteil"269, demzufolge theoretische Erkenntnis stets nur zeitgebundene und damit relative Gültigkeit für eine bestimmte geschichtliche Lage besitzen kann, hält Eucken entgegen, daß die vielfältigen Realitäten geschichtlichen wirtschaftens allein durch Anwendung des allgemeingültigen, zeitlosen morphologischen Systems, das die "Urformen" beinhaltet ${ }^{270}, \mathrm{zu}$ erkennen sind. Die Konstruktion ständig neuer, reiner Formen und besonderer Theorien für jede geschichtlich verwirklichte wirtschaftsordnung ist zum einen ein undurchführbares Unterfangen, zum anderen hätten solche einzelfallbezogenen, theoretischen studien nur die zusammenhanglose Anhäufung theoretischen Wissens zur Konsequenz, das im Hinblick auf die Untersuchung anderer historischer Wirtschaftsordnungen inhaltsleer und nichtssagend und darüber hinaus außerstande wäre, die geschichtlichen Veränderungen der Wirtschaft aufzuzeigen und nachvollziehbar zu machen ${ }^{271}$. Nur die Anwendung des morphologischen Apparates und der theoretischen sätze läßt die jeweiligen Besonderheiten geschichtlicher ordnungen offenbar werden und stellt sie in den Kontext geschichtlichen seins und werdens. "Bach und Mozart und Beethoven und andere Musiker haben ihre werke in 
Kombination einer begrenzten zahl von Tönen, die alle brauchen, geschaffen. In der Besonderheit der Konstruktion besteht auch die Besonderheit des einzelnen Meisters oder des einzelnen Werkes, nicht etwa in der Neuschaffung von Tönen"272. Gleiches gilt für die wirtschaftsordnungen, die in ihrer Individualität nicht durch "jeweils ganz neue reine Formen", sondern durch die besondere Art der Verschmelzung der jeweils verwirklichten, in ihrer zahl begrenzten und übersehbaren reinen Formen des wirtschaftens gekennzeichnet $\operatorname{sind}^{273}$.

Dem von Eucken nicht bestrittenen Umstand, daß sein morphologisches system bereits aufgrund des angewandten wissenschaftstheoretischen Systems kein Abbild der konkreten Wirklichkeit ist und über diese nichts sagt, wird Abhilfe dadurch zuteil, daß die idealtypischen ordnungsformen in einer "doppelten synthese" an die geschichtliche wirklichkeit herangeführt und "aktualisiert" werden. In einer ersten Synthese sind die als "Bauelemente" der konkreten Wirtschaft erkannten und damit "aktuellen" Bestandteile des morphologischen Systems zur Einheit der wirtschaftsordnung zusammen und in einem zweiten schritt "in die jeweilige natürlichgeistige-politisch-soziale Umwelt" einzufügen ${ }^{274}$. Die von den konkreten geschichtlichen zusammenhängen zeitweise abgelöste wirtschaftsordnung wird in die jeweilige geschichtliche Gesamtsituation eingestellt und damit auch nach ihren nichtwirtschaftlichen Zusammenhängen transparent ${ }^{275}$. "Die Ordnungsformen haben rein nur im Denken Bestand, aber verschmolzen konstituieren sie jede ordnung" ${ }^{276}$.

Die zum Einsatz kommenden ordnungsformen bilden darüber hinaus die einfachen, überschaubaren Bedingungskonstellationen, auf deren Grundlage die jeweils einschlägigen theoretischen Sätze zur Anwendung kommen, durch die die Erfassung des jeweiligen wirtschaftsablaufes gelingt. "Wie also die Erkenntnis der konkreten geschichtlichen ordnungen durch Anwendung des morphologischen Apparates durchgeführt wird, 
so die Erkenntnis des konkreten wirtschaftsablaufes durch Anwendung der theoretischen Sätze"277.

Die grundsätzliche Unterscheidung, die Eucken demnach vollzieht, ist die zwischen "Wahrheit" und "Aktualität" des von inm erarbeiteten theoretischen Instrumentariums. Wie bei einem bestimmten Wort nur bestimmte Buchstaben des Alphabetes aktuell sind, "braucht auch bei Bestimmung einer konkreten Wirtschaftsordnung nur ein Teil des Alphabetes der reinen Formen angewandt werden"278. Über die in Kraft gesetzten Teile des morphologischen Apparates gewinnen dann auch die einschlägigen allgemein-gültigen, theoretischen Sätze an Aktualität. Aus dem vorhandenen Bestand an zeitlos gültiger, wahrer Erkenntnis werden die jeweils passenden und einschlägigen Teile aktualisiert. Die übrigen harren als "unbenutztes Inventar der Wissenschaft" 279 der anderweitigen Verwendung.

Dieser letzte Schritt der Aktualisierung des theoretischen Werkzeugkastens scheint letztlich doch noch zur Bildung von Wirklichkeitsaussagen über den Bereich der wirtschaft $z u$ führen, die Aufschluß über die konkrete Wirtschaftsordnung und Einblicke in den historisch-individuellen wirtschaftshergang durch Einschränkung des totalen Spielraums der 10gisch möglichen Handlungen und Ergebnisse des Wirtschaftsprozesses auf einen räumlich und zeitlich bestimmten Geltungsbereich gewähren. Der mögliche Erklärungswert der "aktualisierten" Theorie wäre um so größer, je präziser die in der Wenn-Komponente erfaßten Idealtypenkombinationen bereits der wirklichkeit entsprächen. Allein die Kommentierung des Aktualisierungsprozesses durch Eucken selbst zeigt, daß diese Wendung $\mathrm{zu}$ den Sachen nicht gelingen kann, vielmehr der Vorwurf, den er im Zusammenhang mit der schaffung einer zeitgebundenen Theorie gegenüber vielen "hervorragenden Nationalökonomen" erhebt, die zwar auf die dringende Notwendigkeit einer Theoriebildung hingewiesen, aber "bis zum heutigen Tage noch nicht eine einzige solche Theorie mit 
Erfolg konstruiert" hätten ${ }^{280}$, auch für ihn selbst Gültigkeit besitzt.

Voraussetzung für die Erarbeitung einer Theorie sind nach Eucken übersehbare, einfache Bedingungskonstellationen. Damit kann die "Aktualisierung" der theoretischen sätze nicht darin bestehen, für alle möglichen Verschmelzungen der reinen ordnungsformen jeweils "eine besondere Theorie zu konstruieren"281. Ein solches Vorhaben müßte schon deshalb mißglücken, weil die Zahl der denkbaren Formelemente vielgestaltig und komplex ist. Die auf der Basis der Idealtypen entwickelten Theorien sind nach Ansicht Euckens ausreichend, um den individuell-historischen Aufbau der wirtschaft und den konkreten Wirtschaftsablauf zu erklären ${ }^{282}$.

Die nationalökonomische Theorie ist, das wird damit deutlich, als universales Erkenntniswerkzeug ungeeignet, da niemals "der einzelne konkrete Fall in seiner Besonderheit" 283 beschrieben wird. Die Theorie kann, wenn überhaupt, Teilaspekte wirtschaftlicher Wirklichkeit erfassen ${ }^{284}$, denn es ist nicht möglich, "nach dem Zusammensetz- oder 'Baukasten'Prinzip"285 die Gesamtzusammenhänge des wirtschaftlichen Al1tages theoretisch einsichtig zu machen, da die Verschmelzung der reinen ordnungsformen je nach Art und Grad ihrer verbindung jeweils eine "neuartige situation" schafft ${ }^{286}$. Diese jeweils neue, individuelle wirtschaftliche situation ist mit dem theoretischen Instrumentarium Euckens nicht zu erklären. "Jeder korrekt gewonnene theoretische Satz ist stets 'wahr', aber er wird nur dann 'aktuell', wenn an bestimmtem ort und zu bestimmter zeit die Bedingungskonstellation verwirklicht ist, für die er gilt"287. Da eine solche Konstellation im Hinblick auf die "Gesamtheit der Formen, in denen die Lenkung des alltäglichen wirtschaftsprozesses in concreto" stattfindet ${ }^{288}$, nicht denkbar ist, bleibt die nationalökonomische Theorie Euckens zwar "wahr", sie wird jedoch aufs Ganze gesehen niemals "aktuell". Wenn aber die Aktualität gegen Null strebt, ist letzten Endes auch die Wahrheit ohne Wert ${ }^{289}$. 
Der Schritt zur Wirklichkeit bringt damit die kritischen Anmerkungen zur nationalökonomischen Theorie Euckens nicht ins Wanken, denn es gilt auch für ihn der Satz A. Feuerbachs: "Zwischen dem Absoluten und der Geschichte (...) gibt es keine Versöhnung" 290 .

\section{Abschnitt \\ Die wirtschaftspolitischen Grundsätze}

\section{A. Das Verhältnis von theoretischer Erkenntnis und wirt- schaftspolitischer Entscheidung}

\section{Das duale Wissenschaftsverständnis Walter Euckens}

Der zweigeteilte Aufgabenbereich der Nationalökonomie, den Eucken - allgemeiner - als die zwei Seiten der Sozialwissenschaften bezeichnet ${ }^{291}$, hat die prinzipielle Unterscheidung von nationalökonomisch-theoretischer Erkenntnis und wirtschaftspolitischer Entscheidung zur Grundlage.

Die Erforschung der varianten und rasch wechselnden wirtschaftsordnungen mit Hilfe des dargestellten rationalistischen Abstraktionsverfahrens, das die konstituierenden, unveränderlichen Merkmale dieser ordnungen rein zum Vorschein brachte, war die eine große, wissenschaftliche Aufgabe, die Eucken in den "Grundlagen der Nationalökonomie" zu lösen suchte ${ }^{292}$.

Die theoretische Arbeit bildet ihrerseits die Basis für die Bewältigung der zweiten Aufgabe: die Entscheidung, in welcher Form die "ordnende Ratio" die moderne, industrialisierte Welt zu gestalten hat ${ }^{293}$. Jede einzelne, zu diesem Zweck in Angriff genommene Maßnahme muß nach der Vorstellung Euckens in ihren Auswirkungen auf die Gesamtordnung und den Gesamtprozeß begriffen werden, die ihrerseits in ihrer wirt- 
schaftspolitischen Relevanz nur durch die Anwendung des morphologischen Apparates und die theoretischen Sätze einsichtig werden. Nur dann, wenn sich der wirtschaftspolitisch Verantwortliche damit des Euckenschen Kastens voller theoretischer Instrumente bedient, kann er sicher sein, die ordnungsproblematik richtig erfaßt und eine angemessene Lösung für die anstehenden ordnungsfragen parat $z u$ haben ${ }^{294}$.

Damit ist das Verhältnis von Theorie und Politik, die die Gestaltung der ordnung der wirtschaftlichen und gesellschaftlichen Wirklichkeit zum Gegenstand hat, dem Grunde nach gekennzeichnet. Die theoretischen Grundlagen geben die Folien ab, auf denen die wirtschaftliche wirklichkeit nachgezeichnet wird ${ }^{295}$, genauer: die reinen ordnungssysteme werden zu Vorlagen wirtschaftspolitischer Gestaltungsmöglichkeiten. Mit diesem Funktionswandel ist nun allerdings noch keine Aussage darüber verbunden, welches der beiden zur Auswahl stehenden, theoretischen systeme - Verkehrswirtschaft oder zentralgeleitete Wirtschaft - der Verwirklichung würdig ist. Die Resultate der Theorie allein sind wertfrei, der der Erkenntnis und Erklärung der wirtschaftlichen wirklichkeit dienende theoretische Apparat muß um eine teleologische Stellungnahme ergänzt werden, die die von Eucken konstruierten Modelle und Modellzusammenhänge als Grundlage für eine wirtschaftspolitische Entscheidung dem Bereich der normativen Sozialordnung ${ }^{296}$ zuweist. Die mit einer solchen stellungnahme verbundene Bewertung der in vorurteilsfreier ${ }^{297}$, wissenschaftlich-theoretischer Arbeit entwickelten Idealtypen und theoretischen Sätze kennzeichnet dann diejenige ordnung der wirtschaft, die als wirtschaftspolitische Handlungsalternative bestimmten zielvorstellungen korrespondiert. Der zweite, der Wissenschaft von Eucken übertragene Aufgabenbereich der wertenden Gestaltung der Realität fordert damit, den Boden der sicheren theoretischen Urteile über das wirtschaftliche sein $z u$ verlassen und "in das verbotene und unheimliche Gelände der 'Werturteile', das von den Warnungstafeln Max Webers umstellt ist" 298 , einzudringen. Die Ausein- 
andersetzung Euckens mit M. Weber und dessen Postulat der Wertfreiheit wissenschaftlicher Erkenntnis kommt deshalb nicht überraschend ${ }^{299}$.

Das von Eucken festgestellte "Bedürfnis nach einer praktisch brauchbaren Wissenschaft" ${ }^{300}$ und die damit grundsätzlich verbundene stellungnahme zur Frage der Wertfreiheit wissenschaftlicher Erkenntnis ${ }^{301}$ werden indes nur dann verständlich, wenn man die von Eucken der Kritik unterzogene wissenschaftliche Position M. Webers und dessen strikte Ablehnung der "Vermischung wissenschaftlicher Erörterung der Tatsachen und wertender Räsonnements"302 dem Euckenschen Wissenschaftsverständnis kontrastiert ${ }^{303}$.

1. Zur grundsätzlichen Unterscheidung von theoretischem Idealtypus und politischem Ideal nach Max Weber

Für M. Weber liegt der Zweiteilung des Aufgabenbereiches der Wissenschaft "die an sich höchst triviale Forderung" zugrunde, "daß der Forscher und Darsteller die Feststellung empirischer Tatsachen (...) und seine praktisch wertende, d.h. diese Tatsachen als erfreulich oder unerfreulich beurteilende, in diesem sinne 'bewertende' stellungnahme unbedingt auseinander halten solle, weil es sich da nun einmal um heterogene Probleme handelt". Denn: "Ob Blondinen den Brünetten vorzuziehen seien, oder (...) ähnliche subjektive Geschmacksurteile (...) sind Probleme der Wertphilosophie, nicht der Methodik der empirischen Disziplinen. Worauf allein es für diese ankommt, ist: daß einerseits die Geltung eines praktischen Imperativs als Norm und andererseits die Wahrheitsgeltung einer empirischen Tatsachenfeststellung in absolut heterogenen Ebenen der Problematik liegen und da $\beta$ der spezifischen Dignität jeder von beiden Abbruch getan wird, wenn man dies verkennt und beide sphären zusammenzuzwingen sucht" ${ }^{304}$. 
Hinter dieser Verbindung, oder besser: fehlenden Verbindung von Tatsachen- und Werterkenntnis steht das, was bei $M$. Weber als der grundlegendste aller Gegensätze erscheint, nämlich derjenige "von Sein und Sollen oder zwischen wirklichkeit und Norm und Wert"305. Dies Trennung und die dadurch hervorgerufene scheidung in die Bereiche von wissenschaft und Politik, deren jeweils autonome Behandlung notwendig wird ${ }^{306}$, birgt zugleich die Antwort auf die Webersche Frage nach der Geltung der Werturteile und der Möglichkeit deren "wissenschaftlicher Erörterung" 307.

$\mathrm{Da}$ es keine logisch durchgängige Begründungssequenz gibt, die den Schluß von der wissenschaftlichen Tatsachenerkenntnis auf den normativen wertcharakter einer realitätsgestaltenden Tätigkeit zuläßt, muß M. Weber die Ansicht, "daß die Nationalökonomie Werturteile aus einer spezifisch 'wirtschaftlichen Weltanschauung' heraus produziere und $z u$ produzieren habe (...) grundsätzlich ablehnen, denn wir sind der Meinung, daß es niemals Aufgabe einer Erfahrungswissenschaft sein kann, bindende Normen und Ideale zu ermitteln, um daraus für die Praxis Rezepte ableiten zu können"308. Der Fähigkeit und der Notwendigkeit, zwischen intersubjektiv überprüfbaren, theoretischen Aussagen und normativen Werturteilen, insbesondere wirtschaftspolitischen zielsetzungen unterscheiden zu können bzw. zu müssen ${ }^{309}$, fällt notwendigerweise die Möglichkeit zum opfer, "die Maßstäbe seines Urteils dem 'Stoff' $z u$ entnehmen, d.h. die 'Idee' im sinne des Ideals aus der 'Idee' im Sinne des 'Idealtypus' herauswachsen zu lassen", da für dieses Unternehmen "keinerlei (rationales oder empirisches) wissenschaftliches Verfahren irgendwelcher Art" zur Verfügung steht ${ }^{310}$. Deshalb können die zu theoretischen Zwecken "nützlichen Fiktionen der reinen oekonomik (...) nicht zur Grundlage von praktischen Wertungen (...) gemacht werden" ${ }^{311}$.

Entgegen dem von Eucken gegenüber $M$. Weber erhobenen Vorwurf, einem positivistischen Vorurteil zu erliegen - mit der 
Folge, daß "Entscheidung und Engagement als philosophisch uninteressant in den Bereich der Subjektivität und Willkür" verwiesen werden ${ }^{312}$ - bedeutet für letzteren das Prinzip der Wertfreiheit "keineswegs, daß Werturteile deshalb, weil sie in letzter Instanz auf bestimmten Idealen fußen und daher 'subjektiven' Ursprungs sind, der wissenschaftlichen Diskussion überhaupt entzogen seien" ${ }^{113}$.

Der von Eucken vermeintlich festgestellte, pauschale Rückzug M. Webers aus der Welt der Werte ist demnach erheblich differenzierter $z u$ betrachten. Ausgehend von dem Grundsatz, daß "Gesinnungslosigkeit und wissenschaftliche 'objektivität' keinerlei innere Verwandtschaft" besitzen, bleibt zu prüfen, was wissenschaftliche Kritik in diesem Zusammenhang bedeutet und bezweckt und in welchem Umfang allgemeingültige Wahrheiten "auf dem Boden der Wissenschaft (...) überhaupt" möglich sind $^{314}$.

M. Webers diesbezügliche Überlegungen lassen deutlich werden, daß für ihn sowohl die empirische Gedankenarbeit ${ }^{315}$ als auch die logischen Ableitungszusammenhänge im Hinblick auf die "objektiven Werturteile" 316 und im Rahmen einer logischen Analyse insbesondere deren Rückführung auf "letzte weltanschauungsmäßige Grundpositionen" in den Bereich rationaler Kritik fallen ${ }^{317}$. Die Webersche Wertaskese betrifft lediglich die über das Verstehen und Nachvollziehen hinausgehende, kritische Beurteilung der Entscheidung für die "letzten Wertmaßstäbe" oder "Wertaxiome" und das im konkreten Fall aus ihnen abgeleitete Werturteil ${ }^{318}$.

Der Beitrag der wertfreien Wissenschaft erschöpft sich demnach in der Möglichkeit, "dem Wollenden zur selbstbesinnung auf diejenigen letzten Axiome, welche dem Inhalt seines Wollen zugrundeliegen", $z u$ verhelfen. Diesen Inhalt "zum Bewußtsein $\mathrm{zu}$ bringen, ist nun allerdings das Letzte, was sie, ohne den Boden der spekulation zu betreten, leisten kann" ${ }^{319}$. Soll die Vermischung von Tatsachenerkenntnis und Werterkenntnis vermieden werden und lehnt man deshalb mit $M$. 
Weber eine empirische Ableitung der letzten ziele des Handelns, einen naturalistischen Fehlschluß vom sein auf das Sollen ab, will man aber "dennoch normative Konsequenzen ziehen, dann muß man das betreffende Aussagensystem normativieren, d.h. durch explizite Werturteile ergänzen"320, die ihrerseits wiederum logisch von Prämissen abhängig sind, die rechtfertigender Maßstab der vorgenommenen Wertung sind ${ }^{321}$. Dieser, aufgrund der Trennung von Erkennen und Beurteilen unumgängliche Rekurs auf besondere quellen der Werterkenntnis im Hinblick auf die letzten "praktischen stellungnahmen"322 mußte auch bei $M$. Weber neben der Frage der methodischen Rechtfertigung empirischer Aussagen das Problem der Erkenntnisbedürftigkeit normativer Aussagen entstehen lassen. Die Verwendung des Begriffs "Axiom" deutet "in diesem Zusammenhang (...) darauf hin, daß er sich den Wertungszusammenhang etwa in Form eines axiomatisch-deduktiven systems" vorstellte, was den Gedanken nahelegt, daß ex sich auch im normativen Bereich am "klassischen Rationalitätsmodell" Leibnizscher Prägung orientierte ${ }^{323}$.

Allerdings muß auch die logische Analyse im Rahmen der Werteproblematik an der erkannten "Schranke der Rationalität" 324 scheitern: in keinem Fall können die Wertprämissen selbst und ihr Zustandekommen durch methodisch begründetes Vorgehen thematisiert werden. Die "schlichte intellektuelle Rechtschaffenheit" des wissenschaftlers gebietet ihm, die über das verstehende Erklären hinausreichende Geltung letzter Wertaxiome als "Sache des Glaubens", des Gewissens und der persönlichen Weltanschauung $z u$ beurteilen ${ }^{325}$. Denn es gilt, daß "jene innersten Elemente der 'Persönlichkeit', die höchsten und letzten Werturteile, die unser Handeln bestimmen und unserem Leben Sinn und Bedeutung geben" ${ }^{1326}$, einer rationalen Begründung durch irgendwelche methodischen Prozeduren entzogen und damit wissenschaftlich nicht beweisbar sind ${ }^{327}$. Damit ist es ausgeschlossen, mit dem Anspruch wissenschaftlicher objektivität und Wahrheit an die letzten, bekenntnismäßig eingeführten Axiome heranzutreten. Die Konsequenzen 
aus einer solchen Auffassung liegen auf der Hand. Es kann keine wissenschaftlich gerechtfertigte Erkenntnis allgemeingültiger Art geben, die verbindlich Werte in Form eines praktischen "Generalnenners für unsere Probleme" nachweist und dem jeweiligen politischen Handeln als Imperativ vorschreibt, sondern es bedarf der Einsicht in "die Möglichkeit prinzipiell und unüberbrückbar abweichender letzter Wertungen" ${ }^{328}$.

Dieser "weltanschauliche Pluralismus" ${ }^{329}$ und das Eingeständnis in die "Irrationalität der obersten normativen Voraussetzungen" allen Handelns führt dazu, daß es keine Autorität geben kann, "auf die die eigenen stellungnahmen als die nachweisbar allein richtigen" zurückgeführt werden könnten ${ }^{330}$. Da durch die bloße Tatsachenerkenntnis eine bestimmte politische Entscheidung nicht indiziert ist, "mußte auch Verfechtern anderer standpunkte die Souveränität ihrer Gewissensentscheidung zugestanden werden" ${ }^{331}$. Politische Anschauungen müssen demnach als "prinzipiell gleichberechtigt und - im Lichte der Wissenschaft - wahrheits-falschheits-indifferent" behandelt werden ${ }^{332}$.

Diese Freiheit, zwischen Werten wählen und entscheiden zu können, läßt für M. Weber die einförmige Ausrichtung und Bindung individueller Wertmaßstäbe nach einer mit allgemeinverbindlichem Anspruch auftretenden Wertordnung als undenkbar erscheinen. Jeder Versuch, den latenten Wertkonflikt beizulegen, muß scheitern. Es bleibt der dauernde Kampf der unterschiedlichen politischen zielsetzungen und Interessenstandpunkte und damit der Kampf der Werturteile im Hinblick auf die "letzten überhaupt möglichen Standpunkte zum Leben" ${ }^{333}$ als konstituierendes Element der politischen Praxis. 
2. Die Notwendigkeit einer praktisch brauchbaren Wissenschaft nach walter Eucken

Der im Weberschen Wissenschaftsverständnis zum Ausdruck kommenden Haltung wirft Eucken Relativismus und insbesondere eine manifeste Verkennung der tatsächlichen politischen Probleme vor. Er gesteht zwar $z u$, daß das Webersche Postulat der Wertfreiheit im Rahmen der ersten Aufgabenstellung der Wissenschaft seine Berechtigung besitze, da die theoretische Erkenntnis der Bedingungszusammenhänge des wirtschaftlichen Alltags ohne "Sentiments und Ressentiments" und vor allen Dingen ohne vorgreiflichen Blick auf die spätere wirtschaftspolitische Verwertung dieser Erkenntnis zu erfolgen hat $^{334}$. Dies ist für Eucken jedoch nur der eine Teil wissenschaftlicher Aufgabenstellung. Indem die wissenschaft die Bedingungszusammenhänge der wirklichkeit aufdeckt, vermag nur sie ein Urteil darüber zu fällen, wie die industrialisierte wirtschaft sinnvollerweise zu ordnen ist. Dem theoretisch fundierten, wissenschaftlichen Denken wächst mit der bewußten Gestaltung der Wirklichkeit "eine neue Verantwortung" $\mathrm{zu}^{335}$.

Diese Notwendigkeit einer praktisch brauchbaren wissenschaft, die theoretische Erkenntnis der Sachgesetzlichkeiten der Wirtschaft und wirtschaftspolitisches Handeln und Entscheiden verknüpft, "- das eben verkennt der Positivismus" Weberscher Prägung ${ }^{336}$. Das "positivistische Vorurteil", wie es Eucken deshalb abwertend nennt ${ }^{337}$, nach dem die Frage wissenschaftlicher Erkenntnis der wirklichkeit und deren wertende Gestaltung zwei heterogene Probleme sind und bleiben müssen - andernfalls sich der Wissenschaftler zum "Demagogen" und "Propheten" erniedrige 338 - bedingt die subordination der wissenschaft unter die Politik, was für Eucken zur Folge hat, daß sich die Wissenschaft als einzig sachkundige Potenz von der ordnungsproblematik fernhält und so den Platz schafft für den Auftritt der wirklichen Propheten und Demagogen. Den von der wissenschaft unbeeinflußten und unbeein- 
flußbaren Raum wirtschaftlicher Entscheidung werden "anarchische, politische und wirtschaftliche Machtgruppen, (...) ihre Funktionäre und Ideologien"339 okkupieren und die ordnungspolitische Aufgabe ohne Beachtung der sachnotwendigen Zusammenhänge nach ihren Vorstellungen lösen. Die Abwendung vom "positivistischen Vorurteil" und die Forderung nach einer gestaltenden "politische(n) ökonomie" 340 überbürdet Eucken allerdings nicht nur die Beweislast für den Maßstab, nachdem sich die Bewertung der in theoretischer Arbeit isolierten ordnungsformen im einzelnen $z u$ richten hat, sondern an erster stelle bedarf es des Nachweises, daß es des ordnenden Zugriffs der Wissenschaft auf die wirtschaftliche wirklichkeit tatsächlich bedarf und damit ein Bedürfnis nach einer praktisch brauchbaren Wissenschaft überhaupt besteht ${ }^{341}$.

In letzter Konsequenz stellt sich Eucken dann das ganz grundsätzliche Problem, wie die Kluft zwischen theoretischer Erkenntnis und politischer Entscheidung überbrückt und die Gestaltung der wirtschaftlichen Realität nach einem bestimmten, als vorzugswürdig erkannten ordnungsschema verbindlich gemacht werden $\mathrm{kann}^{342}$.

B. Die Grundlagen des wirtschaftspolitischen Denkens von walter Eucken

1. Die Notwendigkeit des ordnens

Nach G. Hesse ${ }^{343}$ ist es eine "verbreitete struktur des ordnungsdenkens", daß es seinen Ausgang aus einer situation der Krise nimmt. Dies gilt grundsätzlich auch für Eucken. Ihm ist der optimistische Glaube der Klassiker abhanden gekommen, daß die Wirtschaft nicht "einer genau bestimmten Diät" bedarf $\mathrm{f}^{344}$, sondern daß durch die Gewährung von Freiheit für die in ihrem wohlverstandenen Eigeninteresse wirtschaftenden 
Individuen die "natürliche, gottgewollte ordnung" entsteht und die "unsichtbare Hand" den Wirtschaftsprozeß zum Wohle aller steuern werde 345 . Der "Schöpfungsplan" und damit die "Kräfte der Logik, die Gott in die Dinge" hineingelegt hat und aus denen sich die Naturgesetze auch der wirtschaft ableiten, haben sich nicht verwirklicht, sondern die faktische Entwicklung hat sie eindrucksvoll als nicht existent nachgewiesen ${ }^{346}$.

Fehlentwicklungen der natürlichen ordnung und die Akkumulation der Macht bei einigen wenigen Marktteilnehmern ließen offenbar werden, daß Freiheit auch Freiheit zur zerstörung der Konkurrenz und damit auslösendes Moment für die Transformation in andere Marktformen war, in denen die den Vorstellungen des ordre naturel gerade entgegengesetzten spielregeln herrschten.

Die Durchsetzung der guten ordnung und deren dauerhafte Erhaltung werden, "da Gott im 19. Jahrhundert 'gestorben' ist (Ende des Laissez faire) "347 für Eucken zum Problem ${ }^{348}$. Für ihn beachtlich bleibt allerdings, daß die wirtschaftspolitik des Laissez-faire, die das ordnungsproblem mit "verkehrswirtschaftlichen Methoden" zu lösen suchte, dem Grunde nach richtig war. Allein die Beschränkung der wirtschaftstheoretischen Analyse auf die scheinbar vorgegebene, gottgewollte Naturordnung der vollständigen Konkurrenz verschloß den Blick für die weiteren Marktformen und deren Funktionsbedingungen $^{349}$. Die Kritik an den Mängeln der marktwirtschaftlich organisierten ordnung kann für Eucken in wirklichkeit keine Kritik an der vollständigen Konkurrenz, sondern bestenfalls eine Mängelrüge an denjenigen Marktformen sein, in denen die Preise zur Lenkung des Wirtschaftsprozesses ungeeignet waren. Im zeitalter des Laissez-faire hat sich demnach nicht die generelle Untauglichkeit des Preissystems zur steuerung der wirtschaft, sondern nur dessen mangelnde Lenkungsfunktion im Rahmen gewisser Marktformen herausgestellt ${ }^{350}$. Fazit dieser Erfahrung ist für Eucken daher nicht, "ob überhaupt gelenkt werden soll oder nicht, sondern in welchem Ausmaß 
und mit welchen Mitteln"351. Ansatzpunkt für die Lösung dieser Frage und entscheidendes Kriterium der Abgrenzung ist die bereits eingehend dargestellte Trennung von ordnungsform und Wirtschaftsablauf.

Die Wirtschaftspolitik des Laissez-faire hatte für Eucken gezeigt, daß solange neben der Möglichkeit der individuellen Gestaltung des Wirtschaftsprozesses auch "die Gestaltung der spielregeln, des Rahmenwerks oder der Formen", in denen sich der wirtschaftliche Gesamtprozeß vollzieht, der autonomen Disposition der einzelnen Wirtschaftsteilnehmer überlassen bleibt, die Lenkungsmechanik der Preise auf Dauer nicht funktionieren und damit eine stabile, harmonische ordnung nicht entstehen kann ${ }^{352}$. Im Gegensatz zum politischen Liberalismus, der sehr wohl um die Notwendigkeit der Garantien politischer Freiheiten durch Kodifikationen wußte, blieben dem wirtschaftlichen Liberalismus, eingeschnürt in den Glauben an die göttliche ordnung und deren selbstrealisierung, solche Einsichten verborgen.

Für die Durchsetzung der funktionsfähigen, guten ordnung der Wirtschaft gilt jedoch Gleiches wie für die staats- und Rechtsordnungen: der Schutz ihrer Funktionsbedingungen ist nur gewährleistet, wenn die Formen, in denen gewirtschaftet wird, nicht dem spiel der individuellen Kräfte überlassen bleibt, sondern die wirtschaftspolitik aktiv auf deren Verwirklichung gerichtet ist: "Hier ist 'Planung' nötig" ${ }^{353}$. Nur so gelingt die Herstellung eines funktionsfähigen Lenkungssystems der Preise. Damit ist der zulässige, aber auch notwendige Rahmen wirtschaftspolitischer Gestaltungsfreiheit und Gestaltungsmöglichkeit abgesteckt und die Grenze zwischen individueller wirtschaftlicher planungsfreiheit und dem Zugriff des wirtschaftsordnenden staates gezogen. Die Regel lautet: "Staatliche Planung der Formen - ja; staatliche Planung und Lenkung des Wirtschaftsprozesses - nein" 354. An die Stelle des Naturgesetzes tritt bei Eucken demnach die planende politische Entscheidung. Die Frage bleibt, an welchen Kriterien sich diese Entscheidung zu orientieren hat 
und nach welchem Maßstab der Rahmen des Wirtschaftens auszurichten ist.

\section{Der ordogedanke als Maßstab des ordnens}

Den Maßstab für die Bewertung der idealtypischen ordnungsformen und damit die Grundlage für die ordnungspolitische Entscheidung findet Eucken im Gedanken des ordo.

Ging es bei der Erfüllung der ersten Aufgabe der Wissenschaft um die theoretische Erkenntnis der individuell-historischen Wirtschaftsordnung, die Eucken als die "Gesamtheit der realisierten Formen, in denen in concreto jeweils der alltägliche Wirtschaftsprozeß abläuft", definierte ${ }^{355}$, so wird dieser deskriptive ordnungsbegriff im Rahmen der zweiten Aufgabe der Wissenschaft durch den normativen ordnungsbegriff abgelöst, in dem sich das streben nach einer "Ordnung der Wirtschaft" dokumentiert, die dem "Wesen des Menschen und der sache entspricht" und in der "Maß und Gleichgewicht bestehen" 356 .

Dieser zweite, wertende Ordnungsbegriff ist identisch mit der Idee der Naturordnung, deren Realisierung Eucken als Reaktion auf die krisenhafte Entwicklung der bestehenden konkreten ordnungen als dringendstes Erfordernis ansieht, um der industrialisierten wirtschaft "die fehlende funktionsfähige und menschenwürdige ordnung" zurückzugeben ${ }^{357}$. Zur Kennzeichnung dieses Vorhabens, an dessen Ende die Aufhebung der ungleichgewichtigen und ungerechten zustände zugunsten einer stabilen brauchbaren und gerechten, kurz einer besseren ordnung steht, übernimmt Eucken den aus der Scholastik stammenden Begriff des "Ordo" 358 .

Dieser Gedanke der "sinnvolle(n) Zusammenfügung des Mannigfaltigen zu einem Ganzen" dient Eucken als Sinnbild der "der Vernunft oder der Natur des Menschen und der Dinge" entsprechenden ordnung, die nur zur Entfaltung bringt, was in der 
Wirklichkeit bereits zur weiteren Entwicklung angelegt ist ${ }^{359}$. Die diesen Wertvorstellungen adäquate ordnung muß demnach vor allen Dingen zwei Belangen genügen: sie muß Freiheit und Menschenwürde auch im Zeitalter fortschreitender Industrialisierung gewährleisten und sie muß funktionsfähig und gerecht sein.

1. Der Primat der Freiheit

Indem Eucken die Verwirklichung einer menschenwürdigen und gerechten ordnung als eine Grundnorm des wirtschaftspolitischen Handelns bezeichnet, rückt er das Wesen der Einzelpersönlichkeit und deren wert in den Mittelpunkt seines Denkens. Das ordnungswollen wird individualistisch bestimmt ${ }^{360}$. Für den Individualismus sind Würde und Wesen des Menschen und dessen Integrität indes nur bei Verwirklichung des Anspruchs auf selbstentfaltung und selbstverfügung als wesensbestimmende Grundqualitäten der Persönlichkeit gewährleistet $^{361}$.

Folgerichtig übernimmt Eucken den individualistischen Freiheitsbegriff des 18. und 19. Jahrhunderts, der ohne die Möglichkeit der freien selbstbestimmung die menschliche Existenz korrumpiert sah. Nur wer ein selbstverantwortliches Leben zu führen imstande ist, nur wer autonom handelnd vor Entscheidungen steht, nur der kann wirklich frei wählen. Auch für Eucken manifestiert sich menschliche selbstbestimmung und selbstverwirklichung demnach in der Möglichkeit individueller Handlungs-, Planungs- und Entschlußfreiheit, die zum fundamentalen seinsprinzip wird und ohne die der "Mensch nicht Mensch" ist ${ }^{362}$. Dieses Ideal der personalen Freiheit negieren hieße, das "Leben selber leugnen" ${ }^{363}$.

Durch diese Verabsolutierung der Freiheit, die für Eucken als "personaler Höchstwert" schlechthin gilt ${ }^{364}$, muß sich alles auf die Frage zentrieren, durch welche der ordnungsformen dieser für das Menschsein substantielle Wert gewähr- 
leistet werden kann, denn je nach der Wirtschaftsordnung sind "Freiheitssphäre und selbstbestimmungsrecht" des einzelnen verschieden ausgeprägt. "Die moderne Freiheitsfrage hängt mit der Lenkung des modernen Wirtschaftsprozesses, mit der Frage der Wirtschaftsordnung aufs engste zusammen" ${ }^{365}$. Durch diese strenge Ausrichtung der Freiheitsfrage auf das ordnungsproblem hin, verkürzt Eucken allerdings die verschiedenen Aspekte des Freiheitsbegriffes auf diejenige Freiheit, die sich nach wirtschaftlichen Kausalitäten bemißt und die, so hat es den Anschein, zur Grundlage der Freiheit des Menschen überhaupt wird ${ }^{366}$.

$\mathrm{zu}$ der Einsicht in die Interdependenz von menschlicher Freiheit und Wirtschaftsordnung ${ }^{367}$ kommt Eucken an Hand seiner Analyse der "Wirtschaftspolitik des Laissez-faire". Dieses Zeitalter war nach seiner Auffassung von der Überzeugung geprägt, daß eine "zweckmäßige Wirtschaftsordnung (...) aus den spontanen Kräften der Gesellschaft" von selbst entsteht, wenn Freiheit und Recht gewährleistet sind. Einem gestaltenden Zugriff des staates auf die Formen des wirtschaftens habe man deshalb ablehnend gegenübergestanden ${ }^{368}$. Durch die sich entwickelnde natürliche, gottgewollte ordnung, die man in Form der vollständigen Konkurrenz entdeckt $z u$ haben glaubte, habe die Politik des Laissez-faire zwei Gesichtspunkten Rechnung tragen wollen: zum einen sollten auf nicht vermachteten Märkten Konsumenten den alltäglichen Wirtschaftsproze $\beta$ beherrschen, zum zweiten wurde erwartet, daß Einzelinteresse und Gesamtinteresse harmonieren, d.h. daß durch den "Preisautomatismus" die Koordination der Einzelwirtschaften auf ein allgemeines Gleichgewicht hin vollzogen werde, wodurch wiederum eine optimale Deckung bestehender Bedürfnisse erreicht werde.

Der "Hang zur Monopolbildung" und ein "tiefer Trieb zur Beseitigung der Konkurrenz" hatte jedoch die freie Konkurrenz zunehmend pervertiert und die Labilität der sich selbst überlassenen Freiheit, die sich als Freiheit zur Erhaltung 
des Wettbewerbs in eine Freiheit zu dessen Vernichtung wandelte, gezeigt ${ }^{369}$. Die an den Maximen des Laissez-faire orientierte Wirtschaftspolitik verfehlte nach alledem ihr ziel, in dem durch grundrechtliche Freiheitsverbürgungen ausgegrenzten, staatsfreien und autonomen gesellschaftlichen Bereich mit Hilfe der durch keinen (Rechts-) Zwang gebundenen, individuellen Freiheit der zueinander in wirtschaftliche Beziehung tretenden Bürger die gute und gerechte ordnung der wirtschaft herzustellen. Sie trug den "Keim der Zersetzung" in $\mathrm{sich}^{370}$.

Nur wenn dem Kampf um die ordnungsformen und die spielregeln des Wirtschaftens Einhalt geboten wird, erscheint es nach Auffassung Euckens denkbar und möglich, einen gerechten Ausgleich der kollidierenden privaten Freiheitssphären herbeizuführen. Es bedarf, dies war bereits im einzelnen dargelegt worden, der Realisierung einer bewußt gestalteten und in ihrem Rahmen garantierten, nicht mehr zur Disposition der Wirtschaftsteilnehmer stehenden wirtschaftsordnung. Wirtschaftspolitisches Denken und Handeln werden immer auf dieses ordnungsproblem stoßen. Es ist unausweichlich. Mögen Fragen "der sozialen Gerechtigkeit, der Freiheit oder des Friedens unter den Völkern" zur Lösung anstehen, "(i) mmer führte der Weg auf dieses Problem, das sich so als eine Zentralfrage unseres Zeitalters erweist"371. "Keine geistigreligiöse oder politische Bewegung" wird die Fragen menschlicher ordnungen in den Griff bekommen ${ }^{372}$, wenn es ihr nicht gelingt, insbesondere die der Freiheitsfrage adäquate wirtschaftsordnung $z u$ erkennen und als Vorbedingung für die Verwirklichung dieser Freiheit zu institutionalisieren. Damit sind die Probleme bezeichnet, die nach Ansicht Euckens "die Weltgeschichte aufgibt (..): Herstellung eines möglichst störungsfreien Wirtschaftsprozesses, dadurch Ermöglichung einer zureichenden Gesamtversorgung und auf dieser Grundlage auch einer vernünftigen Verteilung; Entfaltung der Kräfte, die im einzelnen Menschen zur Verwirklichung streben und sinnvolle Einordnung dieser Kräfte in den Gesamtprozeß; mit 
alledem größtmögliche Verwirklichung von Gerechtigkeit, sicherheit und Freiheit im menschlichen Zusammenleben" ${ }^{373}$.

2. Das Erfordernis eines funktionsfähigen Lenkungssystems

Wie das Zitat am Ende des letzten Abschnittes nachweist, besteht die wirtschaftspolitische Aufgabe nicht nur darin, der arbeitsteiligen, industrialisierten wirtschaft eine freiheitliche und menschenwürdige, sondern auch eine funktionsfähige ordnung zu geben, die dazu dient, die Knappheit der Güter als "zentrales Phänomen" allen Wirtschaftens so weitgehend und dauerhauft als möglich zu überwinden ${ }^{374}$. Die maximale Bedarfsdeckung aller am Wirtschaftsproze $\beta$ beteiligten Einzelwirtschaften ist nur dann gewährleistet, wenn es gelingt, "die wirtschaftsordnung mit dem höchsten wirtschaftlichen Wirkungsgrad" einzurichten, da nur verteilt werden kann, was vorher produziert wurde. Maximale Produktivität bei der Gütererzeugung setzt demnach ein funktionsfähiges system zur Lenkung des arbeitsteiligen Wirtschaftsprozesses voraus $^{375}$.

III. Die Wettbewerbsordnung als maßstabsgerechte ordnung

Zur Verwirklichung einer praktisch brauchbaren wissenschaft stehen Eucken infolge seines rigorosen bipolaren ordnungsdenkens ${ }^{376}$ bei der Inangriffnahme der zweiten Aufgabe der Wissenschaften nur die beiden idealtypischen wirtschaftssysteme der zentralgeleiteten wirtschaft und der Verkehrswirtschaft zur Verfügung. Dieses tertium non datur, das die Euckenschen Überlegungen im Hinblick auf die zu verwirklichende ordnung der wirtschaft beherrscht, läßt jede Zwischenlösung als instabil erscheinen, da einer solchen Gemengelage theoretischer systeme stets die "Tendenz zur Trans- 
formation" 377 hin zu einem der beiden äußerlich stabile Archetypen des Wirtschaftens immanent ist ${ }^{378}$. Damit stehen grundsätzlich nur zwei tragfähige systeme und deren Ausformungen zur Wahl, aus denen Eucken die dem Wertungsmaßstab korrelative und damit für das ordnungspolitische Wollen verbindliche ordnungsform auszuwählen hat.

1. Die Wettbewerbsordnung als Programm der Freiheit

Die Suche nach der adäquaten Wirtschaftsordnung unter dem Primat der Freiheit ist nur kurz. Schon die tendenziell durchweg negativ angelegten Ausführungen bei der Entwicklung einer "Theorie der Zentralverwaltungswirtschaft"379 lassen erahnen, daß das Wirtschaftssystem der zentralgeleiteten Wirtschaft diese Freiheitsordnung nicht ist ${ }^{380}$.

Da die Lenkung in diesem system aufgrund eines Planes und nicht einer Vielzahl von unselbständigen Einzelplänen, denen individuelle Bedürfnisse und Bewertungen zugrunde liegen, stattfindet, erfolgt die Bewertung des Planbedarfs ebenso wie die Bewertung des Planzieles global anhand von "Kollektivgrößen" auf der Basis statistischer Mengenrechnungen und nicht von individuellen Vorgaben wie in der Verkehrswirtschaft ${ }^{381}$. Diese zentrale Planung durch globale Bewertung gelingt nur, wenn der Wirtschaftsprozeß durch "Normung, Typisierung, standardisierung" schematisiert wird ${ }^{382}$. Die Gleichförmigkeit der Abläufe und Bedürfnisse, die durchgehende Lenkung und Kontrolle des Wirtschaftsherganges durch Produktionsanweisungen, Rationierungen und Dienstverpflichtungen sind erforderlich, um das ziel der maximalen Deckung des festgesetzten Planbedarfs $z u$ erreichen. Dieses Datensystem von Planbedarf und optimaler Bedarfsdeckung ist der zentrale Punkt, auf den die gesamtwirtschaftlichen Daten auszurichten sind und an dem sich die dirigistischen Eingriffe in den Wirtschaftsprozeß zu orientieren haben. Konkret bedeutet dies die totale Dispositionsbefugnis der Zen- 
tralbehörde über die Arbeitskräfte, Böden, Produktionsmittel, Rohstoffe und Fertigwaren und letztlich über die individuellen Bedürfnisse jedes einzelnen ${ }^{383}$. Zentralgeleitete Wirtschaft heißt damit größte Konzentration der Macht in der Hand eines Planträgers, um Planfeststellung und -durchführung zu gewährleisten. Die Zentralbehörde beherrscht den wirtschaftlichen Alltag des einzelnen und versucht diesen in einem Subordinationsverhältnis durch Befehle von seinen Einzelinteressen weg hin auf die Erfüllung der im Gesamtinteresse stehenden Planziele auszurichten ${ }^{384}$.

Für Eucken wird der Mensch im Rahmen dieser ordnung Mittel zum Zweck, denn zentrale Verwaltung bedeutet nicht nur Verwaltung von Sachen, sondern auch Verwaltung des Menschen selbst, dessen gesamtes Dasein sich auf seinen Wert im Einsatz für den volkswirtschaftlichen Gesamtplan reduziert. Er wird degradiert zum bloßen objekt einer von Egoismus und willkür getriebenen Führerschicht und ihrer Bürokratie, die ihm seine Funktion und stellung in der Gesellschaft vorschreibt und damit Raum für individuelle Lebensäußerungen nur in sehr beschränktem Maße zuläßt" ${ }^{385}$. "Das ganze Leben wird allmählich verstaatlicht" ${ }^{386}$. Zentralgeleitete wirtschaft ist nach alledem gleichzusetzen mit totalitärem system überhaupt, dem durch die Vereinigung von wirtschaftlicher Macht und politischer Gewalt Terror immanent ist und in dem Freiheit nur als Freiheit besteht, "das zu wollen und gern zu tun, was man tun muß"187. Freiheit und Wirtschaftspolitik zentraler Lenkung, das bedarf nach den vorstehenden Ausführungen keiner weiteren Begründung mehr, sind unvereinbar, da Kollision und nicht Adäquanz das prägende Merkmal ihres Verhältnisses ist ${ }^{388}$.

Auf der Grundlage des Unwerturteils über die Zentralverwaltungswirtschaft entwickelt Eucken seine Vorstellungen von einer freiheitssichernden wirtschaftsordnung, die er, da nur noch das wirtschaftssystem der Verkehrswirtschaft zur verfügung steht, zwangsläufig in einer deren Ausprägungen $z u$ 
suchen hat. Er findet sie in der Wettbewerbsordnung, die er als "Programm der Freiheit" präsentiert ${ }^{389}$.

Diese Entscheidung für die Marktform der vollständigen Konkurrenz wird durch die wirtschaftspolitischen Erfahrungen der Vergangenheit mitbestimmt. Die Untersuchung der Wirtschaftspolitik des Laissez-faire hatte gezeigt, daß, trotz aller im einzelnen nachweisbaren Fehlentwicklungen, individuelle Freiheit und die - niemals vollständig verwirklichte - idealtypische Marktform der vollständigen Konkurrenz, die nicht identisch ist mit dem Prinzip des Laissez-faire ${ }^{390}$, wechselbezüglich sind. "So ist der Gedanke der Wettbewerbsordnung entstanden" ${ }^{391}$, in dem das Modell der vollständigen Konkurrenz das "theoretische Rückgrat" bildet ${ }^{392}$.

Die einzelnen Betriebe und Haushalte sind in dieser Ordnung nicht mehr in einen stereotyp ablaufenden Wirtschaftsproze $\beta$ eingebunden, der ihre Initiative und spontaneität bewußt auszuschalten trachtet und sie zu Befehlsempfängern einer übermächtigen Zentralverwaltung degradiert, sondern, frei von kollektivistischer Bedrohung und ausgestattet mit uneingeschränkter Freiheit $z u$ individuellem Planen und Handeln, bestimmen sie über den jeweiligen persönlichen Bedarf sowie den Einsatz der eigenen Arbeitskraft und der vorhandenen Produktionsmittel. Die Unterwerfung allen wirtschaftlichen Tuns unter einen volkswirtschaftlichen Gesamtplan und dessen Erfüllung entfällt, in der Marktform der vollständigen Konkurrenz werden alle Wirtschaftssubjekte in den Wirtschaftsproze $\beta$ integriert und mit Hilfe des Markt- und Preismechanismus koordiniert ${ }^{393}$. Indem durch die Einräumung eines persönlichen Planungs- und Entscheidungsspielraumes ein Höchstmaß an wirtschaftlicher selbstbestimmung und selbstverantwortung beim einzelnen liegt, wird zudem der "Motor" des Selbstinteresses in Gang gesetzt, der die Funktionsfähigkeit der wettbewerbswirtschaftlichen Mechanismen garantiert $^{394}$. 
Für Eucken bietet die am Primat der Freiheit orientierte Wettbewerbsordnung demnach neben der Möglichkeit der ungestörten Entfaltung der spontanen Kräfte des einzelnen auch die Gewähr dafür, daß die komplexe "Lenkungsmechanik der Marktwirtschaft" funktionsfähig wird und erhalten bleibt und dadurch insgesamt eine Förderung des gesellschaftlichen Gesamtwohls stattfindet ${ }^{395}$. Damit steht nicht wie bei der Zentralverwaltungswirtschaft die rationale Gestaltung und Durchorganisation der Wirtschaft und die Kanalisierung persönlicher Interessen im Vordergrund, sondern in der dezentralisierten Wettbewerbsordnung schafft der nach eigenem ökonomischen Gutdünken waltende wirtschaftsteilnehmer, gewollt oder ungewollt, mit Hilfe der marktwirtschaftlichen Mechanismen eine überindividuelle Freiheitsordnung.

2. Die Maximierung volkswirtschaftlicher Produktivität durch die Wettbewerbsordnung

Die Wettbewerbsordnung als "Programm der Freiheit" ist für Eucken nicht nur ein Instrument, um ein "soziales und ethisches ordnungswollen" und damit Menschenwürde und Freiheit $z u$ verwirklichen, sondern sie trägt entscheidend dazu bei, daß die "ökonomischen Sachgesetzlichkeiten" verwirklicht werden $^{396}$.

Den beiden von Eucken unter dem Aspekt des wirtschaftlichen wirkungsgrades näher beleuchteten wirtschaftssystemen ist (noch) gemeinsam, daß sie durch die Kombination von Produktionsmitteln und Arbeitskräften eine Bedarfsdeckung anstreben. Damit aber endet ihre Vergleichbarkeit, denn im wirtschaftssystem zentraler Leitung werden, das wurde bereits deutlich, die individuellen Bedürfnisse, Bewertungen und Pläne zugunsten des gesamtwirtschaftlichen Planbedarfs ausgeschieden. Nicht die individuelle Knappheit ist daher Ausgangspunkt und ziel des wirtschaftens, sondern die Erfüllung des Gesamtplanes wird das maßgebliche problem des zentralgesteuerten Wirtschaftsprozesses, "- auch wenn die indivi- 
duellen Bedürfnisse der Menschen viel weniger befriedigt werden, als sie befriedigt werden könnten" ${ }^{397}$.

Im Gegensatz dazu sieht sich in der Wettbewerbsordnung jeder einzelne als Plansubjekt der Situation des Mangels ausgesetzt, d.h. jeder Wirtschaftsteilnehmer muß die Differenz zwischen den zur Befriedigung seiner aktuellen Bedürfnisse notwendigen und gewünschten und den verfügbaren Gütermengen durch Teilnahme am Wirtschaftsprozeß überwinden. Das Problem der Knappheit ist individueller Natur. Diese spannung von "Bedürfnissen und Mitteln zur Bedürfnisbefriedigung" versucht jeder Haushalt und Betrieb im Wirtschaftsprozeß in Verfolgung des "wirtschaftlichen Prinzips" optimal zu lösen, d.h. es wird versucht, durch entsprechende Plangestaltung einen intendierten Zweck "mit einem möglichst geringen Aufwand an Werten zu erreichen" ${ }^{398}$.

Um den für den jeweiligen Zweck günstigsten Wirtschaftsplan feststellen zu können, bedarf es einer informativen Anzeige, eines "Knappheitsmessers", der die Knappheitsgrade im Hinblick auf das gewünschte Konsumgut deutlich werden läßt und einen zweckrationalen Einsatz vorhandener Mittel ermöglicht ${ }^{399}$. Die entsprechende Verwirklichung und Durchsetzung des jeweiligen wirtschaftlichen Eigeninteresses, mit gegebenem Produktionsapparat und gegebener Arbeitskraft die bestmögliche Versorgung $z u$ erreichen, wird in einer arbeitsteiligen industrialisierten wirtschaft, in der der einzelne als Partikel eines undurchschaubaren, komplexen Wirkungszusammenhanges auf eine Vielzahl weiterer, nach dem ökonomischen Prinzip handelnder wirtschaftseinheiten trifft, damit zum Problem. Wie, so lautet die Frage, können die beim streben nach individueller Nutzenmaximierung auftretenden Plan- und Interessenunterschiede abgestimmt und ausgeglichen und in insgesamt wirtschaftlich effizientes Handeln umgesetzt wer$\operatorname{den}^{400}$, so daß das "wirtschaftliche Prinzip" auch "allgemein" bzw. "objektiv" zum Tragen kommt ${ }^{401}$. Die Neutralisierung und Kanalisierung der egoistisch eingefärbten Privatinteressen 
und ihre Harmonisierung $z u$ einer an den jeweiligen Bedürfnissen ausgerichteten optimalen Güterversorgung aller am Wirtschaftsprozeß Beteiligten ist für Eucken allein und ausschließlich eine Frage der richtigen Wirtschaftsordnung ${ }^{402}$. Die rationale Lenkung der Vielzahl an der Überwindung der individuellen Knappheit interessierten Wirtschaftssubjekte auf das Gesamtwohl hin leistet in der Wettbewerbsordnung der "Knappheitsmesser" Preis, der als "Rechenmaschine" für ökonomisch sinnvolle Verfügungen der Einzelwirtschaften dient und eine Fehlbewertung der vorhandenen knappen Gütermengen vermeidet ${ }^{403}$. Der Marktpreis als Funktion der komplexen Angebotsund Nachfragebeziehungen ist der Dreh- und Angelpunkt der Euckenschen ordokonzeption. Mit seiner Hilfe bestimmen die souveränen Konsumenten bei der individuellen Verfolgung des wirtschaftlichen Prinzips das für den einzelnen nicht erkennbare Gesamtinteresse, der Preis ist für die Marktteilnehmer ein einzelwirtschaftliches Datum, das mittelbar das gesamtwirtschaftliche Datum "Bedürfnisse" feststellt und anzeigt. Drückt sich demnach in den preisen der jeweilige Bedarf der Konsumenten aus, wird jeder Betrieb, da diese Preise "zuverlässige Bedeutungsindices" sind, in die Lage versetzt, mit ihrer Hilfe die nutzbringendste Verwendung der zur Verfügung stehenden produktiven Mittel für die Befriedigung der vorhandenen Bedürfnisse festzustellen ${ }^{404}$.

Die Lenkungsmechanik der Preise beeinflußt unmittelbar die Entscheidungen im Hinblick auf Quantität und Qualität sowie die zusammensetzung der angebotenen Konsumgüter und Leistungen. Indirekt hängt vom Kommando der Preise aber auch die Zahl und Größe der an der Produktion und Verteilung partizipierenden Unternehmer, deren Mitteleinsatz und Leistungsfähigkeit $a b^{405}$. Wer rentabel und mit Gewinn arbeiten will, muß das produzieren, was vom souveränen Konsumenten gebraucht und nachgefragt wird, andernfalls sein Ausscheiden aus dem Wirtschaftsprozeß unumgänglich ist. Der Preis als Lenkungsinstrument der Wettbewerbsordnung entscheidet demge- 
mäß über die optimale Güterproduktion und Allokation der gesamtwirtschaftlichen Ressourcen und ermöglicht eine Maximierung der volkswirtschaftlichen Produktivität, des allgemeinen Wohlstandes und damit eine bestmögliche Versorgung der konsumierenden Einzelwirtschaften ${ }^{406}$.

Der institutionalisierte Rahmen einer freiheitlichen Wettbewerbsordnung bietet damit ganz offensichtlich die Gewähr für einen $z u$ optimalen Ergebnissen führenden Wirtschaftsprozeß.

IV. Die Identifikation von maßstabsgerechter ordnung der Wirtschaft und Wirtschaftspolitik

1. Die instrumentale Betrachtungsweise der maßstabsgerechten ordnung

Die Erkenntnis Euckens, daß sich die Verwirklichung der ordnung der wirtschaft durch "Laissez-faire" allein nicht ergibt und die damit verbundene Ablehnung einer naturgesetzlichen Entwicklung der seinen ordnungspolitischen Wert- und Zielvorstellungen entsprechenden Wirtschaftsordnung mit der Folge der Notwendigkeit des Schutzes ihrer Funktionsbedingungen im Wege planender Gestaltung scheint auf den ersten Blick E. Salins Meinung zu bestätigen, daß es sich bei den "Grundsätzen der Wirtschaftspolitik" um "die erste geschlossene Theorie der Wirtschaftspolitik" handelt 40 . Definiert man Wirtschaftspolitik mit J. Tinbergen als Möglichkeit, durch die "bewußte Handhabung einer Reihe von Mitteln (...) bestimmte ziele zu erreichen"408, wäre für Eucken unter diesem Gesichtspunkt die Wahl der wirtschaftlichen "Organisationstechnik"409 Wettbewerbsordnung das zweckmäßigste, weil optimale Mittel zur Verwirklichung seiner ordovorstellungen ${ }^{410}$. Eine solche Zweck-Mittel-Kombination stünde, um nochmals auf das als Kontrastfolie beigezogene Wissenschaftsverständnis M. Webers zu rekurrieren, auch im Einklang mit dessen Auf- 
fassung, daß "die durch objektive einzelwissenschaftliche Forschung gewonnenen Resultate als Mittel zum zweck in den Dienst der Verwirklichung persönlich erschauter und gewollter Ziele" gestellt werden können ${ }^{411}$. Dabei ist jedoch vom jeweiligen Eigenwert des Mittels zu abstrahieren, "über den wissenschaftlich ebenso wenig $\mathrm{zu}$ befinden ist wie über den des Ziels"412, seine Bewertung orientiert sich ausschließlich an seiner Eignung zur Verwirklichung bestimmter, erklärbarer ziele.

Eine solche ordoorientierte Instrumentalisierung der Wettbewerbsordnung würde sie wissenschaftlicher Kritik aussetzen, da die Diskussion der Frage, ob die Verwendung eines bestimmten Mittels die intendierten wirkungen zeitigt, ein wissenschaftlicher Untersuchung grundsätzlich zugängliches Problem ist und die "Aussage über die Adäquanz des Mitteleinsatzes zur Erreichung vorgegebener Ziele"113 kein Werturteil darstellt $t^{414}$.

Für die wirtschaftspolitische Entscheidung selbst, die aus den zur Verfügung stehenden Alternativen die im sinne der Zielvorstellungen ausgezeichnete wählt, trifft dies nicht zu. Die Entscheidung für ein bestimmtes, zieladäquates Mittel ist ein Werturteil, das durch individuelle Vorstellungen begründet und aus diesen abgeleitet ist. Die Wahl zu treffen - gegebenenfalls unter Beachtung der durch wissenschaftliche Kritik transparent gemachten Probleme - ist Sache des einzelnen und damit ohne Anspruch auf allgemeine Verbindlichkeit.

Das damit wiederum berührte Problem der "Schranke der Rationalität", die Tatsachenerkenntnis und Werterkenntnis trennt ${ }^{415}$, hätte im Hinblick auf die dargestellten Zusammenhänge im Zweck-Mittel-Denken zur Folge, daß der Wettbewerbsordnung als Instrument zur Verwirklichung bestimmter höchstpersönlicher Wertvorstellungen für die praktisch-politische Entscheidung eine verbindliche wirkung nicht zukommt. Um dies $z u$ vermeiden und um die Identifikation von ordnung der Wirtschaft und wirtschaftspolitik zu gewährleisten, bedient 
sich Eucken eines Begründungszusammenhanges, der die "Schranke der Rationalität" und damit das "positivistische Vorurteil" als grundlegenden Irrtum entlarvt und mit dessen Hilfe er nachzuweisen versucht, daß die Verwirklichung der seinen persönlichen Wertvorstellungen entsprechenden ordnung der Wirtschaft der Politik verpflichtend auferlegt ist. Damit wird der erste Anschein korrigiert, daß die "Grundsätze der Wirtschaftspolitik" eine wirtschaftspolitische Theorie im Sinne einer Zweck-Mittel-Kombination entwerfen, denn die den ordovorstellungen Euckens korrelative ordnung der Wirtschaft bleibt nicht nur Instrument, sondern ihre Verwirklichung wird zum verbindlichen ziel wirtschaftspolitischen Handelns.

a) Die Wettbewerbsordnung als naturgegebene ordnung - Der theoretische Idealtypus als werthaftes politisches Ideal

Der erste Schritt auf dem Weg der Einschränkung wirtschaftspolitischer Entscheidungsfreiheit ist die Identifikation von natürlicher ordnung und Wettbewerbsordnung. Die Wettbewerbsordnung mag zwar kein ordre naturel im altliberalen sinne sein, da sie ungeeignet ist, sich selbst zu verwirklichen. Aber sie ist eine "natürliche ordnung oder ordo" in dem Sinne, daß sie die der Natur immanenten "starken Tendenzen", die auf die Durchsetzung der Marktform der vollständigen Konkurrenz drängen, zum Ausdruck bringt. Indem die wirtschaftspolitik diese zwingenden Tendenzen wirksam werden läßt, realisiert sie "das, was der Natur der Sache und den Menschen entspricht"416. Die Wettbewerbsordnung ist demnach keine "Erfindung", kein Produkt theoretisierender Wissenschaft, sondern sie ist die bereits in den Dingen verborgene gute ordnung. Nur durch das, wie es E. Eucken-Erdsiek formuliert hat, "Nachtasten der Linien, die in der Wirklichkeit vorgegeben sind"417, wird das ordnungsprinzip der freien wirt- 
schaft als die einzige, "im Sein verankerte Möglichkeit der ordnung" sichtbar. ${ }^{418}$

Indem die Wirtschaftspolitik diese naturgegebenen strömungen aufnimmt, gestaltet sie nicht wider das geschichtliche Werden, sondern sie bringt nur latent Vorhandenes zur Geltung, das andernfalls in der Vielzahl weiterer wirtschaftspolitischer Tendenzen unterzugehen droht ${ }^{419}$. Damit hat die Wettbewerbsordnung im Schema der "gewachsenen" und "gesetzten" Ordnungen nach Auffassung Euckens eine "Mittelstellung"420. Einerseits ohne Chance der Verwirklichung, wenn sie sich selbst überlassen bleibt und damit auf die sicherung ihrer Funktionsbedingungen im Wege einer wirtschaftspolitischen Entscheidung angewiesen, bezieht diese Gesamtentscheidung andererseits ihren verbindlichen Gehalt aus dem durch die Realität bereits vorgegebenen, der Natur immanenten "Bauplan" der Wettbewerbsordnung ${ }^{421}$.

Der Wettbewerb stellt sich demnach für Eucken nicht mehr als automatischer, einem Naturgesetz gehorchender und sich selbst gestaltender Prozeß der Abstimmung von Angebot und Nachfrage dar, sondern er ist ein in der Natur angelegtes, vom Menschen vorgefundenes, aber infolge seiner mangelnden Selbstverwirklichungkräfte zu veranstaltendes Phänomen. Aus "der 'Naturordnung' wird eine staatliche Veranstaltung", die indes nur die natürlichen Vorgegebenheiten zur Geltung bringt, die im geschichtlichen Werden auf Durchsetzung drängen $^{422}$. Die naturgesetzlich interpretierte "Ordnungssicherungspolitik", die die Wettbewerbsordnung "nicht mehr als die natürliche ansehen kann, dennoch aber ihre naturrechtliche Rechtfertigung" nicht aufgeben will ${ }^{423}$, bedient sich dieser ordnung nicht mehr in ihrer instrumentalen Funktion zur Erreichung und Verwirklichung bestimmter wirtschaftspolitischer zielvorstellungen und damit abstrahierend von einem ihr möglicherweise zukommenden Eigenwert, sondern indem Eucken den Idealtypus der vollkommenen Konkurrenz obwohl nach seinen eigenen Ausführungen kein Abbild der wirtschaftlichen wirklichkeit ${ }^{424}$ - als Verkörperung einer in 
der Natur vorgegebenen Seinsordnungen auffaßt, wird dieser "für die empirische Erforschung des Seienden brauchbare Idealtypus" zu einem "in der Wertsphäre geltende(n) Ideal"425 und damit zum Leitbild praktisch politischen Handelns ${ }^{426}$. "Nicht mehr Mittel, sondern Ziel der Wirtschaftspolitik wird der Wettbewerb zum Selbstzweck"427 und, ausgestattet mit absolutem Verwirklichungsanspruch, zum Imperativ für wirtschaftspolitisches Handel $n^{428}$.

In diesem zusammenhang wird nochmals das korrigierte rationalistische Verfahren von Bedeutung, dessen vollständige Tragweite sich erst im weiteren zusammenhang der wirtschaftspolitik im stile Euckens offenbart.

b) Die doppelte Instrumentalisierung des korrigierten rationalistischen Verfahrens

Die Wirtschaftstheorie, die mit Hilfe des korrigierten rationalistischen Verfahrens die Physik des wirtschaftlichen Seins $z u$ erkunden suchte und die in den idealtypischen ordnungsformen des Wirtschaftens diejenigen Bedingungskonstellationen fand, die die Gesamtzusammenhänge transparent machten, war für Eucken frei von Zwecksetzungen und Wertvorstellungen ${ }^{429}$.

Um bestimmten, auf der Grundlage der theoretischen Analyse herausgearbeiteten, positiv bewerteten ökonomischen sachgesetzlichkeiten, die nur in der Wettbewerbsordnung ihren Ausdruck finden, auch auf der Ebene wirtschaftspolitischer Entscheidung Geltung $z u$ verschaffen, mußte sich Eucken seine bekenntnismäßig eingeführten ordnungsvorstellungen im Wege rationaler Begründung verfügbar machen. Dies gelingt ihm mit Hilfe einer methodischen Vorgehensweise, die als doppelte Instrumentalität des korrigierten rationalistischen Verfahrens gekennzeichnet werden soll.

An sich entworfen, um wahre wissenschaftliche Erkenntnisse in Form von Morphologie und Theorie zu gewinnen, überwindet 
das von Eucken geschaffene, wissenschaftstheoretische Verfahren den Gegensatz von Tatsachen- und Werterkenntnis und beseitigt damit auch das Erfordernis der jeweils autonomen methodischen Behandlung dieser Bereiche. Durch die Identifikation von werthaftem ordo und dem (erkenntnis-) theoretisch konzipierten Idealtypus wird der von Eucken gewählte Wertmaßstab und damit die wirtschaftspolitische Entscheidungsgrundlage theoretischer Erkenntnis zugänglich ${ }^{430}$.

Durch die "Verankerung der Werte" in der Realität ${ }^{431}$ wird deutlich, daß für Eucken werte und Tatsachen im Hinblick auf die Möglichkeit ihrer rationalen Begründung vergleichbar sind. Methodisch gesicherte Erkenntnis geht nicht nur auf das wahre wissen um die funktionellen Zusammenhänge wirtschaftlicher wirklichkeit, sondern in letzter Konsequenz auch auf den Nachweis der werthaften ordnung der wirtschaft, die als verbindlich für politisches Entscheiden und Handeln gilt.

Das korrigierte rationalistische Verfahren wird damit zur Grundlage einer praktischen Erkenntnis die zugleich werthafter politischer wille $e^{432}$ ist und zur Grundlage einer praktischen Metaphysik, die die Geltung eines wirtschaftspolitischen Imperativs durch wissenschaftliche Beweisführung festigt.

Damit sichert Eucken die Wettbewerbsordnung gleich zweimal durch den Rekurs auf Absolutes ab. Neben der - als Werturteil anfechtbaren - Qualifikation als natürliche ordnung kommt ihr zudem das durch das gewählte methodische Verfahren vermittelte Prädikat der Wahrheitsgeltung zu. Die Konsequenzen, die sich aus dieser Prädizierung als "wahre Naturordnung" ergeben, liegen auf der Hand: Eucken kann sie zu einem allgemein verbindlichen wertsystem in Form eines "praktischen Generalnenners"433 für die wirtschaftspolitischen Probleme erklären, des Nachweises einer opinio communis im Hinblick auf inre Geltung und den damit verbundenen Durchsetzungsanspruch bedarf es nicht. 
Die Gefahr des weltanschaulichen Pluralismus und die Anarchie der Werte ist gebannt, da es eine Autorität gibt, die die Voraussetzungen der ordnung der wirtschaft im sinne eines wirtschaftspolitischen Ideals rational $\mathrm{zu}$ begründen in der Lage ist. Die "Souveränität der Gewissensentscheidung" 434 ist dahin, der scheinbar unlösbare und unaustragbare streit der Weltanschauungen wird in der Hauptsache erledigt. Die "Unhaltbarkeit der relativistischen Hypothese"435 hat zur Konsequenz, daß die Wissenschaft wieder zu einer "Lebensmacht von bildender und gestaltender Kraft" ${ }^{436}$ und zu einer politischen Macht wird.

c) Die praktische Verwirklichung wissenschaftlicher Erkenntnis

Wirtschaftspolitik ist für Eucken verwirklichungstechnisch gesehen Veränderung der gesamtwirtschaftlichen Daten, wobei insbesondere das sechste Datum - Rechts- und Sozialordnung Beachtung verdient. Mit diesem Datum umzugehen ist die "wichtigste Kunst der Wirtschaftspolitik", die nur dann erfolgreich $\mathrm{zu}$ sein vermag, wenn sie "gesamtwirtschaftliche Gegebenheiten" in Rechnung stellt und dabei die "Interdependenz aller ökonomischen Größen" beachtet ${ }^{437}$.

Ruft man sich ins Gedächtnis, daß die von Eucken als ordoadäquat erkannte ordnung der Wirtschaft gesetzt bzw. veranstaltet werden muß, bleibt die Frage, wie man sich im Rahmen des sechsten Datums die Einrichtung dieser ordnung vorzustellen hat. Die industrialisierte Wirtschaft "kann nur noch im Rahmen einer einheitlichen Verfassung voll funktionsfähig sein. Um eine solche Verfassung zu begründen, wird man tief schürfen müssen, nicht nur in bezug auf die wissenschaftliche Durchdringung der Probleme, sondern auch im Hinblick auf die Verankerung der gewollten ordnung in den tragenden Ideen unserer vom Untergang bedrohten Zivilisation"438. 
Da die theoretische Arbeit bereits dergestalt geleistet ist, daß dem politischen willen die wahl zwischen den mit Hilfe ordnenden wissenschaftlichen Denkens aus dem wirtschaftlichen Sein isolierten Idealtypen abgenommen, genauer verbindlich vorgeschrieben ist, bleibt nurmehr die Frage: "Wer soll diese ordnung verwirklichen?"439 Auf der Suche nach der "ordnenden Potenz"440, die das "institutionelle Rahmenwerk"441 der Wettbewerbsordnung einzurichten und $\mathrm{zu}$ sichern in der Lage ist, denkt auch Eucken "unwillkürlich an den Staat"442 dessen Aufbau, strukturprinzipien und Kompetenzen deshalb unter Beachtung der im ersten Kapitel gewonnenen ordnungstheoretischen und ordnungspolitischen Erkenntnisse beachtlich werden. 
2. RAPITEL

Der staat im Denken von Walter Eucken

\section{Abschnitt \\ Einführung}

Die Wirtschaftspolitik der Bundesrepublik Deutschland wurde von Eucken entscheidend geprägt. Die Konzeption der Sozialen Marktwirtschaft, die durch seine ordnungstheoretischen Vorarbeiten die entscheidenden Impulse erhielt, hatte sich bis Mitte der fünfiger Jahre, durch L. Erhard vertreten und praktiziert, fast unangefochten Geltung verschafft.

Nachdem Eucken als einer der geistigen Väter der Sozialen Marktwirtschaft eine isolierende Betrachtungsweise der Teilordnungen von staat, Wirtschaft und Gesellschaft abgelehnt und deren wechselseitige Bedingtheiten und Abhängigkeiten hervorgehoben und herausgearbeitet hatte ${ }^{443}$, rückten nach und nach auch die mit seiner erfolgreichen wirtschaftsordnungspolitischen Konzeption verbundenen staatshistorischen und staatstheoretischen Implikationen in den Blickpunkt des Interesses und wurden zum Gegenstand wissenschaftlicher Untersuchungen, denen indes durchweg gemeinsam war, daß sie die wesentlichen Aspekte des Euckenschen Staatsdenkens nicht oder nicht zureichend in den Griff bekommen haben. Kennzeichnend für die Diskussion war, daß selbst die grundsätzliche Frage nach Grad und Intensität staatlicher Mitwirkung bei der Einrichtung und sicherung der Wettbewerbsordnung in völlig konträrer Weise beantwortet und noch nicht einmal ein Konsens dahingehend erzielt werden konnte, daß dem staat nach den Vorstellungen Euckens im Bereich der wirtschaft überhaupt Aufgaben vindiziert sind. Die Auseinandersetzung begann demzufolge bereits damit, ob Eucken ein "liberaler Anti-Staats-Affekt" eigen ${ }^{44}$ und seinem Denken eine "antietatistische Komponente" immanent ${ }^{445}$ oder ob er, gegensätzlicher konnte kaum argumentiert werden, als "anti-egalitärer 
Etatist"446 $\mathrm{zu}$ entlarven ist, der nach einem starken staat hungert, der, "wenn erst von den vielen Braunen und vielleicht auch einigen Roten gesäubert, mächtig sein und klug handeln werde"447. Zwischen diesen beiden Polen der völligen Negation eines staatsbezogenen Denkens und dem Versuch, Eucken als Apologeten eines absoluten staates mit einer "Rousseau'schen Machtneurose" zu apostrophieren ${ }^{448}$, wurden (fast) alle denkbaren, mehr oder weniger schlüssig begründeten Auffassungen zum rubrizierten Thema vertreten. Im Verlaufe der Diskussion rückte jedoch zunehmend die Erkenntnis in den Vordergrund, daß bei Eucken mit der Neubesinnung auf die Grundprinzipien einer marktwirtschaftlichen ordnung zugleich die Neubesinnung auf die tatsächlichen Aufgaben des Staates einhergegangen war ${ }^{449}$, daß nach seiner Auffassung die Möglichkeit der ordnung der Wirtschaft durch Wettbewerb mit der Stärke der staatsmacht steht und fällt $t^{450}$ und daß deshalb ein "nach Vernunftgründen handelnder, in sich einheitlicher staatswillen" notwendig wird ${ }^{451}$, "der ordnungspolitisch engagiert ist, rechtsstaatlich handelt und nichts an sich zieht, was über Märkte und Preise koordiniert werden kann"452.

Bescheinigten die einen Eucken in diesem Zusammenhang den Entwurf einer staatslehre, die auf eindrucksvollen, höchst unbequemen und bis heute nicht ernstlich widerlegten Einsichten gründe ${ }^{453}$, vermißten die anderen die Auseinandersetzung mit dem Wesen des staates, seiner Rechtfertigung und seinen Funktionen und damit "die konstruktive Einheit und die Konsequenz" der staatstheoretischen Überlegungen Euckens überhaupt ${ }^{454}$.

Neben heftigen Kontroversen, die weniger die Klärung des "etatistischen", denn des politischen Standortes Euckens und dessen Haltung während des Nationalsozialismus zum ziel hat$\operatorname{ten}^{455}$, wurden in mehr oder weniger umfangreich begründeten Stellungnahmen einzelne Aspekte des Euckenschen staatsdenkens, insbesondere das Demokratieverständnis und damit die Frage thematisiert, ob und in welchem Umfang die Realisierung des ordo an einen bestimmten staatlichen willensbil- 
dungsprozeß gebunden ist. Auch hier standen sich die Meinungen konträr gegenüber. Der Auffassung, das von Eucken entworfene staatswesen müsse nach demokratischen Prinzipien organisiert sein ${ }^{456}$, wurde mit dem Hinweis widersprochen, daß "die parlamentarische Demokratie, die von Parteien regiert wird, (...) nicht zu dem von Eucken entwickelten Ordnungsbild" paßt ${ }^{457}$. Im Verbund mit der Diskussion um das Demokratieverständnis Euckens kam auch der vermeintlich verbändediskriminierende Aspekt seiner Konzeption zur Sprache ${ }^{458}$, der ebenso wie die mit dem "monozentrischen" Weltbild 459 Euckens verbundenen, antipluralistischen Tendenzen als zwangsläufige Folge der Aufgabenstellung des staates vermutet wurde ${ }^{460}$. Da nur ein von den konfligierenden gesellschaftlichen Interessen unabhängiger staat die Verwirklichung der Wettbewerbsordnung $z u$ gewährleisten vermag ${ }^{461}$, laute ein staatspolitischer Grundsatz Euckens konsequent, die gesellschaftlichen Machtgruppen als potentielle Gegner einer ordoadäquaten Wirtschaftspolitik aufzulösen oder zumindest zu schwächen. Dieser diskutierten Auffassung Euckens, die den staat als ein den gesellschaftlichen Kräften gegenüber unabhängiges und neutrales ordnungsinstrument denkt, wurde neben Realitätsferne ${ }^{462}$ eine eigenartige Antinomie attestiert, da der Ruf nach dem starken, unabhängigen staat als ordnungsrealisierender Institution in völligem Widerspruch zu Euckens grundsätzlicher "Skepsis, Reserve und negativer Beurteilung" staatlicher Gewalt stehe ${ }^{463}$.

Alles in allem hat es nach dieser Bestandsaufnahme den Anschein, als ob Eucken eine "in sich geschlossene staatslehre", die der intendierten praktischen Umsetzung der Wettbewerbsordnung das staatstheoretische Fundament hätte liefern können, nicht hinterlassen hat ${ }^{464}$.

Gesicherter Aufschluß darüber, ob diese Feststellung zutrifft und die Anmerkungen $z u$ Euckens staatstheoretischer und staatspolitischer Konzeption die tatsächlichen Ansätze verifizieren, läßt sich indes nur gewinnen, wenn von den überkommenen und in essentiellen Fragen divergierenden stel- 
lungnahmen $z u$ diesem Themenkreis abstrahiert und in einer Exegese der Quellen und einem Rekurs auf die eigenen Überlegungen Euckens dessen Haltung und dessen Ansichten zum staat bestimmt werden.

\section{Abschnitt}

Der staat als "Hüter der Wettbewerbsordnung"

\section{A. Das Desiderat: Der staat als "ordnende Potenz"}

"Alle Gedanken über die heutige ordnungspolitische Aufgabe, über das Scheitern der vielen wirtschaftspolitischen Experimente und über die Wettbewerbsordnung drängen auf eine Frage hin: Wer soll diese ordnung verwirklichen?" 465

Frei von der klassischen Utopie der selbstverwirklichung der guten ordnung, meinte Eucken jedoch erkannt zu haben, daß eben diese ordnung von der Natur sozusagen vorgeschlagen wird. Es bleibt demnach allein die klärung der Frage, wer als "ordnende Potenz" diesen Vorschlag zu akzeptieren und in gebundener Verwaltung des gewonnenen theoretischen Wissens entsprechende wirtschaftspolitische Maßnahmen ins Werk zu setzen bereit ist.

Auch Eucken bringt die Beantwortung dieser Frage "zunächst unwillkürlich" mit dem staat in Verbindung ${ }^{466}$, wobei sich bei ihm mit dieser Institution allerdings auf den ersten Blick negative Vorstellungen verbinden. Darf man, so sein Einwand, von jenem Gebilde etwas erwarten, das nach seiner "geschichtlichen Entwicklung so viele Enttäuschungen gebracht hat" ? 467

Aus dieser Erfahrung heraus sind für Eucken Vorschläge verständlich, die durch eine staatsersetzende Politik ständischer ordnung Selbstverwaltungskörper oder Berufsstände "als ordnende Potenzen im sinne einer Wettbewerbsordnung" akti- 
vieren möchten ${ }^{468}$. Diesen Versuchen steht Eucken jedoch ebenfalls ablehnend gegenüber, denn die Erfahrung mit selbstverwaltungskörpern "- z.B. im Kohlenbergbau und in der Kaliindustrie Deutschlands seit 1919 -"469 zeigt, daß auch sie der gesamtwirtschaftlichen Lenkungsaufgabe nicht gewachsen sind. Nach seiner Auffassung herrscht bei ihnen die Tendenz vor, sich "zu festgefügten Verbänden monopolistischer Prägung" zusammenzuschließen ${ }^{470}$, das heißt, es würden Institutionen mit der Verwirklichung der Wettbewerbsordnung betraut werden, denen insoweit jedes Interesse fehlt. Als "ordnende Potenzen" vermag sie Eucken "nur unter Aufsicht des Staates" zu akzeptieren, der sie zu unselbständigen "Instrumenten einer Wettbewerbsordnung" degradieren müßte ${ }^{471}$. Als Ergebnis seiner Überlegungen zur berufsständischen Idee hält Eucken fest, daß der Glaube an die ordnungsschaffende Kraft der stände eine "romantische Verklärung des Mittelalters" ist, der "eine gefährliche Rolle" bei der Lösung der anstehenden modernen ordnungsprobleme spielt ${ }^{472}$. Zudem führen die Überlegungen auch unter berufsständischen Aspekten zurück zum Staat, so daß entscheidungserheblich wird, ob dieser grundsätzlich geeignet ist, die ihm übertragenen wirtschaftspolitischen Aufgaben zu bewältigen und welcher organisation und Kompetenzen er dazu im einzelnen bedarf.

Antwort auf diese Fragen versucht Eucken durch eine Analyse des modernen staatsbildungsprozesses zu gewinnen, die ihm Erkenntnisse darüber vermitteln soll, warum der staat in bestimmten Epochen zur ordnung der Wirtschaft außerstande war und welche gesellschaftlichen, wirtschaftlichen und staatlichen Entwicklungen für diese Unfähigkeit verantwortlich zeichneten. 


\section{B. Die Fakten: Die Pathogenese des neuzeitlichen staates}

\section{Die erste Epoche: Der absolute Staat}

"Die politische Geschichte der Neuzeit ist bekanntlich erfüllt von einem großen Prozeß: es ist die Bildung des modernen Staates, die sich seit Ende des Mittelalters vollzieht" 473 .

Erste staatstheoretische Überlegungen Euckens beschäftigen sich demgemäß mit dem ersten Produkt dieses Staatsbildungsprozesses, dem "alten staat", einer chiffre für den "Staat des werdenden und des reifen Absolutismus", dem die wirtschaftspolitik des Merkantilismus entsprach ${ }^{474}$. "Der alte merkantilistische staat des Absolutismus"475 - wie er in der vollständigen Prädizierung Euckens heißt - hatte "sich im Kampf nach außen und nach innen aus dem mittelalterlichen staat" erhoben und war durch eine staatlich-gesellschaftliche organisationsform gekennzeichnet, die die strikte Trennung ihrer beiden Teilbereiche zur Grundlage hatte ${ }^{476}$. "Eine Kluft trennte staat und Gesellschaft"477.

Der absolute Herrscher, so Euckens Erklärung für dieses Phänomen, hatte seine souveränität gegen die stände erkämpft, "Machtpolitik und Heerwesen waren in seine Zuständigkeit übergegangen" 478 . Da es im Prozeß absolutistischer staatsbildung jedoch nicht $z u$ einer vollständigen Beseitigung der ständisch gegliederten, mittelalterlichen Gesellschaft kam, konnte der merkantilistische Fürst das Leben von "Volk und bürgerlicher Zivilisation" wegen der verbliebenen Bindungen und Traditionen und den sich aus ihnen entwickelnden Widerständen zu keiner Zeit einer umfassenden Regelung und Lenkung unterwerfen. Dies entsprach nach Ansicht Euckens letztlich auch nicht seinem willen, da es der absolute Herrscher nicht als seine Aufgabe ansah, den Wirtschaftsprozeß zu ordnen, die wirtschaftlichen Handlungen der einzelnen zu lenken und die überkommenen Wirtschaftsstrukturen insgesamt zu ändern ${ }^{479}$. 
Einzeleingriffe erfuhr der nach der Interpretation Euckens autonome Bereich der Wirtschaft nur, soweit es das "Staatsinteresse", das heißt das Interesse des absoluten Monarchen erforderte. Daß dies keineswegs selten der Fall war, gesteht Eucken $z^{480}$. An seiner Auffassung, daß die Wirtschaft durch die merkantilistische Wirtschaftspolitik weitgehend unbehelligt blieb ${ }^{481}$, vermag dieser Umstand jedoch nichts zu ändern. "Fragen grundsätzlicher ordnung der wirtschaft (...) (wurden) damals nicht oder nicht entscheidend angepackt" ${ }^{482}$. Eine Aufhebung der Trennung von staat und Gesellschaft in der Epoche des "alten Staates" vermag Eucken demgemäß ebenfalls nicht zu erkennen. Vielmehr habe ein "geradezu künstlich ausbalancierte $(r)$ Zustand von Arbeitsteilung und Trennung zwischen Krieg und Frieden, Heerwesen und Volksleben, Machtpolitik und friedlich-bürgerlicher zivilisation" bestanden ${ }^{483}$.

Dieses Gleichgewicht der Kräfte geriet durch die "Episode der Französischen Revolution" ins Wanken, die die Idee der Volkssouveränität als Gegensatz zur absolutistischen Herrschaft des Monarchen ins Bewußtsein der Zeit hob"44. Die "Demokratisierung der staatenwelt"485, die vollständige "Niederlegung der ständischen Schranken" und die Vorstellung, "daß die einzelnen rechtsgleichen Untertanen einem zentralistischen staat gegenüberstehen", war das Konglomerat von Ideen, das eine Wende im staatsbildungsprozeß einleitete, "die sich am Ende des 18. und zu Anfang des 19. Jahrhunderts explosionsartig vollzog" 486 .

Als Phoenix aus der Asche des absolutistischen staates stieg der "liberale staat", der allerdings, so Eucken einschränkend, zumindest die Verwirklichung der demokratischen Idee nicht als seine vordringlichste Aufgabe ansah ${ }^{487}$. 
II. Die zweite Epoche: Der liberale Rechtsstaat

Infolge der durch die Französische Revolution initiierten Wende im staatsbildungsprozeß der Neuzeit hatte sich nach Auffassung Euckens der Staat, entgegen landläufiger Ansicht, nicht aus der Wirtschaft zurückgezogen und ihr völlige Autonomie verliehen, sondern er war im Gegenteil bestrebt, eine neue ordnung zu etablieren. Die Rede von der "staatsfreien wirtschaft" ist daher "einseitig und, wenn man in dieser Einseitigkeit verharrt, falsch"488.

Diese "Intensivierung der Staatsbildung" 489 hatte Eucken in seinem 1932 erschienenen Aufsatz "Staatliche Strukturwandlungen und die Krisis des Kapitalismus"490 noch nicht zur Kenntnis genommen. Er interpretierte dort den "liberalen staat" des 19. Jahrhunderts als Institution, die von der Wirtschaft getrennt war und die die steuerung der Wirtschaft "fast völlig" privaten Unternehmern überließ, die den Humus bildeten, auf dem der Kapitalismus "kräftig heranwachsen konnte" 491

Erst unter dem zunehmenden Eindruck der ordnungsidee entwickelte Eucken in seiner 1938 erschienenen kleinen Schrift "Nationalökonomie - wozu?" und darauffolgend in den "Grundsätzen der Wirtschaftspolitik" das Verhältnis von wirtschaft und staat in der eingangs dargestellten Weise. Der staat scheint sich nach der von Eucken letztlich vertretenen Auffassung nur von der Wirtschaft abgesetzt zu haben. Tatsächlich begab er sich in keiner Phase seiner Entwicklung im 19. Jahrhundert der Möglichkeit der Ingerenz in die Wirtschaft, die ständig in seinem Einwirkungs- und Aufgabenbereich verblieb. Die Wirtschaft konstituierte sich nicht in Abkehr vom, sondern durch den staat.

Diese im Grunde allen gängigen Vorstellungen widersprechende Interpretation des "liberalen Staates" durch Eucken gründet in dessen spezifischer Rechtsstaatsdoktrin. Nur unter deren Einbeziehung sowie der Klärung der Interdependenzen von Rechtsstaat und "Wirtschaftspolitik des Laissez-faire" wird 
deutlich, weshalb Eucken auch in der zweiten Epoche neuzeitlicher staatlichkeit öffentliche Aufgaben im Bereich der wirtschaft ortete.

1. Das Rechtsstaatsprinzip in der Interpretation Walter Euckens

"Der staat soll unter dem Recht stehen"492; er "selbst soll handeln und sich bewegen innerhalb der Grenzen der Vernunft und des Rechts"493. Aus diesem Grund ist es für Eucken "das feierliche Grundprinzip eines solchen Rechtsstaates, die Freiheits- und Rechtssphären der einzelnen Bürger" anzuerkennen und zu schützen, wobei diese Aufgabe janusköpfigen Charakter besitzt. Einerseits geht es um den individuellen Schutz vor staatlicher Zwangsgewalt, die hinter dem Schild öffentlicher Interessen in die Freiheitsräume des einzelnen einzugreifen sucht. Andererseits ist der unter dem Recht stehende und zur Verwirklichung des Vernunftprinzips verpflichtete staat gehalten, den einzelnen vor freiheitsgefährdenden Übergriffen anderer Gesellschaftsmitglieder $z u$ schützen, mag dieser "Nachbar (...) auch groß und einflußreich sein" 194 .

Weitere wesenskonstituierende Merkmale des Rechtsstaates neben dem allumfassenden Schutz der persönlichen Freiheit durch verfassungsmäßig garantierte Grundrechte sind für Eucken die organisatorische "Trennung der drei staatstätigkeiten" sowie die Einrichtung "einer Verwaltungsgerichtsbarkeit, die über die Anwendung des Grundsatzes der GesetzmäBigkeit der Verwaltung" wacht ${ }^{495}$. Dieser von Eucken lediglich in den geschilderten Grundzügen nachgezeichnete Rechtsstaat gilt ihm als Gegensatz zum "Zwangsstaat" oder zur "Tyrannis"496. Er ist das "geschichtlich-universale Phänomen", das überall dort verwirklicht ist, "wo mit der Realisierung der Freiheit Ernst gemacht wird"497. 
In der zweiten Epoche des neuzeitlichen Staatsbildungsprozesses kommt nun folgende "große historische Tatsache" zum Tragen: "Die gesamte Verfassungs- und Rechtspolitik stellt sich in den Dienst der Durchsetzung des Rechtsstaats-Gedankens"498. Die Staaten setzen sich "selbst staatsordnungen oder Verfassungen", um einen im rechtsstaatlichen sinne "funktionsfähigen staatsapparat herzustellen" und die Freiheitssphäre des einzelnen zu sichern; in diesem zusammenhang schufen sie auch "Rechtsordnungen durch umfassende Kodifikationen"499. Diese Entwicklung blieb nicht auf den staatlichorganisatorischen Bereich beschränkt, sondern zeitigte Wirkungen auch für die wirtschaft ${ }^{500}$.

Aufgrund der zum Teil nur andeutenden Einlassungen Euckens zur Frage des Verhältnisses von Rechtsstaat und Wirtschaftsordnung erscheint es schwierig, insoweit Feinheiten auszuloten. Im Wege der Gesamtschau des Euckenschen Werkes werden jedoch die wesentlichen Zusammenhänge sichtbar.

2. Der liberale Rechtsstaat und sein Verhältnis zur Wirtschaft

Durch die rechtsstaatliche Verfassung und die einfachgesetzlichen Regelungen im Bereich des "Eigentums-, Vertrags-, Gesellschafts-, Patentrechts usw." gibt der staat der wirtschaft eine neue Grundlage und trifft eine "Gesamtentscheidung auch für die wirtschaftsordnung"s01.

Nach Auffassung Euckens war die Beziehung zwischen Rechtsstaat und Wirtschaft im Zeitalter des sogenannten Laissezfaire-Liberalismus damit eine wesentlich engere und trug wesentlich andere Kennzeichen als gemeinhin angenommen ${ }^{502}$. 
a) Die "wirtschaftsverfassungsrechtliche Revolution"

Grundlage dieser Verhältnisbestimmung von Wirtschaft und Rechtsstaat sind überlegungen Euckens zur Frage, nach welchen Grundsätzen überhaupt sich die jeweiligen geschichtlichen ordnungen $\mathrm{zu}$ konstituieren vermögen ${ }^{503}$. Zwei Entstehungsalternativen glaubte er insoweit erkennen $\mathrm{zu}$ können. Während sich die historisch "gewachsenen ordnungen" gewohnheitsmäßig und ohne eine bewußte, planvolle Entscheidung herausbildeten, sind die "gesetzten ordnungen" das Produkt einer rationalen, politischen Dezision, die ihren Ausdruck in einer Wirtschaftsverfassung findet ${ }^{504}$.

Demgemäß definiert Eucken die Wirtschaftsverfassung als "die Gesamtentscheidung über die ordnung des Wirtschaftslebens eines Gemeinwesens"505. Da er in diesem Zusammenhang - im Gegensatz zu den maßgeblichen Stellen in den "Grundsätzen der Wirtschaftspolitik"506 - noch zwischen "Ordnung der Wirtschaft", die als synonym für die erstrebenswerte gute ordnung, "die dem Wesen des Menschen und der Sache entspricht" und damit für den ordo steht und der "Wirtschaftsordnung" als dem konkreten, je nach geschichtlicher situation wechselnden, individuellen wirtschaftlichen Tatbestand unterscheidet ${ }^{507}$, werden Struktur und Inhalt der Gesamtentscheidung und damit der Wirtschaftsverfassung deutlich. Sie ist der "Wille", "gewisse allgemeine, rational ersonnene ordnungsgrundsätze"508, die als konstituierende Merkmale der richtigen und guten "Ordnung der Wirtschaft" identifiziert sind, durchzusetzen, um die entsprechende seinsmäßige "Wirtschaftsordnung" $z u$ erzeugen. Die solchermaßen "gesetzten" ordnungen sind demnach nichts anderes als positivierte, nach Funktion und Bedingungszusammenhängen erkannte sollensordnungen ${ }^{509}$.

Ausgehend von diesem Wirtschaftsverfassungsbegriff und seinen Voraussetzungen wird deutlich, worin die "wirtschaftsverfassungsrechtliche Revolution"510 im Zeitalter des "libera- 
len Rechtsstaates" bestand und warum die Rede von der staatsfreien Wirtschaft nach Auffassung Euckens falsch sein muß.

b) Staatsverfassung und Wirtschaftsverfassung

Indem Eucken davon ausgeht, daß der sich durch die rechtsstaatlichen Garantien in Form bringende "liberale Rechtsstaat" eine Entscheidung auch über die Form des Wirtschaftens trifft, da durch die rechtsstaatliche Verfassungsgebung "nicht nur dem einzelnen Freiheit (...), sondern auch dem ganzen ordnung" gegeben wurde $e^{511}$, müssen staatsverfassung und Wirtschaftsverfassung auf den gleichen Prinzipien gründen. Die "wirtschaftsverfassungsrechtliche Revolution" bestand demnach in der ordnungskonstituierenden wirkung der staatsverfassungsnormen, durch die die wirtschaftsordnung des "liberalen Rechtsstaates" gesetzt wurde. Es lag mit anderen Worten eine verfassungsrechtliche Gesamtentscheidung über die ordnung des Wirtschaftslebens im Rechtsstaat des 19. Jahrhunderts vor ${ }^{512}$.

Daß dieser staat die rationale ordnung der wirtschaft überhaupt als seine Aufgabe ansehen und er die Erledigung der ihm nunmehr gestellten Aufgabe mit Hilfe einer staatsverfassung anstreben konnte, die in ihren auf die Wirtschaft bezogenen Teilen auch nach dem Verständnis Euckens auf subjektiven Abwehrrechten mit staatsausgrenzender Funktion beruhte ${ }^{513}$, setzt ein bestimmtes Verständnis von Inhalt und struktur der durch das Verfassungsrecht zu verwirklichenden, "rational ersonnenen ordnungsgrundsätze" ${ }^{514}$ und einen bestimmten "Reifegrad"515 der ordnungstheorie und der auf ihrer Grundlage letztlich erzeugten ordnung voraus ${ }^{516}$.

Die Wende hin zum Wirtschaftsverfassungsdenken im "liberalen Rechtsstaat" und damit die Einsicht in die Möglichkeit der bewußten ordnung des Wirtschaftslebens hätte nach Auffassung 
Euckens nicht ohne die gedankliche Vorarbeit der klassischen Nationalökonomie vollzogen werden können. ${ }^{517}$. Erst sie vermittelte dem wirtschaftspolitisch handelnden staat Einsicht in den Bauplan und die Gesetzmäßigkeiten der Wirtschaft und damit auch Erkenntnisse über die im Wege der Wirtschaftsverfassung $z$ verwirklichenden, konstituierenden ordnungsgrundsätze.

Indem die klassische Nationalökonomie nun die Auffassung vertrat, in der ordnung der vollständigen Konkurrenz "die allein richtige, natürliche, göttliche ordnung entdeckt zu haben", konnte es für sie nur noch darum gehen, diejenigen Ordnungsgrundsätze $z u$ entwickeln bzw. aus der Wirklichkeit zu abstrahieren, die geeignet waren, das "höchst leistungsfähige regulative Prinzip" des Wettbewerbs in Kraft zu setzen $^{518}$.

Es schien insoweit ein "einfaches system der natürlichen Freiheit" ${ }^{519}$ und die Wahrung des Rechtsprinzips zu genügen ${ }^{520}$. Durch die verfassungsmäßige Garantie des Privateigentums, der Vertragsfreiheit und der Wettbewerbsfreiheit mußte sich dann nach den ordnungsvorstellungen der Klassiker "von unten her aus den spontanen Kräften der Gesellschaft von selbst" die gute ordnung bilden und sich die Harmonie von Eigennutz und Gemeinwohl einstellen ${ }^{521}$.

Damit waren diejenigen Aufgaben gekennzeichnet, die der Staat $z u$ erfüllen hat, um den ordre naturel der Gesellschaft, um den sich die physiokratische Lehre zentriert ${ }^{522}$, in den ordre positif der Klassiker $z u$ überführen. Zum einen mußte mit Hilfe der ausgrenzenden rechtsstaatlichen Freiheitsverbürgungen der gesellschaftliche Raum geschaffen werden, in dem das "einfache system der natürlichen Freiheit" funktionieren und eine "wohlgeordnete Wettbewerbswirtschaft" zur Entfaltung kommen konnte ${ }^{523}$. Zum anderen hatte sich der staat, war die Gesamtentscheidung für den sich selbst regulierenden Marktmechanismus erst gefallen, jeder Intervention in die Wirtschaft $\mathrm{zu}$ enthalten. 
Auf der Grundlage dieses ordnungstheoretischen Verständnisses konnte es nicht mehr Aufgabe des liberalen staates sein, über die Gesamtentscheidung hinaus deren Vollzug auch zu überwachen. Er durfte vielmehr nach der Theorie darauf vertrauen, daß die durch die Rechtsordnung mit individuellen Freiheiten ausgestatteten wirtschaftsteilnehmer sich entsprechend der ordovorgabe verhalten und sich dadurch die angestrebte "Ordnung der Wirtschaft" entwickeln werde ${ }^{524}$.

c) Zur Frage der Interdependenz von liberalem Rechtsstaat und Wettbewerbsordnung

Diese theoretischen Überlegungen zugrunde gelegt, schien alles darauf hinzudeuten, daß der Rechtsstaat die gesuchte ordnende Potenz sein kann, die durch ihre verfassung und ihre strukturprinzipien die Gesamtentscheidung für eine "wohlgeordnete Wettbewerbswirtschaft" 525 durchzusetzen vermag. Ein solcher "Parallelismus im rechtspolitischen und wirtschaftspolitischen Denken und Handeln"526 und damit die Feststellung, daß die Wettbewerbsordnung stets die dem Rechtsstaat korrelative Form des wirtschaftens ist, hätte nach Auffassung Euckens zur Konsequenz, daß "die Bildung der Formen des Wirtschaftens und der industrialisierten Welt den wirtschaftenden selbst" überlassen werden könnte und im Rechtsstaat das "ordnungspolitische Problem" beseitigt wä$\mathrm{re}^{527}$.

Daß dieser Parallelismus nicht besteht, folgt für Eucken aus der geschichtlichen Entwicklung.

So seien zwar in der "Epoche liberaler Wirtschaftspolitik" rechtsstaatliche Einrichtungen wie "die verfassungsmäßigen Grundrechte, die Trennung der staatlichen Gewalten, die Gesetzmäßigkeit der Verwaltung und ihre Nachprüfung durch Verwaltungsgerichte" zum Schutz gegen "Zwangs- und Willkürakte staatlicher organe" realisiert worden ${ }^{528}$. Die wirtschaftliche wirklichkeit habe indes gezeigt, wie "die Gewährung von 
Freiheit eine Gefahr für die Freiheit" selbst wurde ${ }^{529}$. Die Vertragsfreiheit z.B., offensichtlich eine Voraussetzung der durch Wettbewerb organisierten Wirtschaft, wurde von den Wirtschaftsteilnehmern in völliger Verkennung ihres Zweckes dazu benutzt, sich zu organisieren, um die Konkurrenz und die Freiheit anderer zum Wettbewerb einzuschränken und durch die erlangte Monopolstellung die eigenen Marktchancen zu verbessern ${ }^{530}$. In den durch einseitige Vermachtung gekennzeichneten, wirtschaftlichen ordnungsformen war der Lenkungsmechanismus der Preise außer Kraft gesetzt, das "Spiel von Angebot und Nachfrage" vermochte weder das Gleichgewicht der wirtschaftlichen Interessen noch das Gleichgewicht der Freiheitssphären herzustellen ${ }^{531}$.

Die unkontrollierte Konzentration wirtschaftlicher Macht führte in der Folge $z u$ instabilen wirtschaftlichen Verhältnissen, provozierte private willkürakte und gefährdete die individuellen Freiheiten und damit auch die Verwirklichung der Wettbewerbswirtschaft selbst, die auf der Annahme beruhte, die freie Entfaltung der spontanen Kräfte und das freie Wirken des Einzelinteresses führe zu gesamtgesellschaftlichem Nutzen ${ }^{532}$.

Im Ergebnis verhinderte der durch Marktmacht mögliche "wirtschaftliche und soziale Druck" für Eucken die Verwirklichung des Rechtsstaates, dessen "feierliche(s) Grundprinzip" es war, die Freiheit des einzelnen nicht nur in der (vertikalen) Beziehung zwischen Bürger und staat, sondern auch auf der horizontalen Ebene vor der "Bedrohung durch andere Bürger" und diese allseitige Freiheitssphäre durch die "verfassungsmäßigen Garantien" zu schützen ${ }^{533}$. Der (Grund-) "Rechtsschutz, den der Rechtsstaat zwischen den Bürgern errichtet" hatte, wurde durch die faktische Entwicklung der Wirtschaft hinfällig ${ }^{534}$. In einer ordnungsform, die durch marktbeherrschende soziale Machtkörper geprägt ist, sind die gesellschaftlichen Voraussetzungen für die "Ausübung" der "Grundrechte" nicht mehr gegeben, denn durch die Berufung des sozial Mächtigeren auf das eigene Freiheitsrecht und 
dessen uneingeschränkte Nutzung werden "rechtlich garantierte Freiheitsrechte" des sozial schwächeren sowie deren Gebrauch "anulliert"535. "Freiheitsrecht hebt Freiheitsrecht auf" ${ }^{536}$. Der durch den Rechtsstaat intendierte Schutz des einzelnen vor staatlicher und privater willkür wurde, "obwohl die verfassungsmäßigen Garantien des Rechtsstaates im 19. Jahrhundert voll entwickelt waren" infolge der beschriebenen wirtschaftlichen und sozialen Abhängigkeiten demzufolge nur einseitig verwirklicht: lediglich gegen willkürakte des staates selbst blieb der einzelne weitgehend geschützt ${ }^{537}$.

Für Eucken wurde der liberale Rechtsstaat demnach seiner selbstgestellten Aufgabe nicht gerecht, "die absolute Freiheit des Naturzustandes (status naturalis) durch Gesetze einzuschränken, in deren Rahmen der einzelne gegen willkür von anderen gesichert" war ${ }^{538}$. Die suche nach dem staat, der diesen "status civilis" 539 als Inbegriff der freien und unbeschränkten Entfaltung der eigenen Fähigkeiten und individuellen Kräfte im Wettbewerb im Verhältnis zu anderen Mitgliedern der Gesellschaft $z u$ gewährleisten vermag, muß "trotz aller Bemühungen um einen Rechtsstaat" deshalb weiterhin Gegenstand rechts- und wirtschaftspolitischen Denkens und Handelns bleiben ${ }^{540}$.

Was Eucken nach alledem im Hinblick auf die Verwirklichung einer "wohlgeordneten Wettbewerbswirtschaft" auf der Verlustliste des Rechtsstaates notiert, ist offenkundig der Widerspruch zwischen rechtlich verfaßter ordnung der wirtschaft und der faktisch existierenden wirtschaftsordnung oder grundrechtstheoretisch auf den Begriff gebracht: die Diskrepanz zwischen abstrakt-normativer Grundrechtsgeltung und der Möglichkeit der konkreten innergesellschaftlichen Grundrechtsnutzung, die gerade nicht in der von der rechtsstaatlichen Verfassung versprochenen Form bestand.

Die "verfassungsmäßigen Garantien" sind, so die nach seiner verfassungsgeschichtlichen Exegese zutreffende Einschätzung 
Euckens, zu formalen Rechtspositionen degeneriert, die für den Großteil der Grundrechtsnutzer ohne tatsächliche Verwirklichungschance blieben ${ }^{541}$.

Aus der mangelnden Übereinstimmung von Verfassungsnorm und Verfassungswirklichkeit und daraus folgend dem Umstand, daß der "objektivierte Zustand Wettbewerb"542 weder automatische noch einzige Nutzungsfolge der garantierten Freiheitsrechte ist, ergibt sich für Eucken die Untauglichkeit der historischen rechtsstaatlichen Verfassung zur ordnung des Wirtschaftslebens durch Wettbewerb. Eine wirtschaftsverfassungsrechtliche Gesamtentscheidung über die ordnung der Wirtschaft unter Beachtung der Ordnungsgrundsätze von Privateigentum, Vertragsfreiheit und Wettbewerb hatte der liberale Staat des 19. Jahrhunderts zwar getroffen, die "faktischen Wirtschaftsordnungen aber, die sich auf dieser wirtschaftsverfassungsrechtlichen Grundlage erhoben"543, trugen diesen Grundsätzen keine Rechnung. Die jeweiligen Wirtschaftsordnungen sind deshalb "nicht etwa den jeweils geltenden Rechtsordnungen gleichzusetzen"544. Was von den verfassungsmäßigen Rechtsgarantien bleibt, ist deren schale, "ihre Funktion ändert sich" je nach "Marktform und mit dem ordnungsgefüge der Wirtschaft überhaupt" ${ }^{545}$.

Die umfängliche und systematische Analyse des "liberalen Rechtsstaates" des 19. Jahrhunderts und dessen Verhältnis zur wirtschaft vermittelt Eucken wesentliche Erkenntnisse im Hinblick auf den von ihm gesuchten staat, der als "ordnende Potenz" die Verwirklichung der guten ordnung der Wirtschaft in Angriff nehmen soll.

Für diesen staat gilt zum einen, daß er über die bloße Rechtssetzung und Verfassungsgebung hinaus weitere Vorkehrungen zur sicherung der ordnung der Wirtschaft zu treffen hat. Rechtsnormen können niemals alleiniges oder primäres Gestaltungsmoment der Wirtschaft $\operatorname{sein}^{546}$, denn sie lassen dem "Kampf in Ordnungsformen"547 freien Lauf. Das Anliegen des Rechtsstaates, dem einzelnen Freiheit und dem ganzen eine 
zureichende ordnung zu geben, wird damit konterkariert. Zum anderen hat sich der gesuchte staat der Bedingungszusammenhänge zwischen seinen eigenen ordnungsprinzipien und den Grundsätzen der ordnung der Wirtschaft zu vergegenwärtigen, andernfalls er mit der einen Hand zerstört, was er mit "der anderen Hand - z.B. durch Trennung der Gewalten, Grundrechte usw. - zu erhalten" sucht ${ }^{548}$.

Trotz der im Grunde wenig ermutigenden Erfahrungen mit dem liberalen staat des 19. Jahrhunderts hält Eucken auch im Hinblick auf seine "neue staatsbildung" an der "Idee des Rechtsstaates" und dem Ziel, durch "rechtsstaatliche Institutionen" 549 dem einzelnen Schutz vor staatlicher und privater Willkür zu gewähren, fest. Der Rechtsstaat ist für ihn "ein geschichtlich-universales Phänomen", das immer dann Anspruch auf Verwirklichung erhebt, wenn "mit der Realisierung der Freiheit Ernst gemacht wird. - So wird es auch in zukunft bleiben" 550 .

Allerdings kann sich der Rechtsstaat "nur dort vollständig durchsetzen, wo zugleich mit seiner staatlich-rechtlichen ordnung eine 'adäquate' Wirtschaftsordnung verwirklicht ist" und die ordnungen von staat und Wirtschaft dementsprechend aufeinander "abgestimmt" sind ${ }^{551}$.

Für Eucken stellt sich auf der Grundlage dieser Erkenntnisse im Hinblick auf die eigene, "neue staatsbildung" damit die grundlegende Frage, wie ein "leistungsfähiger Rechtsstaat" 552 aufgebaut werden kann, der geeignet ist, den ihm vorgegebenen ordnungspolitischen zielsetzungen Rechnung zu tragen und die Fehler des Staatsbildungsprozesses im 19. Jahrhundert zu vermeiden. 
III. Die dritte Epoche: Der totale Wirtschaftsstaat

Im Laufe der zweiten Hälfte des 19. Jahrhunderts löste sich die "alte staatlich-gesellschaftliche organisation" des liberalen Staates, die eine vehemente Entfaltung des Kapitalismus ermöglicht hatte, langsam auf und wurde durch eine "neue, andersgeartete Organisation" ersetzt, die das "Funktionieren des kapitalistischen Mechanismus aufs äußerste erschwert(e)"553. Auf den Begriff gebracht ist es der durch die "Politisierung der Wirtschaft" entstandene "Wirtschaftsstaat", dem dieses negative Urteil Euckens gilt und der die dritte Epoche des Staatsbildungsprozesses der Neuzeit kennzeichnet ${ }^{554}$.

Initiator des "Verflechtungsprozesses von staat und Gesellschaft" war nach Auffassung Euckens der Bismarcksche staat, dessen Eingriffe in den Wirtschaftsprozeß allerdings von der "Idee der Staatsräson" getragen waren ${ }^{555}$. Festigung und Sicherung des Reiches als Motive für den wirtschaftlichen Interventionismus machten ihn deshalb für Eucken konsequent $\mathrm{zu}$ einem "Interventionismus der staatsräson", der sich auch im Falle der "Abkehr vom Liberalismus" und antikapitalistischer Eingriffe in die Wirtschaft einer "moralischen Rechtfertigung" erfreuen durfte ${ }^{556}$.

In der Folge ging diese Rechtfertigung indes verloren. Im Gegensatz zu der von einer zentralen politischen Idee und Kraft bestimmten Politik, die ihre Legitimation aus einem "beherrschende( $n$ ) Willen" empfing und die insoweit der Regierungsform des aufgeklärten Monarchen am Ende des absolutistischen zeitalters vergleichbar war, handelte der nachbismarcksche staat nicht mehr aus eigenem willen, sondern unter dem Druck von Interessenten ${ }^{557}$. Diese Umkehrung der Beherrschungsverhältnisse im Verhältnis staat - Gesellschaft ist für Eucken nur als Folge einer grundlegenden Änderung gesellschaftlicher strukturen zu erklären. 
1. Der Wirtschaftsstaat als Produkt der Säkularisation

Das zeitgeschichtliche Ereignis, das die grundlegende Änderung der Gesellschaftsordnung bewirkte, war die Industrialisierung und Technisierung der Arbeitswelt, die zum Verlust der "alten Gliederung" der Gesellschaft führte ${ }^{558}$. Das Produkt dieser Entwicklung war die Massengesellschaft mit den sie prägenden neuen sozialen schichten der Arbeiter und Angestellten, deren Verhalten im Laufe des 19. und zu Beginn des 20. Jahrhunderts zunehmend durch die "Propaganda politischer und wirtschaftlicher Parteien" und deren Ideologien bestimmt wurde, die nach Auffassung Euckens aus dem Blickwinkel des einzelnen immer mehr zum Maßstab gesellschaftlicher orientierung wurden und den Charakter "säkularisierte(r) Heilslehren" annahmen ${ }^{559}$. Begriffe wie Kapitalismus, Imperialismus und Marxismus beherrschten das Denken vieler, Mythen verdrängten die Ratio 560 . Das "Denken in ordnungen" war nicht nur ohne gesellschaftlichen Rückhalt, die durch die Industrialisierung hervorgebrachten schichten waren vielmehr bestrebt, "die traditionelle ordnung der wirtschaft, Gesellschaft und des staates" einzureißen und die Etablierung von funktionsfähigen und menschenwürdigen ordnungen $z u$ verhinder $n^{561}$.

Auf der Suche nach den Gründen für diese Haltung vermag Eucken soziale Umstände als Rechtfertigung nicht anzuerkennen, da "bekanntlich" keine Verschlechterung, sondern eine Verbesserung der Lebensverhältnisse der Massen im 19. Jahrhundert und $z u$ Beginn des 20. Jahrhundert erfolgte; "ebensowenig sind sie in einer fortwährenden Verschärfung der Gegensätze von Reichtum und Armut zu finden, denn eine solche Verschärfung ist während der Existenz des Kapitalismus - wie Pareto unwiderlegt gezeigt hat - nicht erfolgt"562. Die tatsächlichen Motivationen liegen tiefer und folgen aus dem "Zusammenbruch der überkommenen Lebensordnung" überhaupt ${ }^{563}$. Die Unruhe der Massen, die seit der Französischen Revolution die Staats- und Gesellschaftsordnungen Europas umgewälzt 
hat, erklärt sich für Eucken unter anderem aus der Auflösung der festgefügten, traditionellen gesellschaftlichen strukturen als Folge einer geistigen Entwicklung, die "die Religion nicht mehr dem Ganzen des Lebens als Fundament" unterzulegen bereit war $^{564}$. Das Leben "des einfachen, nicht reflektierenden Menschen" empfing seine sinngebung bis zur Mitte des 18 . Jahrhunderts ausschließlich vom Glauben her ${ }^{565}$. Dieser Bezugspunkt ging in dem Moment verloren, da sich der Mensch im Zeitalter der Aufklärung als von Natur aus gut empfand. Die Säkularisierung der Erlösungstheologie und die Emanzipation des einzelnen vom bloßen Dasein als sünder mit der durch die Religion in Aussicht gestellten Erlösung durch göttliche Gnade hatte eine grundsätzliche Verschiebung aller gesellschaftlichen Werte zur Folge. An die stelle der werte des Glaubens traten nach Eucken die autonomen Werte "von Kultur, Wirtschaft und Staat" 566 . "Diese geistige Umgestaltung" machte sich während des 19. und zu Beginn des 20. Jahrhunderts mit all ihren Konsequenzen im Volke breit ${ }^{567}$. Verlassen von der einheits - und sinnstiftenden Kraft der Religion und konfrontiert mit der breitgefächerten Palette an kulturellen, gesellschaftlichen und staatlichen Werten wurde der einzelne unsicher und innerlich unruhig, - "eine Unruhe, die gerade auch auf sozialem und politischem Gebiet sich in stärkstem Maße auswirken mußte und sich ausgewirkt hat"568. Der sich selbst und seiner Umgebung entfremdete Massenmensch, ohne letztgültigen Bezug $z u$ einem Grundwert, wurde bei dem Versuch, das entstandene geistig-religiöse Vakuum zu füllen, anfällig für Ideologien und aufgrund seiner mangelnden intellektuellen Widerstandskraft zwangsläufig deren opfer.

Zwei grundsätzliche ideologische Richtungen, die sich dem auf der Suche nach sinngebenden Einheiten befindlichen einzelnen als Ersatzreligionen andienten, glaubt Eucken feststellen zu können: "Den "Ökonomismus" und den "Politismus"569 - zwei Begriffe, die in seinem Werk singulären Charakter behielten. 
a) Der ökonomismus

Hinter dem Begriff des "Ökonomismus" verbirgt sich der "Sozialismus marxistischer Prägung", der durch die "Milieutheorie" alles "innere Unglück, alles Elend und alle Unzufriedenheit" als Produkt der sozialen Umwelt im allgemeinen und dem "Aufbau der Wirtschaft" im besonderen erklärt ${ }^{570}$.

Nach "ökonomistischer" Lesart findet das Elend der Massen und die Ausbeutung des Proletariats erst dann ein Ende, wenn die Beseitigung der für diesen Zustand verantwortlichen Wirtschaftsform und deren umfassende Neugestaltung gelingt. In der Fixierung auf dieses ziel wird "dem ganzen Tun des einzelnen Menschen wieder ein umfassende( $r$ ) Sinnzusammenhang" gegeben ${ }^{571}$. Die Errichtung einer Plan- oder Gemeinwirtschaft und die Aufhebung der alten Klassen und Klassengegensätze wird zum religionsersetzenden Akt ${ }^{572}$.

\section{b) Der Politismus}

Für die weitere Entwicklung des staates entscheidend war nach Auffassung Euckens jedoch diejenige Ideologie, die er mit dem Begriff "Politismus" kennzeichnet.

Nachdem die wiederherstellung des durch die geschilderte geistesgeschichtliche Entwicklung verlorengegangenen sinnzusammenhangs des Lebens auf den verschiedensten Gebieten erfolglos versucht worden war, wuchs die Neigung, mit Hilfe des staates alle Lebensfragen zu lösen und ihn als allzuständigen Krisenhelfer und Therapeuten auch für persönliche Probleme einzusetzen 573 . Hatte der einzelne ehedem sein "wirtschaftliches Unglück als Schicksal hingenommen"574 und die Schuld bei sich selbst gesucht, so wich diese Haltung im Zuge der Entwicklung "politistischen" Denkens einem konsequent staatsbezogenen Anspruchsdenken und einer Lebensanschauung, die vom staate forderte, Sorge auch für das indi- 
viduelle wirtschaftliche und seelische wohlergehen zu tragen $^{575}$. "Vom Staate her, durch Aufgehen des einzelnen im Staat soll dem Leben wieder ein umfassender sinngehalt verliehen werden".

Der "leidenschaftliche Glaube an den staat", "und zwar an den totalen, alles beherrschenden staat" wird zum "Religionsersatz" und zur Grundlage und zum Mittelpunkt allen gesellschaftlich-sozialen Lebens" ${ }^{576}$. "Staats-Glaube" ersetzt "Gottes-Glaube"577. Aus dieser politistischen Haltung heraus, die für Eucken insgesamt gekennzeichnet ist durch eine "eigentümliche Mischung wirtschaftlicher Interessen, antikapitalistischer stimmungen, nationalpolitischer Bestrebungen und quasi religiöser Überzeugungen" ${ }^{578}$ wird vom staat verlangt, auch die ordnung der Wirtschaft zu bestimmen.

\section{Die Zerstörung des altkapitalistischen Systems}

Folge dieses Drängens nach interventionistischen Eingriffen in die wirtschaft ist die zerstörung des altkapitalistischen Systems $^{579}$. Indem sich der staat zum ordnenden Eingriff in alle Bereiche des gesellschaftlichen Lebens und damit auch zur Politisierung der Wirtschaft legitimiert glaubt, zerstört er jene staatlich-gesellschaftliche Konstellation, in der der "ungemein komplizierte, arbeitsteilige, kapitalistische Wirtschaftsapparat" zu funktionieren vermochte ${ }^{580}$.

Mit der Ablösung des "liberalen Rechtsstaates" durch den totalen "interventionistischen wirtschaftsstaat" 581 wurde der empfindliche und wirkungsvolle Regulator des Preises, der die Bewegungen des alltäglichen Wirtschaftsherganges und die zahlreichen Wirtschaftspläne der einzelnen Wirtschaftsteilnehmer ins Gleichgewicht brachte, mit großer Genauigkeit lenkte und alle produktiven Kräfte in Beschäftigungen hineindirigierte, ausgesetzt. Die ordnungsprinzipien liberaler Wirtschaftspolitik wurden übergangen bzw. überhaupt nicht mehr verstanden, das "Denken in Ordnungen" verfiel ${ }^{582}$. 
Was sich infolge der geschilderten Entwicklung des staates etablieren konnte, war ein "staatlich gebundener Kapitalismus", dem durch die stillegung des Knappheitsmessers eine funktionstüchtige steuerung fehlte ${ }^{583}$. "Marktregulierungen wurden zur Massenerscheinung"584. Fehlleitungen sowohl im Produktions- als auch im Verteilungsproze $\beta$ waren die Folge. Im Bereich der Wirtschaft wurde durch den Einfluß der "Parteien und den von ihnen organisierten Massen und Interessentengruppen" sowie durch deren politistisches Denken, das vom staat "einen verstärkten und unsystematischen Protektionismus" erzwang und zur "Politisierung der Preisbindung" führte, die bislang "exakt geordnete Volkswirtschaft" zum "Chaos"585. Ordnungsrahmen und Wirtschaftsablauf waren "von den Zufälligkeiten politischer Machtgruppierungen abhängig" 586 . Korrelativ zur anarchisch-pluralistischen zersetzung des Staates entstand auch wirtschaftlich Anarchie. Die "Versumpfung des Kapitalismus"587 erreichte ihren Höhepunkt: "Die zum staat gewordene Gesellschaft wird ein Wirtschaftsstaat" ${ }^{588}$.

Die Entwicklung des Staates im Rahmen der von Eucken eingegrenzten sogenannten 3. Epoche zeigt nach seiner Auffassung schlüssig, daß die mit der Lenkung und ordnung der wirtschaft durch Wettbewerb auftretenden Probleme keine diesem System immanenten Mängel sind ${ }^{589}$, sondern daß Funktionsunfähigkeit und Entartung der wirtschaftsordnung in wesentlichem Maße das Resultat der der säkularisation entspringenden Staatsform waren ${ }^{590}$, die es den Massen erlaubte, ihre wünsche und Forderungen in den staat hineinzutragen und ihn zu Eingriffen in die wirtschaft $z u$ veranlassen ${ }^{591}$. Was Eucken in diesem Zusammenhang präzise anprangert, ist die "Demokratisierung" des Staates und der Welt überhaupt ${ }^{592}$. 
3. Die identitäre Demokratie als staatsform der Säkularisierung

Die metaphysisch fundierte "politistische" staatsgesinnung, das subjektive Bewußtsein vom staat als einer virtuell allzuständigen, alles menschliche Leben umfassenden Macht war nach Ansicht Euckens der Initialzünder für eine weitere "historische Entwicklungsreihe"593, durch die die politistischen Neigungen der Massen erst institutionalisiert und legitimiert und der "Staats-Glaube" zur verbindlichen Maxime praktisch politischen Handelns wurde. Es war dies die "Demokratisierung der Welt" 594 , die Eucken eindrucksvoll und in ihren Wirkungen prägnant schildert.

$\mathrm{Zu}$ Beginn des 17. Jahrhunderts erschien der staat als ein Gebilde für sich, so daß Hugo Grotius sagen konnte, "daß der Krieg die Bürger nichts angehe und lediglich sache der soldaten sei" ${ }^{595}$.

Auch der Bismarcksche staat war nicht auf eine Legitimation durch seine Untertanen angewiesen und an ihr auch nicht interessiert. Er war eine in sich durch ihren bloßen Bestand gerechtfertigte Größe. Der Dualismus von staat und Gesellschaft überließ jeden der beiden Bereiche seinen jeweils spezifischen Funktionsgesetzen.

Dies änderte sich grundlegend mit dem Moment, als sich durch die "Demokratisierung der Welt" der Legitimationsbedarf des Staates ebenso änderte wie das zurechnungsprinzip von staat und Gesellschaft. Die durch das "demokratische allgemeine stimmrecht und die demokratische allgemeine wehrpflicht" zumindest der Idee nach angestrebte "engere Verknüpfung von Volk und staat oder - wenn man so will - der Idee nach die Identität von beiden"596 machte den staat zur "Selbstorganisation der Gesellschaft"597. Durch das "Ineinanderwachsen von staat und Gesellschaft" öffnete sich der bislang nur der "Staatsräson", das heißt einer "beherrschende(n), politische(n) Idee" und einem Willen verpflichtete Bereich des staates gesellschaftlichen Interessen, persönlichen wünschen 
und damit unberechenbaren psychologischen Disponiertheiten ${ }^{598}$. Über die Folgen einer solchen Entwicklung hin zu einem Staat, der die Freiheit seiner Bewegung sowie seiner willensbildung einbüßt, bestehen bei Eucken keine zweifel. Die demokratische Infiltration des staates durch die völker und ihre Leidenschaften, die Interessengruppen und die in Parteien organisierten chaotischen Massen und deren Einfluß auf die "Leitung des Staates" läßt politische Entscheidungen zum "Produkt der Stimmungen von moralisierenden Massen und Demagogen" werden ${ }^{599}$. Gegründet auf "innere Gärungen der völker" hat alle wirtschaftliche und politische "Sicherheit ein Ende" 600 , denn die mit der "Demokratisierung der Welt (...) vollzogene Entfesselung dämonischer Gewalten" oder genauer, die durch die Idee der Volkssouveränität indizierte Teilhabe der Massen am politischen willensbildungs- und Entscheidungsproze $\beta$ setzt die "alten ordnenden Prinzipien außer Kraft" ${ }^{601}$.

Die staatlichen strukturwandlungen durch die Vergesellschaftung des Staates und die Verstaatlichung der Gesellschaft äußern sich im einzelnen in einer zunehmenden "Größe des staatsapparates" 602 sowohl auf wirtschaftlichem als auch auf sozialem Gebiet, die, da durch die gesellschaftlichen Machtund Interessengruppen veranlaßt, keineswegs ein zeichen von Macht, Unabhängigkeit und Autorität des Staates sind, sondern im Gegenteil dessen Schwächung bedeuten und in letzter Konsequenz seine Auflösung zur Folge haben ${ }^{603}$. Der Staat "ist total aus Schwäche"1004.

Neben der Tatsache, daß der Staat auf Gedeih und Verderb "mit dem jeweiligen stand der Konjunktur verknüpft ist", wodurch jede wirtschaftskrise zur staatskrise wird, dokumentiert sich der Verfall staatlicher Autorität weiterhin in der mangelnden Möglichkeit, das "reine Staatsinteresse" in einem eigenständigen, staatlichen willensbildungsproze $\beta$ zur Geltung $z u$ bringen ${ }^{605}$. Die Erledigung aller Staatsaufgaben ist 
gekennzeichnet durch die organisierten Einwirkungen der Massen, die ihre gesellschaftlichen Antagonismen über den demokratischen Transmissionsriemen in den Prozeß der staatswillensbildung hineintragen und denen der staatsapparat nur noch als Mittel zur Durchsetzung ihrer eigenen, individuellen oder kollektiven wünsche und Vorstellungen in den Blick kommt ${ }^{606}$.

Verliert der staat jedoch seine Eigenschaft als unabhängige Größe und vermag er nicht mehr aus "eigenem Willen", auf dem "seine Existenz beruht", zu handel $n^{607}$, dann entsteht auch auf Seiten des Staates "Gruppenanarchie oder Pluralismus" 608 .

"Abhängig von einem Geschiebe von Machtgruppen, das ist das Bild, das der heutige staat gewährt"609.

Durch die demokratische Kollektivierung der Herrschaft mit der Folge der gegenseitigen Durchdringung der Sphären von staat und Gesellschaft wird nach alledem für Eucken originäre staatlichkeit zugunsten einer nur abgeleiteten aufgegeben. Indem sich die staatswillensbildung hin zu den gesellschaftlichen Machtzentren verschiebt, wird der staat zum bloßen Koordinationsinstrument disparater gesellschaftlicher Interessen und zum fremd- und interessenbestimmten Handlungszentrum mit der Aufgabe der Verwirklichung der jeweiligen gesellschaftlichen Kompromisse.

Dem Kampf um staatliche Funktionen korrespondiert der Kampf "um das Recht, Recht zu setzen"610. Auch in diesem Bereich hat der staat der 3. Epoche schwere Verluste zu verzeichnen. Durch das "autonome Recht der Allgemeinen Geschäftsbedingungen", das heißt "das selbstgeschaffene Recht der Wirtschaft" wird der staatliche Anspruch auf ausschließliche Befugnis zur Rechtsetzung ausgehöhlt, "das staatlich gesetzte Recht an die Seite (ge)drückt" und damit staatliche Autorität weiter geschmälert ${ }^{611}$. 
In einer Bewertung der von ihm festgestellten pluralistischen Zustände und Entartungen im totalen wirtschaftsstaat der 3. Epoche drängt sich Eucken der Vergleich mit dem mittelalterlichen Feudalismus auf. Ausgerüstet mit staatlicher Macht "treten im staate dem staate selbstberechtigte, öffentlich-rechtliche Persönlichkeiten gegenüber, deren Recht nicht der Verfassung des staates unterliegt". In diesem Staat der stände stand dem Herrscher zwar keine "gleichförmige Masse von Untertanen gegenüber wie im modernen staat", sondern er bildete "die Spitze einer Pyramide von Hoheitsträgern", die dem Monarchen allerdings durch "(m)oralische Bindungen der Treue" verpflichtet waren. Demgegenüber ist für Eucken das Verhältnis der Bürger zum neufeudalen, totalen Wirtschaftsstaat "ein reines spiel der Macht" mit dem letzten ziel, sich diesen staat zu unterwerfen ${ }^{612}$.

\section{Die neue staatsbildung Walter Euckens}

I. Die Folgerungen aus dem Staatsbildungsprozeß der Neuzeit

Die Analyse des Staatsbildungsprozesses der Neuzeit führte Eucken zu eindeutigen Ergebnissen und bestätigte im übrigen seine Vorbehalte gegenüber der Institution staat. Ein die Wettbewerbsordnung und damit die gesamtwirtschaftliche Rationalität des Wirtschaftsprozesses gewährleistender, "festgefügter staat" steht nicht zur Disposition ${ }^{613}$. Damit scheint "(a) lle Wirtschaftspolitik (...) in Frage gestellt, weil der Staat als ordnende Potenz versagt" 114.

Angesichts dieses Ergebnisses verfällt Eucken jedoch nicht in Resignation, sondern er ist bestrebt, nunmehr den "Punktualismus" im Wissenschaftsbetrieb zu überwinden ${ }^{615}$. Die gewonnenen Ergebnisse aus der Untersuchung des Staatsbildungsprozesses der Neuzeit lassen es für ihn als notwendig erscheinen, "über das engere Fachgebiet" hinaus Problemlagen 
$z u$ erkennen und auch auf die sich jenseits der Fachgrenzen stellenden Fragen Antworten $z u$ suchen $^{616}$. Die Einsicht in die strukturen der in der Vergangenheit verwirklichten staatsformen und den damit verbundenen Entwicklungen in den ordnungen von Wirtschaft und Gesellschaft ist als Grundlage für ein solches Vorhaben unabdingbar, aber nicht allein ausreichend. "(E) benso wichtig ist die andere Frage, wie das Problem, welches die (staatliche) Entwicklung stellt, bewältigt werden kann"617. Die ordnung des staates offenbart sich demnach für Eucken, wie zuvor schon die ordnung der wirtschaft, als ein theoretisches Problem.

Der naheliegende Gedanke, sich zur Lösung dieses Problems der an sich zuständigen Staatslehre zu bedienen, um Lösungsvorschläge zu rezipieren, wird von Eucken allerdings ohne weiteres verworfen, da diese staatslehre mit "einer veralteten Begriffsapparatur" hantiere, die ihr den Blick für "die faktische Entwicklung des realen Staates" verstelle $e^{618}$. Eine Ausnahme bei seiner grundsätzlich negativen Einschätzung der zeitgenössischen staatslehre macht er insofern, als er konzediert, daß zumindest $c$. Schmitt in seinen Veröffentlichungen nicht jeden Realitätsbezug habe vermissen lassen und daß zumindest dieser staatslehrer auf die Notwendigkeit einer neuen staatlichkeit hingewiesen habe. Allerdings gelingt es nach Ansicht Euckens auch c. Schmitt nicht, das ordnungspolitische Problem in der industrialisierten Massengesellschaft $z u$ erkennen und $z u$ durchdenken ${ }^{619}$. Letztlich ist damit auch dessen Staatslehre im Hinblick auf den von Eucken gesuchten staat ohne entscheidenden Wert. Einzelne Gedankengänge $c$. Schmitts haben, was im folgenden zu zeigen sein wird, gleichwohl auf das staatsdenken Euckens abgefärbt, wobei indes stets $z u$ beachten ist, daß die politische Grundhaltung Euckens mit der $c$. Schmitts grundsätzlich inkompatibel blieb.

Da das Problem, das die staatliche Entwicklung stellt, demgemäß "noch offen ist"620, ist der Weg frei zu einer Konzeption des Staates, die den Wunschvorstellungen Euckens ent- 
spricht. Dieses Argumentationsschema erinnert an ein anderes, bereits bekanntes Muster.

Auch die Grundlegung der Nationalökonomie hatte Eucken unter vollständiger Bereinigung des wissenschaftlichen Terrains durch Verwerfung aller überkommenen Lehrmeinungen ansatzlos begonnen und unter Beachtung des gesammelten historischen Materials durch neue, radikal geänderte Fragestellungen eine Wende in der nationalökonomischen wissenschaft vollzogen. So umfassend wie die geschilderte Grundlegung der Nationalökonomie geht Eucken den ins Auge gefaßten staatlichen Paradigmenwechsel nicht $a^{621}$. Das "Problem als ganzes (überschreitet) weit den Rahmen unserer Untersuchung. Alle Fragen der staatsform und des öffentlichen Rechts, auch des völkerrechts gehörten" an sich hierher ${ }^{622}$.

Unbeschadet dieser salvatorischen Klausel benennt Eucken dezidiert einige Merkmale, die den staat als "Hüter der Wettbewerbsordnung" unabdingbar auszeichnen müssen.

\section{Die Natur des wirtschaftsordnenden staates}

Die Natur des wirtschaftsordnenden staates wird durch seine Aufgabenstellung bestimmt. Deshalb ist es "notwendig auch von seiten der Wirtschaftspolitik das Problem zu stellen eben weil ohne die ordnende Potenz des staates eine zureichende Wirtschaftsordnung nicht aufgebaut werden kann und weil umgekehrt eine neue staatsbildung im Zusammenhang mit dem Aufbau der Wirtschaftsordnung" stehen muß ${ }^{623}$. Den ordnungsbemühungen um den Aufbau eines "leistungsfähigen Rechtsstaates" sind damit die ziele gesteckt. Es besteht vor allem anderen "die Notwendigkeit eines stabilen staatsapparates, der genug Macht besitzt", um "bestimmte, genau umschriebene ordnungsaufgaben" erfüllen zu können ${ }^{624}$. 
Der staatsbildungsprozeß der Neuzeit und insbesondere die Entwicklung in der 3. Epoche dieses Prozesses geben Aufschluß darüber, welche Grundsätze bei der neuen staatsbildung $z u$ beachten sind, "um den staat als ordnende Potenz aktionsfähig zu machen"625.

Der interventionistische Wirtschaftsstaat, der infolge einer "politistischen" Haltung als "übermenschliches, alles vermögendes Wesen" begriffen wurde, dem Aufgaben in fast unbegrenztem Maße übertragen werden können ${ }^{626}$, kann nach Auffassung Euckens wegen mangelnder Autorität, Schwäche und der Verpflichtung, auf partikulare gesellschaftliche Interessen vielfältigster Art Rücksicht zu nehmen, "niemals als ordnende Kraft der Volkswirtschaft" ${ }^{627}$ wirken.

Das "politistische" Denken verkennt, daß der staat, der als sinngebende und religionsersetzende Einheit leidenschaftlich gewünscht wird, auf der Grundlage der mit ihm gemachten Erfahrungen weder als die "Wirklichkeit der sittlichen Idee", als die ihn Hegel beschrieben hat, noch als das "großartigste sittlichste Instrument zur Erziehung des Menschengeschlechtes", als das ihn G. Schmoller sah, gelten kann, sondern dieser staat ist im Verlaufe seiner Entwicklung letztlich zu einem "Absolutum" erwachsen, das sich dem Prinzip der Amoral verschrieben hat und dem sittliche und ordnungspolitische Maßstäbe grundsätzlich nicht mehr eigen sind ${ }^{628}$.

Der sich als sinngebende Einheit gerierende, totale staat ist demnach keineswegs der "unabhängige und wohlwollende Vater seiner Bürger"629, sondern ein machtorientiertes Kollektiv, dem die ordnung der Wirtschaft unter den Gesichtspunkten von Freiheit, Gerechtigkeit und sozialer sicherheit und damit ein "soziales und ethisches ordnungswollen"630 fremd ist. Der "interventionistische wirtschaftsstaat"631, der sich zur Lenkung des gesamten Wirtschaftsprozesses motivational legitimiert sah und in dem die simplifizierende Vorstellung vorherrschte, in den alltäglichen wirtschaftshergang deshalb eingreifen zu müssen, weil die vom "liberalen Rechtsstaat" 
gesetzte, freie wirtschaft versagt habe, ist demnach gerade das Gegenteil desjenigen Staates, der als "ordnende Potenz" und "Hüter der Wettbewerbsordnung" zu handeln in der Lage ist. Wer anderes behauptet, "sieht in Wahrheit weder das faktisch gegebene Lenkungsproblem noch den faktisch gegebenen Staat" ${ }^{632}$.

Diese Überlegungen zugrunde gelegt, ergibt sich ohne weiteres die Natur des wirtschaftsordnenden staates. Erst wenn sich dieser staat der Gefahren bewußt wird, die ihm aus seiner Verknüpfung mit der Gesellschaft und aus seiner Teilnahme am Wirtschaftsprozeß deshalb drohen, weil er in den allgemeinen Interessen- und Wirtschaftskampf hineingezogen wird und er so in die Hand von wirtschaftlichen Machtgruppen fällt, die seine willensbildung bestimmen und seine Autorität unterhöhlen und er "die kraft findet, sich von dem Einfluß der Massen" und dem Druck der partikularen Gewalten und ihrer "Funktionäre und Ideologien" freizumachen"633, vermag für Eucken das im Sinne der Erledigung der anstehenden ordnungsaufgaben "funktionsfähige staatswesen" $z u$ entstehen ${ }^{634}$. "Die ganze Gefahr des autoritären staates muß in gleicher Weise gesehen werden wie die Notwendigkeit eines stabilen staatsapparates, der genug Macht besitzt"635, um die ordnung der Wirtschaft durch Wettbewerb durchzusetzen. Eine grundlegende Maxime der neuen staatsbildung muß demgemäß die generelle Entpolitisierung des staates sowie die Festigung der staatsmacht sein. Nur durch eine staatliche strukturwandlung zurück zur "Staatsautorität"636 vermag sich der staat als diejenige Potenz herauszubilden, die durch eine "einheitliche und konsequente willensbildung" und die Konzentration auf einen "klar bezeichnete(n) Tätigkeitsbereich" zur ordnung der arbeitsteiligen, industrialisierten wirtschaft "unentbehrlich" ist ${ }^{637}$.

Die Unabhängigkeit des Staates sowie dessen Autorität, aus eigenem willen zu handeln und nicht mehr in neufeudalen $\mathrm{Ab}-$ hängigkeiten befangen und auf die "innere(n) Gärungen der 
Völker" Euckenschen staates kennzeichnenden Merkmale. Sie finden sich als - allerdings stark verkürzte - Handlungsanweisungen im ersten "staatspolitischen Grundsatz der Wirtschaftspolitik" wieder:

"Die Politik des staates sollte darauf gerichtet sein, wirtschaftliche Machtgruppen aufulösen oder ihre Funktionen zu begrenzen. Jede Festigung der Machtgruppen verstärkt die neufeudale Autoritätsminderung des staates"639.

III. Die Grenzen der Wirksamkeit des wirtschaftsordnenden staates

Der erste staatspolitische Grundsatz der Wirtschaftspolitik ist "auf den Aufbau einer zureichenden Staatsordnung gerichtet"640. Diese ordnungsbemühungen bringen allerdings eine Aporie zum Tragen, die nach dem Verständnis Euckens indes jedem staatswesen immanent ist. "Es gibt kein Sozialleben ohne Machtpositionen, weil für jedes Leben in der Gemeinschaft Autorität notwendig ist" ${ }^{641}$. Das gilt, wie soeben dargelegt, auch für den wirtschaftsordnenden staat. Nun ist Macht allerdings "an sich böse", andererseits kann "(0)hne Macht (...) jedoch kein staat existieren"642. Der Überwindung dieses Dilemmas sind Euckens Überlegungen zu den Grenzen der wirksamkeit des wirtschaftsordnenden staates gewidmet.

Die "großen Staatsdenker des 17. und 18. Jahrhunderts - wie z.B. Grotius, Locke, Pufendorf und Montesquieu - bereiteten die Verfassungen und den Rechtsstaat des 19. Jahrhunderts vor"643. Das Problem staatlicher Macht und die Notwendigkeit ihrer Begrenzung war diesen Denkern und ihrer Zeit bewußt. Durch die industrielle Revolution und den durch sie hervorgerufenen Problemen der Gesellschaft mit "ihren Massen und ihren neuen wirtschaftlichen und sozialen Machtgebilden" 
erhielt die Frage der Bändigung staatlicher Macht für Eucken jedoch eine neue Qualität 644 . Wie und in welcher Form soll nunmehr "die Grenze der staatstätigkeit gezogen werden?"645. Die Lösung des Problems staatlicher Macht hat sich für Eukken nach wie vor am Vorstellungsbild des Rechtsstaates zu orientieren, in dem "die Freiheitsrechte des einzelnen gerecht gegeneinander abgegrenzt" sind und Schutz vor staatlicher Willkür besteht ${ }^{646}$. Allerdings bedarf dieses Bild im Rahmen der neuen Staatsbildung einer Korrektur insoweit, als die aus der Analyse der 2. Epoche des Staatsbildungsprozesses gewonnenen Erkenntnisse $z u$ verwerten sind. Demgemä $\beta^{647}$ hat sich der Aufbau des "leistungsfähigen Rechtsstaates" Euckenscher Prägung grundsätzlich an wirtschaftstheoretischen Erkenntnissen und an den zur Verwirklichung einer funktionsfähigen und menschenwürdigen Wirtschaftsordnung notwendigen Prinzipien auszurichten.

Seine Überlegungen zur wirtschaftlich legitimen staatstätigkeit beginnt Eucken mit einem Hinweis auf $w$. v. Humboldts "Ideen zu einem Versuch, die Grenzen der wirksamkeit des staates $z u$ bestimmen"648. In der Einleitung zu dieser schrift geht W. v. Humboldt davon aus, "daß die Untersuchung des Zweckes und der Schranken der wirksamkeit des staates eine große wichtigkeit hat und vielleicht eine größere, als irgend eine andere politische" ${ }^{169}$. Für Eucken ist die Humboldtsche Aufgabenstellung mit dem ziel der sicherung individueller Freiheit gleichfalls "eine zentrale", aber nicht die letztgültige, denn er sucht "diese Grenzen unter dem besonderen Gesichtspunkt der Wirtschaftspolitik, und zwar mit der Fragestellung: Wie kann der staat zu einer ordnenden Potenz für eine funktionsfähige und freie ordnung der industrialisierten Wirtschaft werden?"650. Die von Eucken aufgeworfene Frage beantwortet sich ohne weiteres, zieht man seine bislang gewonnenen wirtschaftstheoretischen, wirtschaftspolitischen und staatshistorischen Erkenntnisse bei. 
Die Durchsetzung der guten ordnung der wirtschaft gelingt demnach nur, wenn die Formen, in denen gewirtschaftet wird, nicht dem spiel der individuellen wirtschaftlichen Interessen überlassen bleiben, sondern die wirtschaftspolitik darauf gerichtet ist, diese Formen zu konstituieren und für deren Erhaltung Sorge zu tragen. Nur insoweit ist der wirtschaftsordnende staat gefordert. "So unerträglich es ist, die Gestaltung der wirtschaftsordnung im zeitalter der Industrie, der modernen Technik, der großen städte und der Massen sich selbst zu überlassen, so unfähig ist der staat zur Führung des Wirtschaftsprozesses selbst"651. Es gilt deshalb der Grundsatz: "Staatliche Planung der Formen - ja, staatliche Planung und Lenkung des Wirtschaftsprozesses - nein" 652 . Ihre Zusammenfassung findet diese Erkenntnis, daß es sich bei der Frage nach den Grenzen der wirksamkeit des Staates "nicht um ein quantitatives, sondern um ein qualitatives Problem" handelt, in dem zweiten staatspolitischen Grundsatz der Wirtschaftspolitik: "Die wirtschaftspolitische Tätigkeit des staates sollte auf die Gestaltung der ordnungsform der wirtschaft gerichtet sein, nicht auf die Lenkung des Wirtschaftsprozesses" 653 .

IV. Exkurs: Zur Unvereinbarkeit von Rechtsstaat und Wirtschaftspolitik zentraler Leitung

Im Zusammenhang mit der von ihm entwickelten Lehre der notwendigen Interdependenz von wirtschaftsordnung und staatsordnung ging Eucken auch der Frage nach, ob der von ihm konzipierte und zur ordnung der wirtschaft berufene "leistungsfähige Rechtsstaat", obwohl spezifisch auf den Aufbau einer Wettbewerbsordnung ausgerichtet, wider Erwarten und in Entfremdung seines ursprünglichen Zweckes auch zur Durchsetzung einer wirtschaftspolitik zentraler Leitung geeignet ist. 
Daß die von Eucken vorgenommene Prüfung nicht unbegründet ist, ergibt sich bereits aus dem Umstand, daß auch die wirtschaftspolitik zentraler Leitung einen starken, unabhängigen staat erfordert. Euckens weitere Untersuchungen ergaben jedoch deren Inkompatibilität mit der rechtsstaatlichen Komponente seines staates, denn die praktische Verwirklichung einer Wirtschaftsordnung zentraler Planung führt nach seiner Auffassung zwangsläufig $z u$ einer nachhaltigen Beeinträchtigung der individuellen Freiheiten und zu einer Mißachtung rechtsstaatlicher Grundrechtsgarantien. Der einzelne wirtschaftsteilnehmer wird in Ausübung seiner Freiheitsrechte inhaltlich abhängig von den Verfügungen der öffentlich-rechtlichen Planstellen ${ }^{654}$. Die Gewerbefreiheit ist, "- auch wenn sie in der Verfassung feierlich garantiert ist - durch die wirtschaftspolitik dadurch beseitigt, daß der staat selbst sie in Verwaltungsakten ausschließt" ${ }^{655}$. Das gilt in gleichem Maße für die Vertragsfreiheit und das Recht auf. Freizügigkeit ${ }^{656}$. Die Durchführung der Pläne würde gefährdet oder gar unmöglich, würde sich jeder Grundrechtsinhaber auf die rechtsstaatlichen Garantien berufen. Die Planstellen sind deshalb "gerade gezwungen", diese Garantien zu mißach$\operatorname{ten}^{657}$. Für Eucken steht damit fest, daß "die Grundrechte durch die Methode zentraler Wirtschaftslenkung faktisch aufgehoben" werden ${ }^{658}$.

Ein weiterer Aspekt der Inkompatibilität von Rechtsstaat und wirtschaftspolitik zentraler Leitung kommt hinzu. Ein konstitutives Element des Rechtsstaates ist für Eucken die Möglichkeit, Verwaltungsentscheidungen einer gerichtlichen Nachprüfung $\mathrm{zu}$ unterwerfen. Eine solche verwaltungsgerichtliche Kontrolle kann in einer zentral verwalteten wirtschaft nicht geduldet werden, sollen die Planstellen in ihrer Lenkungsaufgabe nicht beeinträchtigt werden ${ }^{659}$. Die "Nachprüfung der Gesetzmäßigkeit" der planenden und lenkenden Verwaltung ist demnach mit einer "zentrale( $n)$ Lenkung des Wirtschaftsprozesses aus sachlichen Gründen unvereinbar" ${ }^{660}$. Wo dieses 
Instrument jedoch fehlt, "hat der Rechtsstaat aufgehört $z u$ bestehen"661. Zentrale Planung kollidiert nach Auffassung Euckens darüber hinaus mit dem Prinzip des Föderalismus, der über den Aspekt der vertikalen Gewaltenteilung mit dem Rechtsstaatsprinzip verzahnt ist ${ }^{662}$.

Ein föderalistischer staat widersetzt sich aufgrund seiner vertikalen Machtaufspaltung zwischen "Bundesstaat" und Gliedstaaten einer zentralen Lenkung durch "Planstellen der Bundesregierung", bei denen sich die gesamte Lenkungsmacht bündelt, da den "Einzelstaaten" aufgrund ihrer Größe das Potential fehlt, selbst steuernd in den wirtschaftsproze $\beta$ einzugreifen und der "Wirtschaftsproze $\beta$ des ganzen Bundesstaates $z u$ eng miteinander verflochten ist", als daß er einer nur regional beschränkten Leitung zugänglich wäre ${ }^{663}$. Unter Umgehung eines gegebenenfalls in der Verfassung festgeschriebenen föderalistischen Prinzips würde sich im Falle einer gleichzeitig zulässigen Wirtschaftspolitik der zentralen Leitung der "Bundesstaat" faktisch zum unitarischen staat entwickeln ${ }^{664}$. Die Elemente der vertikalen Gewaltenteilung und der Pluralismus der politischen Leitungs- und Entscheidungsgewalt, die Eucken im dezentralisierten, tatsächlich föderalistisch organisierten staat ausmacht, würden ohne revolutionären Akt ausgeschaltet. Auch der einzelne wird nun "von den wirtschaftlichen Zentralstellen der Bundeshauptstadt abhängig"665. Unter diesem Begriff der "Zentralstellen der Bundeshauptstadt" rubriziert Eucken eine weitere Verschiebung im system der gegenseitigen Kontrolle und $\mathrm{Ba}-$ lance der Gewalten. Durch die Konzentration der Macht bei einer zentral und straff organisierten Bürokratie, die per Verwaltungsakt die wirtschaftlichen Verwendungen dirigiert, wird die angestrebte Zernierung der Macht durch horizontale Gewaltenteilung hinfällig und zugunsten eines administrativen Übergewichts aufgegeben ${ }^{666}$. Dann erscheint die Judikative als "Hemmschuh"667 bei der Erfüllung der Verwaltungsaufgaben, eine parlamentarische Kontrolle entfällt, da es dem Gesetzgeber unmöglich ist, sich mit allen Fragen der steuerung des 
Wirtschaftsprozesses zu befassen. Er ist deshalb gezwungen, der Verwaltung in weitem Rahmen Befugnisse "durch Ermächtigungsgesetze und Generalklauseln" einzuräumen ${ }^{668}$. Durch einen solchen administrativen Gewaltenmonismus auf der Ebene des "Bundesstaates" wird die Idee des Rechtsstaates aufgegeben. Durch Akkumulation staatlicher Gewalt entsteht der "unkontrollierte Verwaltungsstaat" 669 oder, wie es Eucken an anderer Stelle nennt, die "Tyrannis"670. Die "Gesamtentscheidung" für die Politik zentraler Leitung der wirtschaft ist mit der "Gesamtentscheidung für den Rechtsstaat nicht vereinbar", da diese ordnungsformen "kollidieren"671.

Für Eucken steht demgemäß fest, daß seine beiden staatspolitischen Grundsätze, die "auf den Aufbau einer zureichenden staatsordnung" und weiterhin darauf ausgerichtet sind, "den staat als ordnende Potenz wirksam werden zu lassen", nur und ausschließlich mit denjenigen Prinzipien harmonieren, "die für den Aufbau einer zureichenden Wirtschaftsordnung gelten. Diese Feststellung ist wesentlich"672.

Indem sich der staat von der wirtschaftsgesellschaft absetzt, sich aus neufeudalen Abhängigkeiten löst und so die Macht erhält, partikulare gesellschaftliche Gruppen aufzulösen, gelingt es ihm zugleich, aus einheitlichem, ungeteiltem willen kompromißlos dem "Wirtschaftsprozeß eine zureichende Lenkung durch Konkurrenzpreise zu geben"673. Auch die Beschränkung des staatlichen Aufgabenbereichs "auf die Beeinflussung der Form des Wirtschaftens" wird den Fähigkeiten des staates und seiner organe gerecht und ist darüber hinaus "genau das, was sich als notwendig erweist, um eine zureichende Wirtschaftsordnung entstehen zu lassen"674.

Eucken vergleicht seine beiden staatspolitischen Grundsätze mit dem Prinzip der Gewaltenteilung. Zwar beziehe sich der letztgenannte Grundsatz "auf eine andere seite staatlicher ordnung", indem er den einzelnen vor staatlicher Macht schütze ${ }^{675}$. Demgegenüber haben seine staatspolitischen Grundsätze den Zweck, "dem staat eine unabhängige Willensbildung 
zu ermöglichen" ${ }^{676}$, um die ordnung der Wirtschaft durch Wettbewerb zu verwirklichen.

Eucken vermag demgemäß festzustellen, daß die ordnung des nach seinen Grundsätzen errichteten staates und die ordnung der wirtschaft durch Wettbewerb "konform" sind"77. Diese Konformität kommt indes nicht überraschend, war der staat von Eucken doch von vorneherein nur unter der Prämisse seiner Tauglichkeit als "Hüter der Wettbewerbsordnung" untersucht und letztlich in seinen Grundzügen auf diese Bestimmung hin konzipiert worden. Bemerkenswert ist jedoch, daß Eucken nach seiner kategorischen Ablehnung der "veralteten Begriffsapparatur"678 der überkommenen staatslehre selbst nicht zu einer eigenen, geschlossenen staatslehre findet. Soweit er inhaltlich bestimmte strukturprinzipien seines staates vorstellt $z$ denken ist hier insbesondere an die Figur des "leistungsfähigen Rechtsstaates" - bleibt unausgesprochen, wie diese Prinzipien in ihrer konkreten Ausgestaltung zu denken sind und wie sie sich in das Bild vom staat insgesamt einfügen.

Wichtigste Bestandteile seiner Lehre vom staat sind und bleiben indes unabhängig von deren weiterer Konkretisierung und Detaillierung die beiden staatspolitischen Grundsätze der Wirtschaftspolitik, die zum "Aufbau einer zureichenden staatsordnung" in jedem Fall notwendig, aber auch ausreichend sind ${ }^{679}$.

Der staat in seiner aktuellen Verfassung mag als "ordnende Potenz" derzeit untauglich sein. Aber "(s)o falsch es ist, im vorhandenen staat einen allweisen und allmächtigen Betreuer allen wirtschaftlichen Geschehens zu erblicken", so unzutreffend ist es auch, "den faktisch vorhandenen, von Machtgruppen zersetzten staat als Datum hinzunehmen und dann - folgerichtig - an der Bewältigung des wirtschaftspolitischen ordnungsproblems $z u$ verzweifeln"680. In Beachtung und Anwendung seiner staatspolitischen Grundsätze der Wirtschaftspolitik muB es nach Auffassung Euckens gelingen, den staat zu einer Institution zu machen, die als "Hüter der 
Wettbewerbsordnung" zur Durchsetzung und dauerhaften sicherung der ordnung der wirtschaft durch Wettbewerb geeignet ist.

V. Die staatstheoretischen Implikationen der neuen staatsbildung Walter Euckens

War bislang im Rahmen der Darstellung seiner staatskonzeption hauptsächlich und selbstredend Eucken zu Wort gekommen, so geht es nunmehr darum, die von ihm nicht oder völlig unzureichend diskutierten Konsequenzen seines staatsdenkens für den Aufbau des staates, seine organisatorische struktur sowie seine Kompetenzen aufzuzeigen. Erst danach wird ein abschließendes Urteil über sein staatsverständnis möglich und zulässig.

\section{Der staat als wertverwirklichende Institution}

Das von Eucken gezeichnete Bild des modernen staates ist das Ergebnis einer wohl bewußt stark vereinfachenden Realanalyse, die, zutiefst der dialektischen Verfallstheorie $c$. Schmitts verpflichtet ${ }^{681}$, wie ihr Vorbild nur das "Ende aller Staatlichkeit" zu diagnostizieren wei $\beta^{682}$.

$O b$ und in welchem Umfang diese Analyse dem Wesen der verschiedenen, in der historischen Realität nachweisbaren staatstypen tatsächlich gerecht $z u$ werden vermag, braucht im einzelnen nicht erörtert $z u$ werden und wäre aufgrund der teilweise stark vergröbernden Darstellung durch Eucken kaum erfolgversprechend. Es geht letztlich auch um anderes.

Die eindringliche Schilderung des staatlichen Niedergangs durch Eucken, von H. Willgerodt als "eindrucksvoll", "höchst unbequem" und "bis heute nicht ernstlich widerlegt" bewertet ${ }^{683}$, ist nicht als objektive Interpretation staatlich-historischer Realität gedacht, sondern sie ist eine durch be- 
stimmte Grundüberzeugungen genährte und geleitete Deutung der geschichtlichen Entwicklung des Staates. Die Überzeugungen sind ihrerseits das Ergebnis der auf einer bestimmten ordnungstheorie basierenden Verhältnisbestimmung von wirtschaft und staat bzw. von Gesellschaft und staat überhaupt. "Wie man den Staat versteht, seine Aufgaben, seine Funktion, hängt auch von der Gesellschaftstheorie ab, die man offen oder verdeckt, bewußt oder unbewußt zugrunde legt"684. Diese Feststellung $\mathrm{W}$. Schmidts gilt in uneingeschränktem Maße auch für Eucken.

Die Erfahrung mit der Wirtschaftspolitik des Laissez-faire und den unzulänglichen sicherungsmechanismen des liberalen Rechtsstaates hatte die optimistische Einschätzung widerlegt, daß die ordnung der wirtschaft, die dem "Wesen des Menschen und der Sache entspricht" und in der "Maß und Gleichgewicht herrschen ${ }^{685}$, sich von unten her aus den spontanen Kräften der Gesellschaft von selbst zu entfalten vermag, wenn nur die persönliche Freiheit gewährleistet und das "Rechtsprinzip" gewahrt ist ${ }^{686}$. Das individuelle Ertragsstreben führte nicht zu einer selbsttätigen Lösung des Lenkungsund Verteilungsproblems, ganz im Gegenteil verlor mit der zunehmenden Vermachtung der Märkte und der Selbstaufhebung der vollständigen Konkurrenz der Preis seine Funktion als gesamtwirtschaftliche "Rechenmaschine"687.

Diese Entwicklung hatte für Eucken jedoch keineswegs nachgewiesen, daß sich die verkehrswirtschaftliche Methode als wirtschaftsordnendes Prinzip insgesamt nicht $z u$ bewähren vermag $^{688}$. Die verkehrswirtschaftliche ordnungsform der vollständigen Konkurrenz genügt jedenfalls theoretisch dem Maßstab des ordo und damit den Anforderungen an "eine funktionsfähige und menschenwürdige ordnung von wirtschaft und Gesellschaft"689. Was dieser ordnung fehlt, ist einzig die dem ordre naturel immanente kraft, sich selbst $z u$ verwirk1 ichen $^{690}$.

Alle staatstheoretischen Überlegungen Euckens mußten sich deshalb auf die Frage konzentrieren, inwieweit der staat als 
geschichtliche Einrichtung geeignet war und ist, das in phänomenologischer Wesensschau gewonnene Muster der guten ordnung, dem lediglich "die starken Tendenzen" hin zur Naturordnung innewohnen ${ }^{691}$, in den entsprechenden sozialen Zustand $z u$ überführen und dort dauerhaft zu sichern.

Wieviel planung insoweit erforderlich ist und was sich demnach als notwendige ordnungsleistung des staates darstellt, folgerte Eucken ausschließlich aus den theoretisch erarbeiteten Funktionsprinzipien der seinen ordovorstellungen kompatiblen ordnung der wirtschaft und deren geschichtlich festgestellten Funktionsdefiziten.

Indem diese werthafte ordnung und deren praktischer Vollzug zum allein bestimmenden Maßstab für die Funktionen des staates und letztlich dessen "Grundprinzip"692 wird, verliert dieser seinen Charakter als eigenständige Größe. Sein materiales Prinzip "ist nicht Erzeugnis staatlichen Zweckdenkens"693, sondern es wird definiert durch wirtschaftliche Ordnungszusammenhänge ${ }^{694}$ und dementsprechend durch eine dem staat und seiner Politik vorgelagerte Eidetik ${ }^{695}$. Das Politische im sinne des staatlichen verliert jede eigene substanz, der staat wird zur potentiell umfassend instrumentalisierbaren Apparatur ${ }^{6 \%}$, die als Mittel der ökonomischen Ratio nur außerhalb ihrer selbst liegende ziel- und Wertvorstellungen kennt ${ }^{697}$. Der staat Euckens hat sich in seinem Wesen, seiner struktur und seiner wirkungsweise entsprechend dem Zweck der praktisch notwendigen ordnungs- und damit Wertverwirklichung ${ }^{698}$, für die er erdacht und konzipiert wurde, zu formen ${ }^{699}$ und vorrangig unter diesem Aspekt zu rechtfertigen.

Nur unter Beachtung dieser Zusammenhänge von Wirtschaftsund staatstheorie sowie der unverfügbar außerstaatlichen Präformation alles staatlichen ist die Realanalyse des geschichtlichen Werdens des Staates durch Eucken verständlich. Ein staat, der als eine stabile, weil ordnungs- und wertverwirklichende Institution, im spezifisch Euckenschen sinne: als "Hüter der Wettbewerbsordnung", aufzutreten bereit und 
imstande gewesen wäre, hat historisch nicht existiert. Eukken konnte ihn in dem von ihm ausgebreiteten und untersuchten geschichtlichen Material folgerichtig nicht entdecken. Es hat den Anschein, als ob er, dieses Ergebnis bereits vor Augen, durch die retrospektive Projektion des eigenen, positiven staatsbildes den geschichtlichen Niedergang des Staates eindrucksvoller feststellen und belegen zu können glaubte. Auch sein Staatsdenken ist, dem Denken in Wirtschaftsordnungen vergleichbar, demnach polemisches Denken, das die Einführung des eigenen staatlichen Paradigmas in der Auseinandersetzung mit selektiven, historischen Formen staatlichen Seins und dessen Fehlentwicklungen vollzieht, um die notwendigen staatspolitischen optionen für den angestrebten "Umbau" der staatsordnung ${ }^{700}$ und die "neue staatsbildung"701 um so wirkungsvoller vortragen $\mathrm{zu}$ können. Diese optionen sind mehrfacher Art.

2. Die unabhängige staatsgewalt als Topos antidemokratischen Denkens

Im "Staat der Idee"702 Euckens kann Herrschaft legitim nur dann ausgeübt werden, wenn ihr Einsatz der Verwirklichung der Wettbewerbsordnung dient. Das muß unmittelbare Konsequenzen für die Natur der staatsgewalt haben. Die Realanalyse Euckens hatte ergeben, daß der staat spätestens seit dem Abgang Bismarcks von der politischen Bühne eines seiner hervorragensten Merkmale verloren hatte: er konnte nicht mehr auf eine statische raison d'état verpflichtet werden, die "herrschende politische Idee" einschließlich der notwendigen Autorität ihrer Durchsetzung waren langsam verloren gegangen, bis sie letztlich der identitären Demokratie des 20. Jahrhunderts zum opfer fielen. Die Kollektivierung des Staates und staatlicher Herrschaft "im Namen und auf Grund der Volkssouveränität"703 ließ die Durchsetzung eines monistisch gedachten staatsinteresses nicht mehr $z u$, denn im 
Wege der demokratisch initiierten "Vervielfältigung des Staates"704 wurde der einzelne zum legitimen wert- und zwecksetzenden objekt, von dessen willen und vor allen Dingen Bedürfnissen der staat abhängig wurde. Die mit der "Demokratisierung" einhergehende Vergesellschaftung des staates bzw. Verstaatlichung der Gesellschaft lieferte den staatlichen Bereich dem sozialen Pluralismus und den latent heterogenen gesellschaftlichen Zweck- und Zielvorstellungen aus. Der staat wurde zum spielball der verschiedenen partikularen Kräfte, denen er nur noch als Mittel zum Kampf und als "Vollzugs- und Ausdrucksorgan"705 ihrer jeweiligen Ansprüche und Interessen diente.

Diese nochmals gedrängt referierte Charakterisierung der von Eucken festgestellten staatlichen strukturwandlungen weist zutreffend nach, daß es in einem demokratischen staatswesen einen autonomen Bereich staatlicher Willensbildung, in dem sich gleichsam wie in einer gesellschaftlichen Enklave ein festgefügtes, eindimensionales "staatsinteresse" formulieren ließe, das nur einem Wertsystem oder einem Weltbild verpflichtet ist und das nur ein auf diesen Zweck hin ausgerichtetes, politisches Instrumentarium bedingt, nicht gibt. An die stelle der Trennung von staat und Gesellschaft tritt deren Identifikation. Der demokratische staat als "Ausdruck der Gesellschaft"706 ist Kraft seiner Legitimation in der Wahrnehmung seiner Aufgaben, die er für die Gesellschaft erfüllt, grundsätzlich unbeschränkt. Es steht ihm frei, zu jedem Zweck tätig zu werden, solange er durch das demokratische Plebiszit daran nicht gehindert ist.

Ein solcher staat, der naturgemäß keinen abschließenden "gemeinsamen Wertbesitz"707 nachzuweisen vermag, dessen Lebensgesetz vielmehr der offene, dynamische Willensbildungsproze $B$ durch "Konkurrenz der Konzeptionen" und die Konfliktlösung durch Kompromi $\beta^{708}$ ist, kann nicht der "neue staat" Euckens sein $^{709}$, gründet er doch letztlich auf einem Prinzip, das dieser bereits zugunsten einer wirtschaftspolitik, die der Verwirklichung der guten und gerechten ordnung der wirt- 
schaft gewidmet war, vehement bekämpft hatte: dem Postulat der Wertfreiheit wissenschaftlicher Erkenntnis und der daraus abgeleiteten Einsicht, daß es auch im politischen Leben und Denken niemals zu einer Aussöhnung divergierender, letzter standpunkte kommen kann, der dauernde Kampf der Werte und Meinungen mithin das konstituierende Prinzip staatlichen Lebens und politischer Praxis ist ${ }^{710}$.

Diese relativistische Ausgangsposition als "gedankliche Voraussetzung der Demokratie"711 und die damit notwendige Toleranz $^{712}$ gegenüber demjenigen was richtig und demjenigen was falsch ist, steht im Gegensatz zur Euckenschen Forderung an den staat, als "Hüter der Wettbewerbsordnung" nur einem Zweck zu dienen und ein einheitliches wissenschaftliches Weltbild, das seinen Niederschlag in einer bestimmten ordnungsform gefunden hat, $z u$ verwirklichen ${ }^{713}$. Damit wird der immanente widerspruch einer wissenschaftlichen Lehre offenkundig, die ein in methodischer Engführung als vermeintlich wahr nachgewiesenes ordo-Modell der Wirtschaftsgesellschaft zum verbindlichen wert für den staat erklärt, mit der Folge, da $B$ dieser staat der Wettbewerbsordnung selbst, entgegen der von Eucken beschworenen "Interdependenz der ordnungen", nicht nach dem für den Bereich der Wirtschaft absolute Geltung beanspruchenden Prinzip vollständiger Konkurrenz organisiert sein kann, andernfalls auch im Hinblick auf die wirtschaftsordnungspolitik nur das wahr und der Verwirklichung wert wäre, was sich im Kräfteparallelogramm konkurrierender, gleichberechtigter politischer Meinungen und Interessen als mehrheitsfähig herausgeschält hat ${ }^{714}$.

Dieses Dilemma zwischen der Wirtschaftspolitik der Wettbewerbsordnung, die "die sachgesetzlichkeit, die im wirtschaftsprozeß zum Ausdruck kommt, nicht nur anerkennt, sondern ausdrücklich zum zuge bringen will"715 und ihrer sich im demokratischen Verfahren grundsätzlich verknappenden Verwirklichungschance ${ }^{716}$ vermag Eucken, da ein universaler Konsensus im Hinblick auf sein wirtschaftspolitisches Wollen kaum denkbar scheint, nur zu lösen, indem er die durch das 
demokratische system vermittelte Unsicherheit beseitigt und mit Hilfe des entsprechend organisierten "neuen" staates den wirtschaftlichen Sachgesetzlichkeiten zum Durchbruch verhilft.

Solange es noch überall an dem tieferen Verständnis dafür fehlt, "was die Wettbewerbsordnung ist" und für ihre Vorzüge erst "das allgemeine BewuBtsein"717 geschaffen werden muß, erscheint es Eucken unzweckmäßig und wenig erfolgversprechend, diese ordnung einer demokratischen Abstimmung zu unterwerfen. Der dem demokratischen system immanente Zwang zur Rechtfertigung der Wettbewerbsordnung und die Notwendigkeit, sie den wahlberechtigten Massen näherzubringen, zu erklären und sie von diesem ordnungsprogramm zu überzeugen, hätte weiterhin zur Konsequenz, daß die Meinungen der Laien und Interessenten maßgeblich und die wirtschaftspolitik des Wettbewerbs wieder "von den Zufälligkeiten politischer Machtgruppierungen"718, von den Wertvorstellungen der emotionalisierten Massen und den politischen Auseinandersetzungen partikularer Gewalten abhängig wäre ${ }^{719}$. Der Tageswille und die Meinungen der straße hätten das Terrain zurückerobert, das ihnen Eucken durch seine wissenschaftstheoretisch fundierte ordnungskonzeption bereits entzogen glaubte ${ }^{720}$.

Diese mit dem demokratischen Prinzip verbundene Schwierigkeit, in der Konkurrenz der Meinungen zu unterliegen bzw. im Wege des Kompromisses Essentialia der Wettbewerbsordnung aufgeben zu müssen und damit die sachgerechte ordnungsgestaltung gar nicht oder nur unter einschränkenden Bedingungen vornehmen $\mathrm{zu}$ können ${ }^{721}$, mußte Eucken gegen den demokratischen staat optieren lassen.

Sein Bewußtsein, "den staat gegenüber gänzlich neuen Gegebenheiten denken zu müssen"722, die sich in einer statischen Wertewelt und der Notwendigkeit einer kompromißlosen homogenen ordnungsgestaltung von wirtschaft und Gesellschaft manifestieren, hatte eine an diesen gerichtete Herstellungserwartung zur Folge, die in einem demokratisch-pluralisti- 
schen System in ihrer striktheit praktisch nicht zu erfüllen ist ${ }^{723}$.

Der staat, der diesen Erwartungen gerecht zu werden vermag, ist anderer Natur.

3. Der autoritäre staat als "Hüter der Wettbewerbsordnung"

Um sein eigenes ordnungsdenken zu verwirklichen, bedarf es auch nach Auffassung Euckens eines Staates, der genug Macht und Bewegungsfreiheit besitzt, um dieses Denken ungeschmälert umzusetzen. Ein solcher Versuch, das eigene Denken "in den Bereich des ein für allemal Entschiedenen zu verlagern und sich dadurch von dem Erfordernis der Zustimmung einer gegenwärtigen Mehrheit zu dispensieren"724, setzt die "Einsichts- und Entscheidungszentralisierung"72s und damit notwendig den von der Gesellschaft unabhängigen, starken staat voraus.

Nur ein staat, der als übergeordnetes, verselbständigtes Herrschaftssubjekt der Kontrolle durch die überbordenden gesellschaftlichen Kräfte entzogen ist, besitzt die stabilität und unabhängige Regelungskompetenz, um das ins Werk zu setzen, was Eucken inm als Aufgabe gestellt hat: die Wettbewerbsordnung als ordokompatible wirtschaftsform praktisch zu vollziehen ${ }^{726}$. Durch seinen Rückzug aus der Gesellschaft und der damit verbundenen Konsolidierung seiner Gewalt wird der staat den Vorstellungen Euckens entsprechend die mit überlegener Macht- und Handlungsfülle ausgestattete Herrschaftsorganisation, die den staatswillen oder in der Diktion Euckens: die "staatsräson" bestimmt. Er ist damit, worauf es Eucken entscheidend ankam, nicht nur das bloße Instrument seiner Bürger und deren problematisierender Einzelwillen und motivationaler Lagen, sondern er konstituiert sich als eine "nicht mehr parteiliche Instanz autoritativer Gewißheit" "27, an die der gesellschaftliche Interessenstreit nicht mehr heranreicht und die die von Eucken definierten staatsnotwen- 
digkeiten erfüllt. Ein solcher staat mit seiner "einheitlichen und konsequenten willensbildung", der die vielfalt und die Gegensätze im Bereich der Wirtschaft zu regeln und $z u$ einem einheitlichen Ganzen zu formen vermag, ist für Eucken "unentbehrlich", solange die faktische wirtschaftsordnung hinter der erkannten idealen ordnung der Wirtschaft durch Wettbewerb zurückbleibt und insoweit ein ordnungspolitischer Handlungsbedarf ent- und besteht ${ }^{728}$.

Diese machtgeprägte Dimension des Euckenschen Staates, die notwendig ist, um die theoretische ordnungsidee zur faktischen ordnung werden zu lassen, begegnet den bereits dargestellten Bedenken Euckens ${ }^{729}$, der Macht als an sich böse qualifiziert, jedoch andererseits erkennt, daß ohne Macht kein staat zu existieren vermag" ${ }^{730}$. Um der "Entwicklung zur Tyrannis" vorzubeugen und das Dilemma zwischen dem für die Einrichtung der Wettbewerbsordnung einerseits unentbehrlichen staat und den mit seiner Konstituierung andererseits verbundenen Utbeln $z u$ beseitigen, muß Eucken die Frage nach der Kontrolle staatlicher Macht beantworten und allgemein die Grenzen der wirksamkeit des von ihm konzipierten neuen staatswesens bestimmen ${ }^{731}$.

\section{Die Grenzen der Wirksamkeit des autoritären Staates}

Der Ruf nach dem starken staat war auch bei Eucken die Antwort auf eine konkrete historische Problemlage ${ }^{732}$, die in der Erkenntnis ihren Ausdruck fand, daß "kein festgefügter staat", der die drängenden wirtschaftlichen ordnungsaufgaben hätte bewältigen können, vorhanden war ${ }^{733}$. Nachdem dieser staat nunmehr in Form der einheitlichen, autoritären staatsgewalt gefunden ist, scheint Eucken deren Bändigung und Mäßigung mit Hilfe der Formel vom "leistungsfähigen Rechtsstaat"734 $\mathrm{zu}$ verbinden. In diesem Zusammenhang hatte er der wirksamkeit des Staates ganz konkrete Grenzen gesetzt: "Wir aber suchen diese Grenzen unter dem besonderen Gesichtspunkt 
der Wirtschaftspolitik und zwar mit der Fragestellung: Wie kann der staat zu einer ordnenden Potenz für eine funktionsfähige und freie ordnung der industrialisierten wirtschaft werden"735. Damit scheinen auf den ersten Blick der Rechtsstaat und die schrankenbestimmende Wirtschaftspolitik der Wettbewerbsordnung im Hinblick auf die MäBigung und Kontrolle der souveränen staatlichen Herrschaftsgewalt Identisches leisten zu können. Dieser erste Eindruck ist indes unzutreffend.

Eine der wesentlichen Erkenntnisse Euckens im Zusammenhang mit der Analyse liberaler Rechtsstaatlichkeit im Zeitalter der Wirtschaftspolitik des Laissez-faire war, daß der Rechtsstaat nicht nur als eine reine "Abwehrveranstaltung"736 zu begreifen ist, sondern daß die gewährten Grundrechte neben ihrer individualrechtlich-ausgrenzenden wirkung vor dem ordnungspolitischen Hintergrund der Wirtschaftspolitik des Laissez-faire zu "gesellschaftlichen Grundregeln"737 im Hinblick auf die angestrebte organisation von wirtschaft und Gesellschaft werden sollten. Diese Auffassung von der ordnungskonstituierenden wirkung der staatsverfassungsnormen begründete Eucken mit dem Hinweis auf die der 2. Epoche des Staatsbildungsprozesses zugrunde liegende wirtschafts- und Gesellschaftstheorie, die den staat entgegen der landläufigen Auffassung in die pflicht nahm und seine notwendige wirksamkeit darin erblickte, daß er den einzelnen durch die Grundrechte überhaupt zum Erwerb freisetzte, damit sich dadurch im "Rahmen des Rechts eine zureichende wirtschaftsordnung von selbst" entfalten könne ${ }^{738}$. Durch die "wirtschaftsverfassungsrechtliche Revolution" wurde der lediglich zur Freiheitssicherung berufene und von Ordnungsaufgaben entbundene liberale Rechtsstaat in seiner wirksamkeit nachhaltig eingeschränkt. Er stand, da sein ordnungsauftrag lediglich dahin ging, staatsausgrenzende Grundrechte zu gewährleisten, störungen des vorausgesetzten wirtschaftlichen Normalzustandes und hier insbesondere der Vermachtung der Märkte hilflos gegenüber, die er infolge seiner konzep- 
tionellen Ausrichtung mit den ihm zur Verfügung stehenden institutionellen Mitteln nicht zu beseitigen vermochte. Ein solches Muster der Kontrolle staatlicher Macht durch das Recht kann für den Euckenschen staat in seiner Funktion als "Hüter der Wettbewerbsordnung" nicht einschlägig sein, da dieser staat gerade nach eigenem willen, unabhängig und ungehindert auch vom Recht die ordnungspolitische Entscheidung treffen können muß. Sind es demnach nicht mehr die herkömmlichen sicherungsmechanismen des rechtsstaatlichen Apparates, die als konstitutioneller "Mantel" die staatsgewalt "umkleiden" und bändigen ${ }^{739}$, muß sich das von Eucken gesuchte Prinzip der Kontrolle staatlicher Macht, die in der Ausübung des normativ indifferenten ordnungswillens zutage tritt und die die latente Gefahr des Rückfalls in staatliche Beliebigkeit und schrankenlose Willkürherrschaft birgt, an anderen als rechtsstaatlichen Grundsätzen ausrichten. Die "praktischen Prinzipien", die die Grenzen der wirksamkeit des Staates "unter dem besonderen Gesichtspunkt der Wirtschaftspolitik" bestimmen ${ }^{740}$, sind jene, die aus der zu sichernden ordnung selbst folgen.

Die Vorstellungen Euckens vom Rechtsstaat, den er mit dem Epitheton "leistungsfähig" versieht und den er offensichtlich als positiv besetzten Begriff nicht aufzugeben bereit ist, erfahren damit eine veränderte Akzentuierung.

a) Das ordoindizierte Schrankensystem staatlicher Macht

Die Frage nach der Kontrolle staatlicher Macht beantwortet sich für Eucken nur unter Beachtung der dem Staat vorgegebenen Teleologie, das heiBt des ihm vorgegebenen staatszwek$\operatorname{kes}^{741}$. Seine wirksamkeit ist durch seine "Berufsidee" geprägt ${ }^{742}$. Diese Idee eines "Hüters der Wettbewerbsordnung" und die dadurch bedingte, spezifische Inpflichtnahme durch den objektiven staatszweck des praktischen vollzuges und der sicherung der guten ordnung der wirtschaft bestimmt den 
legitimen wirkungskreis des staates. Da eine den staat selbst transzendierende Idee nach Verwirklichung strebt, in der die immanente Rationalität der ordnung der wirtschaft zum bindenden Richtmaß allen staatlichen Tuns wird, ist der staat der Wettbewerbsordnung in seiner Funktion grundsätzlich beschränkt.

Diese teleologische Reduktion auf eine bestimmte positive ordnungsleistung als essentielle staatsaufgabe macht staatliche Herrschaft zur bloßen Technik der Ordnung. Das, was sich in der Vorstellung Euckens als Einsichts- und Entscheidungszentrale $e^{743}$ über der vielfalt gesellschaftlicher Interessen etablieren soll, ist damit tatsächlich nicht mehr als ein sozialtechnisches ordnungsmittel, dem, ohne daß ihm Mitwirkungs- bzw. Selbstbestimmungsrechte betreffend die staatsaufgaben eingeräumt wären, mit der Verwirklichung der fordernden idealtypischen sachgesetzlichkeiten des Wettbewerbs die abschließenden Handlungsvollmachten erteilt sind. Macht und Herrschaftsgewalt des autoritären staates, die zur Durchsetzung der ordnung der wirtschaft "unentbehrlich"744 sind, erfahren so ihre Mäßigung durch Umformung in eine zweckorientierte Herrschaft. Es wird offenbar, daß Eucken dem prima facie absoluten staatlichen willen in den vorpoli$t$ ischen ordnungszusammenhängen der Wettbewerbsordnung diejenigen Bestimmungsgründe entgegensetzt, die ihn prägen und ausrichten ${ }^{745}$ und die den "neuen staat" auf enumerativ ableitbare Funktionen, die sich programmatisch aus den Euckenschen staatspolitischen Grundsätzen der Wirtschaftspolitik ergeben, beschränken. Es bleibt nurmehr Raum für einen "pragmatischen Begriff der Souveränität"746 und die Hoffnung, daß sich der staat die ihm vorgegebene Teleologie $z u$ eigen macht. 
b) Die Realität des "leistungsfähigen Rechtsstaates"

Die aufgezeigten Grenzen der Wirksamkeit des "funktionsfähigen Staatswesens", das nach Ansicht Euckens die ziele zu verwirklichen vermag, die sich "der Rechtsstaat von ehedem gesteckt hatte" 147 , weisen nach, daß sich der von ihm hergestellte Bezug zum Rechtsstaatsgedanken in einer Reminiszenz an denjenigen staat erschöpft, der für ihn als der gute und richtige überhaupt gegolten haben mag und dessen sittlichen Anspruch er als identisch mit dem ordnungswollen seines "leistungsfähigen Rechtsstaates" unterstellt ${ }^{748}$. Tatsächlich jedoch hat der von Eucken konzipierte Rechtsstaat mit seinem Vorbild wenig gemein. Er ist, wie dargelegt, einseitig auf die speziellen Belange der Wirtschaft ausgerichtet und in seiner Funktion und in seinen Kompetenzen auf diejenigen beschränkt, die zur Verwirklichung der ordnung der wirtschaft notwendig sind. Die Absicht Euckens, die "veraltete Begriffsapparatur"749 der staatslehre zu ersetzen, ist damit in die Tat umgesetzt, allerdings entgegen seiner anderslautenden Beteuerungen in der Art, daB die Wirtschaftsordnung zum "Unterbau" wird, auf dem "sich die Ordnungen der Gesellschaft, des staates, des Rechtes und andere ordnungen" erheben $^{750}$. Daß eine solche ökonomische Zweckbestimmung nicht ohne wirkung für die strukturprinzipien des Rechtsstaates "von ehedem"751 bleibt, belegt die Euckensche Darstellung des Gewaltenteilungsprinzips sowohl in seiner vertikalen wie horizontalen Ausrichtung.

aa) Die horizontale Gewaltenteilung

Die Verwirklichung der Wettbewerbsordnung bedeutet für Legislative, Exekutive und Judikative die Beachtung besonderer Verhaltenspflichten. "Eine Armee, die so geführt wird, daß ohne Zusammenhang ein Truppenteil hierhin, ein anderer dahin marschiert, kann nicht zu einem sinnvollen Aufmarsch kommen, 
und ihre schlagkraft wird gering bleiben. Wenn aber die Aktionen aller Truppenteile ineinander greifen und so ein sinnvoller Aufmarsch zustande kommt, werden Schlagkraft und Erfolgschancen außergewöhnlich gesteigert. Entsprechendes gilt für die wirtschaftspolitik"752. Vergegenwärtigt man sich, daß die Führung einer Armee auf dem Prinzip von Befehl und Gehorsam gründet, so bedeutet das von Eucken herangezogene Beispiel aus dem militärischen Bereich nur die nochmalige Bestätigung des Umstandes, daß die staatlichen Gewalten den Sachgesetzlichkeiten des Wettbewerbs zu gehorchen und sie ineinandergreifend $\mathrm{zu}$ verwirklichen haben. Dabei sind die "Aufmarschpläne" der Legislative, der Exekutive sowie der Judikative verschiedener Art.

\section{Die Gesetzgebung}

Es genügt für Eucken keineswegs, "daß allein die Gesetzgebung die Prinzipien der Wettbewerbsordnung" verwirklicht, obwohl sie an erster stelle geeignet scheint, "die Einheit der Wirtschaftspolitik durch die Koordination der einzelnen wirtschaftspolitischen Akte zu gewährleisten"753. Wie die legislative sicherung der Wirtschaftspolitik der Wettbewerbsordnung im einzelnen zu gestalten ist, hat Eucken über den vorstehend referierten Ansatz hinaus nicht weiter verfolgt. In eingehenderem Maße hat er sich demgegenüber mit derjenigen Gewalt auseinandergesetzt, die sich durch ihre unbotmäßige Haltung in Ansehung der Prinzipien des Wettbewerbs in der Vergangenheit mehrfach exponiert hat: die Rechtsprechung.

\section{Die Rechtsprechung}

Der Grund dafür liegt in der primären Konfrontation der Rechtsprechung mit faktischen Fehlentwicklungen im Bereich der wirtschaft, meist verbunden mit dem Antrag, diese Ent- 
wicklungen als rechtswidrig zu stoppen bzw. als gesetzlichen Normalzustand $z u$ bestätigen.

Demnach kommt der Rechtsprechung "eine unentbehrliche und selbständige Rolle" bei der Verwirklichung der ordnung der wirtschaft $z u^{754}$. Eucken nennt insoweit beispielhaft die "berühmten" Entscheidungen des Reichsgerichts vom 25. Juni $1890^{755}$ und vom 4. Februar 1897"56, durch die "Kartellverträge und Marktpreisbindungen sowie Kartellzwang (Sperren) für zulässig" erachtet wurden ${ }^{757}$. Diesen Entscheidungen kam nach Auffassung Euckens eine erhebliche wirtschaftspolitische Bedeutung $z u$, da sie die Grundlage für die Kartellgesetzgebung im Laufe der folgenden Jahrzehnte wurde ${ }^{758}$.

Nach dieser Bestandsaufnahme kommt Eucken ohne Umschweife zur Sache. Was ihn an der nachgezeichneten Entwicklung stört, ist die richterliche Unabhängigkeit und demgemäß die fehlende Möglichkeit, im Bereich der Rechtsprechung bestimmten ordnungspolitischen Ansichten verbindlich Geltung $z u$ verschaffen. Aus diesem Grund ist es "nötig, daß der Richter sich der wirtschaftsverfassungsrechtlichen Gesamtentscheidung unterordnet" und nicht nach richterlichem Ermessen mit Hilfe der Generalklauseln von Treu und Glauben oder der guten sitten judiziert ${ }^{759}$. Dabei gilt es insbesondere, das defiziente wissen der Richterschaft im Hinblick auf wirtschaftliche ordnungstatsachen zu beseitigen und ihnen einen Einblick in die gesamtwirtschaftlichen Zusammenhänge zu vermitteln, denn "Rechtsprechung ist oft Wirtschaftspolitik. Aber wirtschaftspolitik kann erfolgreich nicht nach rechtsdogmatischen Grundsätzen getrieben werden"760.

Versteht man mit $K$. Larenz unter Rechtsdogmatik die "nicht unmittelbar praxisbezogene jurisprudentielle Theorie" 761 , so scheint nach der soeben zitierten Auffassung Euckens die Rechtsprechung vom Boden der Rechtstheorie gelöst und einer wirtschaftsdogmatischen sichtweise unterstellt $\mathrm{zu}$ sein. Andererseits gilt auch für Eucken, daß richterliche Entscheidungsfindung auf dem Boden des Rechts oder genauer, "auch in Anwendung der wirtschaftsverfassungsrechtlichen 
Grundsätze" zu erfolgen hat ${ }^{762}$. Das dabei auftretende Problem, "wie die wirtschaftsverfassungsrechtliche und die rechtsdogmatische Behandlung der Probleme ineinandergreifen" soll ${ }^{763}$, wird bei Eucken nicht als solches erkannt, da es für ihn offenkundig verschiedene Kategorien des Rechts gibt, die je nach Anwendungsbereich und Regelungssubstrat durch die dogmatischen Erkenntnisse und Besonderheiten der jeweils geregelten Materie bestimmt werden ${ }^{764}$.

Für die Rechtsprechung gibt es demnach bei Entscheidungen, die den Bereich der Wirtschaft betreffen, nur eine Bindung an wirtschaftsdogmatisch fundiertes Recht, da nur so die Gewähr für die "Einheit der Wirtschaftspolitik"765 und die Funktionsfähigkeit der Wettbewerbsordnung dauerhaft gegeben ist. Warum Eucken einer solchen Abdankung der Rechtsdogmatik für den Bereich der wirtschaft das Wort redet, läßt sich nur vermuten. Es mag das mangelnde zutrauen in die Rechtsprechung sein, der die "Bewältigung je neuer Sozialkonflikte (...) nur aus dem Vorrat an Normen und (rechts-) dogmatischer Kunst" 766 möglich ist sowie der Zweifel, daß auf dieser Grundlage adäquate Problemlösungen für die ordnung der Wirtschaft gefunden werden können.

\section{Die Verwaltung}

Auch die dritte Gewalt unterliegt dem durch die wirtschaftsverfassungsrechtliche Gesamtentscheidung in besonderer Weise geprägten Recht und zwar nicht nur in den obersten Behörden, sondern auch in den "lokalen Verwaltungsstellen", die so z.B. nicht dazu beitragen sollen, "mit baupolizeilichen Mitteln (...) aufkommende Konkurrenz im Handwerk einer stadt zu verhindern"767. Diese kurze stellungnahme zur Verwaltung zeigt, daß Eucken sie nicht als Problem begreift, denn bloBer Gesetzesvollzug läßt kaum die Möglichkeit der Gestaltung und damit der Veränderung tatsächlicher Verhältnisse zu. Ist 
das richtige Recht geschaffen, ist die Verwaltung automatisch ausgerichtet.

Die Überlegungen Euckens zur Frage der horizontalen Gewaltenteilung im "leistungsfähigen Rechtsstaat" machen trotz ihrer Kürze das dahinterstehende, grundsätzliche Interesse deutlich. Die überkommene Trennung der Gewalten muß aufgehoben und ihre Tätigkeit auf die Verwirklichung der Sachgesetzlichkeiten des Wettbewerbs ausgerichtet werden, was sich nur im übergreifenden Zusammenwirken der Gewalten bewerkstelligen läßt. Damit setzt sich Eucken dem gleichen Vorwurf aus, den er gegen die Wirtschaftspolitik zentraler Leitung erhoben und der er die Unvereinbarkeit mit dem Gewaltenteilungsprinzip als konstitutivem Bestandteil des Rechtsstaatsprinzips vorgeworfen hatte.

bb) Die vertikale Gewaltenteilung

Nicht nur das Prinzip der horizontalen Gewaltenteilung sieht sich durch das geänderte Rechtsstaatsverständnis Euckens in völlig neuem Licht. Dasselbe gilt auch für das vertikale Gewaltenteilungssystem in Form des bundesstaatlichen Prinzips, nach dem sich der staat selbst wirkungsvoll in seiner Machtfülle beschränken kann, indem er in der föderativen Aufteilung der staatsgewalt und dem darin begründeten wechselseitigen Angewiesensein von Zentralstaat und Gliedstaat ein System der vertikalen Gewaltentrennung und Gewaltenbalancierung schafft, das durch Zuständigkeitsregelung und -verteilung weder bei der einen noch bei der anderen Instanz alle Aufgaben und Befugnisse anhäuft ${ }^{768}$. Ein - cum grano salis - zweigliedriger Verwaltungsbau beschreibt dementsprechend den Normalzustand im Bundesstaat.

ob der "neue Staat" Euckens durch eine solche Dezentralisierung von Entscheidungsbefugnissen gekennzeichnet ist oder ob die Wirtschaftspolitik der Wettbewerbsordnung der ganzen Kraft eines föderativ nicht behinderten Einheitsstaates be- 
darf, läßt sich nicht abschließend klären. $\mathrm{zu}$ vermuten steht, daß einer Wirtschaftspolitik aus einem Guß und der einer solchen Politik korrelativen Form des autoritären Staates die Tendenz zum Einheitsstaat immanent ist, weil nur in einem solchen staat die Zentralisierung der politischen Entscheidungsgewalt gegeben und die föderative Interessenvielfalt vermieden ist, die der einen, richtigen politischen Entscheidung hindernd entgegenstünde.

\section{Abschnitt}

wissenschaft als potesta constituens für die ordnungen von staat und wirtschaft

Die Lehren aus dem Staatsbildungsprozeß der Neuzeit und die Einsicht, daß der "moderne staat (...) zwar keine zureichende ordnende Potenz" ist ${ }^{769}$, um die angestrebte ordnung der Wirtschaft zu verwirklichen, daß er aber unter Beachtung der von Eucken entwickelten staatspolitischen Grundsätze der Wirtschaftspolitik eine solche Potenz zu werden vermag, führen nun allerdings nicht zur Lösung der ordnungsproblematik, sondern geradewegs in ein Dilemma.

Infolge der "Interdependenz von staatsordnung und wirtschaftsordnung" kann der ordnungsaufbau von beiden nur "in einem Zuge in Angriff" genommen werden" ${ }^{70}$. "Ohne eine Wettbewerbsordnung kann kein aktionsfähiger staat entstehen und ohne einen aktionsfähigen staat keine Wettbewerbsordnung" 71 . Der zur Durchsetzung der ordnenden Prinzipien in der wirtschaft berufene staat und dessen "entschlossene staatsführung"72 sind nach dieser Junktimklausel demnach erst das Produkt einer Wirtschaftspolitik, als deren Initiatoren sie vorausgesetzt sind ${ }^{773}$.

Die erkannte gegenseitige Abhängigkeit von staatsordnung und Wirtschaftsordnung sowie die Feststellung, daß weder die gute ordnung der wirtschaft noch das dieser ordnung adäquate 
Staatswesen verwirklicht ist, läßt die Frage nach der ordnenden "Superpotenz" aufkommen, die den "Umbau" von staat und Wirtschaft insgesamt in Angriff $z u$ nehmen imstande ist und so das erkannte Dilemma zu beseitigen vermag ${ }^{74}$.

Eucken kommt in diesem Zusammenhang auch auf die Kirchen zu sprechen und analysiert deren Fähigkeiten zur ordnungsgestaltung.

Die katholische Kirche, so Eucken, pflege seit Thomas von Aquin traditionell das Denken in ordnungen und befürworte insbesondere seit den beiden Enzykliken Rerum Novarum (1891) und Quadragesimo Anno (1931) mit dem Subsidiaritätsprinzip einen Gestaltungsgrundsatz gesellschaftlichen Lebens, der einer nach dem Prinzip des Wettbewerbs geordneten Wirtschaft entspreche. Unvereinbar mit diesem Prinzip sei jedoch die vom Quadragesimo Anno ebenfalls vorgeschlagene, ständestaatliche ordnung, die das allgemeine Gleichgewicht des wirtschaftsprozesses störe, das Voraussetzung für eine gerechte Verteilung der Güter und eine möglichst weitgehende Befriedigung der individuellen Bedürfnisse ist.

Die evangelische Kirche sieht Eucken auf einem generellen Rückzug aus dem ordnungspolitischen Tagesgeschäft. Grund für die resignative Einstellung ist die Sekpsis, daß die gute und richtige ordnung der Wirtschaft überhaupt zu erkennen und durchzusetzen ist. Deshalb überlasse die evangelische Kirche die Wirtschaftsordnung sich selbst und stehe jedem Engagement fern ${ }^{775}$.

Sind beide Institutionen, sowohl die katholische als auch die evangelische kirche demnach für die ordnungspolitische Entscheidung im sinne Euckens ungeeignet, bleibt die Frage nach der ordnenden Potenz von staat und Wirtschaft, die Eucken in in einer ausholenden Darstellung einführt.

Geschichte, so sein Ansatz, wird vom Denken der Menschen und deren Vorstellungen bestimmt, nicht von einem naturnotwendigen Entwicklungsgesetz" $z^{76}$. Mit der Absage an den "Mythos der Zwangsläufigkeit" geschichtlicher Entwicklung gilt gleich- 
zeitig der Grundsatz, daß ordnungspolitisches "Denken, Wollen und Glauben" Einfluß auf die Geschichte durch Einfluß auf den denkenden Menschen als Träger der Geschichte zu nehmen vermag, um einer bestimmten ordnungsidee zum Durchbruch zu verhelfen ${ }^{77}$.

Das bisherige Versagen des modernen staates im Hinblick auf die ihm übertragenen ordnungsaufgaben und die Feststellung, daß andere ordnende Potenzen hier bislang nicht in die Bresche zu springen vermochten, bedeutet deshalb keineswegs das Ende aller Wirtschaftspolitik, denn es "bleibt die Möglichkeit, durch geistige Arbeit und durch ihren Einfluß ordnungen in staat und Gesellschaft" zu schaffen ${ }^{778}$. Das Denken selbst wird zur "ordnenden Potenz" 779 .

In diesem Zusammenhang ist jedoch für Eucken beachtlich, daß Denken nicht gleich Denken ist. Was als ordnende Kraft von vorneherein auszuscheiden hat, sind die "Denkleistungen des Alltagsmenschen", denn diese sind meist gering und den sich stellenden komplexen Problemen nicht gewachsen ${ }^{780}$. Der Mensch der Masse spricht nur nach, was andere ihm vorsagen ${ }^{781}$. Als diejenige Potenz, die staat und wirtschaft ordokonform umzubauen vermag, ist demgegenüber der "überlegene Geist" gefordert, der sich durch "Leistung, vitalität und selbstsicherheit" auszeichnet ${ }^{782}$.

Solchen Geist vermutet Eucken im Einklang mit seiner Gesellschaftstheorie nur bei einer Führerschicht, die die Massengesellschaft leitet und die demgemäß in der Lage ist, in entscheidendem Maße Geschichte $z u$ machen ${ }^{783}$. Diese Führerschichten sind nach Ansicht Euckens allerdings keineswegs homogen. Es gilt demnach aus den Eliten in ihrer Gesamtheit diejenige herauszufinden, die als berufen gilt, das umfassende ordnungsproblem in staat und Gesellschaft zu lösen. Für diese Aufgabe sicherlich nicht prädestiniert sind jene politischen und wirtschaftlichen Führungsgruppen, die mit ihren "säkularisierten Heilslehren" nur danach trachten, die Massen hinter sich $\mathrm{zu}$ bringen und die in dieser pragmati- 
schen Ausrichtung einen festen und dauerhaften ordnungsstandpunkt nicht nachzuweisen vermögen ${ }^{784}$.

Eucken sucht demgegenüber die unabhängige, sachverständige und intellektuelle Instanz, die Einblick in die gesamtwirtschaftliche Lenkungsproblematik und Kenntnis der "sachnotwendigen zusammenhänge" hat und die insoweit autoritative Gewißheit für sich in Anspruch zu nehmen vermag ${ }^{785}$. Unter Beachtung dieses Anforderungsprofils reduziert sich die Anzahl der denkbaren elitären ordnungspotenzen auf eine: nur das Denken der "Männer der Wissenschaft" mit seiner "strengen theoretisch-ökonomischen Schulung", die weder Laien noch Ideologen nachzuweisen vermögen, kommt als ordnende Kraft grundsätzlich in Betracht ${ }^{786}$. Aber auch insoweit ist nochmals zu differenzieren.

Die Aufgabe, die der datumsgestaltenden wissenschaft gestellt ist, setzt ein bestimmtes Programm und intellektuelles Leistungsvermögen des letztinstanzlich zuständigen Sachverstandes voraus. In Frage kommt nur, und diese Wendung vermag kaum $z u$ überraschen, die Wissenschaft im stile Eukkens. Der verantwortungsvollen "bewußte(n) Gestaltung der ordnungen" ist nur dieses wissenschaftliche Denken gewachsen, das den Historismus und den Punktualismus ebenso überwindet wie das positivistische Vorurteil und das solchermaBen zur wirklich ordnenden Potenz reift ${ }^{787}$. Indem Eucken glaubt, mit Hilfe des von ihm konzipierten korrigierten rationalistischen Verfahrens $\mathrm{zu}$ wahrer, zeitungebundener wissenschaftlicher Erkenntnis im Hinblick auf die Bedingungskonstellationen und -zusammenhänge im Bereich der wirtschaft zu kommen, wird es ihm, ausgehend von dieser gesicherten Erkenntnis, möglich, "über das engere Fachgebiet" hinaus neben Fragen der wirtschaftlichen Gesamtordnung das Problem der Interdependenz von wirtschafts- und staatsordnung mit letztgültiger Gewißheit zu klären und auch im Hinblick auf den staat relativistische Haltlosigkeit und falsches Entwicklungsdenken zugunsten eines ordokonformen Staatsverständnisses $\mathrm{zu}$ überwinden ${ }^{788}$. 
Wissenschaft im stile Euckens ist diejenige Autorität, die nicht nur im Besitz der theoretischen, sondern auch der praktisch-politischen wahrheit ist, die sie zur einzig anerkannten "Lebensmacht von bildender und gestaltender Kraft"789 macht. Damit ist die Akzeptanz anderer Wertvorstellungen ausgeschlossen, das frühere positivistische Subordinationsverhältnis von Wissenschaft und den "politischen Mächten" sowie deren pragmatischer Tagespolitik sind zugunsten einer exklusiven Leitungs- und ordnungsfunktion der Wissenschaft in staat und Gesellschaft abgelöst ${ }^{790}$.

Diese Wendung hin zur Wissenschaft als ordnender Potenz mag nach Ansicht Euckens früher, als die "Völker stärker aus der Tradition heraus lebten" und damit vielfachen Bindungen unterworfen waren, weniger dringlich und notwendig gewesen sein"71. "Seit 1789 ist das anders"792. Nunmehr ist eine ordnende Kraft gefordert, die der Auflösung der Ordnungen Einhalt gebietet. Entzieht sich die wissenschaft dieser Aufgabe, entsteht "in der Führung der Nationen (...) ein geradezu verhängnisvolles Vakuum", das von Politfunktionären und sozialen Machtgruppen ausgefüllt wird ${ }^{793}$. Über deren Untauglichkeit zur Lösung der anstehenden Probleme bestehen bei Eucken keine Zweifel.

Der Rückzug wissenschaftlicher Führungsschichten aus der Verantwortung, insbesondere in geschichtlichen "Momenten der Krisis" und Notlagen, die auf eine Neuordnung von staat und Wirtschaft drängten, war nach Auffassung Euckens nur als deren Eingeständnis in die eigene Hilflosigkeit angesichts der sich stellenden Probleme zu werten ${ }^{794}$.

Was bislang fehlte, um das bestehende Vakuum auszufüllen, waren Konzeptionen einiger weniger Personen, die dank "ihre(r) irrationalen Kraft des Wollens und ihre( $r$ ) Kraft der Vernunft" die unübersehbar scheinenden schwierigkeiten zu bewältigen und die Grundsätze der wirtschafts- und staatspolitik zu bestimmen vermochten ${ }^{795}$.

Diese Überlegungen Euckens belegen eingängig, weshalb im "Moment der Krisis" nach 1945 die Freiburger Schule auf der 
Höhe der zeit war und ihre politischen Vorstellungen eine solch eminente Bedeutung gewinnen konnten.

Die von Eucken inaugurierte Vorstellung von der Wissenschaft als staats- und wirtschaftsordnender Potenz beantwortet zugleich die Frage nach dem quis judicabit und begründet die Zuständigkeit einer den politischen Machtkämpfen entzogenen, dem Druck von Sonderinteressen enthobenen, unabhängigen Instanz, die unter Berufung auf die "Herrschaft des reinen Sachverstandes"796 über die organisation von staat, wirtschaft und Gesellschaft unkontrolliert und unkontrollierbar bestimmt.

Einzelheiten über den Berufungsmodus der Fachleute sowie organisatorische Details hat Eucken nicht erläutert. Es liegt jedoch nahe, anzunehmen, daß alle wichtigen Funktionsträger Anhänger der richtigen wissenschaftlichen Lehre zu sein haben, um die Durchsetzung eben dieser Lehre zu garantieren und eine bestimmte ordnung in staat, wirtschaft und Gesellschaft zu installieren ${ }^{797}$.

Die von Eucken entworfene Konzeption, die die Wissenschaft als "ordnende Potenz" in der Pflicht sieht, legt einen Vergleich nahe, der bereits von w. v. Simson im Hinblick auf die verfassungsrechtlichen Ideen F.A. v. Hayeks angestellt wurde ${ }^{798}$.

Worin so fragt w. v. Simson, "unterscheidet sich diese Forderung von dem, was in kommunistischen staaten praktiziert wird? Ist nicht auch dort eine bestimmte ökonomisch-gesellschaftliche Lehre einem von keiner allgemeinen Wahl und $\mathrm{Zu}-$ stimmung abhängigen Gremium anvertraut"? Und weiter: "Versucht man nicht auch dort, die einmal etablierte Lehre in Schutz zu nehmen vor dem Unglauben, der Ignoranz, der Selbstsucht oder schließlich überhaupt dem Freiheitsdrang der Uneingeweihten?"799

Der gemeinsame Nenner dieser beiden, im übrigen scharf zu trennenden Konzeptionen, liegt in der Art und Weise der 
Lösung des Legitimationsproblems, das im Hinblick auf die richtige ordnung in staat und Wirtschaft auf selbstberufene Instanzen "verschoben" 800 wird und der Lösung im Rahmen bestimmter Verfahren nicht mehr bedürtig ist. Das Ergebnis einer solchen Verlagerung hin zur Legitimation nur durch Vernunft und Wissen ist voraussehbar. In dem Moment, in dem sich eine selbstbestimmte, kleine Schicht wissender zutraut, letztgültige Antworten auf die Fragen, die die Geschichte stellt, parat zu haben, "macht sie sich zum Gegenteil dessen, was sie zu sein beansprucht, und leitet aus Umständen, die ihr vielleicht manches an rationaler Einsicht gestatten, irrationale Herrschaft ab"801.

Eine potesta constituens, die die substanz von staat und Wirtschaft auf der Grundlage bestimmter wissenschaftlicher Einsichten bestimmt, wird ihre puristische Lehre auf Dauer nur mit Hilfe von Zwangsmaßnahmen gegen divergierende Meinungen und den Zweifel überhaupt schützen können.

Daß die Euckensche Konzeption geradewegs, wie vermutet wur$\mathrm{de}^{802}$, in eine aufgeklärte Diktatur führt, mag übertrieben scheinen und dem freiheitlichen ordnungswollen Euckens nicht gerecht werden.

Eine Herrschaft der Wissenden, die zumeist eine Herrschaft der Kompromißlosen ist, trägt, wenngleich den besten Vorsätzen hörig und auf das allgemeine Beste ausgerichtet, einen solchen Keim jedoch stets in sich. 


\section{KAPITEL}

Die praktische Verwirklichung der wettbewerbsordnung - zugleich ein Beitrag zum Rechts- und Verfassungsverständnis walter Euckens

Die Notwendigkeit einer ordnungspolitischen Gesamtentscheidung für die Wettbewerbsordnung stellt den staat vor die Frage, welcher Vorkehrungen es im einzelnen bedarf, um diese ordnung der Wirtschaft einzurichten und in ihrem Bestand dauerhaft $z u$ sichern. Es sind ihm mit anderen Worten diejenigen "positiven Prinzipien"803 wirtschaftspolitischen Handelns an die Hand zu geben, die notwendig, geeignet und tauglich sind, die Gesamtentscheidung für die Wettbewerbsordnung in concreto durchzusetzen und diese ordnung $z u$ konstituieren und $z u$ erhalten.

Auch insoweit hat Eucken versucht, die Grundlagen $\mathrm{zu}$ schaffen.

\section{Abschnitt}

\section{Die Entscheidung}

\section{A. Das Denken in "Wirtschaftsverfassungen"}

Die Kritik des Mythos vom Geschichtsmechanismus allein reicht nicht aus. Das Denken in Ordnungen muß das Denken in historischen Zwangsläufigkeiten verdrängen und letztlich ablösen. "Geschichte und somit auch Wirtschaftspolitik bestehen aus menschlichen Handlungen. Sie dürfen nicht einseitig als 'Prozeß' aufgefaßt werden"804. Wirtschaftspolitik hat die Freiheit und muß es sich zur Aufgabe machen, die ordnungsformen der Wirtschaft zu gestalten und diejenigen Bedingungskonstellationen $z u$ schaffen, die stabile ordnungen bewirken und die nicht ungewollt verhängnisvolle wirtschaftspolitische Tendenzen und Entwicklungen in Gang set$z_{e n}^{805}$. Die Erfüllung dieser "geradezu entscheidenden ge- 
schichtlichen Aufgabe" kann jedoch nicht durch "Ideologien über Kapitalismus, Sozialismus usw.", sondern nur durch ordnendes Denken sowie die "Kenntnis der einzelnen ordnungsformen, der Zusammenhänge des wirtschaftsprozesses und der Interdependenz der ordnungen" bewerkstelligt werden ${ }^{806}$. Wirtschaftspolitik darf ferner nicht nur "punktuell" betrieben werden, sondern vor jeder staatlichen Einzelmaßnahme im Bereich der wirtschaft muß grundsätzlich die Entscheidung für eine bestimmte ordnung der Wirtschaft stehen, das heißt es muß Klarheit darüber herrschen, welche "Wirtschaftsverfassung" gelten soll. Das "Denken in Wirtschaftsverfassungen" steht bei Eucken gleichbedeutend für die "politische Gesamtentscheidung über die ordnung des nationalen wirtschaftslebens"807. Es muß "eine Wirtschaftsverfassung erarbeitet werden, die ordnung schafft, ohne dem staat oder dem einzelnen mehr zuzumuten, als sie zu leisten vermögen", die zugleich jedoch die optimale Entfaltung der wirtschaftlichen Kräfte und deren effizientesten Einsatz gewährleistet ${ }^{808}$.

Begriff und Definition der wirtschaftsverfassung sind nun keine Schöpfung Euckens, der insoweit Bezug auf denjenigen staatsdenker nimmt, dessen Ansichten und Publikationen zum Staat ihm bereits bei Prüfung der Frage, an welchen staatslehren sich eine neue staatsbildung auszurichten hat, einzig erwähnenswert schien: C. Schmitt.

Art und Umfang der inhaltlichen Übereinstimmung von Schmittschem Verfassungsbegriff und dem von ihm (vorgeblich) abgeleiteten wirtschaftsverfassungsbegriff Euckens sind indes keineswegs eindeutig und letztlich streitig geblieben. $O b$ sie "ganz oberflächlicher, terminologischer Art" sind, wie W. Weber behauptet ${ }^{809}$ oder ob, wie vielfach angenommen, nicht doch auch "materiales" Verfassungsdenken C. Schmitts in den Euckenschen Wirtschaftsverfassungsbegriff eingeflossen ist, war bislang kaum Gegenstand eingehender wissenschaftlicher Prüfung und - vielleicht gerade deshalb - Gegenstand heftiger, über das normale Maß wissenschaftlicher Auseinandersetzung hinausgehender, emotionalisierter Kontroversen. 
Es mag in diesem Zusammenhang der Hinweis auf die Auseinandersetzung zwischen J.H. Kaiser ${ }^{810}$ und B. Rüthers ${ }^{811}$ genügen, die sich gegenseitig zum Vorwurf machten, das wirtschaftsverfassungsdenken Euckens nicht bzw. nicht hinreichend begriffen $\mathrm{zu}$ haben. So hielt B. Rüthers seinem Kontrahenten vor, viele Mitglieder und Freunde der "Freiburger Schule" seien durch den Versuch überrascht worden, dem ordo-Liberalismus ein Denkmal zu errichten, "in dessen Fundamenten das 'konkrete ordnungsdenken' c. Schmitts einen Eckstein" bil$\mathrm{de}^{812}$. Da es $\mathrm{C}$. Schmitt offenkundig und einzig um die Errichtung der "konkreten, im voraus erdachten ordnung" für den NS-Staat gegangen sei, könne die von J.H. Kaiser zumindest gedanklich hergestellte Verbindung zur Gruppe der "Freiburger", der "Männer von der politischen Überzeugung eines $W$. Eucken, C. v. Dietze, W. Röpke, F. Böhm, A. Rüstow und F.A. v. Hayek" angehörten, nur verwundern ${ }^{813}$.

Diesen, mit "Polemik, Ignoranz und Malice" 814 vorgetragenen Invektiven begegnete J.H. Kaiser zum einen mit dem Hinweis darauf, daß die von B. Rüthers inkriminierte widmung seines Werkes unter anderem mit der witwe Eucken besprochen worden sei. Zum anderen sei sowohl von F. Böhm als auch in seinem Gefolge von Eucken auf das Entscheidungsdenken als "Eckstein" des neoliberalen Denkens hingewiesen worden. Beide hätten in der Gesamtentscheidung für ein bestimmtes ordnungsprinzip die "Grundlegung der Wirtschaftsverfassung" gesehen $^{815}$. Diese problemlos nachweisbare Verknüpfung Schmittschen Entscheidungs- und Ordnungsdenkens mit den "Grundlagen der Freiburger Schule" ist denn auch für J.H. Kaiser "Anlaß genug, auf mögliche zusammenhänge zwischen ordo und ordnungsdenken" zu reflektieren ${ }^{816}$.

Er selbst folgt dieser Anregung nicht, da zum einen das rezensierte Werk und zum anderen die "unsorgfältig präparierte Attacke" B. Rüthers kein Anlaß seien, dies zu vertiefen $^{817}$.

Da für die vorliegende Arbeit solche exkulpierenden Umstände nicht vorliegen, vielmehr die Klärung der von J.H. Kaiser 
aufgeworfenen Frage zum Verständnis des Euckenschen Wirtschaftsverfassungsbegriffes unumgänglich ist, wird eine zumindest grobe - Skizzierung auch des schmittschen Verfassungsdenkens erforderlich, um zu dessen behaupteter Koinzidenz mit dem Euckenschen Wirtschaftsverfassungsbegriff stellung nehmen zu können.

\section{B. Der "positive Verfassungsbegriff" Carl schmitts}

C. Schmitt hatte in seiner 1931 erschienenen Schrift "Der Hüter der Verfassung" unter dem Eindruck, daß der staat die wirtschaft in weitem Maße beherrscht und beeinflußt, festgestellt, daß dem faktischen wirtschaftsstaat eine wirtschaftsverfassung fehle $e^{818}$. Deutschland, so $C$. Schmitt weiter, besitze in der Weimarer Reichsverfassung lediglich eine "politische Verfassung", die ihr Vorbild im staat der liberalen, konkurrenzorientierten Wirtschaftsgesellschaft habe. Dementsprechend sei der Weimarer staat der Auffassung, gegenüber der Wirtschaft neutral bleiben zu müssen. Für die politische Verfassung sei der einzelne immer nur "citoyen", niemals "producteur"819.

Der Versuch, die "offensichtliche Diskrepanz" eines Wirtschaftsstaates ohne Wirtschaftsverfassung $z u$ beheben, kann nach $C$. Schmitt nur durch eine Harmonisierung von Verfassung und Verfassungswirklichkeit nach einer Richtung hin vollzogen werden. Entweder wird der staat von all denjenigen Elementen gereinigt, die ihm das Gepräge eines wirtschaftsstaates verleihen, d.h. er wird entökonomisiert oder aber die politische oder "Nicht-Wirtschaftsverfassung" wird durch eine wirtschaftsverfassung ersetzt, also der staat konsequent auch rechtlich verwirtschaftlicht ${ }^{820}$.

Der Möglichkeit einer Entökonomisierung des staates steht $c$. Schmitt skeptisch gegenüber. Den sozialen und wirtschaftlichen Mächten stünden, trotz anderslautender Verfassungs- 
proklamationen, eine vielzahl durch den Verfassungs- und Gesetzgeber nicht faßbarer Möglichkeiten offen, um ihren Einfluß geltend $z u$ machen und neue Beherrschungstaktiken und -praktiken zu entwickeln.

Demgegenüber hat das uneingeschränkte Bekenntnis zur Wirtschaftsverfassung den Vorteil der Ehrlichkeit und der Anpassung an die Wirklichkeit ${ }^{821}$.

Für c. Schmitt haben nur zwei staaten die notwendige Angleichung von ökonomischer Verfassungswirklichkeit und Verfassungsrecht im zweiteren sinne über die Einrichtung einer Wirtschaftsverfassung gelöst, das kommunistische Rußland mit seinem Sowjetsystem und das faschistische Italien mit seinem stato corporativo. Kennzeichnend für diese staaten ist nach c. Schmitt eine straff zentralisierte Parteiorganisation bzw. die organisation als Ein-Parteien-Staat ${ }^{822}$.

Ein staat, der sich für die Beseitigung der Diskrepanz von Verfassung und Verfassungswirklichkeit durch eine wirtschaftsverfassung entscheidet, muß - so die Folgerung $c$. Schmitts - offenkundig stark und in seiner Meinungsbildung ungeteilt sein.

Die für den Teilbereich der Wirtschaftsverfassung gewonnenen Erkenntnisse decken sich mit dem von C. Schmitt entworfenen, allgemeinen Verfassungsbegriff und den daraus für den staat als Hüter der Verfassung abgeleiteten organisations- und Entscheidungsprinzipien.

Es gilt, daß "(a)lles rechtswissenschaftliche Denken sowohl mit Regeln, wie mit Entscheidungen, wie mit ordnungen und Gestaltungen" arbeitet. "Aber die letzte, rechtswissenschaftlich gefaßte Vorstellung, aus der alle anderen juristisch abgeleitet werden, ist immer nur eins: entweder eine Norm (im Sinne von Regel und Gesetz), oder eine Dezision, oder eine konkrete ordnung" ${ }^{823}$.

Je nachdem, wie "das eine aus dem anderen abgeleitet oder auf das andere zurückgeführt wird", unterscheidet c. Schmitt "die drei Arten des Regeln- und Gesetzes-, des Entscheidungs- und des konkreten Ordnungs- und Gestaltungsdenkens" ${ }^{824}$. 
Unter Zugrundelegung dieser Zusammenhänge postuliert er, daß Verfassungsdenken immer nur Entscheidungsdenken sein kann. "Eine Verfassung beruht nicht auf einer Norm, deren Richtigkeit der Grund ihrer Geltung wäre"1825. Verfassung ist auch nicht "der konkrete Gesamtzustand praktischer Einheit und sozialer ordnung eines bestimmten Staates" ${ }^{826}$, sondern Verfassung im absoluten, "positiven Sinne" ist die "Gesamtentscheidung über Art und Form der politischen Einheit" und damit die konkrete Entscheidung über die politische Daseinsform eines bestimmten staates in seiner Gesamtheit ${ }^{827}$. Die wirkliche politische Verfassung erfordert demnach die reine, autoritäre Entscheidung des staates für eine bestimmte Idee, die ihren Ursprung weder in einer Norm noch in einer konkreten ordnung hat. Die Verfassung im dezisionistischen sinne steht somit logisch und dogmatisch vor dem in der Rechtsverfassung enthaltenen Gebot ${ }^{828}$, denn dieses gilt erst aufgrund der Verfassung im positiven sinne und hat diese zur Voraussetzung ${ }^{829}$.

Nach der Verfassungslehre $C$. Schmitts kann es demzufolge ein "geschlossenes Verfassungssystem rein normativer Art" nicht geben $^{830}$, denn gegenüber der vorgängigen Gesamtentscheidung müssen alle normativen Regelungen sekundär bleiben. Dies ist der - grob skizzierte - Hintergrund der bekannten schmittschen Abschichtung von "Verfassung" und "Verfassungsgesetz", wonach letzteres nur die "ausführende Normierung des verfassungsgebenden willens" ist ${ }^{831}$. Es wird evident, daß C. Schmitt die verfassungsgebende Entscheidung unabhängig von jeder Rechtsnorm denkt. Die Entscheidung selbst muß jedoch, um konstituierend wirken zu können, ihren Niederschlag in einer Rechtsnorm finden. "'Aus dem Nichts' stammt die grundlegende politische Totalentscheidung also lediglich 'normativ gesehen'"832, denn hinter jeder Dezision steht ein geistig-politischer wille in Form einer einheitlichen staatsidee, die den Entscheidungs- und damit letztlich auch den Norminhalt determiniert ${ }^{833}$. 
"Dilatorische Formelkompromisse", Indizien einer inhomogenen staatsidee, sind als Entscheidungsgrundlage untauglich ${ }^{834}$, es ist zwischen den begrenzten, eindeutigen Möglichkeiten zu entscheiden ${ }^{835}$, denn: "Wer über eine Frage etwas aussagen will, muß sie auch entscheiden können" ${ }^{836}$.

Soweit das trotz vieler Untersuchungen in weiten Bereichen bei sich selbst gebliebene Denken c. Schmitts im vorliegenden zusammenhang von Interesse ist, bleibt festzuhalten, da $B$ ordnung nur dadurch $z u$ entstehen vermag, daß der jeweilige Träger der staatsgewalt im sinne einer bestimmten Idee entscheidet ${ }^{837}$. Die Dezision ist causa für eine bestimmte konkrete ordnung, die ihrerseits immer nur Folge dieser Entscheidung sein $\mathrm{kann}^{838}$.

Vor dem Hintergrund des solchermaßen konkretisierten Verfassungsdenkens $C$. Schmitts bleibt zu prüfen, ob sich spezifische Besonderheiten seines dezisionistischen und konkreten ordnungsdenkens im wirtschaftsverfassungsdenken Euckens finden.

\section{c. Der positive wirtschaftsverfassungsbegriff walter Euckens}

Ausgangspunkt aller Überlegungen zum "positiven" wirtschaftsverfassungsbegriff Euckens und seiner zutreffenden Einordnung ist die Unterscheidung in "gesetzte Ordnungen" und "gewachsene Ordnungen"839. Diese Unterscheidung führt nochmals kurz zurück in grundsätzliche Überlegungen wirtschaftlicher Art.

Die wirtschaft der industrialisierten staaten der Neuzeit ist aufgrund ihrer komplexen struktur und ihrer "ins unabsehbar Große" gewachsenen Lenkungsproblematik "als ein Ganzes" ordnungsbedürftig ${ }^{840}$. Fallweise Eingriffe in diesen dyna- 
mischen Proze $\beta$ machen keinen Sinn, solange sie sich nicht einem "Gesamtplan" fügen, in dem die ordnende ratio zur Geltung kommt ${ }^{841}$.

Vor jeder wirtschaftspolitischen Einzelmaßnahme muß sich der staat deshalb im klaren darüber sein, welche "Wirtschaftsverfassung" es zu verwirklichen gilt, d.h. welcher Ordnungsmechanismus in Gang $z u$ setzen ist. Der Wille, bestimmte gesamtwirtschaftliche ordnungszusammenhänge zu verwirklichen, erfordert die "Gesamtentscheidung über die ordnung des Wirtschaftslebens eines Gemeinwesens". Diese "Idee einer Wirtschaftsverfassung", die die "Spielregeln" einer bewußt gesetzten Ordnung zur Geltung bringt, hat sich an den Ergebnissen der wissenschaftlichen Morphologie zu orientieren, die ihr die denkbaren Möglichkeiten aufzeigt ${ }^{842}$. Niemals kann es für Eucken deshalb in diesem Zusammenhang nur darum gehen, "durch Normen und Urteile die bereits vorhandene wirtschaftsordnung umzuformen"843.

Die Basis für die Verwirklichung der "Idee der Wirtschaftsverfassung" hat Eucken durch seine Grundlegung der Nationalökonomie geschaffen, deren Ergebnis bekannt ist: Die Zahl der möglichen ordnungsalternativen ist gering, genau genommen reduziert sie sich auf das rigide Entweder-oder der konstitutiven ordnungsformen. Es bleibt nur die wahl zwischen der zentralen Leitung des Wirtschaftsprozesses und der verkehrswirtschaftlichen Lenkungsmethode. Eine Vermengung beider ordnungsformen, ein "dilatorischer Formelkompromiß" im Sinne C. Schmitts, ist auch für Eucken nicht denkbar. Die Gesamtentscheidung, die aus der zur Verfügung stehenden, begrenzten Zahl der Ordnungsformen die "Auslese" trifft, darf nicht spekulativ sein, sondern sie muß realistisch getroffen werden ${ }^{844}$.

Es gilt auch für Eucken, daß derjenige, der Fragen über die ordnung der Wirtschaft und die Gestaltung der Wirtschaftsformen aufwirft, diese Fragen abschließend entscheiden können muß. Maßstab der Entscheidung ist die brauchbare Wirtschaftsverfassung, d.h. diejenige "funktionsfähige und men- 
schenwürdige ordnung, die dem Wesen der Natur des Menschen und den Dingen allgemein entspricht" ${ }^{845}$. Diese ordnung ist bekannt. Es ist die des Wettbewerbs.

Der aus der Erkenntnis der Wettbewerbsordnung als vorgefundener werthafter Naturordnung abgeleitete Verwirklichungsanspruch einerseits sowie die aus der Erkenntnis mangelnder Selbstrealisierung dieser ordnung andererseits von Eucken gefolgerte faktische Herstellungsproblematik münden in die Forderung nach einer "positiven Wirtschaftsverfassungspolitik", deren ziel die Durchsetzung der "Marktform der vollständigen Konkurrenz" 146 ist. Das Problem der Umsetzung in den "ordre positif" 847 , bei c. Schmitt durch die (zumindest theoretisch) trennscharfe Abschichtung von "positiver" Verfassung und Verfassungsgesetz gekennzeichnet, wird bei Eucken nicht in einer dem "dezisionistischen Vorbild" entsprechenden Art gelöst ${ }^{848}$.

Die Wirtschaftsverfassung als singulärer Akt des Ordungsstiftens, der zur Aufgabe hat, einen im sinne eines bestimmten Wertmaßstabes als optimal erkannten, wirtschaftstheoretischen Idealtypus in die Wirklichkeit zu implantieren und damit ein bestimmtes "Ganzes" für das Gemeinwesen verbindlich zu machen, ist bei Eucken nicht mehr die getrennte und vorgängige Entscheidung ${ }^{849}$, die als unantastbare Größe alles weitere staatliche Handeln bestimmt. Zwar ist es auch bei ihm der unabhängige politische wille, der die Entscheidung für die Wettbewerbsordnung trifft ${ }^{850}$. Dieser entscheidende wille bedient sich jedoch ausschließlich und ohne verkomplizierende Abschichtung in "positive" Verfassung und Verfassungsgesetz des Rechts als ordnungsgestaltender Potenz. w. Schluep hat diesen Vorgang treffend beschrieben, als er von der Wirtschaftsverfassung als "Verrechtlichung des Koordinationssystems durch Normierung des politischen Grundentscheids" sprach ${ }^{851}$.

Ist die "Gesamtentscheidung für eine Wirtschaftsverfassung des Wettbewerbs" 852 gefallen, ist der "Wettbewerb als Grund- 
prinzip der Wirtschaftsverfassung" 853 und sind die mit seiner Verwirklichung verbundenen modelltheoretischen Erkenntnisse insgesamt zu normieren ${ }^{854}$. Es geht Eucken um nicht mehr und nicht weniger, als das funktionsfähige Preissystem vollständiger Konkurrenz zum "wirtschaftsverfassungsrechtlichen Grundprinzip" zu erheben ${ }^{855}$. Damit erhält der ordnungsplan Euckens und bekommen seine wirtschaftlichen ordnungsvorstellungen Rechtsqualität ${ }^{856}$. Wie H. Ehmke zutreffend festgestellt hat, geht bei Eucken damit die "Frage der 'Positivierung' der 'Wirtschaftsverfassung' (...) in ihre Verrechtlichung über" 857 .

Die durch die Gesamtentscheidung bestimmte ordnung wird durch das Recht "gesetzt" und "ein integrierender Bestandteil der Rechtsverfassung"858, die sich ihrerseits der rezipierten ordnung zu öffnen hat.

Es erscheint unter diesen Voraussetzungen nicht angebracht, Eucken zu unterstellen, er habe das "Verwirklichungsproblem" durch die "Übernahme des dezisionistischen Verfassungsbegriffes" C. Schmitts zu lösen versucht ${ }^{859}$. Die nicht-normative politische Gesamtentscheidung Schmittscher Denkart ist Ausdruck des politischen Willens, der, mit entsprechender Macht und Autorität ausgestattet, die konkrete Gesamtentscheidung über Art und Form der politischen Existenz trifft und die Existenz der politischen Einheit im Ganzen bestimmt ${ }^{860}$. Demgegenüber hat die "wirtschaftsverfassungsrechtliche Gesamtentscheidung"861 Euckenscher Prägung lediglich die Aufgabe, die ordnung des Wirtschaftslebens als eines von mehreren Teilbereichen des Gemeinwesens normativ zu fixieren. Versteht man Euckens Postulat der wirtschaftsverfassungsrechtlichen Gesamtentscheidung in diesem sinne als Auftrag zur Verfassungsgebung im normativen sinne mit dem ziel der ordnung der Wirtschaft, so bestätigt sich $w$. Webers Annahme, daß die "Anlehnung an das Gedankengut von C. Schmitt (...) ganz oberflächlicher, terminologischer Art" ist ${ }^{862}$. Man mag Eucken die Rezeption einer solchen Terminologie, die durch 
zwiespältige Inhalte belastet ist, zum Vorwurf machen und darauf hinweisen, daß die übernahme der auch in der Rechtswissenschaft umstrittenen Begrifflichkeiten C. Schmitts erklärungsbedürftig gewesen wäre, um in der Folge MiBverständnisse über den tatsächlich in Anspruch genommenen wirtschaftsverfassungsbegriff $z u$ vermeiden. Denn nur auf der Grundlage solcher Mißverständnisse scheint es denkbar, Eukken eine "unsichere Verwendung" 863 des Verfassungsbegriffs vorzuwerfen. Ohne, daß er das von ihm geplante "Buch über Wirtschaftsverfassung" ${ }^{864}$ noch schreiben und seine diesbezüglichen Vorstellungen weiter konkretisieren konnte, wird anhand der einschlägigen stellungnahmen Euckens, insbesondere in den "Grundsätzen der Wirtschaftspolitik" evident, daß der staat im zusammenhang mit der Verwirklichung der Wettbewerbsordnung gehalten ist, diese bestandssichernd zum Gegenstand der Rechtsverfassung $\mathrm{zu}$ machen. Dogmatische Schwierigkeiten und Unsicherheiten sind insoweit nicht erkennbar.

Die Probleme des Euckenschen Wirtschaftsverfassungsbegriffs liegen tatsächlich in einem gänzlich anderen Bereich, dem der Verwirklichung der institutionalisierten ordnung.

\section{Abschnitt}

Die Verwirklichung der Entscheidung

\section{A. Die konstituierenden Prinzipien der wettbewerbsordnung}

Die institutionelle Garantie des Wettbewerbs durch Anerkennung und Aufnahme in die Rechtsverfassung ${ }^{865}$ mag den Sanktionscharakter der eingerichteten ordnung dadurch zur Folge haben, daß die Wettbewerbsordnung mit Hilfe der "institutionalisierenden Potenz der rechtlichen Norm" ${ }^{866}$ zur verbindlichen Veranstaltung und das "wirtschaftsverfassungsrechtliche Grundprinzip" zur verpflichtenden Handlungsanweisung für 
jede "praktische Wirtschafts- und Rechtspolitik" wird, die "in allen Einzelheiten der Gesamtentscheidung für die Wettbewerbsordnung zu entsprechen hat" 867 .

Diese "wirtschaftsverfassungsrechtliche Gesamtentscheidung" durch Institutionalisierung der Wettbewerbsordnung ist indes nur die Grundlage und nicht zugleich die Verwirklichung der ordo-adäquaten Form des Wirtschaftens, die des praktischen Vollzuges und der funktionsfähigen Gestaltung nach dem theoretisch erarbeiteten "Bauplan" bedarf $f^{868}$. Es sind mit anderen Worten diejenigen Bedingungskonstellationen herzustellen, in deren Rahmen sich die Wettbewerbsordnung zu entfalten ver$\operatorname{mag}^{869}$.

Alle Überlegungen $z u$ diesen ordnungsbegründenden "Mitteln", die in ihrer Gesamtheit geeignet sind, "die Gesamtentscheidung in concreto durchzusetzen", zentrieren sich in Euckens Lehre von den "konstituierenden Prinzipien" der Wettbewerbsordnung und deren Ausgestaltung als entscheidungsvollziehende Instrumente ${ }^{870}$. Als für alle "konstituierenden Prinzipien" vor die klammer zu ziehender Grundsatz gilt, daß sie in ihrer "positiven" Ausrichtung in dem durch die Gesamtentscheidung festgelegten Grundprinzip des wirtschaftens "ihren gemeinsamen Mittelpunkt finden" ${ }^{871}$.

Diese Zweckbestimmung macht sie nach Auffassung Euckens zu Teilen der Wirtschaftsverfassung und damit zu Prinzipien der "positiven Wirtschaftsverfassungspolitik"872. Diese Beurteilung sowie die Gemengelage von faktischem und rechtlichem Gehalt des Grundprinzips selbst ${ }^{873}$ legt es nahe, zu prüfen, ob es sich bei den "konstituierenden Prinzipien" der ordnung der wirtschaft tatsächlich um positiv-rechtliche Vorkehrungen zur Verwirklichung der Wettbewerbsordnung handelt.

Den Gedanken einer rechtssatzmäßigen Konkretisierung der Gesamtentscheidung lehnt Eucken scheinbar kurz und bündig $a b$. Der "positive" Sinn und Zweck der "konstituierenden Prinzipien" liege allein in ihrer zusammenwirkenden Kraft, die die Verwirklichung der Wettbewerbsordnung gewährleiste. 
Demnach kann es sich bei ihnen nicht um rechtsdogmatische und "nicht um naturrechtliche Prinzipien" handeln ${ }^{874}$. Einzelne Grundsätze wie die Vertragsfreiheit, die (zivilrechtliche) Haftung oder das Privateigentum mögen, so Eucken "von Philosophen und Rechtsdenkern auch als reine Rechtsprinzipien entwickelt worden" sein, "etwa als Prinzipien des Naturrechts"1775. Infolge ihrer teleologischen Ausrichtung kann diese Ableitung für seine "konstituierenden Prinzipien" jedoch keine Gültigkeit besitzen. "Zum Beispiel wird die Forderung, Privateigentum herzustellen, vielfach aus der Natur des Menschen deduziert und als ein Gebot des Naturrechts begründet. - Hier geschieht dies nicht"876. Damit scheinen die "konstituierenden Prinzipien" Euckens auf den ersten Blick der Rechtssphäre entzogen ${ }^{877}$. Dieser erste Eindruck täuscht indes, denn Eucken negiert zwar ihren Charakter als "reine" Rechtsgrundsätze, bezeichnet sie jedoch im Zusammenhang mit ihrer Darstellung im einzelnen als "Rechtsinstitute" und spricht vom "Recht auf Vertragsfreiheit" oder der rechtlichen "Institution des Privateigentums".

Um Aufschluß über die nähere Ausgestaltung der "konstituierenden Prinzipien", ihren tatsächlichen Charakter und das Maß der "Rechtsabweichung" zu erhalten, sind sie in ihrer Eigenschaft als ordnungsverwirklichende und -vollziehende Faktoren einerseits sowie in ihrer von Eucken interpretierten Ausformung als reine Rechtsprinzipien andererseits darzustellen und voneinander abzuheben.

\section{B. Natur und struktur der konstituierenden Prinzipien}

Die rechtliche "Institution des Privateigentums" ebenso wie das "Recht auf Vertragsfreiheit" und das "Rechtsinstitut der Haftung" sind unentbehrlich für den Aufbau einer Wettbewerbsordnung ${ }^{878}$. 
Allerdings weist Eucken in diesem Zusammenhang auf die Fragwürdigkeit eines Ansatzes hin, der allein das Recht und "reine Rechtsprinzipien" als ordnungskonstituierende Faktoren in die pflicht nimmt. Es mag insoweit der abermalige Hinweis auf seine Kritik der Wirtschaftsverfassung des liberalen Rechtsstaates genügen ${ }^{879}$, die die Mängel einer Verfassungskonzeption aufgedeckt hat, die durch die bloßen Garantien eines einfachen systems natürlicher, individueller Freiheiten die gute ordnung der Wirtschaft einzurichten gedachte. In stringenter Anwendung der insoweit gewonnenen Einsichten in die wirkungsweise des Rechts entwirft Eucken den Plan für das heikle Ineinandergreifen von normativen Bestimmungsgründen der wirtschaft und vornormativen Sachgesetzlichkeiten.

Daß die "reinen Rechtsprinzipien" als gestaltbestimmende Faktoren der wirtschaftsordnung untauglich sind, lag nach seiner Auffassung an ihrem Inhalt als liberale Freiheitsrechte. Einerseits als ordnungskonstituierende Einrichtungen gedacht, hatte die struktur der Freiheitsrechte als subjektive Abwehrrechte mit dem Anspruch auf Unterlassung von Eingriffen in die individuelle Rechts- und Freiheitssphäre das intendierte ordnungsprogramm nicht fixieren können. Freiheit, verstanden als individuelle willkür, führte zur Ausbildung sozialer Machtkörper die das Gleichgewicht der privaten Freiheitsrechte störten bzw. ein solches Gleichgewicht erst gar nicht zur Entstehung kommen ließen. Dieses Verständnis rechtlicher Freiheit als individueller willkür und als eine ihrem Inhalt nach nicht begrenzte Handlungsmöglichkeit aufgrund individueller Zwecksetzung ließ sich nur vor dem Hintergrund einer wirtschaftstheorie rechtfertigen, die annahm, "im Rahmen des Rechts" 880 werden sich per se eine zureichende wirtschaftsordnung schon deshalb entwickeln, weil die eingeräumten Handlungsbefugnisse in sozial verträglichem Maße und vernunftgeleitet sowie kompromißbereit genutzt werden würden. Nachdem Eucken diese Auffassung als liberale Utopie entlarvt hatte, fielen auch die liberalen Freiheitsrechte dem Zweifel anheim. "Abstrakte Freiheits- 
rechte sind wichtig" ${ }^{881}$, ihr Gebrauch darf jedoch ihren wirtschaftlichen Zweck nicht konterkarieren.

Damit stellt sich für Eucken die Frage, ob und gegebenenfalls in welcher Form die von ihm grundsätzlich bejahte Idee der sicherung individueller Freiheit durch Rechtsgarantien mit deren zweckbestimmtem Einsatz im Rahmen der Verwirklichung einer bestimmten Ordnungsidee in Einklang zu bringen ist.

Euckens Problemlösung greift auf überlegungen zurück, die er im Zusammenhang mit der Darstellung seines Freiheitsbegriffes angestellt hatte ${ }^{882}$. Es ist die Einsicht, daß Freiheit und ordnung keine Gegensätze, sondern aufeinander bezogen und einander bedingend sind ${ }^{883}$. Damit ist Freiheit und sind die Freiheitsrechte in ihrem Inhalt bestimmt und definiert durch die jeweilige ordnung, in deren Rahmen sie zur Ausübung kommen. Für den Bereich der Wirtschaft bedeutet dies: "Die moderne Freiheitsfrage hängt mit der Lenkung des modernen Wirtschaftsprozesses aufs engste zusammen"884. Die (Wert-) Relativität des liberalen Freiheitsbegriffes wird beseitigt durch dessen Anreicherung mit "wirtschaftlichen ordnungstatsachen", die sich zugleich als diejenigen "Vorgegebenheiten" darstellen, an denen Freiheit ihre schranken und ihren "Widerstand" findet ${ }^{885}$.

Das Wesen der Freiheit besteht demzufolge (nur) "gerade darin, daß sie dem Gesetz der Dinge sein Recht läßt und sich demnach als das, was sie ist, behauptet. Dadurch unterscheidet sich Freiheit von Willkür"886. Da sich nach Eucken das "Gesetz der Dinge" allein in den Sachgesetzlichkeiten des Wettbewerbs manifestiert, bedeutet dies die inhaltliche Bestimmung des Freiheitsbegriffs durch die Gesetze des Marktes, denn "wenn der Markt herrschen soll, dann darf man sich auch nicht weigern, sich ihm anzupassen"887. Damit sind die Voraussetzungen geschaffen, denenzufolge die freie Betätigung des einzelnen durch die Freiheitssphäre des anderen begrenzt und solchermaßen im Rahmen der vorgegebenen ordnung die Freiheiten ins Gleichgewicht gelangen. 
Für die Natur der "konstituierenden Prinzipien", die originär als Rechtsprinzipien entwickelt wurden, bedeutet diese Erkenntnis, daß sie nach Inhalt und Funktionsweise an die durch die Gesamtentscheidung gesetzte ordnung des Wettbewerbs gekoppelt und nur im Rahmen einer gesamtwirtschaftiichen Rationalität verständlich sind und wirksam sein können $^{888}$. Das von Eucken ausgegebene Motto, "die Rechtsordnung als Wirtschaftsverfassung $\mathrm{zu}$ begreifen und $\mathrm{zu}$ formen" ${ }^{889}$, bewirkt im Hinblick auf die als "konstituierende Prinzipien" in die Verwirklichung der Wettbewerbsordnung involvierten Freiheitsrechte, daß sie ihren "eigentlichen" und das heißt "volkswirtschaftlichen sinn" 890 durch die $z$ u verwirklichende ordnung selbst vermittelt erhalten, wodurch sie die gesuchten "ökonomisch und sozial brauchbaren Instrument(e) des ordnungsaufbaus" werden ${ }^{891}$.

Einerseits als Rechtsgarantien konzipiert, die dem einzelnen wohl auch nach Ansicht Euckens nach wie vor grundsätzlich individuelle Handlungsfreiheit gewährleisten sollen, wird diese Freiheit durch Ausübungsschranken eingeengt, die sich aus dem volkswirtschaftlichen sinn und zweck der "konstituierenden Prinzipien", das heißt aber aus dem Grundprinzip selbst ergeben, das dem Recht als BezugsgröBe vorausliegt und es in seiner materiellen Bedeutung abschließend bestimmt ${ }^{892}$.

Diese Funktionalisierung von Recht und Freiheit ${ }^{893}$ mit dem ziel der Verwirklichung der ordnung der Wirtschaft wirft neben rechtspraktischen und rechtssystematischen auch - von Eucken selbst angesprochene $e^{894}$ - rechtsdogmatische Probleme auf, die nachfolgend im Zusammenhang mit der Frage, ob die Überlegungen Euckens zur Institutionalisierung der wirtschaftsverfassung und zur Natur der "konstituierenden Prinzipien" als Ansätze einer eigenständigen Rechts- und Verfassungstheorie begriffen werden können, aufzunehmen und abzuhandeln sind. 


\section{Abschnitt}

\section{Ansätze einer Rechts- und Verfassungstheorie bei walter Eucken}

Trotz aller (verbalen) Vorbehalte gegen das Recht und die "reinen Rechtsprinzipien" ist auch im Rahmen der ordnungspolitischen Konzeption Euckens wirtschaften nur als rechtlich geregelter und durch den sichernden charakter der Rechtsnorm geschützter ProzeB denkbar, wobei jedoch, wie im einzelnen gezeigt, das Recht infolge seiner zweckrationalen Begründung und Ausrichtung nur instrumentalen Charakter haben kann.

Diese Kausalitäten lassen sich prägnant durch das Begriffspaar von Form und Inhalt beschreiben, denn das Recht gibt in der Euckenschen Konzeption die Form ab, die den wirtschaftlichen stoff aufzunehmen hat. G. Schmölders hat dieses $\mathrm{Zu}-$ sammenspiel präzise formuliert ${ }^{895}$ und Eucken hat dessen Darstellung zustimmend in den "Grundlagen der Nationalökonomie" zitiert ${ }^{896}$. Danach ist wirtschaftskonstituierendes Recht nach seinem materialen Gehalt im wesentlichen durch diejenigen Vorgaben gekennzeichnet, die ihm von seiten der wirtschaftspolitik gemacht und die durch die Notwendigkeiten des Regelungssubstrates wirtschaft selbst bestimmt werden ${ }^{897}$.

Das Recht ist demnach bloßer Reflex der zweckmäßigen wirtschaftsordnung und deren sachgesetzlichkeiten unterworfen. Es bildet sich so eine "arteigene Rechtssphäre" ${ }^{898}$ der wirtschaft, die von den "gewohnte(n) Erscheinungsformen des Rechts" abstrahiert ${ }^{899}$ und jedwede rechtsdogmatischen Überlegungen als dem wesen dieses Rechts fremd ablehnt. Nur die spezifischen Methoden der inhaltsbestimmenden Wissenschaft, deren theoretische Erkenntnisse und politische Zielvorgaben sind die anerkannten Bezugsgrößen ${ }^{900}$.

Indem das Recht nach Inhalt und Auslegung durch die im wege der wirtschaftsverfassungsrechtlichen Entscheidung festgelegte ordnung der wirtschaft bestimmt wird, ist das Verhältnis von Recht und wirtschaft in seiner Einseitigkeit bezeichnet. 
Es liegt nahe, hinter dieser Entwicklung und dem Entwurf einer "arteigenen Rechtssphäre" bei Eucken ein Denken zu vermuten, das Recht nicht mehr in positivistischer überhöhung zu akzeptieren bereit ist, sondern das sich, enttäuscht durch die Einsicht in dessen unzureichende ordnungsfixierende Leistung und in das Unvermögen, den einzelnen Normadressaten $\mathrm{zu}$ ordnungsgerechtem Verhalten $\mathrm{zu}$ zwingen, der Rechtssphäre bemächtigt, um diese den ökonomischen Erfordernissen anzupassen und entsprechend den $z u$ verwirklichenden wirtschaftlichen Sachgesetzlichkeiten auszuformen. Eine solche Negation spezifischer Rechtsinhalte bedeutet zum einen, daB die rechtliche Regelung stets nur die Form des sozialen Lebens abgibt und materielles Recht allein durch wirtschaftliche Vorgänge regelhafter Art bestimmt wird. Die instrumentale Konzeption des Rechts und das rein technische Rechtsverständnis Euckens bewirken damit zum anderen, daß das Recht ohne eigenen wert bleibt. Gerechtigkeit wird nicht mehr durch rechtliche Kategorien bestimmt, sondern der Gerechtigkeitsausgleich vollzieht sich nach vorrechtlichen Wertungsmaßstäben, die bestimmt und geprägt sind von der Erkenntnis, daß nur durch die Herstellung einer den ordovorstellungen kongruenten, funktionsfähigen und gleichgewichtigen wirtschaftsordnung Gerechtigkeit vermittelt wird ${ }^{901}$.

Die von Eucken vorgenommene Identifikation der für die Bereiche von Recht und Wirtschaft maßgeblichen Wertungsmaßstäbe, die für das Recht notwendig den Verlust seiner materialen selbständigkeit bewirkt, miBachtet die kategoriale Verschiedenheit der zueinander in Beziehung gesetzten und miteinander verwobenen Bereiche ${ }^{902}$ und läßt insbesondere außer acht, daß Gerechtigkeit als die dem Recht immanente, alles überragende Idee als Folge einer funktionsfähigen wirtschaftsordnung allein nicht zu gewährleisten ist. Das bedeutet nicht, daß der Nationalökonomie Gerechtigkeitsvorstellungen abgesprochen und deren diesbezügliche Erkenntnisse als wertlos verworfen werden. Sinn und zweck des Rechts sind jedoch Größen, die durch spezifisch wirtschaft- 
liche Methoden und Erkenntnisse nicht zu erfassen und $z u$ definieren sind.

L. Raiser hat im einzelnen die Schwierigkeiten einer Position dargelegt, die diese kategoriale Differenzierung übergeht und den primat der Rechtszwecke durch die Idee des ökonomisch Besten zu ersetzen sucht ${ }^{903}$.

Die erste Wirkungsweise des Rechts entspricht derjenigen, die Eucken ausschließlich akzeptiert. Es ist seine Dienstbarmachung zur Realisierung einer bestimmten zielen verpflichteten wirtschaftspolitik. In dieser instrumentalen Ausrichtung kann sich die Funktion des Rechts jedoch nicht erschöpfen, denn jede Rechtsordnung "hat eine ihr eigentümliche Struktur; ihr Aufbau folgt eigenen, nicht von den wirtschaftlichen zielen her bestimmten Regeln"904. Das Recht ist nicht nur Form, die ihrem Inhalt nach ökonomischer Rationalität verpflichtet ist, sondern die "Regelhaftigkeit und Gesetzmäßigkeit allen Rechts" verbürgt die "Gleichmäßigkeit der Beurteilung sozialen Handelns" einerseits und ermöglicht die "Vorhersehbarkeit künftiger Beurteilung" andererseits ${ }^{905}$. $\mathrm{Zu}$ diesem Aspekt der Rechtssicherheit gesellt sich die rechtsstaatliche Komponente in Form der Garantie geregelter Verfahren zur Durchsetzung und Verwirklichung des Rechts. Rechtssicherheit und Rechtsstaatlichkeit "ergeben sich aus dem immanenten Wesen jeder Rechtsordnung. Inr Sinn und Wert läßt sich daher auch nicht mit dem wechselnden Maßstab ökonomischer Zweckmäßigkeit messen"906. Die Aufgabe des Rechts, "inhaltserfülte, materiale Gerechtigkeit" zu gewährleisten, kann als höchste stufe seiner wirkungsweise keinesfalls an der ökonomischen Rationalität orientiert werden, denn auf dieser stufe ist das "Reich autonomer Werte von absolutem Geltungsanspruch" angesiedelt, in deren Namen das Recht zu fordern in der Lage ist, was auch die funktionsfähigste und mit höchster Effizienz arbeitende ordnung der Wirtschaft nicht zustande zu bringen vermag: eine gerechte Sozialordnung ${ }^{907}$. Um dieses ziel zu erreichen, muß sich das Recht Entscheidungen vorbehalten, die materiale Gerech- 
tigkeitsvorstellungen gegen das wirtschaftliche Prinzip durchsetzen, das die Gewähr für die Verwirklichung einer solchen Sozialordnung nicht ohne weiteres ständig und immerzu bietet. Deshalb kann und muß "(v)ereinfachend ausgedrückt, (...) die ZweckmäBigkeit der wirtschaft durch die Gerechtigkeit des Rechts eingeschränkt werden"908.

Vor dem Hintergrund der herrschenden Rechtstheorie, für die stellvertretend die Auffassung L. Raisers entwickelt wurde, mag bereits die Institutionalisierung des gesellschaftlichen Sachverhaltes Wettbewerb in die Rechtsverfassung problembehaftet sein. Der Versuch Euckens, diese institutionalisierte ordnung mit Hilfe eines ausschlieBlich auf ihre Inhalte und ihre Verwirklichungsansprüche zugeschnittenen systems von einzelnen Rechtssätzen zu verwirklichen, muB indes scheitern, da sich das Recht solchen Absichten, soll es als ordnung zwischenmenschlicher Beziehungen unter dem materialen Prinzip der Gerechtigkeit von Bestand sein, nicht beugen darf.

Die von Eucken angestrebte Verwirklichung der Gesamtentscheidung für die Wettbewerbsordnung stößt damit im Recht auf ein ihre Durchsetzung hinderndes Moment. 


\section{CHLU8BBETRACHTUNG}

"Einen Geist kann nichts verletzten, als was ihm die Freiheit raubt, und er beweist die seinige, indem er das Formlose bildet. Nur wo die Masse schwer und gestaltlos herrscht und zwischen unsicheren Grenzen die trüben Umrisse wanken, hat die Furcht ihren Sitz. Jedem Schrecknis (...) ist der Mensch überlegen, sobald er ihm Form zu geben und es in sein objekt zu verwandeln weiß". Das Schiller-zitat, das die "Grundsätze der Wirtschaftspolitik" abschließt ${ }^{909}$, bezeichnet programmatisch Grundhaltung und Atmosphäre, aus denen heraus sich Eucken zu seiner gesamtheitlichen Betrachtung menschlicher ordnungen veranlaßt sah. Es war das Gefühl, in "lähmender Enge und unentrinnbarer Verhaftung in Schicksal oder Pseudowerte" 1910 den Problemen der Zeit hilflos ausgeliefert zu sein, es war der Eindruck, mit ansehen zu müssen, wie in völliger Verkennung der tatsächlichen wirtschaftlichen und gesellschaftlichen Probleme durch ein einzelfallbezogenes, grundsatzloses Kurieren an Symptomen wissenschaft und Politik in ein auswegloses Dilemma gerieten und es war die zeit der "Scharlatane und Volksverführer"911, deren simplifizierende Reduktion der komplexen wirtschaftlichen Probleme auf einfache, eingängige Begrifflichkeiten die Massen in ihren Bann schlugen, die Eucken dazu drängten, seiner "inneren Überzeugung durch das Medium der Worte"1912 Ausdruck zu verleihen und ein wissenschaftliches Gesamtwerk vorzulegen, dessen Zweck es war, dem "Schrecknis" und der "geistesgeschichtlichen Krisis (...), deren Folgen sich - über den geistigen Bereich hinaus - in schweren Erschütterungen des politischen und sozialen Gefüges" manifestierten ${ }^{913}$, Herr zu werden.

Die Anamnese der Krisis hatte für Eucken offenbart, daß infolge der durch die Aufklärung bewirkten Zerstörung bislang fraglos akzeptierter gesellschaftlicher Werte der sinnzusammenhang des Lebens verloren gegangen war und die politischen 
Lehren die sozial entwurzelten Massen in eine scheinbar ausweglose situation hineingeführt hatten.

Diese Erkenntnis bewog Eucken zu dem Versuch, Wissenschaft und Politik durch eine geistige Reformation an Haupt und Gliedern in den stand zu versetzen, "über die zerstörung der Werte hinaus" im Rahmen einer funktionsfähigen und menschenwürdigen Ordnung "zu deren Neuaufbau" $z u$ kommen"14. Die Verwirklichung dieses Vorhabens und der Wunsch nach einer Alternative zu den bestehenden chaotischen, anarchischen und kollektivistischen (Un) ordnungen hatte als conditio sine qua non zum ersten einen "bestimmte(n) Grad von bewußter Verfügbarkeit über die Sozialordnung" zur Voraussetzung ${ }^{915}$. Zum anderen war auch der Versuch Euckens, die Krisis zu überwinden und ordnung in Wirtschaft, staat und Gesellschaft zu schaffen - wie jeder andere Versuch dieser Art - mit der Legitimationsproblematik und damit der Frage konfrontiert, warum gerade seine ordnungsvorstellungen und nicht irgendwelche anderen Konzeptionen Anspruch auf Geltung und Verwirklichung erheben.

Den Nachweis für den überlegenen Durchsetzungsanspruch der von ihm als richtig und gut erkannten sozialordnung und damit verbunden dem Umstand, daß allein die wissenschaft im Stile Euckens "als Lebensmacht von bildender und gestaltender Kraft" für die "Bildung des Menschen und zur Neuschaffung der wirklichkeit" geeignet ist ${ }^{916}$, versuchte Eucken mit Hilfe seines korrigierten rationalistischen Verfahrens zu führen, das ihm als der die Legitimationsproblematik erledigende Erkenntnisprozeß galt.

In den durch isolierende Abstraktion in beachtenswerter, wenngleich die faktischen zusammenhänge auszehrender und verkürzender stringenz aus der geschichtlichen vielfalt des wirtschaftens hervorgehobenen, konstitutiven Grundformen glaubte Eucken, die box of tools gewonnen zu haben, die es ihm erlaubte, abschließend zwischen "versagende $(n)$ und ungerechte(n) Ordnungen" einerseits sowie "der Wesensordnung oder Naturordnung" andererseits zu unterscheiden ${ }^{917}$. 
Der Weg aus der Krise durch die Reintegration des einzelnen in eine "umfassende geistige Lebensordnung"918 konnte für Eucken nur im Zeichen des ordo stehen. Nur diejenige ordnung, in der der "architektonische Gestaltungsplan der Welt" zum Ausdruck kommt und "in der Maß und Gleichgewicht" herrschen, vermag die "Absurdität der konkreten Zustände" dauerhaft zu überwinden ${ }^{919}$. Diese ordnung, die, anders als die aus den Fugen geratenen faktischen ordnungen, "der Vernunft oder der Natur des Menschen und der Dinge entspricht" und die als ordre naturel Leitbild für die bislang fehlende "funktionsfähige und menschenwürdige ordnung der wirtschaft, der Gesellschaft, des Rechts und des staates" ist ${ }^{920}$, kann, diese Erkenntnis hatte Eucken in einer eingehenden Kompatibilitätsprüfung der von ihm isolierten Grundformen des wirtschaftens gewonnen, nur die Wettbewerbsordnung sein. Damit ist das Fundament gelegt. Das Gesetz des Wettbewerbes muß herrschen und gegen alle widerstände durchgesetzt werden. Denn: "Wenn der Markt herrschen soll, dann darf man sich auch nicht weigern, sich ihm anzupassen. Man darf Unsicherheit nicht dadurch bekämpfen wollen, daß man neue Unsicherheit schafft"921. Sobald die Gesamtentscheidung für die Wettbewerbsordnung gefallen ist, "muB nach ihr konsequent bis in alle Einzelheiten hinein gehandelt werden (...) Ein solches konsequentes Handeln aus der Erfahrung heraus ist das Gegenteil von Doktrinarismus. Doktrinär handeln heißt: Gegen die Lehre der Erfahrung seinen Kopf durchsetzen. Konsequentes Handeln aber ist zwecksicheres Handeln. Nur in ihm liegt die Voraussetzung für den Erfolg"922.

Dieser absolute Geltungs- und Verwirklichungsanspruch der Wettbewerbsordnung hat weitreichende Konsequenzen. Sie darf als Absolutum von den Teilnehmern am wirtschaftsprozeß nicht angetastet werden ${ }^{923}$. Indem sie sich so der individuellen Verfügbarkeit entzieht, wird sie unproblematisch, weil fortan nicht mehr mit der Frage nach dem Grund ihrer Geltung belastet. Durch die Gesamtentscheidung für die Wettbewerbsord- 
nung und deren Verwirklichung wird endgültig und abschlieBend geklärt, daß "das, was ist, auch sein soll"924. Das solchermaßen sakrosankt gestellte, von ökonomischen Sachgesetzlichkeiten geprägte Weltbild Euckens wird als "unantastbarer Fixpunkt"925 zur Grundlage allen Denkens und Handelns. Dem "freien Schweifen des Geistes" bleibt kein Raum ${ }^{926}$.

Die Wettbewerbsordnung ist demnach keine nur vorläufige ordnung und als solche Bestandteil einer pluralistischen, interessendifferenzierten Gesellschaft, in der sich die für das politische Handeln maßgeblichen ziel- und Wertbestimmungen aus einem alle Bürger integrierenden, offenen Proze $\beta$ der Konkurrenz der Konzeptionen, durch Konflikt und KompromiB ${ }^{927}$, kurz: durch Versuch und Irrtum ergeben, sondern als die vorgegebene natürliche seinsordnung ist sie - einmal eingerichtet - der archimedische Punkt, um den sich alles dreht und an dem sich alles auszurichten hat. Diese Bindungswirkung hat zur Folge, daß das gesellschaftlich zulässige Konfliktpotential auf das Laissez-faire innerhalb des ordnungsrahmens beschränkt bleibt ${ }^{228}$. Nur insoweit besteht die Möglichkeit der freien Entfaltung der spontanen Kräfte und des freien wirkens der Einzelinteressen, nur hier können und dürfen individuelle wünsche und Vorstellungen als "Motoren des Wirtschaftsprozesses" wirksam sein"29. Dies führt dazu, daß geschichtliche Veränderungen und neue soziale Lagen ohne Beachtung bleiben, denn es wird zwar gewirtschaftet, aber durch die systemimmanente Beschränkung des Konflikts gibt es keine Geschichte mehr, die "als "Ganzes (...) vielleicht keinen sinn, Fortschritt, wirkliche 'Entwicklung' (zeigt) aber wenn diese Kategorien nicht die je einander folgenden Momente verknüpfen, so gäbe es keine Geschichte, sondern nur ein Geschehen"930. Nur das "Absolute" als Ausgangspunkt läßt es $z u$, daß Geschichte, in der "über die Zukunft erst entschieden wird" und in der demgemäß grundsätzliche Freiheit und gesellschaftliche Zuständigkeit für die ordnungsgestaltung besteht, bei Eucken nach der Entscheidung für eine 
bestimmte ordnung aufgehoben ist" ${ }^{931}$. Auch bei ihm "gab es eine Geschichte, aber es gibt keine mehr"932, der Wirtschaftsproze $\beta$ wird zum mit jeweils gleichem Ergebnis beliebig reproduzierbaren Geschehen, zur "Nichtgeschichte""933. Die stellung des einzelnen in diesem Prozeß ist zwangsläufig vorgegeben ${ }^{934}$. Er ist "in der Regel nur ein Atom. Er soll es sein, denn nur, wo es der Fall ist, kann die Naturordnung funktionieren"935.

Diese Kompromißlosigkeit des wirtschaftlichen ordnungswollens bleibt nicht ohne Auswirkungen auf die Teilordnung des Staates, den Eucken nach anfänglichem Zögern und Zweifeln als ordnende Potenz bestimmt. Dieser staat, der als "Hüter der Wettbewerbsordnung" aufzutreten hat, muß sich vom demokratischen Erfordernis der Zustimmung einer gegenwärtigen Mehrheit oder allgemeiner: von plebiszitären Rechtfertigungsmodellen lösen, um die ordnung der wirtschaft durch Wettbewerb gegen die latent heterogenen gesellschaftlichen Zweck- und Zielvorstellungen durchsetzen zu können. Dazu bedarf es an der spitze des staates einer entschlossenen staatsführung, die als sachverständige, intellektuelle Instanz die von Eucken postulierten staatspolitischen Grundsätze der Wirtschaftspolitik in die Tat umsetzt.

Diese von Eucken entworfene staatsdoktrin, die einer durch einen bestimmten Wissens- und Erkenntnisstand ausgezeichneten Schicht von Wissenschaftler-Politikern die Führung aus der Krise und den Neuaufbau von staat, wirtschaft und Gesellschaft überantwortet, bedarf $\mathrm{zu}$ ihrer Verwirklichung einer bestimmten geschichtlichen situation.

"Vielleicht kommt der Menschheit der historische Zufall zur Hilfe, ähnlich wie es im ausgehenden Altertum der Fall war. Damals ist der sieg des Christentums in seinem Jahrhunderte dauernden Kampfe dadurch wesentlich erleichtert worden, daß der Kapitalismus des römischen Reiches aus politischen und wirtschaftlichen Gründen zerfiel" ${ }^{936}$.

Diese von Eucken 1926 paradigmatisch beschriebenen Voraussetzungen zur Verwirklichung seiner ordnungsvorstellungen 
sollten keine zwanzig Jahre später Realität werden. Nach der politischen und wirtschaftlichen zerstörung des Deutschen Reiches trat deshalb folgerichtig die von ihm geführte Gruppe als die auf die Krisenbewältigung vorbereitete, entschlossene intellektuelle Instanz ins Rampenlicht und bestimmte den Neuaufbau entscheidend mit ${ }^{937}$.

J. Isensee charakterisiert diesen Vorgang treffend, wenn er darauf hinweist, daß das neue westdeutsche Gemeinwesen "weniger von den Einsichten einer staatslehre als von denen einer Wirtschaftstheorie geprägt" und "weniger vom Wesen des staates als vom Wesen der Gesellschaft her konzipiert worden" sei"

Spätestens jedoch nachdem sich die deutsche staatslehre neu konstituiert hatte und ihre Auffassung zum Verhältnis von staat und Wirtschaft auf der Basis des neu geschaffenen Grundgesetzes vorzutragen vermochte, wurde offenbar, daß das von Eucken entworfene Bild des Staates als "Hüter der Wettbewerbsordnung" den staatsstrukturprinzipien der neuen Verfassung nicht vollständig entsprach. Evident wurde dies im Zusammenhang mit dem streit um die wirtschaftsverfassung des Grundgesetzes. Ohne diesen streit und die in ihm vertretenen Positionen im einzelnen nachzuzeichnen ${ }^{939}$, schälte sich als cantus firmus der jahrzehntelangen Diskussion heraus, daß das Grundgesetz eine bestimmte wirtschafts- und Sozialordnung nicht festlegt und gewährleistet. Diese wirtschaftspolitische Neutralität garantiert die offenheit des politischen Prozesses mit der Folge, daß sich der Übergang von ein für alle Mal vorgegebenen $z u$ veränderbaren und in ihrer Konzeption ständig neu aufgegebenen ordnungen vollzogen hat, wobei indes stets die grundsätzlichen Wertentscheidungen der Verfassung, insbesondere die Freiheitsrechte sowie die Staatsstrukturprinzipien beachtlich bleiben ${ }^{940}$. Der Idealtypus, der vorgibt, die Bedingungszusammenhänge der Wirklichkeit richtig wiederzugeben und der aus diesem Grund Anspruch auf Allgemeingültigkeit erhebt, gehört nicht zum verfassungsrechtlichen "Gerüst des Unbezweifelten"941. Als gesicher- 
te Erkenntnis kann insoweit lediglich gelten, daß jede situation établie stets nur eine vorläufige ist, um deren Bestand im widerstreit der divergierenden gesellschaftlichen Interessen gerungen werden $\mathrm{mu}^{942}$. Die essentiellen Fragen des Gemeinwesens und damit auch diejenige nach der organisation der wirtschaft müssen immer wieder neu gestellt werden können und dürfen durch eine Dezision für ein bestimmtes Modell nicht präkludiert sein. Dies vorausgeschickt wird deutlich, daß der Versuch Euckens, die Verfassung als einen Wertkodex zu gestalten, mit dessen Hilfe "ein system dogmatischer Wahrheiten über diese Welt" von einigen wenigen Wissenden verwaltet wird ${ }^{943}$, grundlegenden verfassungsrechtlichen strukturprinzipien wie der Mitwirkung des einzelnen bei der Bildung des Staatswillens sowie der Kontrolle seiner Ausübung, dem Wechsel von Mehrheit und Minderheit und der - vorausgesetzten - Bereitschaft, sich einem Mehrheitsentscheid zu beugen $^{944}$, widerspricht.

Als Ergebnis bleibt festzuhalten, daß Euckens Desiderat, wirtschaft und staat $z u$ seinem objekt $z u$ machen und nach seinem Weltbild zu formen, Anklänge an ein (neo-)absolutistisches Denken erkennen $1 a ̈ B t^{945}$. Wenngleich seine ideelle Ambiance aufgeklärt wirkt, begibt sich das Euckensche Denken damit in die Gefahr, Prinzipien verhaftet zu bleiben, die bereits die erste Epoche des Staatsbildungsprozesses der Neuzeit geprägt haben.

Der Versuch der "zukünftige(n) Rückgewinnung eines vergangenen Zustandes" 946 steht aber weder mit der geltenden Verfassung in Einklang noch ist er unter den Bedingungen der evolutionären Industriegesellschaft realistisch. Nur die demokratische Verfassung vermag der Dynamik und dem ständigen Wechsel in wirtschaft und Gesellschaft durch ein entsprechendes Wertberücksichtigungspotential gerecht zu werden.

Eucken hatte die Idee des ordo entworfen und die zu ihrer verwirklichung notwendigen Bedingungen in staat, wirtschaft 
und Gesellschaft dargelegt, um sie der "totalitären Konzeption entgegensetzen" zu können" ${ }^{947}$. Sie war seine Antwort auf eine bestimmte geschichtliche situation, die durch den Verfall der Weimarer Republik und damit einhergehend des Kapitalismus gekennzeichnet war. Das Grundgesetz hat diese geschichtlichen Erfahrungen um die der nationalsozialistischen Gewaltherrschaft erweitert und auf die Frage nach dem ordo die demokratische Antwort gegeben, die jeder anderen Konzeption, mag deren Anliegen freiheitlich und mögen ihre Motive unbestritten redlich sein, die Anerkennung versagt.

Euckens Idee des ordo ist jedoch auch unter dem Grundgesetz maßgeblich, insoweit sie "für die Sache der Freiheit" 948 und gegen die "Vergewaltigung des Menschen" 949 kämpft. Unter diesem Aspekt werden Euckens Überlegungen aktuell bleiben müssen. 


\section{Anmerkungen}

1) Preiser, E., Walter Eucken in memoriam, Jahrbücher für Nationalökonomie und Statistik, Bd. 162 (1950), S. 241.

2) Welter, E., Walter Eucken (1891-1950), in: Geschichte der Volkswirtschaftslehre, hrsg. v. A. Montaner, S. $297 \mathrm{ff}$. (301).

3) Welter, E., aao. (Anm. 2), S. 297.

4) Dazu exemplarisch das berühmte ofen-Beispiel in den Grundlagen, S. $1 f$.

5) Böhm, F., Die Idee des ordo im Denken Walter Euckens, Ordo III (1950), S. XVff. (XLf.).

6) Salin, E., Nachwort, in: Eucken, W., Grundsätze, S. 382 .

7) Böhm, F., aaO. (Anm. 5), S. XXXIX.

8) Zur "Freiburger Schule", benannt nach dem jahrzehntelangen Wirkungsort Euckens, statt vieler Dürr, E.-W., Wesen und Ziele des ordo-Liberalismus, S. $1 \mathrm{ff}$.

9) Eucken, W., Grundlagen, S. XI.

10) Dafür mag ein Artikel des Nachrichtenmagazins "Der Spiegel" (39. Jahrgang, $\mathrm{Nr} .3$ vom 14. Januar 1985) über den beamteten staatssekretär im Wirtschaftsministerium otto Schlecht als Beispiel dienen. "Der spiegel" schreibt: "Schlecht hatte nicht nur Glück mit seinen Ministern. Zuerst - und viel wichtiger - hatte er Glück mit seinem Lehrmeister. Denn was der Doktor der Volkswirtschaft otto schlecht (...) während seines studiums in Freiburg beim Nestor der ordo-Liberalen, bei Walter Eucken, gelernt hat, das hält ein ganzes Leben".

11) In dieser familiär-wissenschaftlichen Vater-Sohn-Beziehung ist sicherlich ein Grund für die originalität des Werkes von Eucken zu suchen. E. Welter aaO. (Anm. 2), S. 298, empfiehlt in diesem Zusammenhang die Lebenserinnerungen des Vaters Rudolf Eucken $\mathrm{zu}$ lesen. Hierzu auch Klüber, F., Wirtschaftsheorie und Wirtschaftsethik im Denken walter Euckens, Jahrbuch des Instituts für Christliche Sozialwissenschaften der Westfälischen wilhelms-Universität Münster, 1966/67, S. 583ff. (587). Eucken selbst bestätigt diesen Einfluß, wenn er sich als Schüler des Vaters bezeichnet (unter dem Pseudonym Kurt Heinrich, Die geistige Krise und der Kapitalismus, Die Tatwelt, Jahrgang II, Heft $1 / 3$ (1926), S. 13ff., wieder abgedruckt in Frankfurter Allgemeine Zeitung vom 31. Januar 1981, Nr. 26, S. 14). 
12) Lutz, F.A., Geleitwort, in: Eucken, w., Grundsätze, S. $x$.

13) Lutz, F.A., aaO. (Anm. 12), S. X.

14) So der Titel des 1939 erschienenen theoretischen Hauptwerkes Walter Euckens.

15) So der Titel des 1952 erschienenen wirtschaftspolitischen Hauptwerkes Walter Euckens.

16) Lutz, F.A., aao. (Anm. 12), S. IX.

17) Eucken, W. , Kapitaltheoretische Untersuchungen, S. 11; ders., Grundlagen, S.1.

18) Eucken, W., Grundlagen, S. 1f., 8, IX.

19) Eucken, W., Kapitaltheoretische Untersuchungen, S. 1; ders., Grundlagen, S. 2 .

20) Berkeley zit. nach Eucken, w., Grundlagen, s. 11.

21) Alle Zitate Eucken, W., Kapitaltheoretische Untersuchungen, S. 1; ders., Grundlagen, S. 224, 11.

22) Eucken, W., Grundlagen, S. 2.

23) Eucken, W. , Grundlagen, S. 27, S. 243 Anm. 1 ("Es ist die Ursünde jeder Erfahrungswissenschaft nicht von den Tatbeständen und nicht von den faktischen problemen auszugehen. Häufig verdrängt das wort die Tatsache, die Analyse von Begriffen die Analyse von Sachverhalten").

24) Eucken, W. , Grundlagen, S. 27, 28.

25) Dieses System von Begriffen, das die Begriffsnationalökonomie auch "Theorie" nennt, hat mit echter theoretischer Forschung an Sachproblemen nach Auffassung Eukkens nichts gemein (Grundlagen, S. 27, 29).

26) Eucken, W., Grundlagen, S. 29.

27) Böhm, F./Großmann-Doerth, H./Eucken, W., Unsere Aufgabe, S. 96 .

28) Eucken, W., Grundlagen, S. $27 \mathrm{ff.,} \mathrm{29,} \mathrm{8.} \mathrm{Die} \mathrm{Art} \mathrm{und}$ Weise des Wechsels dieses Begriffsrahmens wird im weiteren Verlauf der Arbeit noch in einzelnen deutlich werden.

29) Eucken, W., Kapitaltheoretische Untersuchungen, S. 13; ders., Grundlagen, S. 8, 67. 
30) Dazu auch, wenngleich z.T. in anderen Zusammenhängen, Amonn, A., Nationalökonomie und wirtschaftliche wirklichkeit, Jahrbücher für Nationalökonomie und statistik, Bd. 153 (1941), S. 156; Brinkmann, C., Grundlagen der Nationalökonomie. Bemerkungen zu Walter Euckens Buch, Finanzarchiv N.F. Bd. 7 (1940), S. 255; Stackelberg, H. V., Die Grundlagen der Nationalökonomie. Bemerkungen zum gleichnamigen Buch von Walter Eucken, Weltwirtschaftliches Archiv, Bd. 51 (1940 I), S. 245; Schäfer, M., Die logische struktur des Idealtypus bei Max Weber, Walter Eucken und Wilhelm Vershofen, Diss. Nürnberg 1951, S. 45; Jöhr, W.A./Singer, H.W., Die Nationalökonomie im Dienste der Wirtschaftspolitik, S. 19ff.; Weippert, G., Walter Euckens Grundlagen der Nationalökonomie, Zeitschrift für die gesamte staatswissenschaft, Bd. 102 (1942), S. 2 .

31) Eucken, W., Grundlagen, S. IX. "Energische Wendung zu den Fakten, ihre Untersuchung von Grund aus, nicht Weiterspinnen bisheriger Gedanken" sind die Anforderungen (daselbst, s. $\mathrm{x}$ ).

32) Eucken, W., Grundlagen, S. XII. Die Kompatibilität mit seinen "Grundlagen der Nationalökonomie" ist für Eucken der alleinige Maßstab für die Wissenschaftlichkeit einer Lehrmeinung, so daß die Inkommensurabilität mit diesen Grundlagen das Verdikt der Unwissenschaftlichkeit zur Folge hat.

Alle anderen Aspekte einer Lehre müssen auf die neuen Grundlagen hin umgearbeitet werden (Eucken, w., Grundlagen, S. X a.E.). Das damit angesprochene Verhältnis zwischen neuer Lehre und traditioneller Nationalökonomie war ein wesentlicher Ansatzpunkt der Kritik, die Eucken eine "Selbsttäuschung" vorwarf, insofern er verkenne, daß jeder Forscher mit einem durch das studium und den dort vermittelten Lehrinhalten geprägten Vorverständnis an die Bearbeitung wissenschaftlicher Fragestellungen herangehe und daher die Ignoranz der tradierten Meinungen schlicht unmöglich sei (Amonn, A., aao. (Anm. 30), S. 13, 15f., 27f.; Ritschl, H., Wandlungen im objekt und in den Methoden der Volkswirtschaftslehre, Schmollers Jahrbuch für Gesetzgebung, Verwaltung und Volkswirtschaft, 67. Jahrgang (1943 II), S. 404; dazu m.w. Nachw. Nawroth, E.E., Die Sozial- und Wirtschaftsphilosophie des Neoliberalismus, S. 278f.). Diese Kritik verkennt, daß die Erneuerung der Grundlagen (fast) nie ansatzlos geschieht, sondern immer abhängig ist von Erfahrungen und Einsichten, die die "alte" Wissenschaft gewonnen hat. Das ist für Eucken ganz selbstverständlich. "Natürlich müssen wir die überkommene Wissenschaft kennen und verwenden", d.h. man kann sich nicht "so hinstellen... wie die steinzeitmenschen" (Grundlagen, S. IX). Aber wenn die bisherige Wissenschaft zur Lösung der ihr gestellten Probleme untauglich wird, dann darf man "nicht einfach das 
Gegebene weiterführen" - was nicht "Verachtung der großen Leistungen der Vergangenheit" bedeutet (Eucken, W. Grundlagen, S. X, 68), sondern muß Neues schaffen, um dann "im Verlauf der Untersuchung ein richtiges Verhältnis $z u$ den wirklich großen wissenschaftlichen Leistungen der Vergangenheit" zu gewinnen (Eucken, W., Grundlagen, S. 68).

Eine völlig andere Frage, der hier nicht nachgegangen wird, ist, ob das Werk Euckens dem Anspruch der Grundlagenrevision genügt oder ob ihm letztlich nur eine Neuformulierung und substantielle Erweiterung alter Grundlagen gelungen ist. Im letzteren Sinne im Hinblick auf die "Grundlagen der Nationalökonomie" Jöhr, W.A., Walter Euckens Lebenswerk, Kyklos, Vol. IV (1950), S. 266f.; Ruppin, H., Allwissenschaft oder ökonomische Spezialtheorie? Ein aktuelles Problem, Jahrbücher für Nationalökonomie und Statistik, Bd. 156 (1942), S. 106; Amonn, A., aao. (Anm. 30), S. 28; Weippert, G., aaO. (Anm. 30), S. 2; Stackelberg, H. v., aao. (Anm. 30), S. $259 f$.

33) Kuhn, T.S., Die Struktur wissenschaftlicher Revolutionen, S. 89.

34) Kuhn, T.S., aaO. (Anm. 33), S. 25, $37 \mathrm{ff}$.

35) Die programmatische Grundlegung Euckens findet sich bereits in den 1934 erschienenen "Kapitaltheoretischen Untersuchungen" (hier zitiert nach der 2. Auflage 1954) in dem einleitenden Kapitel "Was leistet die nationalökonomische Theorie?". Eucken baut auf diesen tuberlegungen in den "Grundlagen der Nationalökonomie" auf, ohne explizit Bezug auf sie zu nehmen.

36) Eucken, W., Grundlagen, S. 14 ; ähnlich ders. , Die Überwindung des Historismus, S. 204 ; ders., Kapitaltheoretische Untersuchungen, s. 3; ders., Nationalökonomie wozu?, S. 14 .

37) So auch Hesse, G., Staatsaufgaben, S. 220; zur Auseinandersetzung Euckens mit dem Historismus auch Jöhr, W.A., aaO. (Anm. 32), S. $259 \mathrm{ff}$.

38) Eucken, W., Die Überwindung des Historismus, S. 76; ders., Kapitaltheoretische Untersuchungen, S. 4.

39) Eucken, W., Kapitaltheoretische Untersuchungen, S. 4 .

40) Eucken, W., Grundlagen, S. 271; ders., wissenschaft im Stile Schmollers, S. 473.

41) "Was bedingt ist durch geschichtliche Verhältnisse, ist auch in seinem Werte relativ", Dilthey zit. nach Eukken, w., Die Überwindung des Historismus, S. 200. 
42) Eucken, W., Die Überwindung des Historismus, S. 193: Die Historisierung des Wissens, der Vernunft und des Wertens führte zur Anerkennung nur einer absoluten Größe: "Eben das wandelbare Leben".

43) Eucken, W., Die Überwindung des Historismus, S. 196. Dies hatte zur Folge, daß sich die Wissenschaft von jedweden anderen Unternehmungen nicht durch besondere Leistungen abheben konnte.

44) Rudolf Eucken zit. nach Eucken, w., Die Utberwindung des Historismus, S. 192 .

45) Zur Unterscheidung der einzelnen Aspekte des Historismus vgl. Böhm, F./Großmann-Doerth, H./Eucken, W., Unsere Aufgabe, S. $89 \mathrm{ff}$.

46) Eucken, W., Die Überwindung des Historismus, S. 198, 196. Der von Eucken "komponierte" Historismus (so Hesse, G., Staatsaufgaben, S. 221, der unter Verweis auf Laum, B., Entgegnung zu Euckens Aufsatz, Schmollers Jahrbuch für Gesetzgebung, Verwaltung und Volkswirtschaft, 62. Jahrgang (1938 I), S. 216 darauf hinweist, daß es einen festen Begriffsinhalt des "Historismus" nicht gibt) wird dann auch von so gegensätzlichen Personen wie Marx und Dilthey, Nietzsche und Hume, spengler und Heidegger repräsentiert (Eucken, w., Grundsätze, S. 201; ders., Die Überwindung des Historismus, S. 194).

47) So der Titel des Aufsatzes von Eucken, W., in: Weltwirtschaftliches Archiv, Bd. 52 (1940 II), S. $468 \mathrm{ff}$.; dazu auch Böhm, F./Großmann-Doerth, H./Eucken, W., Unsere Aufgabe, S. 92 .

48) "Wer also meint, Schmoller und seine Anhänger seien nicht Gegner, sondern Freunde der 'Theorie' hat recht. Nur muß Klarheit darüber bestehen, daß diese Theorie des Empirismus etwas völlig anderes ist als die Theorie, die notwendig ist, um $\mathrm{zu}$ wissenschaftlicher Erkenntnis zu kommen" (Eucken, W., Grundlagen, S. 36); ders., Die Leistung der deutschen Volkswirtschaftslehre, S. 231: ein "leistungsschwacher Empirismus, dem die Fähigkeit der Analyse fehlt". Zum empirischen Verfahren allgemein vgl. Eucken, W., Kapitaltheoretische Untersuchungen, S. $8 \mathrm{ff}$., $47 \mathrm{ff}$.

49) Eucken, W., Kapitaltheoretische Untersuchungen, S. 47; ders., Grundlagen, S. 230; ders., wissenschaft im stile Schmollers, S. 502 .

50) Husserl, E., Philosophie als strenge wissenschaft, Logos 1911 zit. nach Eucken, w., Grundlagen, S. 245 Anm. 4 (Beginn S. 244). 
"Wir Nationalökonomen fragen also nicht nur, welche Wege unsere Wissenschaft beschritten hat, um die Verknüpfungen der wirtschaftlichen wirklichkeit aufzudekken, sondern wir fragen darüber hinaus, ob ein Weg tatsächlich zum ziel objektiver Wahrheitserfassung führt oder nicht" (Eucken, W., Kapitaltheoretische Untersuchungen, S. 5). Das Verhängnisvolle an der relativistisch-fatalistischen Haltung wird erst vollständig deutlich, wenn ein vorgreifender Blick von der wirtschaftstheorie auf die Wirtschaftspolitik fällt. Weil die Wissenschaft als "Trabant des Lebens" nicht mehr gilt, als andere Meinungen und weil sie den Gesamtzusammenhang nicht durchschaut, ist sie keine "gestaltende Macht" mehr (Böhm, F./Großmann-Doerth, H./Eucken, W. , Unsere Aufgabe, S. 88; Eucken, W., Die Überwindung des Historismus, S. 205). Der Einsatz für eine bestimmte übergeordnete Idee erscheint zwecklos (Böhm, F./ Großmann-Doerth, H./Eucken, W. , Unsere Aufgabe, S. 91), der resignative Rückzug aus der Wirtschaftspolitik ist damit vorprogrammiert. Die Schaffung eines Weltbildes, das den Entwicklungsgesetzlichkeiten und nicht-relativen Wahrheiten eine Absage erteilt, hat damit auch den wirtschaftspolitischen Zweck, die Formen des Wirtschaftens zu beeinflussen. Grundsätzliches Denken dieser Art kumuliert für Eucken in der Wirtschaftsverfassung, der damit ganz offensichtlich eine wesentliche Aufgabe bei der "Bildung des Menschen und der Neuschaffung der Wirklichkeit" (Eucken, W., Die Überwindung des Historismus, S. 198) und damit auf dem Weg zum "wahren Sein" zuzukommen scheint.

51) "Alle Wissenschaften entstehen aus Problemen. Ihre Absichten, Methoden und Ergebnisse können daher nur von ihren Problemen her verstanden werden" (Eucken, W., Nationalökonomie - wozu?, S. 12). Dazu auch Kade, G., Die Verdächtigung der exakten Wirtschaftstheorie. Kritische Bemerkungen zum Aufsatz von F. Ottel, Jahrbücher für Nationalökonomie und Statistik, Bd. 169 (1958), S. 9 .

52) "Das Nebeneinander der einzelnen Erscheinungen durch Entdeckung der Bedingungszusammenhänge in ein Ineinander zu verwandeln" ist die Aufgabe (Eucken, W., Kapitaltheoretische Untersuchungen, S. 3; ähnlich Böhm, F./ Großmann-Doerth, H./Eucken, W., Unsere Aufgabe, S. 95, wonach die "Einzelfragen der Wirtschaft... als Teilerscheinung einer höheren Einheit zu sehen" sind). Zusammenfassend Eucken, W., Grundlagen, S. 230: "Weil das wirtschaftliche Geschehen... ein interdependentes Ganzes darstellt, muß die Nationalökonomie ein innerlich zusammenhängendes Ganzes von Erkenntnissen bieten".

53) Eucken, W., Kapitaltheoretische Untersuchungen, S. 5.

54) Husserl, E., Logische Untersuchungen, S. 15. 
55) Eucken, W., Grundlagen, S. 230: "Die Systematik tragen wir nicht an die Tatbestände heran, sondern wir finden sie in den Tatbeständen vor". "Systematisch heißt: Einheitlich geordnet und in Zusammenhang gebracht" (Eucken, W., Grundlagen, S. 232). Dazu auch Husserl, E., aaO. (Anm. 54). Die genannten Husserl-zitate finden sich durchweg auch bei Eucken, W., Grundlagen, S. 230.

56) "Dieses Buch ist kein methodologisches Buch. Die wirtschaftliche Wirklichkeit ist sein Gegenstand. Emporwuchern methodologischer Reflexionen ist ein Krankheitszeichen für jede Wissenschaft; aber durch Methodologie allein ist noch nie eine kranke Wissenschaft geheilt worden" (Eucken, W., Grundlagen, S. IX). Diese Einordnung seiner "Grundlagen der Nationalökonomie" hat Eucken von seiten der Rezensenten den heftigsten widerspruch eingetragen, vgl. dazu Jessen, J., Besprechung: walter Eucken, Die Grundlagen der Nationalökonomie, Schmollers Jahrbuch für Gesetzgebung, Verwaltung und Volkswirtschaft, 64. Jahrgang (1940 I), S. 359; Stakkelberg, H. V., aao. (Anm. 30), S. 245 ("... hat Eucken durch seine sachgemäße Grundlagenforschung - teils implicite, teils expressis verbis - eine Methodenlehre entwickelt, wie wir sie heute dringend benötigen"); Amonn, A., aao. (Anm. 30), S. 10f. ("Das Buch ist, und zwar von Anfang bis Ende - es würde mir leid tun, den Verfasser damit $z u$ verletzten - ein methodologisches Buch"); Weippert, G., aao. (Anm. 30), S. 12f. ("Sein Buch ist eine 'Methodologie', dieses Wort teils im Sinne von Wissenschaftslehre, von Grundlagenforschung und von Methodologie im eigentlichen Verstande genommen"); Peter, H., Die neue Methodologie Walter Euckens. Bemerkungen zu dem Buch: "Die Grundlagen der Nationalökonomie", Finanzarchiv, N.F. Bd. 8 (1941), S. 158 .

57) "Die Methode einer Wissenschaft ist von weit größerer Bedeutung als irgend eine einzelne Entdeckung", Cuvier zit. nach Eucken, W., Grundsätze der Wirtschaftspolitik, S. 369 .

58) Eucken, W., Kapitaltheoretische Untersuchungen, S. $4 \mathrm{f}$.

59) "In Wahrheit gibt es wissenschaftliche Fragestellungen, Methoden und Ergebnisse, die weit über die zeit ihrer Entstehung hinaus Gültigkeit besitzen und die sich gleichsam von der Umwelt, in der sie geschaffen wurden, befreien" (Eucken, W., Wissenschaft im stile Schmollers, S. 473). Dies wurde von dritter seite auch auf die Euckenschen Überlegungen bezogen: "Über das spezielle Anwendungsgebiet der Nationalökonomie hinaus hat der von Eucken gewiesene Weg für alle Erfahrungswissenschaften Bedeutung", Veit, O., Geschichte und Erfahrungswissen, Die Tatwelt, Jahrgang 16 (1940), S. 155.

60) Weippert, G., aaO. (Anm. 30), S. 13. 
61) Eucken, W., Kapitalteoretische Untersuchungen, S. $5 f$.

62) Eucken, W., Kapitaltheoretische Untersuchungen, S. 6 .

63) Eucken, W., Die Leistung der deutschen Volkswirtschaftslehre, S. 230.

64) Eucken, W., Die Überwindung des Historismus, S. 214 ; grundlegend ders., Kapitaltheoretische Untersuchungen, S. $7 f ., 11 \mathrm{ff}$.

65) Eucken, W., Wissenschaft im Stile Schmollers, S. 502; ders., Kapitaltheoretische Untersuchungen, S. $15 \mathrm{ff}$.

66) Eucken, W., Kapitaltheoretische Untersuchungen, S. $20 \mathrm{ff} ., 38 \mathrm{ff}$.

67) Eucken, W., Kapitaltheoretische Untersuchungen, S. 34, 8: "Der einzelne theoretische Satz enthält also ein hypothetisches, allgemein gültiges Urteil über einen notwendigen Bedingungszusammenhang; die moderne nationalökonomische Theorie als Ganzes stellt das in sich geschlossene einheitliche Gesamtsystem solcher Urteile dar."

68) Eucken, W. , Kapitaltheoretische Untersuchungen, S. 37.

69) Eucken, W., Kapitaltheoretische Untersuchungen, S. 29f., $34 \mathrm{ff.} \mathrm{(37);} \mathrm{ders.,} \mathrm{Die} \mathrm{Überwindung} \mathrm{des} \mathrm{Historis-}$ mus, S. 213.

70) Eucken, W. , Kapitaltheoretische Untersuchungen, S. 37.

71) Eucken, W., Grundlagen, S. 6, 2: "Wie erfolgt die Lenkung dieses gewaltigen arbeitsteiligen Gesamtzusammenhanges, von dem die Versorgung jedes Menschen mit Gütern, also jedes Menschen Existenz, abhängt?"

72) Eucken, W., Grundlagen, S. 2ff. Zu diesen fünf Teilproblemen gesellt sich noch die Frage der Konjunkturschwankungen, die als "Verschiebungen des konkreten wirtschaftlichen Alltages" begriffen werden (Eucken, W., Grundlagen, S. 6).

73) Dietzel zit. nach Eucken, W., Grundlagen, S. 244 Anm. 2 .

74) Eucken, W., Grundlagen, S. $5 f$.

75) Eucken, W., Wissenschaft im Stile Schmollers, S. 493.

76) Dazu eingehend S. $12 \mathrm{f}$.

77) Eucken, W., Grundlagen, S. 9. 
78) Eucken, W., Grundlagen, S. $15 \mathrm{ff}$.

79) Eucken, W., Grundlagen, S. 18, 16.

80) Eucken, W., Grundlagen, S. 17. "Der jeweilige wirtschaftliche Alltag ist selbst Geschichte", weil "(a) 1les menschliche Tun Geschichte ist" (Eucken, W., Grundlagen, S. 16).

81) Eucken, W., Grundlagen, S. 18ff.; ders., Die Leistung der deutschen Volkswirtschaftslehre, S. 213.

82) Eucken, W., Grundlagen, S. $20 \mathrm{f} ., 227$.

83) "Die Spannung, welche diese Antinomie in sich schließt, muß in ihrer ganzen Schärfe begriffen werden: Der geschichtliche Charakter des Problems verlangt Anschauung, Intuition, Synthese, Verstehen, Einfühlung in individuelles Leben; - der allgemein-theoretische Charakter indessen fordert rationales Denken, Analyse, Arbeiten mit gedanklichen Modellen. Hie Leben - da Ratio" (Eucken, W., Grundlagen, S. $22 \mathrm{f}$.).

84) Eucken, W. , Grundlagen, S. 242.

85) Eucken, W. Grundlagen, S. 20. Peter, H., aaO. (Anm. 56), S. 159f. bezeichnet die "große Antinomie" als das "logische Kernstück" der Euckenschen Methodenlehre und als ein "Lehrstück der Methodologie", das die beiden gegensätzlichen Verfahrensweisen des Empirismus und des Rationalismus $\mathrm{zu}$ vereinen suche. Auch für Brinkmann, C., aaO. (Anm. 30), S. 353 ist die "große Antinomie" nur ein neuer Name für den alten Methodenstreit zwischen "theoretischer" und "historischer" Schule in den Wirtschaftswissenschaften. Diese Auffassungen kommen nicht von ungefähr. Zwar ist für Eucken mit dieser Antinomie auch der Dualismus von Geschichte und Theorie bezeichnet. Da dieses spannungsverhältnis jedoch als identisch mit dem (methodischen) Gegensatzpaar Rationalismus - Empirismus begriffen wird, reduziert es sich auf eine bloße Methodenfrage (Eucken, W., Kapitaltheoretische Untersuchungen, $S$. 45). Diese Reduktion läßt sich nur mit der großen Bedeutung des methodischen Vorgehens überhaupt im Euckenschen Wissenschaftsverständnis erklären, demzufolge methodische Prozeduren nicht lediglich Verfahren zur Erlangung wissenschaftlicher Erkenntnis sind, sondern zugleich Einsichten in die qualitative Ausstattung dieser Aussagen liefern: die korrekt gewonnenen theoretischen sätze sind stets wahr (Eucken, W., Kapitaltheoretische Untersuchungen, S. $28 \mathrm{ff}$.; dazu auch Hesse, G., Staatsaufgaben, S. 224). Eine kritische Analyse dieses zentralen Problems der Euckenschen Grundlegung findet sich bei weippert, G., aao. (Anm. 30), S. $24 \mathrm{ff}$., der nachzuweisen sucht, daß Eucken in der "großen Antinomie" mehr als nur das Theo- 
rie-Geschichte-Problem oder den Methodendualismus konfundiert hat: "Da nun Eucken sich des Unterschieds der zur Bestimmung und Charakterisierung der Antinomie hereingenommenen Gegensatzpaare nicht bewußt ist, so kann er auch des Glaubens sein, etwa durch Vermeidung von Rationalismus einerseits - Empirismus andererseits der Antinomie Herr zu werden" (ebd., S. 26f.).

86) Eucken, W., Grundlagen, S. 22: ein "oberflächlicher Kompromiß zwischen theoretischer und historischer Forschung ist zwecklos".

87) Eucken, W., Grundlagen, S. 23.

88) Eucken, W., Grundlagen, S. 22 ; ders., Kapitaltheoretische Untersuchungen, S. 15: "Die Gleichförmigkeit der konkreten Bewegungen von Körpern oder der chemischen Reaktionen oder des Blutkreislaufs oder des Wachstums der Pflanzenarten ermöglichte es allein, das Problem der Bewegung, des Blutkreislaufs usw. allgemein zu stellen und allgemein Problemlösungen zu geben, die für alle individuellen Fälle Gültigkeit beanspruchen".

89) Eucken, W., Grundlagen, S. 22.

90) Die Einführung des Problems der Physik des Wirtschaftsprozesses kommt ohne Kenntnis des in der wissenschaftstheoretischen Exposition entworfenen methodischen Grundgerüstes unvermittelt und überraschend, denn es wird in den "Grundlagen der Nationalökonomie" keineswegs deutlich, daß die Reduktion der Wirklichkeit auf gleichförmige Tatbestände eine Grundvoraussetzung für den Einsatz des gewählten Verfahrens ist. Interessant in diesem Zusammenhang Kade, G., aaO. (Anm. 51), S. 30: "Nun ist es aber nicht so, daß schon die Anwendung der Mathematik als solche eine Theorie in den Erfahrungswissenschaften schafft, sondern es muß innerhalb einer empirischen Wissenschaft einen Bereich geben, der von sich aus hypothetisch-deduktiv darstellbar ist. Eine Wissenschaft ist also nur insoweit mathematisierbar, als sich innerhalb ihres konkreten Gegenstandsgebietes ein Erkenntnisobjekt absondern läßt, das eine mathematische struktur hat".

91) Eucken, W., Grundlagen, S. $27 \mathrm{ff.,} 34 \mathrm{ff}$. und vorne S. $7 f$. und $11 f$.

92) Ihr wird zwar die Erkenntnis der Frage nach dem "Gesamtzusammenhang des ökonomischen Geschehens" zugute gehalten, aber ihre Theorien waren der Vielfalt des geschichtlichen Lebens nicht angepaßt, weil sie nur "einen Fall", die vollkommene Konkurrenz, zur Grundlage ihrer wissenschaftlichen Utberlegungen machte (Eucken, W., Grundlagen, S. $24 \mathrm{ff}$.). 
93) Eucken, W., Grundlagen, S. 30ff. Für den Hauptvertreter dieser Richtung, $c$. Menger, gibt es "zwei verschiedene Wissenschaften mit zwei verschiedenen Denkweisen" (zitiert nach Eucken, W., Grundlagen, S. 247 Anm. 10), nämlich die historische und die theoretische Nationalökonomie. Indem jede Richtung versuchte, ihr jeweiliges Erkenntnisziel zu erreichen, verlieren beide die probleme der "eine( $n)$ Welt" aus den Augen. Es gilt der Satz: "Soweit mit der spaltung von theoretischer und historischer Nationalökonomie Ernst gemacht wird, fallen die Probleme ungelöst zu Boden. Es kommt nicht zu wissenschaftlicher Erfahrung und die Wissenschaft verfehlt ihren Zweck" (Eucken, W., Grundlagen, s. 32). Zur Kritik der Kritik Euckens am Dualismus vgl. Amonn, A., aaO. (Anm. 30), S. $20 \mathrm{ff}$.

94 ) Eucken, W. , Grundlagen, S. 38ff. Durch Wirtschaftsstufen und Wirtschaftsstile werden die Wirtschaftsweisen in bestimmten Phasen zeitlich und räumlich "monistisch" gekennzeichnet. Die Subsumtion ganzer Epochen unter ein "einförmiges Schema" (Grundlagen, S. 59) läßt das Wesentliche der geschichtlichen wirklichkeit nicht offenbar werden; gegen diese Beurteilung der Lehre von den Wirtschaftsstufen und Wirtschaftsstilen durch Eukken Haller, H., Typus und Gesetz in der Nationalökonomie, S. 71f. und Kempski, J. v., Zur Logik der ordnungsbegriffe, besonders in den Sozialwissenschaften, Studium Generale, 5. Jahrgang (1952), S. 209.

95) Eucken, W., Grundlagen, S. 41.

96) Eucken, W., Grundlagen, S. 50.

97) Zum Ordnungsgefüge, das synonym dem Begriff der Wirtschaftsordnung gebraucht wird vgl. insbesondere Eucken, W. , Grundlagen, S. 43, 49,50f., 56, 58, 64 und 66. Nur die Frage nach dem ordnungsgefüge der Wirtschaft eröffnet "den Zugang zur wirtschaftlichen Wirklichkeit einer Zeit", ders., ebenda, s. 58 .

98) Stackelberg, H. V., aao. (Anm. 30), S. $248 \mathrm{f}$; ; Weippert, G., aao. (Anm. 30), S. 53 .

99) Eucken, W., Grundlagen, S. 49.

100) Eucken, W., Grundlagen, S. $48,58$.

101) Eucken, W., Grundlagen, S. 66.

102) Eucken, W., Grundlagen, S. 24 .

103) Eucken, W., Grundsätze, S. $19 \mathrm{ff}$.

104) Eucken, W., Grundlagen, S. 169. 
105) Eucken, W., Grundlagen, S. 50. Bei einer Betrachtung der Erde aus der Vogelperspektive würde sich, ausgelöst durch das "Gewimmel von Menschen" Tätigkeiten und Abläufe die Frage stellen: "Im Rahmen welcher ordnung vollzieht sich alles dieses? Eine solche Frage ist richtig gestellt" (Eucken, W., Grundlagen, S. 50).

106) "Der Wirtschaftsprozeß läuft stets und überall ... innerhalb einer geschichtlich gegebenen wirtschaftsordnung $a b$. Die geschichtlich gegebenen, positiven ordnungen mögen schlecht sein; aber ohne ordnung ist überhaupt ein Wirtschaften undurchführbar" (Eucken, W., Grundlagen, S. 50).

107) Zur Invariantenproblematik vgl. bereits vorne S. 15.

108) "Da der jeweilige alltägliche wirtschaftshergang je nach der Gestalt der vorhandenen wirtschaftsordnung verschieden abläuft, ist die Erkenntnis der wirtschaftsordnung sogar der erste Schritt zur Erkenntnis der wirtschaftlichen Wirklichkeit" (Eucken, w., Grundlagen, S. 58).

109) Eucken, W., Unser Zeitalter der Mißerfolge, S. 65; ders., Kapitaltheoretische Untersuchungen, S. $45 \mathrm{f}$.

110) Eucken, W., Grundsätze, S. 8 .

111) Eucken, W., Grundlagen, S. 211, 222; ders., Grundsätze, S. $8,100,352$.

112) V. Zwiedineck-Südenhorst zit. nach Eucken, W., Grundlagen, S. 212 .

113) Eucken, W. , Grundsätze, S. 377, 20; ders., Grundlagen, S. 78, 230; ders., Kapitaltheoretische Untersuchungen, S. 269; ders., Wettbewerb, Monopol und Unternehmer, S. 9 .

114) Hesse, G., Staatsaufgaben, S. 233; dazu auch Blum, R., Soziale Marktwirtschaft, S. 56.

115) Eucken, W., Grundlagen, S. 150, 152f.; ders., Grundsätze, s. 2 f.

116) Eucken, W., Grundsätze, S. 4, 6; ders., Grundlagen, S. 150 .

117) Dazu Hesse, G., Staatsaufgaben, S. 234, der nachweist, daß in der Eigenwirtschaft damit rationales Handeln und Plänemachen nicht mehr identisch sind, denn es handeln zwar alle in dieser Wirtschaftsform zusammengefaßten Individuen rational, aber die Kompetenz zur Planerstellung konzentriert sich bei dem "einen Kopf". Damit ist aber auch klargestellt, daß Euckens "archimedischer 
Punkt" nicht das übliche rationale Handeln eines Subjekts ist, sondern eine bestimmte Form der interpersonellen Koordination von Handlungen: "die plangemäße, von einem Plansubjekt gelenkte", Hesse, G., ebenda, S. 235 .

118) Eucken, W., Grundsätze, S. 4 .

119) Eucken, W., Grundsätze, S. 5f.; ders., Das ordnungspolitische Problem, S. 57.

120) Eucken, W., Grundsätze, S. 6.

121) Eucken, W., Grundsätze, S. 353, 116.

122) Hesse, G., Staatsaufgaben, S. 236.

123) Eucken, W., Grundsätze, s. 7, 9.

124) Eucken, W., Grundsätze, S. 81f., 163, 169, 187, 369.

125) So im Ergebnis auch Hesse, G., Staatsaufgaben, S. 236.

126) Eucken, W., Grundlagen, S. 69, 226.

127) Eucken, W., Nationalökonomie - wozu?, S. 25; ders., Grundlagen, S. 226 .

128) Die Ordnungsformen gedenkt Eucken "in den Tatbeständen" zu finden, "dort sind sie. Die Wissenschaft hat sie dort zu entdecken" (Grundlagen, S. 269 Anm. 66 a.E.). Für das gewählte Verfahren der "pointierend-hervorhebenden Abstraktion" selbst beruft sich Eucken, W., Grundlagen, S. 254 Anm. 28 "besonders" auf Husserl, E., Logische Untersuchungen, 2. Bd., 1. Teil, 2. Aufl., 1914 , S. 106ff. und 216f. und beschreibt das Verfahren wie folgt: "Bei der pointierend-hervorhebenden Abstraktion, deren volle Entfaltung erst der neuzeitlichen Wissenschaft gelang, erfolgt eine steigerung der einzelnen Seiten eines konkreten Tatbestandes und so die Gewinnung von reinen Formen wie das im Text an einer Haushaltung, einem Industriebetrieb, einem Bauernhof, einem Fronhof gezeigt ist"; ähnlich Eucken, W., Grundlagen, S. 226. Über diese Anmerkung in einer Fußnote hinaus enthalten die "Grundlagen der Nationalökonomie" keine näheren Erläuterungen des gewählten Abstraktionsverfahrens, was bei der entscheidenden Rolle, die es im Rahmen der Verwirklichung des zu objektiver wissenschaftlicher Erfahrung führenden Erkenntnisprozesses hat, einigermaßen erstaunen mag; dazu auch Schäfer, M., aao. (Anm. 30), s. 52 .

Kritisch zur Möglichkeit, aus der Analyse ausschließlich eines Tatbestandes durch pointierend-hervorhebende Abstraktion die Grundformen allen wirtschaftens $\mathrm{zu}$ finden, Amonn, A., aao. (Anm. 30), S. 131ff.; Haller, 
H., aao. (Anm. 94), S. 73f.; Ritschl, H., aaO. (Anm. 32), S. 396. Die Beschränkung der Untersuchung auf einen wirtschaftlichen sachverhalt erscheint auch aus methodischer sicht wenig angezeigt, da insbesondere die Suche nach Gleichförmigkeiten nicht oder doch nur mit viel Phantasie möglich $z u$ sein scheint. Eine Erklärung für das methodische Vorgehen Euckens in den "Grundlagen der Nationalökonomie" mag der nicht offengelegte Zusammenhang zum einleitenden Kapitel "Was leistet die nationalökonomische Theorie?" in den Kapitaltheoretischen Untersuchungen, s. 1ff. sein, wo er bereits die entscheidende Idee des Plans eingeführt hatte (insbesondere S. 16f.), so daß sich eine bereits geordnete Wahrnehmung in den Grundlagen auf die einzelnen Erscheinungen beschränken kann.

129) Eucken, W., Kapitaltheoretische Untersuchungen, S. 20.

130) Damit führt "anschaulichste Anschauung ... zur Theorie", Eucken, W., Nationalökonomie - wozu?, S. 26.

131) Eucken, W., Grundlagen, S. 67.

132) Eucken, W., Grundlagen, S. 78; ders., Kapitaltheoretische Untersuchungen, S. 16f.; ders., Grundsätze, S. $20 f f$.

133) Durch die Analyse der Haushaltung des "Angestellten A", der mit "seiner Familie von drei Köpfen in einem Siedlungshaus" wohnt, erkennt Eucken, daß diese Haushaltung einmal eine selbst wirtschaftende Einheit, d.h. "Träger einer kleinen Eigenwirtschaft" ist, daß sie aber zum anderen kein "Sonderdasein führt, sondern mit Betrieben und anderen Haushaltungen aufs engste verknüpft ist", d.h. sie ist "Glied einer großen Verkehrswirtschaft" (Grundlagen, S. 70).

134) Eucken, W. , Grundlagen, S. 70, 78f., 80, 87, 163, 168, $226 \mathrm{ff.;} \mathrm{ders.,} \mathrm{Grundsätze,} \mathrm{S.} 21 \mathrm{f}$.

135) Für M. Weber ist der Idealtypus ein "Idealbild" der tatsächlichen Vorgänge, das durch einseitige gedankliche steigerung eines oder mehrerer Elemente der wirklichkeit gewonnen ist (Wissenschaftslehre, S. 190). Dieser "Abstraktionsprozeß, der durch Analyse und gedankliche Isolierung der Bestandteile des unmittelbar Gegebenen" vollzogen wird, verwandelt Wirklichkeit "in ein Gedankengebilde" (Wissenschaftslehre, S. 275), das in "begrifflicher Reinheit" ausgewählte Tatsachen und Zusammenhänge des geschichtlichen Lebens zu einem in sich geschlossenen Kosmos ideeller Zusammenhänge vereinigt (Wissenschaftslehre, S. 190f.). Auf Grund seiner Konstruktion ist der Idealtypus für M. Weber eine "Utopie" (Wissenschaftslehre, S. 191), deren Verhältnis zur Wirklichkeit lediglich darin besteht, einzelne heraus- 
gehobene zusammenhänge und ausgewählte seiten der "stets unendlich mannigfaltigen Einzelerscheinungen" (Wissenschaftslehre, S. 178, 181) "pragmatisch $z u$ veranschaulichen und verständlich zu machen". Niemals, so M. Webers Ergebnis, ist er jedoch "eine Darstellung des Wirklichen" (Wissenschaftslehre, S. 190).

136) Die Darstellung der Entwicklung und Verwendung des Typusbegriffs seit Platon endet bei $M$. Weber, dem Eukken nicht nur das Bruchstückhafte, sondern auch "schwere Mängel" bei der Bildung von Idealtypen vorwirft (Grundlagen, S. 268 Anm. 66). "Weil seine Ansichten uber die Typenbildung noch heute herrschen und eine Klärung dieses wichtigen Problemkomplexes ohne eine Auseinandersetzung mit Max Weber unmöglich ist, ist Kritik an ihm unvermeidlich" (Eucken, W., Grundlagen, S. 269 Anm. 66).

137) Die "beiden Arten von Typen (werden) dauernd durcheinander geworfen, logisch ganz verschiedenartige Gebilde (wurden) gleich benannt" (Eucken, W., Grundlagen, S. $41 \mathrm{f}$.$) . Auch diese mangelnde Unterscheidung zwischen$ Idealtypen und Realtypen geht auf das Konto von $M$. Weber: "Er erkannte weder den fundamentalen Unterschied ... noch den logischen charakter von beiden, noch die Verschiedenheit der Abstraktionsverfahren, die zur Bildung der beiden Typen führten" (Eucken, W., Grundlagen, S. $268 \mathrm{Anm}$. 66). Kritisch zu dieser Differenzierung Euckens Amonn, A., aao. (Anm. 30), S. 131f.; Kempski, J. v., aaO. (Anm. 94), S. 209ff.; Neuhauser, G., Modell und Typus in der Nationalökonomie, Jahrbuch für Sozialwissenschaft, Bd. 15 (1964), S. 160; Ritschl, H., aaO. (Anm. 32), S. $397 \mathrm{f}$.

138) Eucken, W., Grundlagen, S. 70, 254 Anm. 28.

139) Eucken, W. , Grundlagen, S. 254 Anm. 28.

140) Eucken, W., Grundlagen, S. 41, 123, 269 Anm. 66. "Indem wir sie einzeln pointierend heraushoben, also gedanklich aus der Verschmelzung lösten, in der sie sich in der wirklichen wirtschaft befinden, und sie so in reiner Form gewannen, besitzen wir Typen, die einzeln wirtschaftliche Realität nicht abbilden", (Eucken, w., Grundlagen, S. 269 Anm. 66). Sie sind "weder Photographien noch Gemälde" des wirtschaftlichen Alltags (Eucken, w., Grundlagen, S. 163).

141) Eucken, W., Grundlagen, S. 123. Zwar wollte Eucken nicht "gegen Weber einen neuen Begriff des Idealtypus... entwickeln, sondern... das, was Weber nicht klar und nur teilweise sah, exakt und vollständig... bestimmen" (Grundlagen, S. 269 Anm. 66). Dieses Ziel, den "im ersten Anlauf steckengebliebenen" Idealtypusbegriff $M$. Webers (Brinkmann, C., aao. (Anm. 30), S. 256) umfas- 
send zu klären, scheint Eucken nach dem, was er zu dieser Frage im einzelnen darlegt bzw. darzulegen unterläßt, wenig näher gekommen zu sein. Die zum Teil vehemente Kritik an M. Weber (Eucken, W., Grundlagen, S. 268f., 123) bleibt im Grunde ohne Folgen für das eigene Werk, da Eucken über bereits vorgetragene Positionen nicht hinauskommt, vielmehr im Gegenteil typisch Webersches Gedankengut rezipiert. Dazu im einzelnen Schäfer, M., aao. (Anm. 30), S. 13ff., S. $44 \mathrm{ff}$. Zur methodischen Verwandtschaft des Weberschen Verfahrens der einseitigen gedanklichen steigerung einzelner oder mehrerer Aspekte der Wirklichkeit und des Husserlschen Verfahrens der pointierend-hervorhebenden Abstraktion Tichy, G.E., Theoretische Grundlagen der politischen ökonomie. Beiträge zur ganzheitlichen wirtschafts- und Gesellschaftslehre, S. 163.

142) Eucken, W., Grundlagen, S. 194.

143) Vleugels, W., Volkswirtschaftslehre als Lehre von der geschichtlichen Wirklichkeit der Wirtschaft. Zu Walter Euckens neuem Werk "Die Grundlagen der Nationalökonomie", Jahrbücher für Nationalökonomie und statistik, Bd. 152 (1940), S. 504 .

144) Eucken, W., Grundlagen, S. 79.

145) Eucken, W., Grundlagen, S. 79.

146) Eucken, W., Grundlagen, S. 79ff.; ders., Grundsätze, S. $21 \mathrm{f}$.

147) Eucken, W., Grundlagen, S. $80 \mathrm{ff.} \mathrm{(81).}$

148) Eucken, W., Grundlagen, S. $82 f$.

149) Eucken, W. , Grundlagen, S. 83ff. (83); dazu auch Hedtkamp, G., Wirtschaftssysteme, S. 110 .

150) Eucken, W., Grundlagen, S. 88; ders., Grundsätze, S. 22 .

151) Hierzu sogleich.

152) Eucken, W., Grundlagen, S. 93.

153) Eucken, W., Grundlagen, S. 93f. (94).

154 ) Eucken, W., Grundlagen, S. 94f. Die Preisbindung zweiter Hand, durch die Betrieben der Verkaufspreis ebenfalls als Datum vorgegeben ist und mit deren Hilfe das liefernde Unternehmen den Konsumgütermarkt unter Überwindung einer Absatzstufe in seinen Marktbereich und in seine Preispolitik einzubeziehen sucht, rechnet Eucken je nach Ausgestaltung dem Monopol, Teilmonopol oder dem 
Oligopol zu (Grundlagen, S. 95). Gleiches gilt für den Fall, daß die marktbeteiligte Einzelwirtschaft durch eine "öffentlich-rechtliche Preisfestsetzung" in der Preisgestaltung eingeschränkt ist (Grundlagen, S. 95, 104).

155) Eucken, W., Grundlagen, S. $101 \mathrm{f}$.

156) Eucken, W., Grundlagen, S. 103.

157) Eucken, W., Grundlagen, S. 106.

158) Eucken, W., Grundlagen, S. $95 \mathrm{f}$.

159) Eucken, W., Grundlagen, S. 110f. Die vier Ausprägungen sind "beiderseits offen, beiderseits geschlossen oder nur auf einer Seite des Angebots oder der Nachfrage geschlossen bzw. offen" (Eucken, W., Grundlagen, S. 111). Angebot und Nachfrage sind offen, "wenn jeder Mensch oder ein - im Verhältnis zum Markt - großer Kreis von Personen als Anbieter oder Nachfrager zum Markt zugelassen wird und wenn jeder einzelne soviel anbieten und nachfragen darf, wie er für richtig hält" (Eucken, W., Grundlagen, S. 91). Geschlossen sind Angebot und Nachfrage, "wenn nicht jeder Mensch als Anbieter oder Nachfrager auf dem Markt erscheinen darf" (Eucken, W., Grundlagen, S. 92).

160) Eucken, W., Grundlagen, S. 113.

161) Eucken, W., Grundlagen, S. $112 \mathrm{f}$.

162) Eucken, W., Grundlagen, S. $113 \mathrm{f}$.

163) Eucken, W., Grundlagen, S. 114. Eucken nennt als Beispiele für eine allgemein anerkannte, den Kurswert der anderen Geldsorten bestimmende währung den byzantinischen Goldsolidus im Mittelalter bzw. den römischen Goldaureus, der bis in das 3. nachchristliche Jahrhundert die Wertmaßfunktion erfüllte.

164) Eucken, W., Grundlagen, S. 115.

165) Eucken, W. , Grundlagen, S. 116.

166) Eucken, W., Grundlagen, S. 121.

167) Eucken, w., Grundlagen, s. 17.

168) Eucken, W., Grundlagen, S. 117.

169) Eucken, W., Grundlagen, S. 117, 122.

170) Eucken, W., Grundlagen, S. 119. 
171) Eucken, W., Grundlagen, S. $118 f$.

172) Eucken, W., Grundlagen, S. $120 f$.

173) Zum folgenden auch Kempski, J. v., aao. (Anm. 94), S. $209 \mathrm{ff}$.; Haller, H., aao. (Anm. 94), S. $75 f$.

174) Eucken, W., Grundlagen, S. 124.

175) "Es ist die Frage aufgeworfen worden, wie sich die 'reinen Formen' oder 'Idealtypen' zu den 'Modellen' verhalten. - Nun: Die reinen Formen, welche die Wissenschaft aus der wirklichen wirtschaft pointierend heraushebt, werden als Modelle benutzt, an denen die theoretischen Ableitungen erfolgen" (Eucken, W., Grundlagen, S. 269 Anm. 66 a.E.). Damit kann jeder Idealtypus zur Grundlage eines theoretischen Systems werden.

176) Neuhauser, G., Grundfragen wirtschaftswissenschaftlicher Methodik, in: Enzyklopädie der geisteswissenschaftlichen Arbeitsmethoden, 8. Lieferung: Methoden der Sozialwissenschaften, 1967, S. 113.

177) Eucken, W., Nationalökonomie - wozu?, S. 28.

178) Eucken, W., Grundlagen, S. 124; ähnlich ders., Grundsätze, S. 24 .

179) Eucken, W., Grundlagen, S. 22.

180) Eucken, W., Grundlagen, S. 234, 96.

181) Eucken, W., Grundlagen, S. 234, 51.

182) Eucken, W., Grundlagen, S. 51.

183) Eucken, W., Grundlagen, S. 78. "Erst nach Erkenntnis dieser Formelemente... kann die Erkenntnis des jeweiligen konkreten Ordnungsgefüges glücken" (Eucken, W., Grundlagen, S. 164).

184) Eucken, W., Grundlagen, S. 78.

185) "Schon damals (das war im kritischen, die geschichtlichen Entwicklungen aufnehmenden Teil der Grundlagen der Nationalökonomie) waren wir genötigt, bei der Bestimmung der Wirtschaftsordnung eines Volkes und einer Zeit die Formelemente herauszuheben, aus denen sie bestand. Mochte das nun die ägyptische Wirtschaft der augusteischen Zeit oder die Nürnberger Wirtschaft des späten 15. Jahrhunderts sein. Allerdings benutzten wir damals nur die wichtigsten reinen Formen. Aber auch dies war ein Vorgriff. Freilich ein notwendiger. Denn anders läßt sich die wirtschaftsordnung einer Zeit überhaupt nicht erfassen" (Eucken, W., Grundlagen, S. 167). 
186) Diemer, A., Edmund Husserl, S. 104; Biemel, W., Husserls Encyclopaedia-Britannica-Artikel und Heideggers Anmerkungen dazu, in: Noack, H. (Hrsg.), Husserl, S. $282 \mathrm{ff}$. (291ff.).

187) Husserl, E., aaO. (Anm. 54), S. 224.

188) Biemel, W., aaO. (Anm. 186), S. 291.

189) Biemel, W., aaO. (Anm. 186), S. 290, 293f.; zu diesem auch von Eucken hervorgehobenen Aspekt ders., Grundlagen, S. 69f., 226; ders., Nationalökonomie - wozu?, S. 25 .

190) Eucken, W., Nationalökonomie - wozu?, S. 13.

191) Husserl, E., zit. nach Biemel, W., aao. (Anm. 186), S. 294.

192) Bocheñski, J.M., Die zeitgenössischen Denkmethoden, S. $26 f ., 29$.

193) Dazu bereits vorne Anm. 128 .

194) Biemel, W., aaO. (Anm. 186), S. 295.

195) Husserl, E., aao. (Anm. 54), S. $216 \mathrm{ff}$.

196) Eingehend hierzu die Ideen zu einer reinen Phänomenologie und phänomenologischen Philosophie, 1913.

197) Natorp, P., Husserls "Ideen zu einer reinen Phänomenologie", in: Noack, H. (Hrsg.), Husserl, S. 36ff. (37).

198) Janssen, P., Edmund Husserl, S. 95ff.; Diemer, A., aaO. (Anm. 186), S. 105f.

199) Diemer, A., aaO. (Anm. 186), S. 107.

200) Husserl, E., Erfahrung und Urteil, S. 411.

201) Husserl, E., Die Idee der Phänomenologie, S. 51.

202) Levinas, E., Über die "Ideen" Edmund Husserls, in: Noack, H. (Hrsg.), Husserl, S. $87 \mathrm{ff.}$ (91).

203) Husserl, E., aao. (Anm. 201), S. 26.

204) Levinas, E., aao. (Anm. 202), S. 93: "Die Tatsachenwissenschaften hängen also von den eidetischen Wissenschaften $a b$. Und es sind diese eidetischen Wissenschaften, welche die Tatsachenwissenschaften rationalisieren".

205) Zusammenfassend Levinas, E., aao. (Anm. 202), S. $93 f f$. 
206) Biemel, W., aao. (Anm. 186), S. $295 f$.

207) Weber, M., Wissenschaftslehre, S. 171.

208) Weber, M., Wissenschaftslehre, S. 170.

209) Weber, M., Wissenschaftslehre, S. 175; Neuhauser, G., aao. (Anm. 176), S. 123; Amonn, A., aao. (Anm. 30), S. 12f.: "Die Wertideen, die in den empirischen Wertungen nur unklar in die Wirklichkeit treten, werden in ihm (dem Idealtypus) zu gedanklicher Klarheit, Eindeutigkeit und innerer widerspruchslosigkeit erhoben".

210) Weber, M., Wissenschaftslehre, S. 178.

211) Dürr, E. -W. , aao. (Anm. 8), S. 71 (man begnügt sich bei der isolierenden Abstraktion mit "geordneten Wahrnehmungen bezüglich des Gesamtzusammenhangs, versucht nicht, das 'Ding an sich' zu erklären").

212) Dazu eingehend Kuhn, T.S., aao. (Anm. 33), S. $124 \mathrm{ff}$.

213) Dazu im einzelnen vorne S. $16 \mathrm{ff}$.

214) Dazu vorne S. $20 f f$.

215) Hesse, G., Staatsaufgaben, S. 228 und allgemein zur Möglichkeit der Wesensschau von ordnungen Neuhauser, G., aao. (Anm. 137), S. 160 (174f.); Haller, A., aao. (Anm. 94), S. 74 .

216) Dürr, E.-W., aaO. (Anm. 8), S. 71.

217) Eucken, W., Grundlagen, S. 69.

218) Eucken, W., Kapitaltheoretische Untersuchungen, S. 17.

219) Eucken, W., Grundlagen, S. 78.

220) Eucken, W., Grundlagen, S. 78; ders., Grundsätze, S. 21 .

221) Neuhauser, G., aao. (Anm. 137), S. 174; dies., Die wirtschaftspolitische Konzeption als Problem der theoretischen Wirtschaftspolitik, in: Seraphim, H.J. (Hrsg.), zur Grundlegung wirtschaftspolitischer Konzeptionen, S. $23 \mathrm{ff}$. (45).

222) Husserl, E., aao. (Anm. 200), S. 434 ; ebenso Weber, M., Wissenschaftslehre, S. $201 \mathrm{ff}$.

223) Schütz, A., Der sinnhafte Aufbau der sozialen Welt, S. 219 . 
224) Heitmüller, w., wirtschaftstheorie im Umbau, Wirtschaftsdienst, N.F. XXVII. Jahrgang, 2. Halbjahr 1942, S. $967 f$. nennt es schlicht einen Denktrick.

225) Eucken, W., Grundlagen, S. 50, 224.

226) Zum selben Ergebnis, allerdings mit völlig anderer Begründung kommt auch Gundlach, G., Eucken's Grundlegen der Nationalökonomie, Gregorianum XXXIV (1953), S. $680 f f$.

227) Hesse, G., Staatsaufgaben, S. $226 \mathrm{ff}$.

228) Eucken, W., Grundlagen, S. 123.

229) Kempski, J. v., aao. (Anm. 94), S. $209 f$.

230) Spiethoff, A., Anschauliche und reine volkswirtschaftliche Theorie und ihr Verhältnis zueinander, in: Synopsis, Festgabe für Alfred Weber, S. 584. Zur Frage, ob die Euckenschen Idealtypen als Konstruktivmodelle (wogegen sich Eucken heftig wehrt, vgl. ders., Grundlagen, S. $270 \mathrm{Anm}$. 66) oder Reduktivmodelle zu bewerten sind, eingehend Ritschl, H., aaO. (Anm. 32), S. 399ff. und Kempski, J. V., aaO. (Anm. 94), S. 210. Zur Belanglosigkeit dieser Unterscheidung Haller, H., aaO. (Anm. 94), S. 106 Anm. 8; Machlup, F., Idealtypus, Wirklichkeit und Konstruktion, Ordo XII (1961), s. 46; Albert, H., Der logische Charakter der theoretischen Nationalökonomie, Jahrbücher für Nationalökonomie und statistik, Bd. 171 (1959), S. 6f. Bei Albert, H., Ökonomische Ideologie und politische Theorie, S. 112 findet die Euckensche Idealtypenbildung ihre bislang grundlegendste und sprachlich radikalste Kritik: Die Behauptung, daß neben den beiden reinen Formen der Verkehrswirtschaft und der zentralgeleiteten wirtschaft "weitere reine wirtschaftsformen nicht denkbar sind..., bezieht sich erstens ausschließlich auf die sphäre bloßer Denkmöglichkeiten in der solche marginalen Typen allein ihre ärmliche Existenz zu fristen vermögen..., und sie geht zweitens auf ein Einteilungsprinzip zurück, dessen Bescheidenheit angesichts der vorliegenden Probleme kaum überboten werden kann".

231) Brinkmann, C., aao. (Anm. 30), S. 360f.; Peter, H., aao. (Anm. 56), S. 169; Ritschl, H., aaO. (Anm. 32), S. 390; Fischer, E., Wirtschaftsordnung und Wirtschaftsstil. Eine Untersuchung des Euckenschen und Spiethoffschen Versuches zur Lösung des Theorie-Geschichte-Problems in der Nationalökonomie, Diss. Frankfurt 1952, S. 58 .

232) Eucken, W., Grundlagen, S. $173 \mathrm{ff.,} 178 \mathrm{f}$.

233) Hedtkamp, G., aao. (Anm. 149), S. 110. 
234) Die "persönliche Erfahrung, die Deutung der Grundelemente der beobachteten wirtschaftsordnungen und ihre Prognose sind rein subjektive Elemente seiner Theorie und auch bei der suche nach dem dominanten Kriterium spielen Wertungen eine hervorragende Rolle. Die Frage nach dem möglichen Wirtschaftssystem scheint so von diesem Ansatz her schon problematisch". (Hedtkamp, G., aao. (Anm. 149), S. 110).

235) Gundlach, G., aaO. (Anm. 226), S. 687.

236) Eucken, W., Grundlagen, S. 169.

237) Hedtkamp, G., aao. (Anm. 149), S. 109 Anm. 151. Dazu auch Machlup, F., aao. (Anm. 149), S. 242; Gundlach, G., aao. (Anm. 226), S. 684ff.; Weippert, G., aao. (Anm. 30), S. 50ff.; Wulff, M., Die neoliberale Wirtschaftsordnung, S. 5; eingehend hierzu auch Runge, U., Antinomien des Freiheitsbegriffs im Rechtsbild des ordo-Liberalismus, S. $49 \mathrm{ff}$.

238) Eucken, W., Grundlagen, S. 264 Anm. 54, 172f.; ders., Kapitaltheoretische Untersuchungen, S. $28 \mathrm{f}$.

239) Eucken, W., Grundlagen, S. 264 Anm. 54.

240) Eucken, W., Grundlagen, S. 172f.; ders., Kapitaltheoretische Untersuchungen, s. 28f. Die theoretischen Sätze enthalten "überhaupt keine Urteile über das Auftreten bestimmter Tatbestände an bestimmtem ort $\mathrm{zu}$ bestimmter zeit. Sie antworten nicht auf Fragen nach dem Wann und Wo" (Eucken, W., Kapitaltheoretische Untersuchungen, S. 28 ).

241) Eucken, W., Grundlagen, S. 264 Anm. 54; ders., Kapitaltheoretische Untersuchungen, S. 29.

242) Eucken, W. , Kapitaltheoretische Untersuchungen, S. 30.

243) Dazu bereits vorne S. $6 \mathrm{f}$.

244) Albert, H., Probleme der Theoriebildung. Entwicklung, Struktur und Anwendung sozialwissenschaftlicher Theorien, in: Theorie und Realität, hrsg. von H. Albert, S. $14 \mathrm{ff.;}$ ders., Ökonomische Ideologie und politische Theorie, S. 170f.; ders., Traktat über kritische Vernunft, S. 8ff.; ders., Plädoyer für kritischen Rationalismus, S. $8 \mathrm{ff}$.

245) Albert, H., Ökonomische Ideologie und politische Theorie, aao. (Anm. 230), S. 171 .

246) Eucken, W., Grundlagen, S. 264 Anm. 54. 
247) Dazu im einzelnen Albert, H., Probleme der Theoriebildung, aao. (Anm. 244), S. 24f. (Anm. 16).

248) Albert, H., Theorie und Prognose in den Sozialwissenschaften, Schweizerische Zeitschrift für Volkswirtschaft und statistik, 93. Jahrgang (1957), S. 62f.; Kade, G., aao. (Anm. 51), S. 16f., 30f.; zum Aufbau des axiomatischen systems vgl. auch Bocheñski, J.M., aaO. (Anm. 192), S. 78ff.; Kraft, V., Erkenntnislehre, S. $187 \mathrm{ff} . ;$ Mathias, W., Wirtschaftswissenschaftliche Theorie und Modellbildung aus der sicht der modernen Wissenschaftstheorie, Diss. Köln 1971, S. $68 \mathrm{f}$.

249) Haller, H., aao. (Anm. 94), S. 45; Neuhauser, G., Modell und Typus in der Nationalökonomie, aao. (Anm. 137), S. 168; dies., Grundfragen wirtschaftswissenschaftlicher Methodik, aao. (Anm. 176), S. 115.

250) Eucken, W., Kapitaltheoretische Untersuchungen, S. 30.

251) Morgenstern, 0., Logistik und Sozialwissenschaften, in: Logik der Sozialwissenschaft, hrsg. von Topitsch, E., S. 318 .

252) Kraft, V., aao. (Anm. 248), S. 185.

253) Die Wahrheit gilt dann für das durch die logische Implikation geschlossene system, also sowohl für die Wenn- als auch für die Dann-Komponente (Kraft, V., aao. (Anm. 248), S. 188, 256; Haller, H., aaO. (Anm. 94), S. $42)$.

254) Albert, H., Ökonomische Ideologie und politische Theorie, aao. (Anm. 230), S. 38 .

255) Fischer, E., aao. (Anm. 231), S. 98ff.; Reigrotzki, E., Exakte Wirtschaftstheorie und Wirklichkeit, S. 28f.; Kade, G., aao. (Anm. 51), S. 17; Neuhauser, G., Grundfragen wirtschaftswissenschaftlicher Methodik, aao. (Anm. 176), S. 116; dies., Modell und Typus in der Nationalökonomie, aao. (Anm. 137), S. 168; Mathias, W., aao. (Anm. 248), S. 69, 86, 101f.; Albert, H., Ökonomische Ideologie und politische Theorie, aao. (Anm. 230), S. 38; ders., Modell-Platonismus. Der neoklassische stil des ökonomischen Denkens in kritischer Betrachtung, Sozialwissenschaft und Gesellschaftsgestaltung. Festschrift für Gerhard Weisser, S. $45 \mathrm{ff}$., wieder abgedruckt und zitiert nach Albert, H., Marktsoziologie und Entscheidungslogik, s. $331 \mathrm{ff}$. (333ff.).

256) Vleugels, W., aaO. (Anm. 143), S. 504 .

257) Die Frage nach dem Informationsgehalt einer Theorie darf nicht mit deren Realitätsbezug verwechselt werden (Albert, H., Modell-Platonismus, aao. (Anm. 255), 
S. $333 \mathrm{ff.}$; ders., Probleme der Theoriebildung, aao. (Anm. 244), S. 22; Mathias, W., aaO. (Anm. 248), S. 89). Es gibt wohl kaum einen realwissenschaftlichen Theoretiker, der den empirischen Bezug seiner wissenschaftlichen Bemühungen selbst in Frage stellt. Für Eucken bedarf dies nach der Darstellung seines Wissenschaftsprogramms keiner gesonderten Begründung mehr. In diesem Zusammenhang vgl. auch Mathias, W., aao. (Anm. 248), S. 92: "Die Analytizität (...) ermöglicht es also, Aussagen mit empirischem Bezug aufzustellen, die gegenüber jeden logischen Widerlegungsversuchen immun sind. Sie verdanken diese Eigenschaft der Tatsache, daß sie unter strikter Beachtung der logischen Gesetze gebildet und damit unter den 'Schutz der Logik' gestellt werden, obwohl sie durch die Verwendung deskriptiver Ausdrücke die Vorstellung erwecken, als würde über die Wirklichkeit gesprochen."

258) Kraft, V., aao. (Anm. 248), S. 191.

259) Eucken, W., Kapitaltheoretische Untersuchungen, S. $28 \mathrm{f}$.

260) Albert, H., Probleme der Theoriebildung, aao. (Anm. 244), S. 25, bezeichnet Euckens Theorie als eine Kombination von "Wahrheit und Leerheit (Mangel an Informationsgehalt)".

261) Albert, H., Ökonomische Ideologie und politische Theorie, aao. (Anm. 230), S. 39; Mathias, W., aao. (Anm. 248), S. 159ff.; Kraft, V., aao. (Anm. 248), S. $241 \mathrm{ff.,}$ 257; Woll, A., Allgemeine Volkswirtschaftslehre, S. 8ff.; Reigrotzki, E., aao. (Anm. 255), S. 16: Eine "hypothesenfreie Wissenschaft (ist) eine Wissenschaft ohne jegliche Realaussagen". zum gegensätzlichen Charakter der hypothetischen Urteile in der Theoriebildung Euckens vgl. nochmals ders., Kapitaltheoretische Untersuchungen, S. $28 \mathrm{ff}$.

262) Albert, H., Modell-Platonismus, aao. (Anm. 255), S. 408; ders., Probleme der Theoriebildung, aao. (Anm. $244)$, S. 23 .

263) Bei Eucken tritt das Problem der Verifikation seiner theoretischen Sätze auf Grund der vermeintlich realitätskonformen Modellkonstruktion überhaupt nicht auf. "Es gibt weder Hypothesenbildung noch Verifikation und Prognose, sondern statt dessen lediglich die Explikation vorausgesetzter Annahmen definitorischen Charakters, deren Formulierung dem Wahrheitssuchenden die Vermutung nahelegt, es handele sich um echte Realgesetze, in denen eine Konstanz des ökonomischen Geschehens zum Ausdruck komme" (Albert, H. Ökonomische Ideologie und politische Theorie, aao. (Anm. 230), S. 40f.; ders., Der logische Charakter der theoretischen Nationalökonomie, aao. (Anm. 230), S. Iff. (8). 
264) Zur Frage der Prüfung wissenschaftlicher Theorien, auf die hier nicht weiter einzugehen ist, im besonderen auch zum Popperschen Kriterium der Falsifikation vgl. Popper, K.R., Logik der Forschung, passim; Albert, H., Probleme der Theoriebildung, aao. (Anm. 244), S. 53ff.; ders., Traktat über kritische Vernunft, S. 29ff. (30); ders., Ökonomische Ideologie und politische Theorie, aao. (Anm. 230), S. 42f.; Richter, R., Methodologie aus der sicht des Wirtschaftstheoretikers, in: Jochimsen, R./Knobel, H. (Hrsg.), Gegenstand und Methoden der Nationalökonomie, S. 190ff. (192). Mit diesem Kriterium wird das Prinzip der zureichenden Begründung zugunsten des Prinzips der kritischen Prüfung abgelöst, was zur Folge hat, daß "an die stelle eines im Grunde dogmatisch-apologetischen Programms das Programm der freien unabhängigen Kritik, einer Kritik ohne Rekurs auf eine Autorität und daher ohne die Annahme einer Wahrheitsgarantie" tritt (Albert, H., ökonomische Ideologie und politische Theorie, aao. (Anm. 230), S. 172, 173; damit wird die Suche nach der Wahrheit von der "Strategie der kritischen Überprüfung von Theorien, die wohl der Wahrheit an sich, nicht aber der Verfolgung eines absoluten Wahrheitsanspruchs verpflichtet" sind, abgelöst (Ruffner, A., Zum Normproblem in der Wirtschaftswissenschaft, S. 76). Diesem Prinzip folgend, ginge der von Eucken gesuchte "archimedische Punkt" letztlich verloren.

265) Wulff, M., aaO. (Anm. 237), S. 17; Ruffner, A., aaO (Anm. 264), S. 82; Hütten, K.W., Die "große Antinomie der Nationalökonomie" und der positive vorschlag Walter Euckens zu ihrer Überwindung, Diss. Heidelberg 1949, S. 148 .

266) Eucken, W., Grundlagen, S. 163.

267) Die "- obwohl aus exakter Beobachtung der Wirklichkeit entstanden - keine Abbilder konkreter Wirklichkeit" sind (Eucken, W., Grundlagen, S. 163).

268) Eucken, W., Grundlagen, S. $162 \mathrm{ff}$.

269) Eucken, W., Grundlagen, S. 172.

270) Eucken, W., Grundlagen, S. 164.

271) Eucken, W., Grundlagen, S. 166f., 171.

272) Eucken, W., Grundlagen, S. 166.

273) Eucken, W., Grundlagen, S. 166.

274 ) Eucken, W., Grundlagen, S. 169.

275) Eucken, W., Grundlagen, S. 170. 
276) Eucken, W., Grundlagen, S. 171.

277) Eucken, W., Grundlagen, S. 172.

278) Eucken, W., Grundlagen, S. 169.

279) Eucken, W. , Grundlagen, S. 169.

280) Eucken, W., Grundlagen, S. 65.

281) Eucken, W., Grundlagen, S. 171.

282) Eucken, W., Grundlagen, S. 171ff., 227, 235.

283) Eucken, W., Grundlagen, S. 173.

284 ) Wodurch sich das von Wulff, M., aao. (Anm. 237), S. $18 \mathrm{f}$. beklagte Fehlen einer aus Idealtypenkombinationen entwickelten Theorie mit bedeutendem Aussagewert erklärt.

285) Haller, H., aaO. (Anm. 94), S. 101.

286) Haller, H., aaO. (Anm. 94), S. $101 \mathrm{f}$.

287) Eucken, W., Grundlagen, S. 173, ähnlich S. 228; ders., Die Überwindung des Historismus, S. 213; ders., Kapitaltheoretische Untersuchungen, s. 30 .

288) Eucken, W., Grundlagen, S. 167.

289) Jessen, J., aao. (Anm. 56), S. 362.

290) Feuerbach, A. zit. nach Dux, G., strukturwandel der Legitimation, S. 221.

291) Eucken, W., Grundsätze, S. 340 .

292) Eucken, W., Grundsätze, S. 340; ders., Grundlagen, S. $238 \mathrm{ff}$.

293) Eucken, W. , Grundsätze, S. 7, 25, 240; ders., Grundlagen, S. $240 f$.

294) Eucken, W. , Grundsätze, S. 9, 11, 340; ders., Grundlagen, S. $240 f$.

295) Lutz, F.A., aao. (Anm. 12), S. XIII; Jöhr, W.A./Singer, H.W., aaO. (Anm. 30), S. 20, weisen darauf hin, daß Inhalt und Rechtfertigung der Euckenschen Theorie darin liegen, "daß sie die 'Grundlagen' liefert, mit deren Hilfe (...) irgendwelche wirtschaftspolitischen Daten behandelt werden können". 
296) Begriff bei Sauermann, H., Zur Problematik der Sozialordnung, in: Wirtschaftsfragen der freien Welt. Zum 60. Geburtstag von Ludwig Erhard, S. 9; Riese, H., Ordnungsidee und ordnungspolitik. Kritik einer wirtschaftspolitischen Konzeption, Kyklos, Vol. XXV (1972), S. 32 .

297) Zum Problem der (eingestandenen oder uneingestandenen) Wertung im Bereich der theoretischen Problemstellung Ferber, Ch. v., Der Werturteilsstreit 1909/1959, Kölner zeitschrift für Soziologie und Sozialpsychologie, 11. Jahrgang (1959), S. 21ff. Weber, M., Die "Objektivität" sozialwissenschaftlicher und sozialpolitischer Erkenntnis, in: Archiv für Sozialwissenschaft und Sozialpolitik, Bd. XIX (1904), S. 58: "Was Gegenstand der Untersuchung wird, und inwieweit diese Untersuchung sich in die Unendlichkeit der Kausalzusammenhänge erstreckt, das bestimmen die den Forscher und seine zeit beherrschenden Wertideen"; Albert, H., Traktat über kritische Vernunft, s. 65.

298) Schiller, K., Neuere Entwicklungen in der Theorie der Wirtschaftspolitik, s. $5 f$.

299) Zum Werturteils- oder "jüngeren Methodenstreit" vgl. Jochimsen, R./Knobel, H., Zum Gegenstand und zur Methodik der Nationalökonomie, in: Jochimsen, R./Knobel, H. (Hrsg.), Gegenstand und Methoden der Nationalökonomie, S. 26ff. Dazu auch Runge, U., aao. (Anm. 237), S. $55 f f$.

300) Albert, H., Traktat über kritische Vernunft, s. 65.

301) "Nichts würde das neoliberale Wissenschaftsverständnis weniger kennzeichnen, als seine Identifizierung mit dem zu Recht oder zu Unrecht Max Weber zugeschriebenen Postulat der 'Wertfreiheit'", Rücker, J., Grenzen neoliberaler strategie im Nord-Süd-Konflikt, s. 21.

302) Weber, M. zit. nach Eucken, W., Grundsätze, S. 340.

303) Vgl. hierzu auch Runge, U., aaO. (Anm. 237), S. 56.

304 ) Weber, M., Wissenschaftslehre, S. 500, 501, 510, $601 \mathrm{f}$.

305) Strauss, L., Die Unterscheidung zwischen Tatsachen und Werten, in: Albert, H./Topitsch, E. (Hrsg.), Werturteilsstreit, s. 75 mit weiteren Nachweisen auf diese Unterscheidung bei $M$. Weber.

306) Albert, H., Traktat uber kritische Vernunft, S. 56.

307) Weber, M., Wissenschaftslehre, S. 147.

308) Weber, M., Wissenschaftslehre, S. 149. 
309) Jochimsen, R./Knobel, H., aaO. (Anm. 299), S. 29.

310) Weber, M., Wissenschaftslehre, S. 200, 508. Es ist deshalb "eine elementare pflicht der wissenschaftlichen Selbstkontrolle und das einzige Mittel zur Verhütung von Erschleichungen, die logisch vergleichende Beziehung der Wirklichkeit auf Idealtypen in logischem Sinne von der wertenden Beurteilung der wirklichkeit aus Idealen heraus scharf zu unterscheiden", ebd., S. 200.

311) Weber, M., Wissenschaftslehre, S. 529.

312) Albert, H., Traktat über kritische Vernunft, S. 58.

313) Weber, M., Wissenschaftslehre, S. 149.

$314)$ Weber, M., Wissenschaftslehre, S. 157, 147, 149.

315) Die empirische Gedankenarbeit betrifft zweierlei: zum einen sind, wenn gemäß einem "bestimmten wirklich eindeutigen Werturteil im Interesse eines bestimmten sollens" gehandelt wird, dann "nach wissenschaftlicher Erfahrung, die und die Mittel" anzuwenden, um den, "jenem Wertaxiom entsprechenden, Zweck zu erreichen". Zweitens wird eine Aussage darüber möglich, in welchem Umfang "nach wissenschaftlicher Erfahrung mit den für die Realisierung dieses Werturteils unentbehrlichen Mitteln noch andere, unbeabsichtigte Nebenerfolge" erzielt werden (Weber, M., Die Produktivität der Volkswirtschaft, Debatte, in: Schriften des Vereins für Socialpolitik, Bd. 132 (1910), S. 582).

316) Weddigen, W., Das Werturteil in der politischen wirtschaftswissenschaft, Jahrbücher für Nationalökonomie und Statistik, Bd. 153 (1941), S. 265.

317) Weber, M., Wissenschaftslehre, S. 608, 510; dazu im einzelnen Albert, H., Traktat über kritische Vernunft, S. 69; ders., Theorie und Praxis. Max Weber und das Problem der Wertfreiheit und der Rationalität, in: Albert, H./Topitsch, E. (Hrsg.), Werturteilsstreit, S. $204 \mathrm{f}$., S. $229 \mathrm{ff}$.; Jochimsen, R./Knobel, H., aaO. (Anm. 299), S. 29f.; Weber, W./Topitsch, E., Das Wertfreiheitsproblem seit Max Weber, in: Jochimsen, R./ Knobel, H. (Hrsg.), Gegenstand und Methoden der Nationalökonomie, S. $137 \mathrm{ff}$.

318) Weber, M., Wissenschaftslehre, S. 151, 157, 153, 501, 503 .

319) Weber, M., Wissenschaftslehre, S. 151.

320) Albert, H., Theorie und Praxis, aao. (Anm. 317), S. 218; ders., Traktat über kritische Vernunft, s. 57. 
321) In diesem Zusammenhang vgl. Weisser, G., Zur Erkenntniskritik der Urteile, in: Albert, H./Topitsch, E. (Hrsg.), Werturteilsstreit, S. 129; Albert, H., Traktat über kritische Vernunft, s. 66.

322) Weber, M., Wissenschaftslehre, S. 603.

323) Albert, H., Theorie und Praxis, aao. (Anm. 317), S. 233; ders., Traktat über kritische Vernunft, S. 69 .

324) Albert, H., Theorie und Praxis, aao. (Anm. 317), S. 205 .

325) Weber, M., Wissenschaftslehre, S. 613, 152, 503, 150.

326) Weber, M., Wissenschaftslehre, S. 152.

327) Vgl. dazu eingehender Dubislav, W., Zur Unbegründbarkeit von Forderungssätzen, in: Albert, H./Topitsch, E. (Hrsg.), Werturteilsstreit, S. 438ff.; Weddigen, W., aao. (Anm. 316), S. 265.

328) Weber, M., Wissenschaftslehre, S. 503, 154 : "Nur positive Religionen - präziser ausgedrückt: dogmatisch gebundene sekten - vermögen dem Inhalt von Kulturwerten die Dignität unbedingt gültiger ethischer Gebote zu verleihen".

329) Weisser, G., aaO. (Anm. 321), S. $147 \mathrm{f}$.

330) Albert, H., Traktat über kritische Vernunft, s. 70.

331) Albert, H., Traktat über kritische Vernunft, s. 70.

332) Lenk, K. , Das Werturteilsproblem bei Max Weber, Zeitschrift für die gesamte staatswissenschaft, Bd. 120 $(1964)$, s. 57 .

333) Weber, M., Wissenschaftslehre, S. 603, 608.

334) Eucken, W., Grundsätze, S. 340.

335) Eucken, W., Grundsätze, S. $340 f$.

336) Eucken, W., Grundsätze, S. 342 .

337) Eucken, W., Grundsätze, S. $340 f$.

338) Weber, M., Wissenschaftslehre, S. 602: "Dem Propheten wie dem Demagogen ist gesagt: 'Gehe hinaus auf die Gassen und rede öffentlich' ... im Hörsaal ... haben Sie zu schweigen" (vollständiges Zitat bei Eucken, w., Grundsätze, S. 341).

339) Eucken, W. , Grundsätze, S. 342 . 
340) Lutz, F.A., aaO. (Anm. 12), S. XIII.

341) Runge, U., aao. (Anm. 237), S. 56.

342 ) Runge, U., aao. (Anm. 237), S. 56.

343) Hesse, G., Staatsaufgaben, S. 230.

344 ) Smith, A. zit. nach Eucken, W., Grundsätze, S. 195.

345) Eucken, W., Grundsätze, S. 73; ders., Die soziale Frage, S. $119 f$.

346) Eucken, W., Grundsätze, S. 53, 27.

347) Hesse, G., Staatsaufgaben, S. 239.

348) Diese Wendung übersieht Doerge, F.W., Menschenbild und Institution in der Idee des Wirtschaftsliberalismus bei Adam Smith, L. v. Mises, W. Eucken und F.A. v. Hayek, Hamburger Jahrbuch für Wirtschafts- und Gesellschaftspolitik, Festausgabe für Eduard Heimann, 4. Jahrgang (1959), S. 90f., in seiner Analyse des Euckenschen Ordnungsverständnisses, wenn er diesem nach wie vor die Suche nach einer "natürlichen gottgewollten ordnung" unterstellt und diese ordnung als Wertmaßstab ordnungspolitischer Entscheidung ansieht.

349) Eucken, W. , Grundlagen, S. 26; ders., Grundsätze, S. $194 \mathrm{f}$. Eucken attestiert den Klassikern jedoch, das Lenkungsproblem "gestellt und mit neuartigen Methoden behandelt" sowie "den Gesamtzusammenhang des ökonomischen Geschehens entdeckt und die Methode wirtschaftstheoretischen Denkens in umfassender Weise entwickelt zu haben" (Grundlagen, S. 243 Anm. 1, 24; ähnl. ders., Grundsätze, S. 194).

350) Eucken, W., Wettbewerbsordnung, S. 7; ders., Grundsätze, S. 55; ders., Die soziale Frage, S. 125.

351) Nawroth, E.E., aao. (Anm. 32), S. 173.

352) Eucken, W., Grundsätze, S. 54, 242, 253; ders., Wettbewerbsordnung, S. 6 .

353) Eucken, W., Die soziale Frage, S. 120; ders., Grundsätze, s. 53; ders. Wettbewerbsordnung, s. 7.

354) Eucken, W., Unser Zeitalter der MiBerfolge, S. 72 ; ders., Grundsätze, S. 242; ders., Wettbewerbsordnung, S. 7, 93; ders., Die soziale Frage, S. 120; ders. Deutschland vor und nach der Währungsreform, S. 182 .

355) Eucken, W., Grundlagen, S. 238, 51, $167 \mathrm{f}$. 
356) Runge, U., aao. (Anm. 237), S. 75f., 56f. "Wir trennen diese Begriffe, indem wir die konkreten 'Wirtschaftsordnungen' von dem streben nach 'Ordnung der wirtschaft' unterscheiden" (Eucken, W., Grundlagen, S. 239).

357) Eucken, W., Grundlagen, S. 239; ders., Grundsätze, S. 14; ders., Wettbewerbsordnung, S. 1; ders., Wettbewerb als Grundprinzip der Wirtschaftsverfassung, S. 48 .

358) Doerge, F.W., aao. (Anm. 348), S. 89, sieht die Entwicklung des Ordogedankens bei Eucken entscheidend beeinflußt durch die Gedankenwelt seines Vaters Rudolf Eucken, der "in der Geschichte der Menschheit nach Syntagmen" forschte, d.h. "jenen Zusammenhängen, die alle Fülle des Lebens in einer Haupterfahrung zusammenfassen, wie es z.B. die christliche Lebensordnung des Mittelalters tat. Die gegenwärtige Lage aber sei durch ein haltloses Schwanken zwischen verschiedenen Lösungen gekennzeichnet. Allgemein werde das Bedürfnis nach einem neuen Lebenszusammenhang empfunden, der (...) die Menschheit einem neuen Höhepunkt zuführen könnte". Diese, von seinem Vater gestellte ordnungsaufgabe, so F.W. Doerge, versuche Eucken durch den ordo, der das Syntagma ablöst, $z u$ bewältigen. Vgl. in diesem Zusammenhang auch Dürr, E.-W., aaO. (Anm. 8), S. 52 und Runge, U., aao. (Anm. 237), S. $75 f$.

359) Eucken, W., Grundsätze, S. 372, 73; ders., Grundlagen, S. 239 .

360) Nawroth, E.E., aao. (Anm. 32), S. $57 \mathrm{ff.;} \mathrm{hierzu} \mathrm{auch}$ Runge, U., aao. (Anm. 237), S. 20ff.; Glahe, W., Theoretische Grundlagen neoliberaler Wirtschaftspolitik und ökonomischer Macht, in: Andreae, C.-A./Glahe, W., Das Gegengewichtsprinzip in der Wirtschaftsordnung, Bd. 1: Wirtschaftliche Macht und Wettbewerb, S. 91.

361) "Das Wesen der menschlichen Person ist Freiheit" (Coing, H., Die obersten Grundsätze des Rechts, S. 64); dazu auch Seidel, B., Industrialismus und Kapitalismus, S. 405 .

362) Eucken, W., Grundsätze, S. 175ff. (176).

363) Canfora zit. nach Eucken, w., Grundsätze, S. 178.

364 ) Nawroth, E.E., aaO. (Anm. 32), S. 76.

365) Alle Zitate Eucken, w., Grundsätze, S. 179.

366) Eingehend dazu und zum Freiheitsbegriff des Neoliberalismus überhaupt Nawroth, E.E., aaO. (Anm. 32), S. 78f.; Runge, U., aao. (Anm. 237), S. 31ff.; Werner, J., 
Wohlstand, S. 49ff.; Seidel, B., aaO. (Anm. 361), S. 408 .

367) "Freiheit und ordnung sind kein Gegensatz. Sie bedingen einander. "Ordnen heißt in Freiheit ordnen'" (Eucken, W. , Grundsätze, S. 179).

368) Alle Zitate Eucken, W., Grundsätze, S. 26f.; ders., Wettbewerbsordnung, s. 4; ders., Unser Zeitalter der Mißerfolge, S. 4.

369) Eucken, W., Grundsätze, S. 30f., 43ff., 48ff., 53f., 176.

370) Werner, J., aao. (Anm. 366), S. 151.

371) Eucken, W., Grundsätze, S. 183.

372) Eucken, W. , Grundsätze, S. 184.

373) Eucken, W. , Grundsätze, S. 190.

374 ) Eucken, W. , Grundsätze, s. 8, 370; ders., Grundlagen, S. 240; kritisch zur nicht hergeleiteten Knappheitsprämisse bei Eucken Moritz, K., Das Argument der wirtschaftsverfassung. Die Verwendung nationalökonomischer Kategorien im juristischen Denken, Diss. Frankfurt 1972, S. 82; Nawroth, E.E., aao. (Anm. 32), S. 336.

375) Eucken, W., Grundsätze, S. 315, 314.

376) Albert, A., Ökonomische Ideologie und politische Theorie, aao. (Anm. 230), S. 112 nennt es "Alternativ-Radikalismus"; dazu und zum folgenden auch Nawroth, E.E., aao. (Anm. 32), S. 60, 358 und Runge, U., aao. (Anm. 237), S. 66 .

377) Eucken, W., Grundsätze, S. 198, 245.

378) Wobei Eucken hier ausschließlich die Befürchtung äuBert, daß diese Transformation in Richtung Zentralverwaltungswirtschaft stattfindet (Grundsätze, S. 198). "Für die Wirtschaftspolitik ergeben sich aus dieser Erkenntnis wichtige Folgerungen. Wenn in gemischten Systemen die Zentralverwaltungswirtschaft für die Verkehrswirtschaft und die Verkehrswirtschaft für die Zentralverwaltungswirtschaft Tod und Siechtum bedeuten, so folgt, daß man sich für die eine oder für die andere ordnung entscheiden und sodann seine ganze sorgfalt darauf verwenden muß, die gewählte ordnung in ihrer Reinheit zu verwirklichen" (Böhm, F., aao. (Anm. 5), S. $\mathrm{XXVf}$.).

379) Dazu insgesamt Eucken, w., Grundsätze, s. 61ff. und ders., on the Theory of the centrally Administered 
Economy. An Analysis of the German Experiment, Economia, Mai und September 1948.

380) Zur einseitig geprägten Sicht Euckens beim Vergleich der Wirtschaftssysteme vgl. auch Salin, E., Walter Eucken in memoriam, Kyklos, Vol. IV (1950), S. 3; Cordes, W., Das ordnungsbild der Gesellschaft und seine Bedeutung für die wirtschaftsverfassung in der Lehre des Kreises um das ordo-Jahrbuch und in der heutigen katholischen Sozialethik, Diss. München 1954, S. 54f.; Riese, H., aaO. (Anm. 296), S. 36; Schachtschnabel, H.G., Wirtschaftspolitische Konzeption, S. 68f.; Moritz, K., aao. (Anm. 374), S. 85; Herder-Dorneich, P., Wirtschaftsordnungen, S. 81, nennt das Weltbild Euckens "(a) usgesprochen monozentrisch", weil "auf die Marktwirtschaft konzentriert".

381) "Allein der Planbedarf der Zentralverwaltung entscheidet", das Problem der "individuellen Äquivalenz von Werten" tritt nicht auf (Eucken, W., Grundsätze, s. $101,67 f$.$) .$

382) Eucken, W., Grundsätze, S. 77.

383) Eucken, W., Grundsätze, S. $77 \mathrm{ff.,} \mathrm{100ff.} \mathrm{Da} \mathrm{es} \mathrm{"keinen}$ Tausch, keinen Markt, keine Lenkung durch Preise" gibt, kann das Lenkungsproblem nur durch "Zuweisung von Rohstoffen, Maschinen usw. an die Betriebe, von Arbeitsplätzen an die Arbeiter, von Konsumgütern an die Konsumenten" gelöst werden (Eucken, W., Grundsätze, S. 101).

384) Eucken, W., Grundsätze, S. 174, 243, 263; ders., Wettbewerbsordnung, S. 12 .

385) Eucken, W. , Grundsätze, S. 126, 131, 177, 179, 365; ders., Grundlagen, S. 87.

386) Eucken, W., Die soziale Frage, S. 116.

387) Eucken, W. , Grundsätze, S. 131, 371.

388) Eucken, W., Grundsätze, S. $128 \mathrm{ff}$.

389) Eucken, W., Grundsätze, S. 370.

390) Eucken, W. , Grundsätze, S. 191, 240.

391) Eucken, W., Grundsätze, s. 245.

392) Meyer-Dohm, P., Wirtschaftsordnungsmodelle und Wirklichkeit, Hamburger Jahrbuch für wirtschafts- und Gesellschaftspolitik, 10. Jahrgang (1965), S. 145; Eukken, W., Grundsätze, S. 198, 244ff., 249, 254f., 374 .

393) Eucken, W., Grundsätze, S. $245 \mathrm{f}$. 
394) "Nur bei freier Entfaltung der spontanen Kräfte, also bei freiem Wirken des Einzelinteresses ist es möglich, das Gesamtinteresse zu fördern. Eine Knebelung der individuellen Freiheit (...) drosselt in den Einzelinteressen der vielen Haushalte und Betriebe die Motoren des Wirtschaftsprozesses, die inn um so besser in Gang setzen und dem Gesamtinteresse dienen, je freier sie sich betätigen können. Dies ist der Gedanke" (Eukken, W., Grundsätze, S. 157). Es wird hier offensichtlich, daß die persönliche Freiheit ökonomisch funktionalisiert wird, um die weitestgehende Überwindung der Knappheit an Gütern zu erreichen, vgl. dazu auch Nawroth, E.E., aaO (Anm. 32), S. $124 \mathrm{ff}$.

395) Eucken, W., Grundsätze, S. 369, $249,357$.

396) Alle Zitate Eucken, W., Grundsätze, S. 370.

397) Eucken, W., Grundsätze, S. 100f. (101), 354 .

398) Eucken, W., Grundlagen, S. 211.

399) Eucken, W., Grundsätze, S. 8; ders., Grundlagen, S. 214 .

400) "Es wird zur großen Aufgabe der Wirtschaftspolitik, die Kräfte, die aus dem Einzelinteresse entstehen, in solche Bahnen zu lenken, daß hierdurch das Gesamtinteresse gefördert wird, $d a \beta$ also eine sinnvolle Koordination der Einzelinteressen stattfindet" (Eucken, W., Grundsätze, S. 360).

401) Eucken, W., Grundsätze, S. 116, 353f.; ders., Grundlagen, S. 214 .

402) Eucken, W., Grundsätze, S. 255f., $366 \mathrm{ff}$.

403) Eucken, W., Grundsätze, S. 8; ders., Grundlagen, S. 214; ders., Deutschland vor und nach der Währungsreform, S. 156 .

404 ) Eucken, W., Grundsätze, S. 161f. (162).

405) Eucken, W., Grundsätze, S. 156, 161, 163, 236f., 245f., 249,300 .

406) Eucken, W., Grundsätze, S. 249, $314 \mathrm{f}$.

407) Salin, E., aao. (Anm. 6), S. 382; dazu auch Riese, H., aao. (Anm. 296), S. 30 .

408) Tinbergen, J., Wirtschaftspolitik, S. 45. 
409) Molitor, B., Theorie der Wirtschaftspolitik und Werturteil, Hamburger Jahrbuch für Wirtschafts- und Gesellschaftspolitik, 8. Jahrgang (1963), S. 86.

$410)$ Peter, H., Freiheit der Wirtschaft, S. 109, 131; Riese, H., aao. (Anm. 296), S. 30.

411) Honigsheim, P., Die Gründung der Deutschen Gesellschaft für Soziologie, Kölner zeitschrift für Soziologie und Sozialpsychologie, 11. Jahrgang (1959), S. 9.

412) Molitor, B., aao. (Anm. 409), S. 93.

413) Woll, A., aao. (Anm. 261), S. 10.

414 ) Weber, M., Wissenschaftslehre, S. 149f.; dazu auch Werner, J., aao. (Anm. 366), S. $15 f$.

415) Dazu bereits eingehend vorne, S. $59 \mathrm{ff}$.

416) Eucken, W., Grundsätze, S. 373.

417) Eucken-Erdsiek, E., Chaos und stagnation, ordo I $(1948)$, S. 8 .

418 ) Hensel, K.P., Ordnungspolitische Betrachtungen zur katholischen Soziallehre, Ordo II (1949), S. 266f.; Böhm, F., aao. (Anm. 5), S. XLVIII: "Die Konzeption dieser ordnung entstammt nicht dem menschlichen Gehirn, sondern ist ein Teil des Gesetzes, nach dem wir angetreten sind", sie ist "die von Menschen vorgefundene, nicht von ihnen geschaffene ordnung".

419) Eucken, W., Grundsätze, S. 374 .

420) Eucken, W. , Grundsätze, s. 374 .

421) Eucken, W., Grundsätze, s. 374 .

422) Miksch, L., Wettbewerb als Aufgabe, S. 12; Eucken, W., Wettbewerb als Grundprinzip der Wirtschaftsverfassung, S. 44; ders., Grundsätze, S. 374. Zur Ersetzung der altliberalen Harmonieerwartung durch die politische Entscheidung im ordo-Liberalismus auch Becker, H.P., Die soziale Frage im Neoliberalismus, S. 132; Riese, H., aaO. (Anm. 296), S. 35; Runge, U., aaO. (Anm. 237), S. 74; Dürr, E.-W., aaO. (Anm. 8), S. 147; Nawroth, E.E., aaO. (Anm. 32), S. 243 .

423) Riese, H., aaO. (Anm. 32), S. 33, 36.

424) Eucken, W., Grundlagen, S. 123.

425) Weber, M., Wissenschaftslehre, S. 537. 
426) Nawroth, E.E., aao. (Anm. 32), S. 308; Riese, H., aao. (Anm. 296), S. 35; dazu auch Ritschl, H., Wirtschaftsordnung und Wirtschaftspolitik, Weltwirtschaftliches Archiv, Bd. 65 (1950 II), S. $218 \mathrm{ff} .$, S. $239 \mathrm{f}$.

427) Runge, U., aaO. (Anm. 296), S. 37; ähnl. Becker, H.P., aao. (Anm. 422), S. 132; Frank, P., Das Dilemma des Neo-Liberalismus, Die neue ordnung, 3. Jahrgang (1949), S. 172. Eine interessante Folge der praktisch brauchbaren Wissenschaft im stile Euckens zeigt R. Blum (Der Wettbewerb im wirtschaftspolitischen Konzept, Zeitschrift für die gesamte staatswissenschaft, Bd. 121 (1965), S. 60ff. (62)) auf, wenn er darauf hinweist, daß das Bundeskartellamt in seinem ersten Tätigkeitsbericht feststellte, daß die "Frage nach der Bedeutung des Wettbewerbs (...) nicht nach Zweckmäßigkeitsgesichtspunkten, sondern nur vom Grundsätzlichen her beantwortet werden" kann.

428) Nawroth, E.E., aaO. (Anm. 32), S. 304. Zu erinnern ist in diesem Zusammenhang nochmals an den Satz $M$. Webers, daß aus der notwendigen Trennung von Erkenntnis und Entscheidung die zwangsläufige Folgerung zu ziehen ist, daß die Maßstäbe des politischen Urteils nicht "dem stoff zu entnehmen" sind, "d.h. die 'Idee' im Sinne des Ideals aus der 'Idee' im sinne des 'Idealtypus'" niemals entwickelt werden kann (Wissenschaftslehre, S. 200).

429) Dazu vorne S. $64 \mathrm{ff}$.

430) Dazu auch Albert, H., Ökonomische Ideologie und politische Theorie, aao. (Anm. 230), S. 11 .

431) Albert, H., Traktat über kritische Vernunft, S. 55.

432) Ross, A., Kritik der sogenannten praktischen Erkenntnis, S. 20. Zur Kritik einer solchen Erkenntnis auch Albert, H., Das Werturteilsproblem im Lichte der logischen Analyse, Zeitschrift für die gesamte staatswissenschaft Bd. 112 (1956), S. 419.

433) Ruffner, A., aao. (Anm. 264), S. 98.

$434)$ Albert, H., Traktat über kritische Vernunft, S. 70.

435) Eucken, W., Grundsätze, S. 143.

436) Eucken, W., Die Überwindung des Historismus, S. 205; ders., Kapitaltheoretische Untersuchungen, S. 3; ders., Unser Zeitalter der Mißerfolge, S. 59. In diesem Zusammenhang muß sich Eucken insbesondere gegen den "Mythos von der Zwangsläufigkeit der Entwicklung" zur Wehr setzen (Grundsätze, S. 200ff.; Böhm, F./Großmann-Doerth, H./Eucken, W., Unsere Aufgabe, S. 90f.). Träfe es zu, 
daß sich die Wirtschaftsordnung mit der "Notwendigkeit eines Naturprozesses" in "unabsehbarer zwangsläufiger Folge" (Grundsätze, S. 200) fortentwickelt, dann wäre jede Wirtschaftspolitik ohne eigenständige Funktion. Der durch die Marxsche Entwicklungstheorie prognostizierte, zwangsläufige Endzustand einer klassenlosen Gesellschaft mit einer Diktatur des Proletariats (Grundsätze, S. 203, 205, 210) nährt den Glauben an ein Fatum: "Aus dieser fatalistischen Geschichtsauffassung ergibt sich die Haltung der müden Resignation" für die es " $(z)$ wecklos oder närrisch erscheint (...), sich dem ehernen Gang der Ereignisse entgegenzustellen oder sich für eine Idee einzusetzen" (Böhm, F./Großmann-Doerth, H. /Eucken, W., Unsere Aufgabe, S. 91). Wirtschaftspolitik wird zur "Vollstreckerin des geschichtlichen Schicksals: ohne Freiheit" (Grundsätze, S. 204), menschliche Vernunft wird machtlos (Grundsätze, S. 211). Eine solche Auffassung stellt für Eucken die "Grundlagen der Wirtschaftspolitik" zur Disposition, da ihr nicht einmal mehr die Chance verbleibt, lebensformend zu wirken. "Wie kann der Geist die Tatsachen gestalten, wenn er sich selbst vor dem Gang der Tatsachen verneigt?" (Böhm, F./Großmann-Doerth, H./Eucken, W., Unsere Aufgabe, S. 92). Nur die völlige Negation einer schicksalhaften Entwicklungslogik schafft "die Freiheit, die Wirtschaftspolitik so zu gestalten, wie es den Erfordernissen des Menschen und der Sache entspricht" (Grundsätze, S. 204) und damit die Möglichkeit, die in diesem sinne als richtig und gut erkannte ordnung bewußt durchzusetzen (Grundsätze, S. 213, 218, 225) . Kurz: Marx ist als "ideologischer Feind des ordo" zu entlarven (Böhm, F., aaO. (Anm. 5), S. LVI). Nur so kann das ökonomische Denken die Funktion, die ihm Eukken zugedacht hat und die er durch den Einbau methodischer Sicherungen erreicht zu haben glaubt, erfüllen: es wird zum wirtschaftlichen Machtfaktor, da es "richtungsgebend das wirtschaftspolitische Handeln" bestimmt und zwar nicht nur als "ein Reflex der jeweiligen wirtschaftlichen und sozialen situation, wie Marx glaubte", sondern es wird zur "selbständigen Potenz" (Unser Zeitalter der Mißerfolge, S. 59).

Der Angriff Euckens auf die marxistische Geschichtslehre dient damit einerseits der Wiedergewinnung der uneingeschränkten Gestaltungsmöglichkeit und zum anderen schafft er erst die Grundlage, um die eigenen Erkenntnisse wirtschaftspolitisch durchzusetzen (Hesse, G. , staatsaufgaben, S. 221). Kritisch zur Auseinandersetzung Euckens mit Marx Beckerath, E. v., Walter Eukkens Grundsätze der Wirtschaftspolitik, ordo V (1953), S. $295 f$.

In seinem Nachruf auf Walter Eucken beschreibt F. Böhm die befreiende Wirkung, die diese Erkenntnis im gesamten Kreis um Walter Eucken hervorrief: "Indem uns Eukken lehrte, in einem Nebeneinander von ordnungsmöglichkeiten, anstatt in einem Nacheinander von geschicht- 
lichen, psychologischen oder soziologischen Zwangsläufigkeiten oder Wahrscheinlichkeiten zu denken, hat er eine wahrhaft befreiende Tat vollbracht. Es ist wie der Durchbruch aus lähmender Enge und unentrinnbarer Verhaftung in Schicksal oder Pseudowerte in eine Welt der freien und verantwortlichen Wahl" (aao. (Anm. 5), S. $\mathrm{XLI}$ ).

437) Eucken, W., Grundsätze, S. 378; ähnl. ebd., S. 251, $221,196 \mathrm{ff}$.

438) Miksch, L. zit. nach Eucken, W., Grundsätze, S. 11; ähnl. Eucken, W., Grundlagen, S. 241 ; ders. Grundsätze, S. 340 ; ders., Wettbewerb als Grundprinzip der Wirtschaftsverfassung, S. 39 .

439) Eucken, W., Grundsätze, S. 325.

440) Eucken, W., Grundsätze, S. 146.

441) Eucken, W., Wettbewerbsordnung, S. 93.

442 ) Eucken, W. , Grundsätze, S. 325.

443) $\mathrm{Zu}$ dieser Interdependenz von Wirtschaftsordnung und Staatsordnung vgl. auch Hensel, K.P., Ordnung der Wirtschaft als wissenschaftliches Problem, ordo XV/XVI (1965), S. 15 und Kloten, N., Der staat in der Sozialen Marktwirtschaft, S. 7f.: "Den staatlichen sektor als in sich geordneten Ausschnitt aus einer Gesamtordnung zu verstehen und zu analysieren, reflektierte ordoliberales Denken. Die Hauptwerke Walter Euckens: "Die Grundlagen der Nationalökonomie" (1940) und die posthum erschienenen "Grundsätze der Wirtschaftspolitik" (1952) fixieren die Basisposition".

$444)$ Badura, P., Das Verwaltungsmonopol, S. 307.

445) Backhaus, J., Öffentliche Unternehmen. Zum Wirtschaftsrecht, den Funktionen und Rechtsformen öffentlicher Unternehmen, S. 39. W. Krelle (Zur Problematik der Grundlagen, in: Planung ohne Planungswirtschaft, S. 63) vermißt im System Euckens den staat und dessen nähere Ausgestaltung insgesamt, ähnl. N. Kloten, (aaO. (Anm. 443), S. 9) der darauf hinweist, daß der theoretische Ansatz Euckens zur Klärung der Frage, wie der staat beschaffen sein muß, der als konstituierendes Element einer Gesamtordnung von Gesellschaft und staat gilt, "kaum hilfreich" ist.

446) Schaeder, R., Gemeinwohl und öffentliche Interessen im Recht der globalen Wirtschafts- und Finanzplanung, in: Wohl der Allgemeinheit und öffentliche Interessen, S. 106 . 
447) Streissler, E., Macht und Freiheit in der sicht des Neoliberalismus, in: Macht und ökonomisches Gesetz, Schriften des Vereins für Socialpolitik, N.F. Bd. 74 II $(1973)$, S. 1424 .

448) Streissler, E., aao. (Anm. 447). Ähnl. Megay, E., AntiPluralist Liberalism: The German Neoliberals, Political Science Quarterly, Vol. LXXXV (1970), S. 433, der den "Rousseauion flavour" des Euckenschen Staatsdenkens zu spüren glaubt.

449) Werner, J., Die Wirtschaftsverbände in der Marktwirtschaft, S. $218 \mathrm{f}$.

450) Lenel, H.O., Walter Euckens ordnungspolitische Konzeption, die wirtschaftspolitische Lehre in der Bundesrepublik und die Wettbewerbstheorie von heute, ordo XXVI (1975)，S. 56 .

451) Böhm, F., aao. (Anm. 5), S. XXVIII.

452) Kloten, N., aaO. (Anm. 443), S. 9.

453) Willgerodt, H., Warum Staatsplanung in der Marktwirtschaft?, Ordo XVII (1966), S. 158.

454 ) Nawroth, E.E., aao. (Anm. 32), S. 243; Strubl, G., Die Staatsauffassung des Neoliberalismus dargestellt am Staatsdenken von Walter Eucken, Wilhelm Röpke und Alexander Rüstow, Diss. Tübingen 1954, S. 73.

455) Die erste größere Auseinandersetzung dieser Art ging um die Frage, ob die Neoliberalen, allen voran Eucken und Böhm, dem Nationalsozialismus konvenierendes, antiliberales Gedankengut vertreten hatten. Dieser von $\mathrm{H}$. Hellwig vertretenen Auffassung (Wir brauchen kein Kartellgesetz, in: Monatsblätter für freiheitliche wirtschaftspolitik Bd. 1, Heft 1, Mai 1955, S. 16ff.) traten F.A. Lutz und F. Böhm in scharfer Form entgegen. F.A. Lutz warf H. Hellwig vor, er habe, "(s) tatt den genannten Männern (...) für ihr - trotz Anfeindungen und Gefahren - unerschütterliches Eintreten für Ideen Anerkennung zu zollen, die nun wirklich von denen des Nationalsozialismus himmelweit entfernt waren, (...) ihre Gedanken in einer seltsamen, geradzu unverständlichen Geschichtsfälschung als mit den Anschauungen des Nationalsozialismus verwandt hingestellt" (Bemerkungen zum Monopolproblem, ordo VIII (1956), S. 19f.). Eine schärfere Tonart schlug F. Böhm an, der in der "denkbar massive(n) Kampfansage des 'liberalen' Herrn Hellwig" den "Versuch einer politischen Brunnenvergiftung à la McCarthy" sah, der er entgegenhielt, daß die gegnerische Haltung Euckens zum Nationalsozialismus offenkundig und bekannt gewesen sei (Freiburger Schule und 
Nationalsozialismus, Frankfurter Allgemeine Zeitung vom 24.5.1955, Nr. 519, S. 7).

In einer weiteren Kontroverse, die sich im Prinzip um die gleiche Frage drehte und die als Kontrahenten H.J. Riese und wiederum F. Böhm sah, wurde abermals der Frage nachgegangen, ob Eucken, "der Apologet des Liberalismus", dem Zeitgeist erlegen und dem faschistischen Führerstaat das Wort geredet habe (so Riese, H., aaO. (Anm. 296), S. 37). Auf die von H. Riese vorgenommene "Generalabrechnung" mit dem "Mythos des ordo-Liberalismus" (Bull, H.P., Die Staatsaufgaben nach dem Grundgesetz, S. 253f.) erwiderte F. Böhm in ähnlicher Weise wie bereits 17 Jahre zuvor. Jeder, der Eucken während der Zeit des Nationalsozialismus persönlich gekannt oder wer sich mit seinem Werk befaßt habe, müsse ihm beipflichten, wenn er seinem Kontrahenten entgegenhalte: "Wie man einem Zeitgeist widersteht, das hätte $\mathrm{H}$. Riese bei Eucken lernen können" (Eine Kampfansage an ordnungstheorie und ordnungspolitik. Zu einem Aufsatz in Kyklos, Ordo XXIV (1973), s. 11ff. (28)).

456) Blum, R., aao. (Anm. 114), S. 63.

457) Beckerath, E. V., aao. (Anm. 436), S. 296; ähnl. Hartwich, H., ORDO-Modell und Konfliktgesellschaft, in: Gegenwartskunde 15 (1966), S. 334; Friedrich, C.J., Das Denken des Neoliberalismus, in: Theorie und Politik der Verfassungsordnung, S. 208; Hesse, G., Staatsaufgaben, S. 233 .

458) Schmölders, G., Einleitung, in: Das Selbstbildnis der Verbände, Schriften des Vereins für Socialpolitik, N.F. Bd. 38 (1965), S. 1.

459) Herder-Dorneich, P., aaO. (Anm. 380), S. 81.

460) Megay, E., aao. (Anm. 448), S. 422f., 433, 436; Marchal, J., Demokratie und Marktwirtschaft in der Theorie des Neoliberalismus, Diss. Gießen 1970, S. 110ff.; a.A. Bernbach, U./Nuscheler, F. (Hrsg.), Sozialistischer Pluralismus, S. 10 .

461) Rüstow, A., Wirtschaftsethische Probleme der sozialen Marktwirtschaft, in: Boarmann, P., Der Christ und die soziale Marktwirtschaft, s. 63.

462) Herrmann, w., Grundsätze der Wirtschaftspolitik. Kritische Anmerkungen zu Walter Euckens nachgelassenem Werke, Zeitschrift für handelswissenschaftliche Forschung, 4. Jahrgang (1952), S. 423: "Wer ist denn dieser staat, der Machtgruppen auflösen soll? Etwa ein Parlament? Wieviele Parlamentarier bleiben in der Geschichte des parlamentarischen staates übrig, wenn man die Vertreter wirtschaftlicher Machtgruppen ausnimmt?" 
463) Müller, J.B., Liberalismus und Demokratie, S. 126f.; Büchi, W., Die Sozial- und Wirtschaftsphilosophie des Neoliberalismus, Die neue ordnung, Jahrgang 15 (1961), S. 63; Nawroth, E.E., aao. (Anm. 32), S. $241 \mathrm{ff} . ;$ Blum, F., aao. (Anm. 114), S. 61; Meyer-Dohm, P., aao. (Anm. 392), S. 151 .

464 ) Strubl, G., aao. (Anm. 454), S. 73.

465) Eucken, w., Grundsätze, S. 325.

466) Eucken, W., Grundsätze, S. 325.

467) Eucken, W., Grundsätze, S. $325 f$.

468) Eucken, W. , Grundsätze, S. 146.

469) Eucken, W., Grundsätze, S. 145.

470) Eucken, W. , Grundsätze, S. 146.

471) Eucken, W., Grundsätze, S. 146, 327.

472) Eucken, W., Grundsätze, S. 148.

473) Eucken, W., Nationalökonomie - wozu?, S. 41.

474) Eucken, W., staatliche strukturwandlungen und die Krisis des Kapitalismus, S. 301.

475) Eucken, W., Nationalökonomie - wozu?, S. 41.

476) Eucken, W., Staatliche strukturwandlungen und die Krisis des Kapitalismus, s. 301f.; ders., Nationalökonomie - wozu?, S. 41 .

477) Eucken, W., Nationalökonomie - wozu?, S. 41.

478) Eucken, W., Nationalökonomie - wozu?, S. 41; ders., Staatliche Strukturwandlungen und die Krisis des Kapitalismus, S. 301. Zu dieser Entwicklung auch Frotscher, W., Regierung als Rechtsbegriff, S. $87 \mathrm{f}$.

479) Eucken, W., Nationalökonomie - wozu?, s. 41; ders. staatliche Strukturwandlungen und die Krisis des Kapitalismus, s. $301 \mathrm{f}$.

480) "Gewiß griff der Fürst mit seiner Wirtschaftspolitik an vielen stelle gerade in das Wirtschaftsleben ein, er wurde vielfach Anreger und Träger des ökonomischen Fortschritts" (Eucken, w., staatliche strukturwandlungen und die Krisis des Kapitalismus, S. 302).

481) Dieser These widerspricht Eucken allerdings selbst mehrfach: "Das natürliche Bestreben des Menschen, sich 
selbst $z u$ verwirklichen und seine Kräfte zu entfalten, ist notwendig, um insgesamt $z u$ einer ausreichenden Güterversorgung zu gelangen. Die Knebelung dieser Kräfte hat sich zu allen Zeiten - mag es im spätrömischen Reich, mag es in der Zeit des Merkantilismus oder in der heutigen Zeit gewesen sein - als schädlich erwiesen", Eucken, W., Grundsätze, S. 360; ähnlich ders., Staatliche strukturwandlungen und die Krisis des Kapitalismus, S. 314, wo festgestellt wird, daß "in der ersten merkantilistischen Epoche der Neuzeit der Kapitalismus vom staate selbst geschaffen wurde"; unklar bleiben insoweit auch die Ausführungen in den Grundsätzen, S. 27, wo Eucken davon spricht, daß die "Aufhebung der ungezählten Regulierungen, der Preisfestsetzungen, Verbote, Zwangsverbände usw., die aus dem Mittelalter und aus merkantilistischer zeit überkommen waren", notwendig wurde.

482) Eucken, W., Nationalökonomie - wozu?, S. 42.

483) Meinecke, F., Die Idee der Staatsräson, 3. Aufl. 1929, S. 516, zit. nach Eucken, w., staatliche Strukturwandlungen und die Krisis des Kapitalismus, S. 320.

484) Eucken, w., staatliche strukturwandlungen und die Krisis des Kapitalismus, S. 310, 302; ders., Grundsätze, S. 181 .

485) Eucken, W., Staatliche strukturwandlungen und die Krisis des Kapitalismus, S. 302 .

486) Eucken, W., Grundsätze, S. 181; ders., Nationalökonomie - wozu?, S. 42 .

487) Eucken, W., staatliche strukturwandlungen und die Krisis des Kapitalismus, S. 302 .

488) Eucken, W., Nationalökonomie - wozu?, S. 43; ders., Unser Zeitalter der Mißerfolge, s. 4.

489) Eucken, W., Nationalökonomie - wozu?, S. 43.

490) Weltwirtschaftliches Archiv, Bd. 36 (1932 II), S. $297 \mathrm{ff}$.

491) Alle Zitate aus Eucken, W., Staatliche Strukturwandlungen und die Krisis des Kapitalismus, S. 302, ähnlich S. 314. Dazu auch Eucken, W., Religion - Wirtschaft Staat, S. 85: Der staat "zieht sich vor allem aus der Wirtschaft, in der sich der Staat des 18. Jahrhundert lebhaft betätigt hatte, wieder zurück".

492) Eucken, W., Grundsätze, S. 48.

493) R. v. Mohl zit. nach Eucken, W., Grundsätze, S. 48. 
494) Eucken, W., Grundsätze, S. 48f., 175, 250.

495) Eucken, W. , Grundsätze, S. 48, $132 f$.

496) Eucken, W., Grundsätze, S. 48, 333.

497) Eucken, W., Grundsätze, S. 48.

498) Eucken, W., Grundsätze, S. 49.

499) Alle Zitate aus Eucken, W., Grundsätze, S. 26.

500) Eucken, W., Grundsätze, S. 26; ders., Grundlagen, S. 52 .

501) Eucken, W., Grundsätze, S. 26; ders., Nationalökonomie - wozu?, S. 43; ders., Unser Zeitalter der Mißerfolge, S. 4 .

502) Eucken, W., Unser Zeitalter der Mißerfolge, S. 4.

503) Eucken, W., Grundlagen, S. $50 \mathrm{ff}$.

504) Eucken, W., Grundlagen, S. 52ff.; ders., Grundsätze, S. 373. Zum Unterschied von "institutio" als gewachsener und "constitutio" als "zielbewußt gestalteter Verfassung" Stern, K., Die Verbindung von Verfassungsidee und Grundrechtsidee zur modernen Verfassung, in: staatsorganisation und staatsfunktionen im Wandel, Festschrift für K. Eichenberger, S. $198 \mathrm{f}$.

505) Eucken, W., Grundlagen, S. 52 ; ders., Die Überwindung des Historismus, S. 208; ähnlich Böhm, F./GroßmannDoerth, H./Eucken, W., Unsere Aufgabe, S. 96 (Die Wirtschaftsverfassung ist die "politische Gesamtentscheidung über die ordnung des nationalen wirtschaftslebens") .

506) Dazu Eucken, w., Grundsätze, S. 26: "Eine Gesamtentscheidung auch für die wirtschaftsordnung war damit gegeben". Diese Aussage ließe sich im Sinne der grundlegenden Definition nur retten, wenn unterstellt wird, daß hier, gleichsam einen schritt weitergedacht, die nach dem Muster des ordo verwirklichte, faktische "Wirtschaftsordnung" gemeint ist. Dafür mag auch die Übernahme der Definition in die "Grundsätze der Wirtschaftspolitik" sprechen, vgl. daselbst S. 373.

507) Dazu nochmals Euckens Definition der Wirtschaftsordnung als der "Gesamtheit der Formen, in denen die Lenkung des alltäglichen wirtschaftsprozesses in concreto hier und dort, in Gegenwart und Vergangenheit - erfolgte und erfolgt" (Grundlagen, S. 167).

508 ) Eucken, W., Grundsätze, S. 52 . 
509) Die (naheliegende) Frage, inwieweit Rechtsnormen diese Wirtschaftsverfassung prägen bzw. zu deren Inhalt gehören, um ökonomisch ordnung $z u$ machen, untersucht Eucken mit einem für das Recht mehr als dürftigen Ergebnis (dazu im folgenden).

510) Eucken, W., Nationalökonomie - wozu?, S. 43.

511) Eucken, W., Nationalökonomie - wozu?, S. 43.

512) So im Ergebnis auch Ballerstedt, K., Das Verhältnis von Recht und Wirtschaft als Aufgabe der Forschung und der Gestaltung, in: Gewerkschaft - Wirtschaft - Gesellschaft, Beiträge zu wirtschaftlichen und sozialen Gegenwartsfragen, Bd. 1 (1963), S. 37f.; mißverständlich allerdings ders., Wirtschaftsverfassungsrecht, in: Die Grundrechte, hrsg. v. Bettermann, K.A./Nipperdey, H.C./ Scheuner, U., 3. Bd., 1. Halbbd., S. $12 \mathrm{Anm}$. 32, wo Eucken falsch zitiert wird. In den "Grundlagen der Nationalökonomie" S. 54 heißt es: "die jeweiligen wirtschaftsordnungen sind nicht etwa den jeweils geltenden Rechtsordnungen gleichzusetzen". K. Ballerstedt, aao., ändert den Begriff Wirtschaftsordnung in wirtschaftsverfassung und kommt so zwangsläufig $\mathrm{zu}$ dem falschen Schluß, daß die letztere nicht mit der Rechtsordnung gleichzusetzen ist, "also nicht ohne weiteres als Rechtsbegriff aufgefaßt werden darf".

513) "Gewiß diese Verfassung (d.i. die staatsverfassung) beruht für alle Teile der Wirtschaft auf Privateigentum, Vertragsfreiheit und Wettbewerb. Deshalb zog sich auch der staat aus unmittelbarer wirtschaftlicher Betätigung möglichst zurück und unterließ unsystematische Einzeleingriffe. Aber wer nur das letztere beachtet, sieht nicht, wie der staat durch die Verfassungsgebung der Wirtschaft eine neue Basis schuf", Eucken, W., Nationalökonomie - wozu?, S. 43.

514) Eucken, W., Grundlagen, S. 52.

515) Ballerstedt, K., Wirtschaftsverfassungsrecht, aao. (Anm. 512), S. 13; dazu auch Stern, K., aao. (Anm. 504), S. 199 .

516) Ballerstedt, K., Das Verhältnis von Recht und wirtschaft, aao. (Anm. 512), S. 39 verneint rundheraus das Euckensche wirtschaftsverfassungsverständnis für das Zeitalter des liberalen Rechtsstaates, denn "der Abbau von Schranken im Vertrauen auf eine selbsttätige Regulierung der freigesetzten Energien ist nicht Herstellung einer Verfassung im Rechtssinne"; ähnlich ders., Wirtschaftsverfassung, aaO. (Anm. 512), S. 14. Die gedanklich schwierige Interpretation der negativen, staatsausgrenzenden Abwehrrechte des einzelnen als wirtschaftsordnungskonstituierende Faktoren hat Eucken 
allerdings selbst nicht durchgehalten. So kam er in einem Vortrag, den er 1950 kurz vor seinem Tode in London hielt (abgedruckt in: Unser Zeitalter der Mißerfolge, S. 1ff.) zu dem Ergebnis, daß die staaten die Verfassungsgebung und Rechtssetzung im zeitalter des "liberalen Staates" forciert und damit einen "Rahmen" geschaffen hätten, innerhalb dessen sich jeder Wirtschaftsteilnehmer zu bewegen hatte. Damit - so Eucken weiter - sei jedoch keine Entscheidung über eine bestimmte Wirtschaftsordnung getroffen worden, da diese "und ihre Gestaltung (...) nicht als besondere staatliche Aufgabe angesehen" wurden (Unser Zeitalter der Mißerfolge, S. 4; ders., Wettbewerbsordnung, S. 3; ders., Deutschland vor und nach der Währungsreform, $S$. 181). Ähnlich konträre Ausführungen finden sich auch in den Grundsätzen, S. 374, wo Eucken erläutert, daß "(a) uch die Politik des Laissez-faire (...) die Wirtschaftsordnungen wachsen lassen" wollte, weil ihr kein "bestimmter Bauplan" zugrunde lag. Hier ging Eucken offensichtlich von einer Nichtentscheidung des liberalen Staates im Hinblick auf die Wirtschaft aus.; insgesamt zutreffend beschreibt stahlmann, G., Die Verwirklichung des sozialen Rechtsstaates als Voraussetzung der individuellen Freiheit, Diss. Göttingen 1973, S. 100, die von Eucken entworfene Theorie des liberalen Rechtsstaates, wenn er darauf hinweist, daß die Grundlage des Ordnungsentwurfes des Laissez-faire "die Zurückhaltung des staates bei seiner eigentlichen Aufgabe, der Sozialgestaltung ist" und demnach "die Theorie des liberalen Rechtsstaates nicht die Gestaltungsfunktion des Staates" erfaßt, "obwohl diese Zurückhaltung gerade sein ordnungsentwurf war".

517) Eucken, W., Nationalökonomie - wozu?, S. 43; ders., Grundlagen, S. 52; ders., Grundsätze, S. 27, 194 .

518) Eucken, W., Grundsätze, S. 27; ders., Grundlagen, S. 52,25 .

519) Adam Smith zit. nach Eucken, W., Grundlagen, S. 52.

520) Eucken, W., Grundsätze, S. $26 f$., 351.

521) Eucken, W., Grundsätze, S. 27, 351, 357; ders. Grundlagen, S. 52, 241. Die grundrechtstheoretisch präzise Beschreibung dieses Vorganges findet sich bei Scholz, R., Koalitionsfreiheit als Verfassungsproblem, S. 11: "Die konkurrierende Ausübung der wirtschaftlichen Freiheiten begründet das wettbewerbliche wirtschaftsverhältnis. Der Wettbewerb kann sich deshalb jedoch auf keine selbständige Verfassungsentscheidung berufen; auch er ist bloß unselbständige Ausübungsfolge".

522) Die physiokratische Lehre wurde vor allem in den Werken von B. Quesnay (Despotisme de la chine) und P.-P. Le 
Mercier de la Rivierès (L'ordre naturel et essentiel des societes politique) systematisch entwickelt.

523) Eucken, W., Grundlagen, S. 52. Zum grundrechtstheoretischen Hintergrund Böckenförde, E. -W., Die Bedeutung der Unterscheidung von Staat und Gesellschaft im demokratischen Sozialstaat der Gegenwart, in: Rechtsfragen der Gegenwart, Festgabe für W. Hefermehl zum 65. Geburtstag, S. 11ff., wieder abgedruckt und zit. nach Böckenförde, E.-W. (Hrsg.), staat und Gesellschaft, S. $395 \mathrm{ff}$. $(402)$.

524 ) Eucken, W., Grundsätze, S. $26 f$.

525) Eucken, W., Grundlagen, S. 52.

526) Eucken, W., Grundsätze, S. 49.

527) Eucken, W., Grundsätze, S. 49.

527) Eucken, W., Grundsätze, S. 49.

528) Alle Zitate aus Eucken, W., Grundsätze, S. 49.

529) Eucken, W., Grundsätze, S. 53.

530) Eucken, W., Grundsätze, S. 538; ders., Deutschland vor und nach der Währungsreform, S. 182; ders., Wettbewerb als Grundprinzip der Wirtschaftsverfassung, s. $36 \mathrm{f}$., s. 49: "Eine wirtschaftspolitisch und sozial unhaltbare Gruppenanarchie mit großen und unkontrollierten Machtballungen entstand".

531) Eucken, W., Grundsätze, S. 358, 307, 372 .

532) Eucken, W. , Grundsätze, S. 174, 176, 178, 198, 356f.; ders., Wettbewerb als Grundprinzip der Wirtschaftsverfassung, S. $36 f$.

533) Eucken, W. , Grundsätze, S. 175, 176, 52. Nach Euckens Vorstellung sollte der einzelne durch die "verfassungsmäßigen Garantien" (Grundsätze, S. 52) vom staat eine Sphäre persönlicher Freiheit erhalten, die auch im Verhältnis der Bürger untereinander von Bestand sein sollte. Grundrechtsadressat ist nach diesem Verständnis nicht nur der staat, sondern jeder Grundrechtsinhaber in seinem Verhältnis zu allen anderen Grundrechtsinhabern. "So wenig der Mensch (...) seine eigene Freiheit selber aufheben darf, so wenig darf er die Freiheitssphäre der anderen mißachten. Hier an der Freiheitssphäre der anderen findet seine Person ihre Grenzen. Indem er diese Freiheitssphäre achtet, übt er Humanität. Freiheit - richtig verstanden - und Humanität und Recht gehören zusammen, sind untrennbar miteinander verbunden" (Grundsätze, S. 176). 
534) Eucken, W., Grundsätze, S. 51f. Die freiheitsmindernden Auswirkungen der monopolistischen Marktform auf die rechtsstaatlichen Freiheitsverbürgungen legt Eucken an mehreren Beispielen dar.

a) Durch Nachfragemonopole auf dem Arbeitsmarkt wurde die persönliche Freiheit trotz deren verfassungsmäßiger Verankerung, ebenso eingeschränkt wie die Gewerbefreiheit durch die Behinderung des freien Zutritts zum Markt zur bloßen Hülse wurde (Eucken, W., Grundsätze, S. 50, 176; ders., Die soziale Frage, S. 113).

b) Das "Recht der Vertragsfreiheit", das zu Beseitigung der Konkurrenz benutzt wurde, "geriet in offenen Konflikt mit dem Prinzip des Wettbewerbs" (Eucken, W., Grundsätze, S. 170). Da sich der Rechtsstaat "niemals klar (...) für freie Konkurrenz à tous prix gegen vertragsfreiheit à tous prix oder für diese gegen jene" ausgesprochen habe (Heckscher, E. zit. nach Eucken, w., Grundsätze, S. 170), verfestigte sich ein Zustand, in dem Vertragsfreiheit "faktisch ausgeschaltet war" (Eukken, W., Grundsätze, S. 170, 174).

c) Weitere freiheitsbeschränkende Kollisionen von Grundrechtsausübungen sieht Eucken im Bereich der staatlich verliehenen Koalitionsfreiheit, die ausgeschlossen wird, "wenn private Machtkörper der Industrie oder der Arbeiterschaft organisationszwang ausüben" und damit die Freiheit in ihr Gegenteil verkehrt wird: es entsteht "Koalitionszwang" (Eucken, w., Grundsätze, S. 50).

535) Alle Zitate aus Eucken, w., Grundsätze, S. 50.

536) Eucken, W., Grundsätze, S. 50.

537) Eucken, W., Grundsätze, S. 52, 128.

538) Eucken, w., Grundsätze, S. 52, $170 f$.

539) Eucken, W., Grundsätze, S. 52. Die Statuslehre übernimmt Eucken von Kant, dessen "Idee zu einer allgemeinen Geschichte in weltbürgerlicher Absicht" von 1784 er zustimmend zitiert (Grundsätze, S. 360).

540) Eucken, W., Grundsätze, S. 52.

541) Eucken, W., Grundsätze, S. 52. "Die sozialistische Kritik hatte mit der Behauptung durchaus recht, daß viele Arbeiter nur formal frei, faktisch aber unfrei seien" (Eucken, W., Grundsätze, S. 50).

542) Scholz, R., aao. (Anm. 521), S. 118 .

543) Eucken, W., Grundlagen, S. 53. 
544) Eucken, W., Grundlagen, S. 54.

545) Eucken, W., Grundlagen, S. 55, 241f .; ders., Grundsätze, S. 50, 104 .

546) Eucken, W., Grundlagen der Nationalökonomie, 1. Aufl. 1940 , S. 66.

547) Eucken, W., Grundsätze, S. 54.

548) Eucken, W., Grundsätze, S. 52 .

549) Eucken, W., Grundsätze, S. 332, 48, 49.

550) Eucken, W., Grundsätze, S. 48.

551) Eucken, W., Grundsätze, S. 52, 133.

552) Eucken, W., Grundsätze, S. $331 f$.

553) Alle Zitate Eucken, W., staatliche strukturwandlungen und die Krisis des Kapitalismus, S. 301.

554) Eucken, W., staatliche strukturwandlungen und die Krisis des Kapitalismus, S. 303; ders., Nationalökonomie wozu?, S. 42: "Im Laufe dieses Prozesses der Staatsbildung wächst (...) der Wille des staates, Form und $\mathrm{Ab}-$ lauf der Wirtschaft zu bestimmen".

555) Eucken, W., staatliche strukturwandlungen und die Krisis des Kapitalismus, S. 303.

556) Eucken, W., staatliche strukturwandlungen und die Krisis des Kapitalismus, S. 303; ders., Grundsätze, S. 330 .

557) Eucken, W., Staatliche Strukturwandlungen und die Krisis des Kapitalismus, S. 303, 307.

558) Eucken, W., Grundsätze, S. 13, 193.

559) Eucken, W., Grundsätze, S. 193, 18.

560) Eucken, W., Grundsätze, S. 18.

561) Eucken, W., Grundsätze, S. 16.

562) Eucken, w., staatliche strukturwandlungen und die Krisis des Kapitalismus, S. 305.

563) Eucken, W., staatliche strukturwandlungen und die Krisis des Kapitalismus, S. 305. 
$564)$ Eucken, W., Religion - wirtschaft - Staat, S. 83; ders., staatliche Strukturwandlungen und die Krisis des Kapitalismus, S. 306.

565) Eucken, W., Religion - Wirtschaft - Staat, S. 82 .

566) Eucken, W., Religion - wirtschaft - Staat, S. 83.

567) Eucken, W., Religion - Wirtschaft - Staat, S. 83. Der einzelne wurde "immer heimatloser, wurzelloser, haltloser, traditionsloser, rechtloser und glaubensloser", er verlor die "sinnerfüllte Lebensmitte" (Mühlenfeld, H., Politik ohne Wunschbilder. Die konservative Aufgabe unserer Zeit, S. $343 \mathrm{ff}$. (343)).

568) Eucken, W., Religion - Wirtschaft - Staat, S. 84. Diese Seite der Entwicklung verdeutlicht Müller-Armack, A., Diagnose unserer Gegenwart. Zur Bestimmung unseres geistesgeschichtlichen standorts, S. 261: "Weit mehr ist es ein im 19. Jahrhundert allgemein einsetzender Vorgang der Ablösung von seelisch-heimatlichen Bindungen, die Auflösung von Glaubens- und Familienbanden (...) Es ist die kollektive seite jener geistigen Auflösung, die seit dem 18. Jahrhundert, vom Religiösen her beginnend, immer mehr Traditions- und Kultursubstanz abträgt und jene Nivellierung schafft, die im letzten Jahrhundert auf immer weitere Schichten überspringt und sie seelisch entleert".

569) Eucken, W., Religion - Wirtschaft - Staat, S. 84 f.

570) Eucken, W., Religion - Wirtschaft - Staat, S. 84.

571) Eucken, W., Religion - Wirtschaft - staat, S. 85.

572) Eucken, W., Religion - Wirtschaft - Staat, S. 85.

573) Eucken, W. , Religion - wirtschaft - Staat, S. 84, 86; ders., staatliche strukturwandlungen und die Krisis des Kapitalismus, S. $305 f$.

574 ) Eucken, W., Nationalökonomie - wozu?, S. 46.

575) Eucken, W., Religion - wirtschaft - staat, S. 75.

576) Eucken, W., Religion - wirtschaft - staat, S. 86; ders., staatliche strukt,urwandlungen und die Krisis des Kapitalismus, S. 306.

577) Eucken, w., Religion - wirtschaft - Staat, S. 87; ders., staatliche strukturwandlungen und die Krisis des Kapitalismus, S. 306 .

578) Eucken, w., staatliche strukturwandlungen und die Krisis des Kapitalismus, S. 306. 
579) Eucken, W., Staatliche strukturwandlungen und die Krisis des Kapitalismus, S. 134 .

580) Eucken, W., staatliche strukturwandlungen und die Krisis des Kapitalismus, S. 309, 303; ders., Nationalökonomie - wozu?, S. 46, S. 51. Vgl. dazu auch Anm. 582.

581) Eucken, W., Staatliche Strukturwandlungen und die Krisis des Kapitalismus, S. 308.

582 ) Eucken, W., Nationalökonomie - wozu?, S. 50; ders., Grundsätze, S. 195. Während in der ersten, merkantilistischen Epoche der Neuzeit der Kapitalismus vom Staate selbst geschaffen wurde, während in der zweiten Epoche die liberale Trennung von staatlicher und wirtschaftlicher Sphäre die weitere Entwicklung des Kapitalismus "trotz Schwierigkeiten in der Ordnungssicherungspolitik ermöglichte, verfällt unter dem Druck der Massen" die staatlich-gesellschaftliche organisation, in deren Rahmen der Kapitalismus entstanden war, und ohne die er weder seine starken Kräfte entfalten noch überhaupt funktionieren kann" (Eucken, W., staatliche strukturwandlungen und die Krisis des Kapitalismus, s. 314).

583) Eucken, W., staatliche strukturwandlungen und die Krisis des Kapitalismus, S. 309. Neben der unmittelbaren Schwächung des Preissystems durch die staatliche Duldung von Monopolen (dazu im einzelnen Eucken, W., Grundsätze, S. 50f.) hat der totale wirtschaftsstaat insbesondere durch direkte "Preisbestimmung auf Arbeits-, Kapital-, Wohnungs-, Lebensmittel- und vielen anderen Märkten Preisverschiebungen verhindert und damit bewirkt, daß angebotene und nachgefragte Quantitäten" nicht zum Ausgleich kamen (Eucken, w., staatliche strukturwandlungen und die Krisis des Kapitalismus, S. 308; ders., Grundsätze, S. 327).

584 ) Eucken, W., Nationalökonomie - wozu?, S. 51.

585) Eucken, W., Staatliche strukturwandlungen und die Krisis des Kapitalismus, S. 306, 313, 309, 315, 320; ders., Religion - Wirtschaft - Staat, s. 85.

586) Eucken, w., staatliche strukturwandlungen und die Krisis des Kapitalismus, S. 309; ders., Nationalökonomie wozu?, S. 52f.

587) Eucken, W., Staatliche strukturwandlungen und die Krisis des Kapitalismus, S. 315.

588) Schmitt, C., Der Hüter der Verfassung, S. 79.

589) Denn "in einem Lande wie Deutschland z.B. fehlt es weder an Unternehmerkräften noch an technischen Möglichkeiten", um den Kapitalismus weiter zu entfalten 
(Eucken, w., staatliche strukturwandlungen und die Krisis des Kapitalismus, S. 314).

590) Vgl. in diesem Zusammenhang auch Schmitt, C., Politische Theologie, S. 49: "Alle prägnanten Begriffe der modernen staatslehre sind säkularisierte theologische Begriffe".

591) Eucken, W., staatliche strukturwandlungen und die Krisis des Kapitalismus, s. $317 \mathrm{f}$.

592) Eucken, W., Staatliche strukturwandlungen und die Krisis des Kapitalismus, S. 306, 302, 311f.

593) Eucken, W., Religion - wirtschaft - staat, S. 85; ders., staatliche Strukturwandlungen und die Krisis des Kapitalismus, S. 306.

594) Eucken, W., Religion - wirtschaft - staat, S. 85; ders., staatliche Strukturwandlungen und die Krisis des Kapitalismus, S. 302, 306, $311 \mathrm{f}$.

595) Eucken, W., Religion - Wirtschaft - Staat, S. 85.

596) Eucken, W., Religion - wirtschaft - Staat, S. 85; ähnlich ders., staatliche strukturwandlungen und die Krisis des Kapitalismus, S. 302 .

597) Schmitt, C., Der Hüter der Verfassung, S. 78, auf den sich Eucken direkt bezieht (vgl. ders., staatliche strukturwandlungen und die Krisis des Kapitalismus, S. 307 Anm. 1).

598) Eucken, W., Religion - wirtschaft - staat, S. 86; ders., Staatliche Strukturwandlungen und die Krisis des Kapitalismus, S. 313.

599) Eucken, w., Staatliche strukturwandlungen und die Krisis des Kapitalismus, S. 303.

600) Eucken, W., Staatliche strukturwandlungen und die Krisis des Kapitalismus, S. 312 unter Hinweis auf Burckhard, J., Briefe an seinen Freund Friedrich von Preen 1864-1893, Brief vom 21. Februar 1878, S. 117.

601) Eucken, W., staatliche strukturwandlungen und die Krisis des Kapitalismus, S. 319, 312; ders., Grundsätze, S. 181 .

602) Eucken, W., staatliche strukturwandlungen und die Krisis des Kapitalismus, S. 307; ders., Grundsätze, S. 327. "Für den totalen staat gibt es keine Grenze seiner Herrschaftszuständigkeit wie seiner Herrschaftsmacht. Er kann und mus jeden Inhalt der gesellschaftlichen 
Existenz ergreifen und ordnen" (Ziegler, H.O., Autoritärer oder totaler staat, S. 6).

603) Eucken, W., staatliche strukturwandlungen und die Krisis des Kapitalismus, S. 307, ähnlich S. 319; ders., Grundsätze, S. 327f.; ders., Religion - Wirtschaft Staat, S. 85 .

$604)$ Schmitt, C., Gesunde Wirtschaft im starken staat, in: Mitteilungen des Vereins zur Wahrung der gemeinsamen wirtschaftlichen Interessen im Rheinland und Westfalen, Nr. 1/1932, S. 18 .

605) Eucken, W., Staatliche strukturwandlungen und die Krisis des Kapitalismus, S. 307; ders., Nationalökonomie wozu?, S. 46; ders., Religion - Wirtschaft - staat, S. 86; ders., Grundsätze, S. 53 und insbesondere S. 327: "Diese Zunahme der Staatstätigkeit nach Umfang und Intensität verschleiert den Verlust der Autorität des staates der mächtig scheint, aber abhängig ist".

606) Eucken, W., staatliche strukturwandlungen und die Krisis des Kapitalismus, S. 307.

607) Eucken, W., staatliche strukturwandlungen und die Krisis des Kapitalismus, S. 307.

608) Eucken, W. , Grundsätze, S. 328.

609) Eucken, W. , Grundsätze, S. 328.

610) Freyer, H., Das soziale Ganze und die Freiheit des einzelnen unter den Bedingungen des industriellen zeitalters, Historische Zeitschrift, Bd. 183 (1957), S. $97 \mathrm{ff.}$, wieder abgedruckt und zitiert nach Böckenförde, E.-W. (Hrsg.), staat und Gesellschaft, S. $199 \mathrm{ff}$. (212).

611) Eucken, W., Grundsätze, S. $328 \mathrm{f}$.

612) Alle Zitate Eucken, W., Grundsätze, S. 329.

613) Eucken, W., Grundsätze, S. 331.

614) Eucken, W., Grundsätze, S. 330.

615) Eucken, W., Grundsätze, S. $344 \mathrm{f}$.

616) Eucken, W., Grundsätze, S. 344 .

617) Eucken, W., Grundsätze, S. 331.

618) Eucken, W., Grundsätze, S. 333 Anm. 1 (beginnend S. 332). 
619) Eucken, W., Grundsätze, S. 333 Anm. 1 (beginnend S. 332).

620) Eucken, W., Grundsätze, S. 331.

621) Herder-Dorneich, P., aaO. (Anm. 380), S. 81.

622) Eucken, W., Grundsätze, S. 332.

623) Eucken, W., Grundsätze, S. 332.

624) Eucken, W., Grundsätze, S. 331. Zu der durch die Untersuchung des liberalen Staates genährten Erkenntnis der Notwendigkeit des "leistungsfähigen Rechtsstaates" vgl. vorne S. $100 \mathrm{ff}$.

625) Eucken, W., Grundsätze, S. 334 .

626) Eucken, w., staatliche strukturwandlungen und die Krisis des Kapitalismus, S. 306, 321; ders., Grundsätze, S. 330 .

627) Eucken, W., staatliche strukturwandlungen und die Krisis des Kapitalismus, S. 306, 321; ders., Grundsätze, S. 330 .

628) Eucken, W., Grundsätze, S. 330, ebd., S. 189, wo er J. Huizinga (Wenn die Waffen schweigen, 1945, S. 186) zitiert: "Je mehr die Mittel und der Bereich des Staates wachsen, desto gefährlicher wurde die Lehre, daß der staat der Moral entraten müsse. Indem der staat sich erkühnt, das Maß aller Dinge sein zu wollen und zugleich seinen eigenen amoralischen charakter verkündet, ist er weniger denn je zur sittlichen Führung des Volkes befugt. Der staat, der für sich die Erhebung über ethische Bindungen beansprucht, erklärt sein Aktionsgebiet zum Asyl der Schlechtigkeit und zieht wie ein Gravitationszentrum die ewig gleichbleibende Bosheit der Menschen an".

629) Eucken, W., Grundsätze, S. 330.

630) Eucken, W. , Grundsätze, S. 370.

631) Eucken, W., Staatliche Strukturwandlungen und die Krisis des Kapitalismus, S. 308.

632 ) Eucken, W., Grundsätze, S. 331. Die Prognose Euckens, abgegeben in einem Diskussionsbeitrag auf der Jenaer Tagung des Eucken-Bundes im November 1931, daß sich der Blick für die geschilderten offenkundigen Mängel des totalen staates schärfen und der idealistische "staatsGlaube" "stärkster Ernüchterung weichen" werde, "wenn das Traumbild" erst verwirklicht sei, ging, wie sich kurze Zeit später erweisen sollte, an den tatsächlichen 
politischen Entwicklungen der Weimarer Republik vorbei, denn es war eben dieser "wildwuchernde Glaube an den totalen Staat", der der Republik den Todesstoß versetzte und den totalen staat inaugurierte (alle zitate Eucken, W., Religion - Wirtschaft - Staat, S. 87).

633) Eucken, W., staatliche strukturwandlungen und die Krisis des Kapitalismus, S. 318; ders., Grundsätze, S. 329,342 .

634) Eucken, W. , Grúndsätze, S. 332 .

635) Eucken, W., Grundsätze, S. 331.

636) Eucken, W., Grundsätze, S. 327, 329.

637) Eucken, W., Grundsätze, S. 329, 335. Dazu auch Schmitt, C., Der Hüter der Verfassung, S. 71, 90: "(N) ur ein starker staat kann entpolitisieren, nur ein starker Staat kann offen und wirksam anordnen, daß gewisse Angelegenheiten" zu erledigen sind.

638) Eucken, W., Grundsätze, S. 334; ders., Staatliche Strukturwandlungen und die Krisis des Kapitalismus, S. 312 .

639) Eucken, W., Grundsätze, S. 334 .

640) Eucken, W. , Grundsätze, S. 337.

641) Eucken, W. , Grundsätze, S. 175.

$642)$ Eucken, W., Grundsätze, S. 175.

643) Eucken, W., Grundsätze, S. 331.

644 ) Eucken, W., Grundsätze, S. 331, 175.

645) Eucken, W. , Grundsätze, S. 336.

646) Eucken, W., Grundsätze, S. 332, 175; ders., Deutschland vor und nach der Währungsreform, S. 18.

647) Vgl. dazu S. $100 \mathrm{ff}$.

648) Eucken, W., Grundsätze, S. 332 Anm. 1.

649) Eucken, W., Grundsätze, S. 332 Anm. 1.

650) Eucken, W., Grundsätze, S. 332 Anm. 1.

651) Eucken, W., Grundsätze, S. 336.

652) Eucken, W., Unser Zeitalter der Mißerfolge, S. 72. 
653) Eucken, W., Grundsätze, S. 336.

654) Eucken, W., Grundsätze, S. 128.

655) Eucken, W., Grundsätze, S. 128.

656) Eucken, W., Grundsätze, S. $128 f$.

657) Eucken, W., Grundsätze, S. 129.

658) Eucken, W. , Grundsätze, S. 129.

659) Eucken, W., Grundsätze, S. 129. Eucken nennt als ein Beispiel die Übertragung von Häuten, die einer Fabrik A gehören und dort beschlagnahmt sind, auf die Firma $B$, die für die Verarbeitung im Sinne des Planes geeigneter ist. "A klagt beim Verwaltungsgericht und verlangt $\mathrm{Zu}-$ rücküberweisung der Häute. Das Verwaltungsgericht erkennt aus rechtlichen Gesichtspunkten nach dem Antrag von A. Hiermit würde die Durchführung der zentralen Planung an einer wesentlichen stelle beeinträchtigt werden. Aber dem Prinzip des Rechtsstaates wäre entsprochen". "Ein ganz grundsätzlicher Konflikt kommt zum Ausdruck" (Eucken, W., Grundsätze, S. 129, 130).

660) Eucken, W., Grundsätze, S. 129; ders., Wettbewerbsordnung, S. 13 .

661) Eucken, W., Grundsätze, S. 129.

662) Stern, K., staatsrecht I, S. 796.

663) Eucken, W., Grundsätze, S. 181f., $332 f$.

664 ) Eucken, W. , Grundsätze, S. 182; ders., Das ordnungspolitische Problem, S. 68 .

665) Eucken, W., Grundsätze, S. 182; ders., Das ordnungspolitische Problem, S. 68.

666) Eucken, W. , Grundsätze, S. 191, 332f. ; ders., Wettbewerbsordnung, S. 13; ders., Das ordnungspolitische Problem, S. 69.

667) Eucken, W., Wettbewerbsordnung, S. 13.

668) Eucken, W., Das ordnungspolitische Problem, S. 69; ders., Wettbewerbsordnung, s. 13.

669) Eucken, W., Wettbewerbsordnung, S. 13.

670) Eucken, W., Grundsätze, S. 333.

671) Eucken, W., Grundsätze, S. 130. 
672) Eucken, W., Grundsätze, S. 337.

673) Eucken, W., Grundsätze, S. $337 f$.

674 ) Eucken, W. , Grundsätze, S. 338.

675) Eucken, W., Grundsätze, S. 337.

676) Eucken, W., Grundsätze, S. 337.

677) Eucken, W., Grundsätze, S. 338 .

678) Eucken, W., Grundsätze, S. 333 Anm. 1 (beginnend S. 332).

679) Eucken, W., Grundsätze, S. 337.

680) Alle Zitate Eucken, W., Grundsätze, S. 338.

681) Schmitt, C., Der Hüter der Verfassung, S. $78 \mathrm{f}$.

682) Schmitt, C., Der Begriff des Politischen. Text von 1932 mit einem Vorwort und 3 Corollarien (1963), S. 10: "Die Epoche der staatlichkeit geht jetzt zu Ende. Darüber ist kein wort mehr zu verlieren."

683) AaO. (Anm. 453), S. 158.

684) Schmidt, W., Die Entscheidungsfreiheit des einzelnen zwischen staatlicher Herrschaft und gesellschaftlicher Macht, AöR 101 (1976), S. 45.

685) Eucken, W., Grundlagen, S. 239; ders., Grundsätze, S. $372 f$.

686) Eucken, W., Grundsätze, S. 27.

687) Eucken, W., Grundsätze, S. 70.

688) Eucken, W., Grundsätze, S. 55. Zusammenfassend Runge, U., aaO. (Anm. 237), S. 11: "Die ordoliberale Kritik am Gesellschafts- und wirtschaftsdenken der klassischen politischen ökonomie stellt nicht das ganze system in Frage, sondern ist bemüht, die wesentlichen Bausteine des liberalen Modells aus ihrem historischen Kontext herauszulösen und sie, gereinigt von allem zeitbedingten Beiwerk, als Elemente von zeitloser Beständigkeit und Gültigkeit dem neuen Gebäude einzufügen."

689) Eucken, W., Grundsätze, S. 369.

690) Eucken, W., Grundsätze, S. $373 f$.

691) Eucken, W., Grundsätze, S. 373. 
692) Eucken, W., Grundsätze, S. 254.

693) Moeller, H., Liberalismus, Jahrbücher für Nationalökonomie und Statistik, Bd. 162 (1950), S. 227. Dazu auch Meinhold, W., Wandlungen des Verhältnisses von staat und Wirtschaft, Gedächtnisschrift für H.J. Seraphim, S. 6, der davor warnt, daß man sich nicht zu einer Staatslehre verleiten lassen dürfe, "die im staat letztlich nur eine Frucht, einen Niederschlag wirtschaftlicher Tätigkeit und wirtschaftlich verursachter staatselemente sieht, derzufolge der staat also gleich einem wirtschaftlichen Gut produzierbar sei".

694) Zu dieser, dem neoliberalen Denken allgemein immanenten Tendenz zur Ausrichtung des staates nach wirtschaftlichen ordnungserfordernissen vgl. Runge, U., aaO. (Anm. 237), S. 125f. und insbesondere Isensee, J., Subsidiaritätsprinzip, S. 137, der mit Blick auf den Neoliberalismus betont, daß es den "im Grunde unpolitischen Charakter des westdeutschen Gemeinwesens" gekennzeichnet habe, daß es "weniger von den Einsichten einer staatslehre als von denen einer wirtschaftstheorie geprägt, daß es weniger vom Wesen des staates als vom Wesen der Gesellschaft her konzipiert worden ist".

695) Deshalb ist es zutreffend, wenn Moritz, K., aao. (Anm. 374), S. 97, davon spricht, daß das Staatsbild Euckens "keiner politischen Theorie, sondern seiner Wirtschaftstheorie" entspringe und sein "idealer staat" nur "gerade die Zwecke, die das wirtschaftliche Modell der Wettbewerbsordnung benötigt", erfülle. Ansonsten bleibt die kurze Analyse des Euckenschen Staatsbegriffes bei K. Moritz den eigentlichen Problemen, denen es in diesem Zusammenhang Beachtung zu schenken gilt, fern.

696) Zu diesem Bild auch Moeller, H., aaO. (Anm. 693), S. 225 .

697) Treffend wird dieser Umstand von R. Smend beschrieben, der den staat "als mechanisch-teleologischen Verwirklichungsmechanismus letzter abstrakter Werte" charakterisiert (Verfassung und Verfassungsrecht, in: Staatsrechtliche Abhandlungen und andere Aufsätze, S. 152f.).

698) Zu dieser Koinzidenz bereits vorne S. $64 \mathrm{ff}$.

699) Schaeder, R., Vergleich der Gesamtsysteme von Wirtschafts- und Staatsordnung, Jahrbuch der Sozialwissenschaft 19 (1968), S. 287ff. (304); Herder-Dorneich, P., aao. (Anm. 380), S. 81 .

700) Eucken, W., Grundsätze, S. 338 .

701) Eucken, W., Grundsätze, S. 332. 
702) Binder, J., Der autoritäre Staat, Logos 22 (1933), S. 133 .

703) Ziegler, H.O., aao. (Anm. 602), S. $9 f$.

704) v. Gayl zit. nach Kohl, H., Pluralismuskritik in der Bundesrepublik, Aus Politik und Zeitgeschichte, Beilage zur Wochenzeitung "Das Parlament", B 12/70, S. 18.

705) Ziegler, H.O., aao. (Anm. 602), S. 26.

706) Ziegler, H.O., aaO. (Anm. 602), S. 15.

707) Smend, R., aao. (Anm. 697), S. 151.

708) Hartwich, H.-H., aao. (Anm. 457), S. 333; Hättich, M., Nationalbewußtsein und staatsbewußtsein in der pluralistischen Gesellschaft, S. 55, weist auf das Dilemma jeder pluralistischen Gesellschaft hin, die einerseits eines gewissen Grundbestandes "an gemeinsamen Werten, Normen, Überzeugungen und Verhaltensregeln" bedarf, andererseits aber durch die Bindung an solche essentiellen Gemeinsamkeiten "die Konkurrenz der Ideen, Meinungen und Interessen" nicht verhindern darf. Man wird mit $M$. Hättich davon auszugehen haben, und in diesem Sinne sind die Ausführungen im Text $z u$ verstehen, daß eine pluralistisch-demokratisch organisierte Gesellschaft eine Gesellschaft ist, "deren Bestand an solchen Gemeinsamkeiten so gering ist, daß die Verschiedenheiten ins Auge fallender sind als die Gemeinsamkeiten" (ebenda, S. 55).

Aus antipluralistischer sicht liest sich dies so: "Die rein subjektive Freiheit der Wertsetzung führt aber $\mathrm{zu}$ einem ewigen Kampf der Werte und der Weltanschauungen, einem Krieg aller mit allen, einem ewigen bellum omnium contra omnes (...) Immer sind es die Werte, die den Kampf schüren und die Feindschaft wach halten. Daß die alten Götter entzaubert und zu bloß geltenden Werten geworden sind, macht den Kampf gespenstisch und die Kämpfer verzweifelt rechthaberisch" (Schmitt, C., Die Tyrannei der Werte, in: Säkularisation und Utopie, Ebracher studien, E. Forsthoff zum 65. Geburtstag, S. 54).

709) So im Ergebnis auch Hesse, G., Staatsaufgaben, S. 229. Bezeichnend ist, daß der in das Sachregister der "Grundsätze der Wirtschaftspolitik" aufgenommene Begriff "Demokratie" durch zwei Fremdzitate eingeführt wird, vgl. ebenda, S. 140, 244.

710) Vgl. dazu auch S. $62 \mathrm{f}$.

711) Radbruch, G., Rechtsphilosophie, S. 84. 
712) Zum "Toleranzproblem in der Demokratie" auch Hättich, M., Civitas, Jahrbuch für christliche Gesellschaftsordnung 4 (1965), S. 15ff., wieder abgedruckt in: Matz, U. (Hrsg.), Grundprobleme der Demokratie, S. $397 \mathrm{ff}$.

713) Eucken, W., Die Überwindung des Historismus, S. $204 \mathrm{f}$.

714) Hesse, G., Staatsaufgaben, S. 229; Krüger, H., Allgemeine Staatslehre, S. 547; Zippelius, R., Allgemeine Staatslehre, S. 251.

715) Eucken, W., Grundsätze, S. 369.

716) Ilau, H., Intervention und demokratischer Kompromiß in der Wirtschaftspolitik, in: Wirtschaftsfragen der freien Welt. Zum 60. Geburtstag von Ludwig Erhard, S. 110.

717) Eucken, W., Grundsätze, S. 371.

718) Eucken, W., Staatliche Strukturwandlungen und die Krisis des Kapitalismus, s. 309.

719) Zu diesen Zusammenhängen auch Werner, J., aaO. (Anm. $449)$, S. $32 f$.

720) Dazu nochmals vorne S. $47 \mathrm{f}$.

721) Hesse, G., Staatsaufgaben, S. 229; Kafka, G.E., Rechtsordnung und Wirtschaftsordnung, in: Wirtschaftspolitische Blätter, Heft 2, Beilage (1965), S. $15 f$.

722) Ziegler, H.O., aaO. (Anm. 602), S. 4.

723) Hedtkamp, G., aao. (Anm. 149), S. 114; ähnlich Luhmann, N., Grundrechte als Institution, S. 17; Kafka, G.E., aao. (Anm. 721), S. 16: "Da die Rangordnung der Ziele und das Gewicht der Interessen in der Demokratie nicht stabilisiert werden können, ist eine wirtschafts- und Sozialpolitik 'wie aus einem Guß' von ihr nicht zu erwarten".

724) Simson, W. v., Das demokratische Prinzip im Grundgesetz, VVDStRL 29 (1971), S. 21.

725) Luhmann, N., aaO. (Anm. 723), S. 17.

726) Runge, U., aao. (Anm. 237), S. 125f. und Ritter, E.-H., Der Wandel der Wirtschaftspolitik und die wirtschaftsverfassungsrechtliche Bedeutung des Gesetzes gegen Wettbewerbsbeschränkungen, Der Betriebsberater 1968, S. 1393ff. (1395), der allerdings zu anderen Ergebnissen kommt.

727) Dahrendorf, R., Gesellschaft und Demokratie in Deutschland, S. 231; dazu auch Krockow, Chr. v., Zur Analyse 
autoritärer Parlamentarismuskritik, Aus Politik und Zeitgeschichte, Beilage zur Wochenzeitung "Das Parlament", B 49/69, S. 39.

728) Eucken, W., Grundsätze, S. $329 f$.

729) Dazu bereits eingehend S. $119 \mathrm{ff}$.

730) Eucken, W., Grundsätze, S. 175.

731) Dazu bereits vorne S. $65 \mathrm{ff},, 103 \mathrm{ff} ., 121 \mathrm{f}$.

732) Häberle, P., Zur gegenwärtigen Diskussion um das Problem der Souveränität, AöR 92 (1967), S. 259ff. (265).

733) Eucken, W., Grundsätze, S. 331.

734 ) Eucken, W. , Grundsätze, S. 331.

735) Eucken, W., Grundsätze, S. 332.

736) Ehmke, H., Wirtschaft und Verfassung, S. 47.

737) Burmeister, J., Vom staatsbegrenzenden Grundrechtsverständnis zum Grundrechtsschutz für staatsfunktionen, S. $50 f$.

738) Dazu und zum folgenden vgl. bereits vorne s. 98ff. u. nochmals Eucken, W., Grundsätze, S. 27.

739) Zu diesem Bild vgl. Forsthoff, E., Der Staat der Industriegesellschaft, s. $70 f$.

740) Eucken, W., Grundsätze, S. 332.

741) Dazu nochmals Eucken, W., Grundsätze, S. 329, 331f., $334,336 f$.

742) Häberle, P., aaO. (Anm. 732), S. 276.

743) Luhmann, N., aaO. (Anm. 723), S. 17.

744 ) Eucken, W., Grundsätze, S. 329.

745) Ähnlich Runge, U., aao. (Anm. 237), S. 128; Marchal, J., aao. (Anm. 459), S. 110 .

746) Simson, W. v., aao. (Anm. 724), S. 70.

747) Eucken, W., Grundsätze, S. 332.

748) Eucken, W., Grundsätze, S. $48 \mathrm{ff.,} \mathrm{133,} \mathrm{175ff.,} 331$.

749) Eucken, W., Grundsätze, S. 333 Anm. 1 (beginnend S. 332). 
750) Eucken, W. , Grundsätze, S. 182.

751) Eucken, W., Grundsätze, S. 332 .

$752)$ Eucken, w., Grundsätze, S. 305.

753) Alle Zitate aus Eucken, w., Grundsätze, S. 306.

754) Eucken, W., Grundsätze, S. 306. Zur wirtschaftspolitischen Funktionalisierung der Rechtsprechung auch Runge, U., aaO. (Anm. 237), S. $158 f$.

755) RGZ 28, $238 \mathrm{ff}$.

756) RGZ 38, $155 \mathrm{ff}$.

757) Eucken, W., Grundsätze, S. 307.

758) Eucken, W. , Grundsätze, S. 307.

759) Eucken, W. , Grundsätze, S. 307.

760) Eucken, W., Grundsätze, S. 307.

761) Larenz, K., Methodenlehre der Rechtswissenschaft, S. 205, 221 .

762) Eucken, W. , Grundsätze, S. 307.

763) Eucken, W. , Grundsätze, S. 307.

764) Dazu eingehend das dritte Kapitel dieser Arbeit.

765) Eucken, W. , Grundsätze, S. 307.

766) Esser, J., Möglichkeiten und Grenzen des dogmatischen Denkens im modernen Zivilrecht, ACP 172 (1972), S. $97 \mathrm{ff}$. (101).

767) Eucken, W. , Grundsätze, S. 307.

768) Zippelius, R., Machtkontrolle durch strukturelle vielfalt und Funktionsteilung, in: Staatsorganisation und Staatsfunktionen, Festschrift für Kurt Eichenberger zum 60. Geburtstag, S. $147 \mathrm{ff}$. m.w. Nachw.

769) Eucken, W., Grundsätze, S. 338.

770) Eucken, W. , Grundsätze, S. 338.

771) Eucken, W. , Grundsätze, s. 336.

772) Eucken, W. , Grundsätze, S. 336. 
773) Ehmke, H., aaO. (Anm. 736), S. 54 Anm. 122 erscheint denn auch der die Wettbewerbsordnung durchsetzende, aktionsfähige staat als "deus ex machina".

774 ) Eucken, W., Grundsätze, S. 338.

775) Eucken, W., Grundsätze, S. $347 \mathrm{ff}$.

776) "Es liegen stets die Elemente, welche die Entwicklung weiterzuführen berufen sind, ebenso sehr im Denken wie im Sein" (Schnabel, F., Deutsche Geschichte, 3. Aufl. 1947 , S. 20, zit. nach Eucken, W., Grundsätze, S. $338 \mathrm{f.})$.

777) Eucken, W., Grundsätze, S. 200ff., 339: Das "Handeln der Menschen ist entscheidend davon abhängig, was gedacht, gewollt und geglaubt wird". In diesem Zusammenhang wird auch die von E. Eucken-Erdsiek (in: Eucken, W. , Grundsätze, Vorwort, S. VI) vorgenommene Charakterisierung ihres Ehemannes interessant: "Walter Eucken pflegte zu sagen, daß es bei diesem Buch weniger auf die Formulierungen ankomme als 'auf das Wollen, das dahintersteht' (...) Hinter diesem Buch steht ein starkes Wollen".

778) Eucken, W., Grundsätze, S. 339.

779) Eucken, W., Grundsätze, S. 340.

780) Eucken, W., Denken - warum?, S. 150.

781) Eucken, W., Grundlagen, S. 11. Zu dieser Einschätzung der Denkleistungen der Masse nochmals Eucken, W., Denken - warum?, S. 151: der "heutige Massenmensch" liebt "das Denken nicht (...), weil es zu unbequem und zeitraubend ist"; deshalb ist es "gänzlich belanglos" ob "Hinz oder Kunz die Ergebnisse richtigen Denkens anerkennen".

782) Eucken, W., Denken - warum?, S. 151; ders., Nationalökonomie - wozu?, S. 40.

783) Eucken, W., Grundsätze, S. 338, 194. Die Gesellschaft "zerfällt - um Paretos Darstellungen zu benutzen - in eine führende Schicht $A$, die relativ klein ist und eine viel breitere, geführte schicht B. Stets ähnelt die Gesellschaft also einer Pyramide" (Eucken, W., Grundsätze, S. 16f.).

784 ) Eucken, W., Grundsätze, S. 18.

785) Eucken, W., Grundsätze, S. 194, 342; ders., Die Überwindung des Historismus, S. 203f.; Böhm, F./GroßmannDoerth, H./Eucken, W., Unsere Aufgabe, S. 87. 
786) Eucken, W., Staatliche strukturwandlungen und die Krisis des Kapitalismus, S. 320; ders., Grundsätze, S. 341 .

787) Eucken, W. , Grundsätze, S. $340 \mathrm{ff}$.; ders., Die Überwindung des Historismus, S. 205.

788) Eucken, W., Grundsätze, S. $342 \mathrm{ff.}$ (344).

789) Eucken, W., Die Überwindung des Historismus, S. 205.

790) Eucken, W., Grundsätze, S. 342 .

791) Eucken, W., Grundsätze, S. 346.

792 ) Eucken, W., Grundsätze, S. 346.

793) Eucken, W., Grundsätze, s. 346.

794 ) Eucken, W., Grundsätze, S. 219, 346.

795) Böhm, F./Großmann-Doerth, H./Eucken, W., Unsere Aufgabe, S. 95; Eucken, W., Grundsätze, S. 219.

796) Eichenberger, K., Leistungsstaat und Demokratie, S. 26; Kübler, F., Über die praktischen Aufgaben einer zeitgemäßen Privatrechtstheorie, S. $37 f$.

797) Dazu auch Veith, O., Ordo und ordnung. Versuch einer Synthese, ordo V (1953), S. 3 f.

798) Simson, W. V., Zu F.A. von Hayeks verfassungsrechtlichen Ideen, Der Staat 18 (1979), S. 403ff. (415); Kübler, F., aao. (Anm. 796), S. $38 f$.

799) Simson, W. v., aao. (Anm. 798), S. 415.

800) Kübler, F., aao. (Anm. 796), S. 39.

801) Adorno, Th.W., Eingriffe, S. $164 \mathrm{f}$.

802) Molitor, B., aaO. (Anm. 409), S. 85 Anm. 11.

803) Eucken, W. , Grundsätze, S. 255.

804 ) Eucken, W. , Grundsätze, S. 217.

805) Eucken, W., Grundsätze, S. 218.

806) Eucken, W. , Grundsätze, S. 218, 241.

807) Eucken, W., Die Überwindung des Historismus, S. 208. Zu den sprachlichen Variationen dieser Definition vgl. Eucken, W., Grundlagen, S. 52, 167; ders., Grundsätze, S. $373 \mathrm{f}$.; ders., Nationalökonomie - wozu?, S. 55; Böhm, 
F./Großmann-Doerth, H./Eucken, W., Unsere Aufgabe, S. 96. Zu diesen Zusammenhängen auch Runge, U., aaO. (Anm. 237), S. 114f., 118 .

808) Eucken, W., Nationalökonomie - wozu?, S. 56.

809) Weber, W., Der ökonomische Begriff der Wirtschaftsverfassung, in: Wirtschaft und Verfassung in österreich, S. 13 .

810) Kaiser, J.H., Die Parität der Sozialpartner, 1973.

811) Die Parität der Sozialpartner. Zugleich Besprechung von: Joseph H. Kaiser: Die Parität der Sozialpartner, AöR 99 (1974), S. $484 \mathrm{ff}$.

812) Rüthers, B., aao. (Anm. 811), S. 486.

813) Rüthers, B., aao. (Anm. 811), S. 386.

$814)$ So der Titel der Entgegnung von J.H. Kaiser in: AöR 100 (1975), S. $145 \mathrm{ff}$.

815) Kaiser, J.H., aaO. (Anm. 814), S. 146.

816) Kaiser, J.H., aaO. (Anm. 814), S. 146.

817) Kaiser, J.H., aao. (Anm. 814), S. 146.

818) Schmitt, C., Der Hüter der Verfassung, S. 96, 98.

819) Schmitt, C., Der Hüter der Verfassung, S. 97.

820) Schmitt, C., Der Hüter der Verfassung, s. 98.

821) Schmitt, C., Der Hüter der Verfassung, s. 99.

822) Schmitt, C., Der Hüter der Verfassung, s. 101.

823) Schmitt, C., Über die drei Arten des rechtswissenschaftlichen Denkens, S. 7 .

824 ) Schmitt, C., Der Hüter der Verfassung, s. $7 \mathrm{f}$.

825) Schmitt, C., Verfassungslehre, S. 76.

826) Schmitt, C., aao (Anm. 825), S. 4 .

827) Schmitt, C., aao. (Anm. 825), S. 20ff., 75ff.; dazu auch Huber, E.R., Verfassung und Verfassungswirklichkeit bei Carl Schmitt, in: Blätter für Deutsche Philosophie, Bd. $5(1931 / 32)$, S. 306 . 
828) Hensel, A., Staatslehre und Verfassung, Archiv für Sozialwissenschaft und Sozialpolitik, 61. Bd. (1929), S. 186 .

829) Schmitt, C., aao. (Anm. 825), S. 20ff. (23): "Vor jeder Normierung liegt eine grundlegende politische Entscheidung des Trägers der verfassungsgebenden Gewalt".

830) Schmitt, C., aao. (Anm. 825), S. 10.

831) Schmitt, C., aao. (Anm. 825), S. 76.

832) Hofmann, H., Legitimität gegen Legalität, S. 131; dazu auch Schmitt, c., Der Hüter der Verfassung, s. 28 .

833) Die Verfassung ist für $c$. Schmitt demnach keineswegs die "Norm der Normen", das heißt "eine grundgesetzliche Regelung" im Sinne eines einheitlich geschlossenen Systems höchster und letzter Normen, aao. (Anm. 825), S. 28,7 .

834 ) Schmitt, C., aao. (Anm. 825), S. $31 \mathrm{ff}$.

835) Hofmann, H., aaO. (Anm. 832), S. 131.

836) Hensel, A., aao. (Anm. 828), S. 184.

837) Schmitt, C., Der Hüter der Verfassung, S. 28 .

838) Schneider, P., Ausnahmezustand und Norm, S. 266.

839) Eucken, W., Grundlagen, S. 51ff.; ders., Grundsätze, S. 373f.; dazu auch Ehmke, H., aao. (Anm. 736), S. 8. In diesem Zusammenhang ist beachtlich, daß Eucken das von ihm angestrebte "Buch über Wirtschaftsverfassung" nicht mehr in Angriff zu nehmen vermochte und deshalb seine diesbezüglichen Überlegungen ohne eine systematische und zusammenhängende Bearbeitung blieben (vgl. dazu Röpke, W., Blätter der Erinnerung an Walter Eucken, ordo XII (1961), S. 4).

840) Dazu im einzelnen S. $16 \mathrm{ff}$.

841) Eucken, W. , Grundlagen, S. 52; dazu bereits eingehend vorne S. $22 \mathrm{ff}$.

842 ) Eucken, W., Nationalökonomie - wozu?, S. 55; ders., Grundsätze, S. $242 \mathrm{ff}$.; ders., Grundlagen, S. $240 \mathrm{f}$.

843) Eucken, W., Grundlagen, S. 56.

844 ) Eucken, W. , Grundsätze, S. 379.

845) Eucken, W., Grundsätze, s. $372 f$. 
846) Eucken, W., Grundsätze, S. 255.

847) Eucken, W., Grundsätze, S. 372; ders., Grundlagen, S. 239 .

848) Ehmke, H., aaO. (Anm. 736), S. 9; Runge, U., aaO. (Anm. 237), S. 131 .

849) Dazu auch Göldner, D., Integration und Pluralismus im demokratischen Rechtsstaat, S. 9, der im Hinblick auf den "positiven" Verfassungsbegriff Euckens darlegt, daß das "Wesentliche" dieses Begriffs "die Reduzierung der Verfassung auf ihren sinnkern und dessen Projektion in die Vorstufe der Entscheidung" ist.

850) Ehmke, H., aao. (Anm. 736), S. 8f.; Runge, U., aao. (Anm. 237), S. $116 \mathrm{ff}$.

851) Was ist Wirtschaftsrecht?, in: Festschrift für walther Hug, S. 75, 77 .

852) Eucken, W., Grundsätze, S. 380.

853) So der Titel des Beitrages von walter Eucken in den Schriften der Akademie für Deutsches Recht, 1942, S. $29 \mathrm{ff}$.

854) Ottel, F., Kann die Gesetzgebung Wettbewerb schaffen?, in: Beiträge zum Wirtschaftsrecht. Festschrift für Rudolf Isay zu seinem 70. Geburtstag, hrsg. v. E. Reimer, S. 78f.; Scheuner, U., Einführung, in: Die staatlichen Einwirkungen auf die Wirtschaft, S. 25, spricht von der "Vermischung ökonomischer Modellgedanken und rechtlicher Aussagen bei Böhm und Eucken".

855) Eucken, W., Grundsätze, S. 254. Dazu auch Coester, F., Die Rolle des staates in der sozialen Marktwirtschaft, ordo socialis, Jg. 10 (1962), S. 103 (Wettbewerbsordnung als Rechnungs- und Abstimmungsinstrument, das durch einen rechtlichen Rahmen dauernd intakt gehalten werden muß).

856) Ebenso Emmerich, V., Das Wirtschaftsrecht der öffentlichen Unternehmen, S. 101; Ballerstedt, K., aao. (Anm. 512), S. 7; ders., aao. (Anm. 512), S. 39f.; Hart, D., Zur Instrumentalisierung des Wirtschaftsrechts am Beispiel der Wirtschaftsverfassung, ZHR 140 (1976)，S. 33; Ritter, E.-H., aaO. (Anm. 726), S. 1395; Strickrodt, G., Die Idee der Wirtschaftsverfassung als Gestaltungsund Interpretationsprinzip, JZ 1957, S. 361, 363. Differenzierend Kaiser, J.H., Ökonomische ordnungspostulate und juristische Normierung, in: Zur Einheit der Rechts- und Staatswissenschaften, S. 51 (deutlich allerdings daselbst, S. 49: "Aus einem nationalökonomischen Lehrsatz wird ein verbindlicher Rechtssatz") . Zur 
"neoliberalen" Wirtschaftsverfassung als Rechtsverfassung vgl. auch Runge, U., aaO. (Anm. 237), S. $117 \mathrm{f}$. Unsicher aber wohl ablehnend, Weber, W., aao. (Anm. 809), S. 14 f.; a.A. auch Zacher, H.F., Aufgaben einer Theorie der Wirtschaftsverfassung, in: Wirtschaftsordnung und Rechtsordnung, Festschrift zum 70. Geburtstag von F. Böhm, S. 79f.; Liesegang, H.C.F., Die verfassungsrechtliche ordnung der Wirtschaft, s. 4; Behlke, R., Der Neoliberalismus und die Gestaltung der Wirtschaftsverfassung in der Bundesrepublik Deutschland, S. 48; Raiser, L., Wirtschaftsverfassung als Rechtsproblem, in: Die Aufgabe des Privatrechts, S. 29; Christen, H.-P., Die Wirtschaftsverfassung des Interventionismus, S. 215f., geht einerseits davon aus, daß "die der Entscheidung konformen wirtschaftlichen Modellgesetze Anspruch auf rechtliche Geltung" erheben, verweist aber andererseits auf den Umstand, daß die Gesamtentscheidung der "Rechtsqualität" entbehrt.

857) Ehmke, H., aao. (Anm. 736), S. 8 .

858) Eucken, W., Grundsätze, S. 307; kritisch dazu Zacher, H.F., aao. (Anm. 856), S. 75 .

859) Ehmke, H., aao. (Anm. 736), S. 9.

860) Schmitt, C., aao. (Anm. 825), S. $75 f$.

861) Eucken, W. , Grundsätze, S. 223.

862) AaO. (Anm. 809), S. 13, allerdings mit anderer Begründung als hier. Inwieweit sich bei Eucken im übrigen die Vorstellung verfestigt hat, daß die Wirtschaftsverfassung als teilbereichsregelnde Gesamtentscheidung unabhängig von der staatsverfassung zu denken ist, also neben den politischen Grundentscheid über die staatsform zusätzlich die Entscheidung über die ordnung des nationalen Wirtschaftslebens zu treten hat, läßt sich positiv nicht nachweisen. Wenn Eucken allerdings davon spricht, daß "Staatsverfassung" und "Wirtschaftsverfassung" "jeweils in gegenseitiger Abhängigkeit voneinander" bestehen (Grundsätze, S. 183) spricht einiges für ein solches Trennungsdenken; dazu auch Ehmke, H., aao. (Anm. 736), S. $7 \mathrm{ff}$.

863) So aber Scheuner, U., aaO. (Anm. 854), S. 24.

864 ) Röpke, W. , aaO. (Anm. 839), S. 4 .

865) Die Institutionalisierung der Wettbewerbsordnung und damit eines vorrechtlichen sinn- und wirkungszusammenhanges ist grundsätzlich problembehaftet. Die Auffassung, Gegenstand institutioneller Verfassungsgarantien könnten auch gesellschaftliche Sachverhalte sein, ist 
vereinzelt geblieben (so insbes. Klein, F., in: Mangoldt, H.v./Klein, F., Das Bonner Grundgesetz, Vorbem. Bd. 1, S. $84 \mathrm{ff}$.). Demgegenüber wird die Institutionalisierung der Wirtschaftsordnung und damit die Schaffung einer wirtschaftlichen situation établie mit Hilfe des Rechts von der ganz herrschenden Rechtslehre abgelehnt (statt vieler und zusammenfassend Klein, H.H., Die Teilnahme des staates am wirtschaftlichen wettbewerb, S. 113; Abel, G., Die Bedeutung der Lehre von den Einrichtungsgarantien für die Auslegung des Bonner Grundgesetzes, S. 83; Strickrodt, G., aao. (Anm. 856), S. 361), da das Zusammenspiel von rechtlicher und faktischer seite der Institution letztlich nicht transparent werde und der Versuch, diese Unklarheit zu beseitigen, zwangsläufig $z u$ einer Schwächung der Rechtsidee führen müssen, denn naturgemäß beanspruche auch die Kategorie des Faktischen Geltung, wodurch das Rechtsdenken in den $\mathrm{Zwiespalt}$ von rechtlicher und faktischer Wertung komme. Die Verpflichtung auf die Idee des Rechts werde deshalb vernachlässigt und unter Umständen letztlich aufgegeben.

866) Runge, U., aaO. (Anm. 237), S. 124 .

867) Eucken, W., Grundsätze, S. 306.

868) Eucken, W., Grundsätze, S. 250, 304.

869) Eucken, W., Grundsätze, S. 289 und insbesondere S. 255: "Die Hauptsache ist es, den Preismechanismus funktionsfähig zu machen. Jede Wirtschaftspolitik scheitert, der das nicht gelingt. Das ist der strategische Punkt, von dem aus man das Ganze beherrscht und auf den deshalb alle Kräfte zu konzentrieren sind".

870) Eucken, W., Grundsätze, S. 289, 253, 254ff. Die konstituierenden Prinzipien sind im einzelnen: 1. Der Primat der Wirtschaftspolitik - der währungspolitische stabilisator, 2. offene Märkte, 3. Privateigentum, 4. Vertragsfreiheit, 5. Haftung und 6. Konstanz der Wirtschaftspolitik.

871) Eucken, W., Grundsätze, S. 255.

872) Eucken, W., Grundsätze, S. 255, 289.

873) Dazu bereits eingehend Anm. 865.

874) Eucken, W., Grundsätze, S. 290.

875) Eucken, W., Grundsätze, S. 290.

876) Eucken, W., Grundsätze, S. 290. 
877) Greitemann, G., Das Stabilitätsgesetz als Schrittmacher des rechts - und wirtschaftswissenschaftlichen Zusammenwirkens, in: Wirtschaftsprüfer im Dienst der Wirtschaft, Festschrift für Ernst Knorr, S. 271, geht ohne näheren Nachweis davon aus, daß Euckens "konstituierende Prinzipien" den ursprünglich "reinen Rechtsprinzipien" entsprechen.

878) Eucken, W., Grundsätze, S. 270ff., 275ff., 279ff. "Somit ist die Frage, ob zur Verwirklichung der Wettbewerbsordnung Privateigentum an Produktionsmitteln erforderlich ist, $z u$ bejahen (...) Privateigentum gehört $\mathrm{zu}$ den Voraussetzungen der Wettbewerbsordnung" (daselbst, S. 271). Auch die Vertragsfreiheit ist "unentbehrlich", da ohne die Möglichkeit des Abschlusses freier, individueller Verträge, die die Umsetzung der Wirtschaftspläne der einzelnen Haushalte und Betriebe darstellen, "eine Lenkung des alltäglichen Wirtschaftsprozesses durch vollständige Konkurrenz nicht möglich" wäre (daselbst, S. 278). Darüber hinaus ist die Haftung als konstituierendes Prinzip erforderlich, um den Leistungswettbewerb funktionsfähig zu machen und durch den Entzug von Haftungsbeschränkungen die "Lenkungsmechanik der vollständigen Konkurrenz" unbehindert in Kraft $z u$ setzen (daselbst, S. $280 \mathrm{f}$.).

879) Dazu eingehend vorne, S. $100 \mathrm{ff}$.

880) Eucken, W., Grundsätze, S. 27.

881) Eucken, W., Grundsätze, S. 178.

882) Dazu vorne, S. $69 \mathrm{ff}$.

883) Eucken, W., Grundsätze, S. 179.

884 ) Eucken, W., Grundsätze, S. 179.

885) Eucken, W., Grundsätze, S. 369.

886) Eucken, W., Grundsätze, S. 369.

887) Eucken, W., Grundsätze, S. 371.

888) "Die Funktion auch dieses Rechtsinstitutes hängt von der Wirtschaftsordnung ab; von der Wirtschaftsordnung, die in concreto gegeben ist oder - wenn es sich um die Wirtschaftspolitik handelt - von der ordnung, die verwirklicht werden soll. Es ist also eine wirtschaftsverfassungsrechtliche Frage, die früher nicht gestellt wurde, der aber jetzt nicht mehr ausgewichen werden kann" (Eucken, W., Grundsätze, S. 280). Dazu auch Runge, U., aao. (Anm. 237), S. 125, 130, 148f., 155, der die instrumentale Funktion und die technizistische Ausrichtung des Rechts im Denken des Neoliberalismus 
beim Vollzug einer "ihre Verbindlichkeit in der Natur der Sache findenden Gesamtordnung" betont.

889) Böhm, F./Großmann-Doerth, H./Eucken, W., Unsere Aufgabe, S. 96 .

890) Eucken, W., Grundsätze, S. 274, 279.

891) Eucken, W., Grundsätze, S. 273. Konkret bedeutet eine solche inhaltliche Verknüpfung von Rechtssatz und wirtschaftlichem Funktionsprinzip für Privateigentum bei vollständiger Konkurrenz

"a) Verfügungsmacht und Verfügungsfreiheit im Dienste der Volkswirtschaft

b) Ohnmacht, die Verfügungsmacht und Freiheit der anderen Eigentümer zu Lasten der Gesamtheit einzuschränken" (Eucken, w., Grundsätze, S. 274).

Dann besteht $z$ wischen den Privateigentümern der Betriebe ein "Gleichgewicht wirtschaftlicher Machtverteilung" (daselbst, S. 274). Nur in dieser kontrollierten Ausübung im Rahmen vollständiger Konkurrenz vermag Eucken privates Eigentum überhaupt zu akzeptieren, da nur in diesem Rahmen seine volkswirtschaftlich effiziente Verwendung unter Vermeidung des Ausübungsmißbrauchs gewährleistet werden kann. Fehlt diese Kontrolle, "muß die Verfügungsmacht über das Privateigentum beschränkt werden" (daselbst, s. 275). Insoweit stimmt Eucken K. Marx zu. Allerdings zog K. Marx aus der grundsätzlich richtigen Erkenntnis nach Ansicht Euckens die falschen Schlüsse. Nicht die Beseitigung des Privateigentums überhaupt und die Herstellung kollektiven Eigentums an den Produktionsmitteln bringt die Lösung, sondern nur die Verwirklichung der Wettbewerbsordnung (Eucken, W., Grundsätze, S. $134 \mathrm{ff}$., 184f., 190). Vergleichbares gilt für die Vertragsfreiheit, die ausschließlich im Rahmen der Wettbewerbsordnung zu dem Zweck gewährt ist, die wirtschaftlichen Dispositionen Privater auf dem Markt durch die freie Wahl des Vertragspartners, die Bestimmung der Modalitäten des Leistungsaustausches und das freie Aushandeln der Vertragsbedingungen umzusetzen. Die privatautonome Gestaltung von Rechtsverhältnissen kann mit anderen worten nur durch Handlungen bewirkt werden, die durch die institutionalisierte ordnung, das "Grundprinzip", sanktioniert sind. Die Ausübungsgrenzen der Vertragsfreiheit finden sich demgemäß dort, wo sie dazu benutzt werden, wirtschaftliche Machtkörper zu bilden und damit die vertragsfreiheit anderer zu beschränken oder zu beseitigen (Eucken, W., Grundsätze, S. $278 \mathrm{f}$. ).

892) Eucken, W. , Grundsätze, S. 275, 279, $280 f$. 
893) Deren Gefahren Eucken selbst erkannt hat, die er aber im Dienste der Wettbewerbsordnung in Kauf nehmen $\mathrm{zu}$ müssen glaubte, vgl. ders., Grundsätze, S. 369.

894 ) Eucken, W., Grundsätze, S. 290.

895) Schmölders, G., Die Weiterbildung des Wirtschaftsrechts, Zeitschrift für die gesamte staatswissenschaft, Bd. 101 (1941), S. $64 \mathrm{ff}$.

896) Eucken, W., Grundlagen, S. 272 Anm. 75.

897) Schmölders, G., aao. (Anm. 895), S. 70, 72f., 80f.; Ritter, E.-H., aaO. (Anm. 726), S. 1295 spricht von einem "lediglich auf volkswirtschaftliche Effizienz ausgerichtete(n) Regelsystem"; ähnlich Weber, W., aao. (Anm. 809), S. 19. Nach Hollmann, H.H., Rechtsstaatliche Kontrolle der Globalsteuerung, S. 103 erscheint das Recht in diesem Kontext "weitgehend als in rechtlicher Form praktizierte Nationalökonomie".

898) Behlke, R., aao. (Anm. 856), S. 96.

899) Dazu auch Hollmann, H.H., aaO. (Anm. 897), S. 102.

900) Prägnant Peter, H., Besprechung von Walter Eucken, Grundsätze der Wirtschaftspolitik, Finanzarchiv 13 (1951/52), S. 730: bei Eucken werde "das Rechtsprinzip inhaltlich durch Funktionsbedingungen des natürlichen gesellschaftlichen Geschehens begründet". Ähnlich Kübler, F., aao. (Anm. 796), S. 37.

901) Runge, U., aao. (Anm. 237), S. 156, 137 .

902) Lukes, R., Zum Verständnis des Wettbewerbs und des Marktes in der Denkkategorie des Rechts, in: Wirtschaftsordnung und Rechtsordnung, Festschrift zum 70. Geburtstag von F. Böhm, S. $214 \mathrm{f}$.

903) Raiser, L., aao. (Anm. 856), S. 29ff.; zum nachfolgenden auch Runge, U., aao. (Anm. 237), S. 172 und Christen, H.-P., aao. (Anm. 856), S. $180 \mathrm{ff}$.

904) Raiser, L., aao. (Anm. 856), S. 31.

905) Raiser, L., aao. (Anm. 856), S. 31.

906) Raiser, L., aao. (Anm. 856), S. 32 .

907) Alle Zitate Raiser, L., aao. (Anm. 856), S. 32.

908) Christen, H.-P., aaO. (Anm. 856), S. 181.

909) Eucken, W., Grundsätze, S. 371. 
910) Böhm, F., aaO. (Anm. 5), S. XLI.

911) Welter, E., aao. (Anm. 2), S. 297.

912) Eucken-Erdsiek, E., aao. (Anm. 777), S. VI.

913) Eucken-Erdsiek, E., aao. (Anm. 777), S. V.

914) Eucken, W., Religion - Wirtschaft - Staat, s. 88.

915) Dux, G., aao. (Anm. 290), S. 17.

916) Eucken, W., Die Überwindung des Historismus, S. 204, 198 .

917) Eucken, W., Grundsätze, S. 372 .

918) Eucken, W., unter dem Pseudonym Kurt Heinrich, aao. (Anm. 11), S. 16 .

919) Eucken, W. , Grundsätze, S. 372.

920) Eucken, W., Grundsätze, s. $372 f$.

921) Eucken, W., Grundsätze, s. 371.

922 ) Eucken, W. , Grundsätze, S. 380.

923) Dazu auch Hesse, G., Staatsaufgaben, S. 230.

924 ) Dux, G., aao. (Anm. 290), S. 17.

925) Hesse, G., Staatsaufgaben, S. 230.

926) Eucken, W., Grundsätze, S. 379. "Vorgegebene Ordnungen schreiben grundsätzlich vor, was erkannt und gemacht werden darf, belegen insofern die wirklichkeit gleichsam mit einem Bann" (Ryffel, H., Pluralismus und staat, in: Staatsorganisation und staatsfunktionen, Festschrift für K. Eichenberger, S. 61).

927) Hartwich, H.-H., aaO. (Anm 457), S. 333.

928) Runge, U., aao. (Anm. 237), S. 163.

929) Eucken, W., Grundsätze, S. 357.

930) Simmel, G. zit. nach Beckerath, E. V., aao. (Anm. 457), S. 295 .

931) Hesse, G., Staatsaufgaben, S. 245, 243; zu dieser Geschichtsauffassung vgl. auch Riese, H., aaO. (Anm. 296), S. 25f.; Runge, U., aao. (Anm. 237), S. 163f.; Meyer-Dohm, P., aao. (Anm. 392), S. 149 . 
932) Hesse, G. Staatsaufgaben, S. 245.

933) Miksch, L., Die sittliche Bedeutung der inneren Koordination, Ordo III (1950), S. 40.

934 ) Nawroth, E.E., aaO. (Anm. 32), S. 304.

935) Miksch, L., Wirtschaftsmoral und Wirtschaftsordnung, Wirtschaftsverwaltung, Heft 14 (1948), S. 4.

936) Eucken, W., aao. (Anm. 11), S. 16.

937) Dazu im einzelnen Müller, G., Die Grundlegung der westdeutschen wirtschaftsordnung im Frankfurter Wirtschaftsrat 1947 bis 1949, passim.

938) Isensee, J., aao. (Anm. 694), S. 137; dazu auch Ehmke, H., aao. (Anm. 736), S. 3 ("An economy in search of a state").

939) Zum Streit um die Wirtschaftsverfassung des Grundgesetzes eingehend Frotscher, W., Grundfälle zum Wirtschaftsverfassungs- und wirtschaftsverwaltungsrecht, Juristische Schulung 1981, S. 513f.; Tettinger, P.J., Neuer streit um die "Wirtschaftsverfassung"?, Der Betriebsberater 1977, S. 1617ff.; Badura, P., Grundprobleme des Wirtschaftsverfassungsrechts, Juristische Schulung 1976, S. 205ff.; Hablitzel, H., Wirtschaftsverfassung und Grundgesetz, Bayerische Verwaltungsblätter 1981, S. 65ff.; Ballerstedt, K., aaO. (Anm. 512), S. $1 \mathrm{ff}$.

940) Ryffel, H., aaO. (Anm. 926), S. 60.

941) Simson, W. V., Die Souveränität im rechtlichen Verständnis der Gegenwart, S. 17, 264.

942 ) Ryffel, H., aao. (Anm. 926), S. 60f., 66f.; Hollerbach, A., Ideologie und Verfassung, in: Ideologie und Recht, hrsg. v. W. Maihofer, S. 50f. (51): "Die Verfassung ist nicht ein Codex, nach dem ein system dogmatischer Wahrheiten über diese Welt verwaltet wird, und erst recht ist sie nicht 'dux ad coelestia'".

943) Hollerbach, A., aaO. (Anm. 942), S. 51.

944 ) Grundlegend BVerfGE 2,1 (12f.); 5, 85ff. (140).

945) Hesse, G., Staatsaufgaben, S. 242 f.; rigider Runge, U., aao. (Anm. 237), S. 166, der die "Tragik des ordoliberalismus" darin zu erkennen glaubt, daß "er auf der Suche nach einer ordnung, in der menschliche Freiheit und würde ihre optimalen Bedingungen finden, unmerklich und in bestem Glauben einem politisch illiberalen und potentiell totalitären system das Wort redet". 
946) Greiffenhagen, N., Das Dilemma des Konservatismus, in: Schumann, H.G. (Hrsg.), Konservativismus, S. 171.

947) Eucken, W., Grundsätze, s. 371.

948) Eucken, W., Grundsätze, s. 371.

949) Eucken-Erdsiek, E., aao. (Anm. 777), S. VI. 
Literaturverzeichnis

Abel, Gunther, Die Bedeutung der Lehre von den Einrichtungsgarantien für die Auslegung des Bonner Grundgesetzes, Berlin 1964.

Adorno, Theodor W., Eingriffe, 5. Auflage, Frankfurt/M. 1963.

Albert, Hans, Der logische Charakter der theoretischen Nationalökonomie. Zur Diskussion um die exakte Wirtschaftstheorie, Jahrbücher für Nationalökonomie und Statistik, Band 171 (1959), S. 1ff.

Albert, Hans, Modell-Platonismus. Der neoklassische Stil des ökonomischen Denkens in kritischer Beleuchtung, Sozialwissenschaft und Gesellschaftsgestaltung, Festschrift für Gerhard Weisser, hrsg. von Friedrich Karrenberg und Hans Albert, Berlin 1963, S. 45ff., wieder abgedruckt und zitiert nach: Albert, Hans, Marktsoziologie und Entscheidungslogik. ökonomische Probleme in soziologischer Perspektive, Neuwied am Rhein 1967, S. 331ff. (Modell-Platonismus).

Albert, Hans, Ökonomische Ideologie und politische Theorie. Das ökonomische Argument in der ordnungspolitischen Debatte, 2. Auflage, Göttingen 1972 (Ökonomische Theorie und Ideologie).

Albert, Hans, Plädoyer für kritischen Rationalismus, München 1971.

Albert, Hans, Probleme der Theoriebildung. Entwicklung, struktur und Anwendung sozialwissenschaftlicher Theorien, in: Theorie und Realität. Ausgewählte Aufsätze zur Wissenschaftslehre der Sozialwissenschaften, hrsg. von Hans Albert, Tübingen 1964 , s. $3 \mathrm{ff}$.

Albert, Hans, Theorie und Praxis. Max Weber und das Problem der Wertfreiheit und der Rationalität, in: Die Philosophie und die Wissenschaften. Simon Moser zum 65. Geburtstag, Meisenheim am Glan 1966, wieder abgedruckt und zitiert nach: Albert, Hans/Topitsch, Ernst (Hrsg.), Werturteilsstreit, 2., um eine Bibliographie erweiterte Auflage, Darmstadt 1979, S. 200ff. (Wege der Forschung Band 175).

Albert, Hans, Theorie und Prognose in den Sozialwissenschaften, Schweizerische Zeitschrift für Volkswirtschaft und Statistik, 93. Jahrgang (1957), S. 60ff.

Albert, Hans, Traktat über kritische Vernunft, 4. unveränderte Auflage, Tübingen 1980. 
Albert, Hans, Das Werturteilsproblem im Lichte der logischen Analyse, Zeitschrift für die gesamte staatswissenschaft, Band 112 (1956), S. $410 \mathrm{ff}$.

Amonn, Alfred, Nationalökonomie und wirtschaftliche Wirklichkeit, Jahrbücher für Nationalökonomie und Statistik, Band 153 (1941), S. 1ff. und $129 \mathrm{ff}$.

Backhaus, Jürgen, Öffentliche Unternehmen. Zum Wirtschaftsrecht, den Funktionen und Rechtsformen öffentlicher Unternehmen, Frankfurt/M. 1977.

Badura, Peter, Grundprobleme des Wirtschaftsverfassungsrechts, Juristische Schulung 1976, S. $205 \mathrm{ff}$.

Badura, Peter, Das Verwaltungsmonopol, Berlin 1963.

Ballerstedt, Rurt, Das Verhältnis von Recht und Wirtschaft als Aufgabe der Forschung und der Gestaltung, in: Gewerkschaft-Wirtschaft-Gesellschaft, Beiträge zu wirtschaftlichen und sozialen Gegenwartsfragen, Band 1 (1963), S. $29 \mathrm{ff}$.

Ballerstedt, Rurt, Wirtschaftsverfassungsrecht, in: Die Grundrechte, Handbuch der Theorie und Praxis der Grundrechte, hrsg. von Karl August Bettermann/Hans Carl Nipperdey/ Ulrich Scheuner, 3. Band, 1. Halbband, Berlin 1958.

Becker, Helmut Paul, Die soziale Frage im Neoliberalismus. Analyse und Kritik, Heidelberg/Löwen 1965 (Die soziale Frage im Neoliberalismus).

Beckerath, Erwin v., Walter Euckens Grundsätze der Wirtschaftspolitik, ordo V (1953), S. $289 \mathrm{ff}$.

Behlke, Reinhard, Der Neoliberalismus und die Gestaltung der Wirtschaftsverfassung in der Bundesrepublik Deutschland, Berlin 1961.

Bermbach, Udo/Nuscheler, Franz (Hrsg.), Sozialistischer Pluralismus. Texte zur Theorie und Praxis sozialistischer Gesellschaften, Hamburg 1973 (Sozialistischer Pluralismus).

Biemel, walter, Husserls Encyclopaedia-Britannica-Artikel und Heideggers Anmerkungen dazu, Tijdschrift voor Philosophie 12 (1950), S. $246 \mathrm{ff}$., wieder abgedruckt und zitiert nach: Noack, Hermann (Hrsg.), Husserl, Darmstadt 1973, S. $282 \mathrm{ff}$. (Wege der Forschung Band 40).

Binder, Julius, Der autoritäre staat, Logos, Internationale Zeitschrift für Philosophie der Kultur, 22 (1933), S. $126 \mathrm{ff}$.

Blum, Reinhard, Soziale Marktwirtschaft. Wirtschaftspolitik zwischen Neoliberalismus und Ordoliberalismus, Tübingen 1969 (Soziale Marktwirtschaft). 
Blum, Reinhard, Der Wettbewerb im wirtschaftspolitischen Konzept, Zeitschrift für die gesamte staatswissenschaft, Band 121 (1965), S. 60ff.

Bocheñski, Joseph K., Die zeitgenössischen Denkmethoden, 8 . Auflage, Bern 1980 .

Böckenförde, Ernst-Wolfgang, Die Bedeutung der Unterscheidung von staat und Gesellschaft im demokratischen Sozialstaat der Gegenwart, in: Rechtsfragen der Gegenwart, Festgabe für Wolfgang Hefermehl zum 65. Geburtstag, stuttgart/ Berlin/Köln/ Mainz 1972, S. 11ff., wieder abgedruckt und zitiert nach: Böckenförde, Ernst-Wolfgang (Hrsg.), Staat und Gesellschaft, Darmstadt 1976, s. 395ff. (Wege der Forschung Band 471).

Böhm Franz, Freiburger Schule und Nationalsozialismus, Frankfurter Allgemeine Zeitung vom 24. Mai 1955, Nr. 119, S. 7 .

Böhm, Franz, Die Idee des ordo im Denken Walter Euckens, Ordo III (1950), S. XV ff.

Böhm, Franz, Eine Kampfansage an ordnungstheorie und ordnungspolitik. Zu einem Aufsatz in Kyklos, Ordo XXIV (1973), S. $11 \mathrm{ff}$.

Böhm, Franz/Großmann-Doerth, Hans/Eucken, walter, Unsere Aufgabe, 1937, wieder abgedruckt und zitiert nach: Lutz, Friedrich, Politische Überzeugung und nationalökonomische Theorie, Züricher Vorträge, Tübingen 1971, S. $87 \mathrm{ff}$. (Unsere Aufgabe).

Brinkmann, Carl, Grundlagen der Nationalökonomie. Bemerkungen zu Walter Euckens Buch, Finanzarchiv, N.F. Band 7 $(1940)$, S. $353 \mathrm{ff}$.

Büchi, willy, Die Sozial- und Wirtschaftsphilosophie des Neoliberalismus, Die neue ordnung, Jahrgang 15 (1961), S. $58 \mathrm{ff}$.

Bull, Hans-Peter, Die Staatsaufgaben nach dem Grundgesetz, 2. Auflage, Kronberg/T. 1977.

Burmeister, Joachim, Vom staatsbegrenzenden Grundrechtsverständnis zum Grundrechtsschutz für staatsfunktionen, Frankfurt 1971 .

Christen, Heinz-Peter, Die Wirtschaftsverfassung des Interventionismus, Zürich/St. Gallen 1970.

Coester, Franz, Die Rolle des staates in der sozialen Marktwirtschaft, ordo socialis, Jahrgang 10 (1962), S. $100 \mathrm{ff}$. 
Coing, Helmut, Die obersten Grundsätze des Rechts. Ein Versuch zur Neugründung des Naturrechts, Heidelberg 1947 (Die obersten Grundsätze des Rechts).

Cordes, Werner, Das ordnungsbild der Gesellschaft und seine Bedeutung für die Wirtschaftsverfassung in der Lehre des Kreises um das ordo-Jahrbuch und in der heutigen katholischen Sozialethik, Diss. München 1954.

Dahrendorf, Ralf, Gesellschaft und Demokratie in Deutschland, München 1965.

Diemer, Alwin, Edmund Husserl. Versuch einer systematischen Darstellung seiner Phänomenologie, 2. Auflage, Meisenheim/ Glan 1965 (Edmund Husserl).

Doerge, Friedrich-wilhelm, Menschenbild und Institution in der Idee des Wirtschaftsliberalismus bei Adam Smith, L. v. Mises, W. Eucken und F.A. V. Hayek, Hamburger Jahrbuch für Wirtschafts- und Gesellschaftspolitik, Festausgabe für Eduard Heimann, 4. Jahrgang (1959), S. $82 \mathrm{ff}$.

Dubislav, walter, Zur Unbegründbarkeit von Forderungssätzen, Theoria, Tidskrift för filosofi och psyklogi, 1937, S. $330 \mathrm{ff}$., wieder abgedruckt und zitiert nach: Albert, Hans/ Topitsch, Ernst (Hrsg.), Werturteilsstreit, 2., um eine Bibliographie erweiterte Auflage, Darmstadt 1979, S. $439 \mathrm{ff}$. (Wege der Forschung Band 175).

Dürr, Ernst-Wolfram, Wesen und Ziele des ordo-Liberalismus, Winterthur 1954 .

Dux, Günter, Strukturwandel der Legitimation, Freiburg (Breisgau)/München 1976.

Ehmke, Horst, Wirtschaft und Verfassung. Die Verfassungsrechtsprechung des Supreme Court zur Wirtschaftsregulierung, Karlsruhe 1961 (Wirtschaft und Verfassung).

Eichenberger, Rurt, Leistungsstaat und Demokratie, Basler Universitätsreden, Heft 62 , Basel 1969.

Emmerich, Volker, Das Wirtschaftsrecht der öffentlichen Unternehmen, Bad Homburg v.d.H. 1969.

Esser, Josef, Möglichkeiten und Grenzen des dogmatischen Denkens im modernen Zivilrecht, Archiv für die civilistische Praxis 172 (1972), S. $97 f f$.

Eucken, walter, Denken - Warum?, Die Tatwelt, Jahrgang 9 (1933), S. $148 \mathrm{ff}$. 
Eucken, walter, Deutschland vor und nach der Währungsreform, in: Vollbeschäftigung, Inflation und Planwirtschaft, hrsg. von Albert Hunold, Erlenbach/Zürich 1951, S. $134 \mathrm{ff}$.

Eucken, walter, Grundlagen der Nationalökonomie, 1. Auflage, Jena 1940, 6. unveränderte Auflage, Berlin 1950 (Grundlagen).

Eucken, walter, Grundsätze der Wirtschaftspolitik, Bern/ Tübingen 1952, 5. unveränderte Auflage, Tübingen 1975 (Grundsätze) .

Eucken, Walter, Kapitaltheoretische Untersuchungen, 1. Auflage 1934, 2. Auflage, ergänzt um drei Aufsätze: 1. Vom Hauptproblem der Kapitaltheorie (zuerst erschienen in: Jahrbücher für Nationalökonomie und Statistik, Band 145 (1937), S. $533 \mathrm{ff.}), 2$. Der Wirtschaftsproze $\beta$ als zeitlicher Hergang (zuerst erschienen in: Jahrbücher für Nationalökonomie und Statistik, Band 152 (1940), s. 113ff.), 3. Die zeitliche Lenkung des Wirtschaftsprozesses und der Aufbau der Wirtschaftsordnung (zuerst erschienen in: Jahrbücher für Nationalökonomie und Statistik, Band 159 (1944), S. 161ff.), Tübingen/Zürich 1954 .

Eucken, walter, Die Leistung der deutschen Volkswirtschaftslehre, Jahrbücher für Nationalökonomie und Statistik, Band 146 (1937), S. 225ff.

Eucken, walter, Nationalökonomie - wozu?, Leipzig 1938, 2. und 3. Auflage, Bad Godesberg 1947.

Eucken, walter, on the Theory of the Centrally Administered Economy. An Analysis of the German Experiment, Economia, New Series, Volume XV, Numbers 57-60 (1948), Part I p. 79, Part II p. 173 .

Eucken, walter, Das ordnungspolitische Problem, ordo I $(1948)$, S. $56 f f$.

Eucken, walter, Religion-Wirtschaft-staat, Die Tatwelt, Jahrgang 8 (1932), S. $82 \mathrm{ff}$.

Eucken, walter, Die soziale Frage, in: Synopsis, Festgabe für Alfred Weber, hrsg. von Edgar Salin, Heidelberg 1948, S. $113 \mathrm{ff}$.

Eucken, walter, staatliche strukturwandlungen und die Krisis des Kapitalismus, Weltwirtschaftliches Archiv, Band 36 (1932 II), S. $297 \mathrm{ff}$.

Eucken, walter, Die Überwindung des Historismus, Schmollers Jahrbuch für Gesetzgebung, Verwaltung und Volkswirtschaft, 62. Jahrgang (1938), S. 191ff. 
Eucken, walter, Unser Zeitalter der Mißerfolge. 5 Vorträge zur Wirtschaftspolitik, Tübingen 1951.

Eucken, Walter, Wettbewerb als Grundprinzip der Wirtschaftsverfassung, in: Schmölders, Günter (Hrsg.), Der Wettbewerb als Mittel volkswirtschaftlicher Leistungssteigerung und Leistungsauslese, Schriften der Akademie für Deutsches Recht, Gruppe Wirtschaftswissenschaften, Heft 6, Berlin 1942 , S. $29 \mathrm{ff}$.

Eucken, walter, Wettbewerb, Monopol und Unternehmer, Bad Nauheim 1953.

Eucken, Walter, Die Wettbewerbsordnung und ihre Verwirklichung, Ordo II (1949), S. Iff.

Eucken, walter, Wissenschaft im stile Schmollers, Weltwirtschaftiches Archiv, Band 52 (1940 II), S. $468 \mathrm{ff}$.

Eucken, walter unter dem Pseudonym Dr. Kurt Heinrich, Die geistige Krise und der Kapitalismus, Die Tatwelt, Jahrgang 2 (1926), S. $13 \mathrm{ff}$.

Eucken-Erdsiek, Edith, Chaos und Stagnation, ordo I (1948), S. $3 \mathrm{ff}$.

Ferber, Christian v., Der Werturteilsstreit 1909/1959. Versuch einer wissenschaftsgeschichtlichen Interpretation, Kölner Zeitschrift für Soziologie und Sozialpsychologie, 11. Jahrgang (1959), S. $21 \mathrm{ff}$.

Fischer, Erich, Wirtschaftsordnung und Wirtschaftsstil. Eine Untersuchung des Euckenschen und Spiethoffschen Versuches zur Lösung des Theorie-Geschichte-Problems in der Nationalökonomie, Diss. Frankfurt/Main 1952.

Forsthoff, Ernst, Der staat der Industriegesellschaft. Dargestellt am Beispiel der Bundesrepublik Deutschland, München 1971 (Der Staat der Industriegesellschaft).

Frank, Paul, Das Dilemma des Neo-Liberalismus, Die neue ordnung, 3. Jahrgang (1949), S. $169 \mathrm{ff}$.

Freyer, Hans, Das soziale Ganze und die Freiheit des einzelnen unter den Bedingungen des industriellen Zeitalters, Historische Zeitschrift, Band 183 (1957), S. 97ff., wieder abgedruckt und zitiert nach: Böckenförde, Ernst-Wolfgang (Hrsg.), Staat und Gesellschaft, Darmstadt 1976, S. 199ff. (Wege der Forschung Band 471).

Friedrich, Carl J., Das Denken des Neoliberalismus, in: Theorie und Politik der Verfassungsordnung. Ausgewählte Aufsätze. Zusammenstellung und redigierte Bearbeitung von Erwin Paul, Heidelberg 1963, S. $205 \mathrm{ff}$. 
Frotscher, Werner, Grundfälle zum Wirtschaftsverfassungsund Wirtschaftsverwaltungsrecht, Juristische Schulung 1981, S. $507 f f$.

Frotscher, werner, Regierung als Rechtsbegriff. Verfassungsrechtliche und staatstheoretische Grundlagen unter Berücksichtigung der englischen und französischen Verfassungsentwicklung, Berlin 1975 (Regierung als Rechtsbegriff).

Glahe, Werner, Theoretische Grundlagen neoliberaler Wirtschaftspolitik und ökonomischer Macht, in: Andreae, clemensAugust/Glahe, Werner, Das Gegengewichtsprinzip in der Wirtschaftsordnung, Band 1: Wirtschaftliche Macht und Wettbewerb, Köln 1966, S. $73 \mathrm{ff}$.

Göldner, Detlev, Integration und Pluralismus im demokratischen Rechtsstaat. Bemerkungen zur Doppelfunktion von Einheit und Gegensatz, Tübingen 1977 (Integration und Pluralismus im demokratischen Rechtsstaat).

Greiffenhagen, Martin, Das Dilemma des Konservatismus, Gesellschaft in Geschichte und Gegenwart. Festschrift für Friedrich Lenz, hrsg. von S. Wendt, Berlin 1961, wieder abgedruckt und zitiert nach: Schumann, Hans-Gerd (Hrsg.), Konservativismus, Köln 1964 , S. $156 \mathrm{ff}$.

Greitemann, Günter, Das Stabilitätsgesetz als Schrittmacher des rechts - und wirtschaftswissenschaftlichen zusammenwirkens, in: Wirtschaftsprüfer im Dienst der Wirtschaft, Festschrift für Ernst Knorr, hrsg. von Erwin Pougin und Klaus v. Wysocki, Düsseldorf 1968, S. $257 \mathrm{ff}$.

Gundlach, Gustav, Eucken's Grundlegen der Nationalökonomie, Gregorianum Vol. XXXIV (1953), S. 680ff.

Hablitzel, Hans, Wirtschaftsverfassung und Grundgesetz, Bayrische Verwaltungsblätter 1981, s. $65 \mathrm{ff}$.

Häberle, Peter, Zur gegenwärtigen Diskussion um das Problem der Souveränität, Archiv des öffentlichen Rechts 92 (1967), S. $259 \mathrm{ff}$.

Hättich, Manfred, Nationalbewußtsein und Staatsbewußtse in in der pluralistischen Gesellschaft, 3. Auflage, Mainz 1966.

Hättich, Manfred, Das Toleranzproblem in der Demokratie, Civitas, Jahrbuch für die Christliche Gesellschaftsordnung 4 (1965), S. 15ff., wieder abgedruckt und zitiert nach: Matz, Ulrich (Hrsg.), Grundprobleme der Demokratie, Darmstadt 1973, S. $397 \mathrm{ff}$. (Wege der Forschung Band 141). 
Haller, Heinz, Typus und Gesetz in der Nationalökonomie. Versuch zur Klärung einiger Methodenfragen der Wirtschaftswissenschaft, stuttgart/Köln 1950 (Typus und Gesetz in der Nationalökonomie).

Hart, Dieter, Zur Instrumentalisierung des Wirtschaftsrechts am Beispiel der Wirtschaftsverfassung, Zeitschrift für das gesamte Handels- und Konkursrecht, Band 140 (1976), S. $31 \mathrm{ff}$.

Hartwich, Hans-Hermann, ORDO-Modell und Konfliktgesellschaft, Gegenwartskunde 15 (1966), S. $325 \mathrm{ff}$.

Hedtkamp, Günter, Wirtschaftssysteme. Theorie und Vergleich, München 1974 (Wirtschaftssysteme).

Heitmüller, W., Wirtschaftstheorie im Umbau, Wirtschaftsdienst, N.F. XXVII Jahrgang, 2. Halbjahr 1942, S. $967 \mathrm{ff}$.

Hellwig, Hans, Wir brauchen kein Kartellgesetz, Monatsblätter für freiheitliche Wirtschaftspolitik, Band 1, Heft 1, Mai 1955, S. 16ff.

Hensel, Albert, Staatslehre und Verfassung. Eine Besprechung von Rudolf Smend: Verfassung und Verfassungsrecht und Carl Schmitt: Verfassungslehre, Archiv für Sozialwissenschaft und Sozialpolitik, 61. Band (1929), S. 168ff. (Staatslehre und Verfassung).

Hensel, K. Paul, ordnung der Wirtschaft als wissenschaftliches Problem, ordo XV/XVI (1965), S. $3 \mathrm{ff}$.

Hensel, R. Paul, Ordnungspolitische Betrachtungen zur katholischen Soziallehre, Ordo II (1949), S. $229 \mathrm{ff}$.

Herder-Dorneich, Philipp, Wirtschaftsordnungen. Pluralistische und dynamische Ordnungspolitik, Berlin 1974 (Wirtschaftsordnungen).

Herrmann, walther, Grundsätze der Wirtschaftspolitik. Kritische Bemerkungen zu Walter Euckens nachgelassenem Werke, Zeitschrift für handelswissenschaftliche Forschung, 4. Jahrgang (1952), S. $420 \mathrm{ff}$.

Hesse, Günter, Staatsaufgaben. Zur Theorie der Legitimation und Identifikation staatlicher Aufgaben, Baden-Baden 1979 (Staatsaufgaben).

Hofmann, Hasso, Legitimität gegen Legalität. Der Weg der politischen Philosophie Carl Schmitts, Neuwied/Berlin 1964 (Legitimität gegen Legalität).

Hollerbach, Alexander, Ideologie und Verfassung, in: Ideologie und Recht, hrsg. von Werner Maihofer, Frankfurt/M. 1969, S. $37 \mathrm{ff}$. 
Hollmann, Hermann H., Rechtsstaatliche Kontrolle der Globalsteuerung. Möglichkeiten und Grenzen einer normativen Kontrolle globalsteuernder Wirtschaftspolitik am Beispiel des Stabilitätsgesetzes, Baden-Baden 1980 (Rechtsstaatliche Kontrolle der Globalsteuerung).

Honigsheim, Paul, Die Gründung der Deutschen Gesellschaft für Soziologie und ihre geistesgeschichtlichen Zusammenhänge, Kölner Zeitschrift für Soziologie und Sozialpsychologie, 11. Jahrgang (1959), S. $3 \mathrm{ff}$.

Huber, Ernst Rudolf, Verfassung und Verfassungswirklichkeit bei Carl Schmitt, Blätter für Deutsche Philosophie, Band 5 $(1931 / 32)$, S. 302ff.

Hütten, Karl Wilhelm, Die "große Antinomie der Nationalökonomie" und der positive Vorschlag Walter Euckens zu ihrer Überwindung, Diss. Heidelberg 1949.

Husserl, Edmund, Erfahrung und Urteil. Untersuchungen $z u$ einer Genealogie der Logik, redigiert und hrsg. von Ludwig Landgrebe, 4. Auflage, Hamburg 1972 (Erfahrung und Urteil).

Husserl, Edmund, Die Idee der Phänomenologie, Fünf Vorlesungen, herausgegeben und eingeleitet von walter Biemel, Den Haag 1950.

Husserl, Edmund, Ideen zu einer reinen Phänomenologie und phänomenologischen Philosophie, Halle a.d. Saale 1913, 4. Auflage als unveränderter Nachdruck der 2. Auflage 1922, Tübingen 1980 .

Husserl, Edmund, Logische Untersuchungen, unveränderter Nachdruck der 2. umgearbeiteten Auflage 1913, Band 1.2, Teil 1.2 , Tübingen 1968 .

Ilau, Hans, Intervention und demokratischer Kompromiß in der Wirtschaftspolitik, in: Wirtschaftsfragen der freien Welt. Festschrift zum 60. Geburtstag von Ludwig Erhard, hrsg. von Erwin v. Beckerath, Fritz W. Meyer, Alfred Müller-Armack, Frankfurt/M. 1957, S. $109 \mathrm{ff}$.

Isensee, Josef, Subsidiaritätsprinzip und Verfassungsrecht. Eine Studie über das Regulativ des Verhältnisses von staat und Gesellschaft, Berlin 1968 (Subsidiaritätsprinzip).

Janssen, Paul, Edmund Husserl, Einführung in seine Phänomenologie, Freiburg i. Br./München 1976 (Edmund Husserl).

Jessen, Jens, Besprechung: Walter Eucken, Die Grundlagen der Nationalökonomie, Jena 1940, Schmollers Jahrbuch für Gesetzgebung, Verwaltung und Volkswirtschaft, 64. Jahrgang (1940 I), S. 359ff. 
Jochimsen, Reimut/Rnobel, Helmut, Zum Gegenstand und zur Methodik der Nationalökonomie, in: dies. (Hrsg.), Gegenstand und Methoden der Nationalökonomie, Köln 1971, S. $11 \mathrm{ff.}$

Jöhr, walter Adolf, Walter Euckens Lebenswerk, Kyklos, Vol. IV (1950), S. $257 \mathrm{ff}$.

Jöhr, Walter Adolf/singer, Hans w., Die Nationalökonomie im Dienste der Wirtschaftspolitik, Göttingen 1957.

Rade, Gerhard, Die Verdächtigung der exakten wirtschaftstheorie. Kritische Bemerkungen zum Aufsatz von F. Ottel, Jahrbücher für Nationalökonomie und Statistik, Band 169 (1958), S. 1ff.

Rafka, Gustav E., Rechtsordnung und Wirtschaftsordnung, Wirtschaftspolitische Blätter (Bundeskammer der gewerblichen Wirtschaft), Heft 2, Beilage, 1965, S. $13 \mathrm{ff}$.

Kaiser, Joseph H., Ökonomische Ordnungspostulate und juristische Normen, in: Zur Einheit der Rechts- und staatswissenschaften. Ringvorlesung der Rechts- und staatswissenschaftlichen Fakultät der Albert-Ludwigs-Universität Freiburg/Br., Wintersemester 1966/67, Freiburger rechts- und staatswissenschaftliche Abhandlungen Band 27, Karlsruhe 1967 , S. $49 \mathrm{ff}$.

Kaiser, Joseph H., Die Parität der Sozialpartner, Karlsruhe 1973 .

Kaiser, Joseph H., Polemik, Ignoranz und Malice. Bernd Rüthers attackiert die widmung meiner "Parität der Sozialpartner" und schreibt aus eigenen Werken, Archiv des öffentlichen Rechts 100 (1975), S. $145 \mathrm{ff}$.

Kempski, Jürgen v., Zur Logik der ordnungsbegriffe, besonders in den Sozialwissenschaften, studium Generale, 5. Jahrgang (1952), S. $205 \mathrm{ff}$.

Rlein, F., in: Mangoldt, Hermann v./Klein, Friedrich, Das Bonner Grundgesetz, Band 1, 2. Auflage, Berlin/Frankfurt 1957.

Rlein, Hans н., Die Teilnahme des staates am wirtschaftlichen Wettbewerb, stuttgart/Berlin/Köln/Mainz 1968.

Kloten, Norbert, Der staat in der Sozialen Marktwirtschaft, Tübingen 1986.

Rlüber, Franz, wirtschaftstheorie und wirtschaftsethik im Denken Walter Euckens, Jahrbuch des Instituts für Christliche Sozialwissenschaften der Westfälischen Wilhelms-Universität Münster, $1966 / 67$, S. $583 \mathrm{ff}$. 
Rohl, Helmut, Pluralismuskritik in der Bundesrepublik, Aus Politik und Zeitgeschichte, Beilage zur Wochenzeitung "Das Parlament", B $12 / 70$, S. 1ff.

Kraft, Victor, Erkenntnislehre, Wien 1960.

Krelle, Wilhelm, Zur Problematik der Grundlagen, in: Planung ohne Planwirtschaft, hrsg. von Alfred Plitzko, Basel/Tübingen 1964, S. $62 \mathrm{ff}$.

Kriele, Martin, Einführung in die Staatslehre, 2. Auflage, Opladen 1981.

Krockow, Christian v., Zur Analyse autoritärer Parlamentarismuskritik, Aus Politik und Zeitgeschichte, Beilage zur Wochenzeitung "Das Parlament", B 49/69, S. $39 \mathrm{ff}$.

Krüger, Herbert, Allgemeine staatslehre, 2. unveränderte Auflage, Stuttgart 1966.

Kübler, Friedrich, Über die praktischen Aufgaben einer zeitgemäßen Privatrechtstheorie, Karlsruhe 1975.

Kuhn, Thomas 8., Die Struktur wissenschaftlicher Revolutionen, 2. revidierte und um das Postskriptum von 1969 ergänzte Auflage, 5. Auflage, Frankfurt/Main 1981.

Larenz, Rarl, Methodenlehre der Rechtswissenschaft, 5. Auflage, Berlin usw. 1983.

Laum, Bernhard, Entgegnung zu Euckens Aufsatz, Schmollers Jahrbuch für Gesetzgebung, Verwaltung und Volkswirtschaft, 62. Jahrgang (1938 I), S. $215 \mathrm{ff}$.

Lenel, Hans otto, Walter Euckens ordnungspolitische Konzeption, die wirtschaftspolitische Lehre in der Bundesrepublik und die Wettbewerbstheorie von heute, Ordo XXVI (1975), S. $22 \mathrm{ff}$.

Lenk, Rurt, Das Werturteilsproblem bei Max Weber, Zeitschrift für die gesamte staatswissenschaft, Band 120 (1964), S. $56 \mathrm{ff}$.

Levinas, Emmanuel, Über die "Ideen" Edmund Husserls, Revue Philosophique de la France et de L'Etranger CVII (1929), S. $230 \mathrm{ff}$., wieder abgedruckt und zitiert nach: Noack, Hermann (Hrsg.), Husserl, Darmstadt 1973, S. $87 \mathrm{ff}$. (Wege der Forschung Band 40).

Liesegang, Helmuth C.F., Die verfassungsrechtliche ordnung der Wirtschaft. Zentralfragen und strukturprinzipien unter besonderer Berücksichtigung grundrechtstheoretischer überlegungen, Hamburg 1977 (Die verfassungsrechtliche ordnung der Wirtschaft). 
Luhmann, Niklas, Grundrechte als Institution, 2. Auflage, Berlin 1974 .

Lukes, Rudolf, Zum Verständnis des Wettbewerbs und des Marktes in der Denkkategorie des Rechts, in: Wirtschaftsordnung und Rechtsordnung, Festschrift zum 70. Geburtstag von Franz Böhm, Karlsruhe 1965, S. $199 \mathrm{ff}$.

Lutz, Friedrich A., Bemerkungen zum Monopolproblem, ordo VIII (1956), S. $19 \mathrm{ff}$.

Machlup, Fritz, Idealtypus, wirklichkeit und Konstruktion, ordo XII (1961), S. $21 \mathrm{ff}$.

Marchal, Jutta, Demokratie und Marktwirtschaft in der Theorie des Neoliberalismus, Diss. Gießen 1970.

Mathias, wolfgang, Wirtschaftswissenschaftliche Theorie- und Modellbildung aus der Sicht der modernen Wissenschaftstheorie, Diss. Köln 1971.

Megay, Edward, Anti-Pluralist Liberalism: The German Neoliberals, Political Science Quarterly, Vol. LXXXV (1970), S. $422 \mathrm{ff}$.

Meinhold, wilhelm, Wandlungen des Verhältnisses von Staat und Wirtschaft in ihrer Bedeutung für das wirtschaftspolitische System, in: Methoden und Probleme der Wirtschaftspolitik, Gedächtnisschrift für Hans-Jürgen Seraphim, hrsg. von Hans Ohm, Berlin 1964, S. 3ff.

Meyer-Dohm, Peter, Wirtschaftsordnungsmodelle und Wirklichkeit, Hamburger Jahrbuch für Wirtschafts- und Gesellschaftspolitik, 10. Jahrgang (1965), S. $141 \mathrm{ff}$.

Miksch, Leonhard, Die sittliche Bedeutung der inneren Koordination, ordo III (1950), S. $29 \mathrm{ff}$.

Miksch, Leonhard, Wettbewerb als Aufgabe. Die Grundsätze einer Wettbewerbsordnung, 2. Auflage, Bad Godesberg 1947 (Wettbewerb als Aufgabe).

Miksch, Leonhard, Wirtschaftsmoral und Wirtschaftsordnung, Wirtschaftsverwaltung, Heft 14 (1948), s. 2 ff.

Möller, Hero, Liberalismus, Jahrbücher für Nationalökonomie und Statistik, Band 162 (1950), S. $214 \mathrm{ff}$.

Molitor, Bruno, Theorie der Wirtschaftspolitik und Werturteil, Hamburger Jahrbuch für Wirtschafts- und Gesellschaftspolitik, 8. Jahrgang (1963), S. 81ff. 
Morgenstern, oskar, Logistik und Sozialwissenschaften, in: Logik der Sozialwissenschaften, hrsg. von Ernst Topitsch, 8 . Auflage, Köln/Berlin 1972, S. $315 \mathrm{ff}$.

Moritz, Rlaus, Das Argument von der Wirtschaftsverfassung. Die Verwendung nationalökonomischer Kategorien im juristischen Denken, Diss. Frankfurt 1972.

Muihlenfeld, Hans, Politik ohne Wunschbilder. Die konservative Aufgabe unserer Zeit, München 1952.

Müller, Georg, Die Grundlegung der westdeutschen Wirtschaftsordnung im Frankfurter Wirtschaftsrat 1947 bis 1949, Frankfurt/M. 1982 .

Müller, Johann Baptist, Liberalismus und Demokratie. Studien zum Verhältnis von Politik und Wirtschaft im Liberalismus, stuttgart 1978 (Liberalismus und Demokratie).

Müller-Armack, Alfred, Diagnose unserer Gegenwart. Zur Bestimmung unseres geistesgeschichtlichen standorts, Gütersloh 1949 .

Natorp, Paul, Husserls "Ideen $\mathrm{zu}$ einer reinen Phänomenologie", Logos, Internationale Zeitschrift für Philosophie der Kultur, 7 (1917/1918), S. $224 \mathrm{ff}$., wieder abgedruckt und zitiert nach: Noack, Hermann (Hrsg.), Husserl, Darmstadt 1973, S. $36 \mathrm{ff}$. (Wege der Forschung Band 40).

Nawroth, Egon E., Die Sozial- und Wirtschaftsphilosophie des Neoliberalismus, Heidelberg/Löwen 1961.

Neuhauser, Gertrud, Grundfragen wirtschaftswissenschaftlicher Methodik, in: Enzyklopädie der geisteswissenschaftlichen Arbeitsmethoden, 8. Lieferung: Methoden der Sozialwissenschaften, München/Wien 1967, S. $95 \mathrm{ff}$.

Neuhauser, Gertrud, Modell und Typus in der Nationalökonomie, Jahrbuch für Sozialwissenschaft, Band 15 (1964), S. $160 \mathrm{ff}$.

Neuhauser, Gertrud, Die wirtschaftspolitische Konzeption als Problem der theoretischen Wirtschaftspolitik, in: Seraphim, Hans-Jürgen (Hrsg.), Zur Grundlegung wirtschaftspolitischer Konzeptionen, Schriften des Vereins für socialpolitik, N.F. Band 18, Berlin 1960, S. $23 \mathrm{ff}$.

ottel, Fritz, Kann die Gesetzgebung Wettbewerb schaffen?, in: Beiträge zum wirtschaftsrecht. Festschrift für Rudolf Isay zu seinem 70. Geburtstag, hrsg. von Eduard Reimer, Köln/Berlin 1956, S. $71 \mathrm{ff}$.

Peter, Hans, Besprechung von Walter Eucken, Grundsätze der Wirtschaftspolitik, Finanzarchiv 13 (1951/52), S. $729 \mathrm{ff}$. 
Peter, Hans, Freiheit der Wirtschaft. Kritik des Neoliberalismus, Köln 1953 (Freiheit der Wirtschaft).

Peter, Hans, Die neue Methodologie Walter Euckens. Bemerkungen zu dem Buch: "Die Grundlagen der Nationalökonomie", Finanzarchiv, N.F. Band 8 (1941), S. $158 \mathrm{ff}$.

Popper, Karl R., Logik der Forschung, 7., durch 6 Anhänge verbesserte Auflage, Tübingen 1982.

Preiser, Erich, walter Eucken in memoriam, Jahrbücher für Nationalökonomie und Statistik, Band 162 (1950), S. $241 \mathrm{ff}$.

Radbruch, Gustav, Rechtsphilosophie, 4. Auflage, stuttgart 1950 .

Raiser, Ludwig, Wirtschaftsverfassung als Rechtsproblem, Festschrift für Julius von Gierke zu seinem goldenen Doktorjubiläum, Berlin 1950, S. 101ff., wieder abgedruckt und zitiert nach: Ders., Die Aufgabe des Privatrechts. Aufsätze zum Privat- und Wirtschaftsrecht aus drei Jahrzehnten, Kronberg/T. 1977 (Die Aufgabe des Privatrechts).

Reigrotzki, Erich, Exakte Wirtschaftstheorie und wirklichkeit, Göttingen 1948 .

Richter, Rudolf, Methodologie aus der sicht des wirtschaftstheoretikers, in: Jochimsen, Reimut/Knobel, Helmut (Hrsg.), Gegenstand und Methoden der Nationalökonomie, Köln 1971, S. $188 \mathrm{ff}$.

Riese, Hajo, ordnungsidee und ordnungspolitik. Kritik einer wirtschaftspolitischen Konzeption, Kyklos, Vol. XXV (1972), S. $24 \mathrm{ff}$.

Ritschl, Hans, Wandlungen im objekt und in den Methoden der Volkswirtschaftslehre, Schmollers Jahrbuch für Gesetzgebung, Verwaltung und Volkswirtschaft, 67. Jahrgang (1943 II), S. $387 \mathrm{ff}$.

Ritschl, Hans, Wirtschaftsordnung und Wirtschaftspolitik, Weltwirtschaftliches Archiv, Band 65 (1950 II), S. $218 \mathrm{ff}$.

Ritter, Ernst-Hasso, Der Wandel der Wirtschaftspolitik und die wirtschaftsverfassungsrechtliche Bedeutung des Gesetzes gegen Wettbewerbsbeschränkungen, Der Betriebsberater 1968, S. $1393 \mathrm{ff}$.

Röpke, wilhelm, Blätter der Erinnerung an Walter Eucken, Ordo XII (1961), S. 3ff. 
Ross, Alf, Kritik der sogenannten praktischen Erkenntnis. Zugleich Prolegomena zu einer Kritik der Rechtswissenschaft, Kopenhagen/Leipzig 1933 (Kritik der sogenannten praktischen Erkenntnis).

Rücker, Joachim, Grenzen neoliberaler Strategie im Nord-SüdKonflikt, Freiburg 1982.

Rüstow, Alexander, Wirtschaftsethische Probleme der sozialen Marktwirtschaft, in: Boarman, Patrick, Der Christ und die Soziale Marktwirtschaft, stuttgart/Köln 1955, S. $53 \mathrm{ff}$.

Rüstow, Alexander, $\mathrm{Zu}$ den Grundlagen der Wirtschaftswissenschaft, Revue de la Faculté des Sciences Economique de 1'Université d'Istanbul, 2. Jahrgang (1940-41), S. 105ff.

Rüthers, Bernd, Die Parität der Sozialpartner. Zugleich Besprechung von: Joseph H. Kaiser: Die Parität der Sozialpartner, Freiburger rechts- und staatswissenschaftliche Abhandlungen, Karlsruhe 1973, Archiv des öffentlichen Rechts $99(1974)$, S. $484 \mathrm{ff}$.

Ruffner, Armin, Zum Normproblem in der Wirtschaftswissenschaft. Betriebswirtschaftliche Forschungsergebnisse, hrsg. von Erich Kosiol, Band 48, Berlin 1970.

Runge, Uwe, Antinomien des Freiheitsbegriffs im Rechtsbild des Ordoliberalismus, Tübingen 1971.

Ruppin, Hans, Allwissenschaft und ökonomische Spezialtheorie? Ein aktuelles Problem, Jahrbücher für Nationalökonomie und statistik, Band 156 (1942), S. $97 \mathrm{ff}$.

Ryffel, Hans, Pluralismus und Staat, in: Staatsorganisation und staatsfunktionen, Festschrift für Kurt Eichenberger zum 60. Geburtstag, hrsg. von Georg Müller u.a., Basel/Frankfurt 1982 , S. 59ff.

Balin, Edgar, walter Eucken in memoriam, Kyklos, Vol. IV (1950), S. $1 \mathrm{ff}$.

sauermann, Heinz, Zur Problematik der Sozialordnung, in: Wirtschaftsfragen der freien Welt. Zum 60. Geburtstag von Ludwig Erhard, hrsg. von Erwin v. Beckerath, Fritz W. Meyer, Alfred Müller-Armack, Frankfurt/M. 1957, S. $88 \mathrm{ff}$.

schachtschnabel, Hans-Georg, Wirtschaftspolitische Konzeption, 3. Auflage, stuttgart 1976.

Bchaeder, Reinhard, Gemeinwohl und öffentliche Interessen im Recht der globalen Wirtschafts- und Finanzplanung, in: Wohl der Allgemeinheit und öffentliche Interessen, Schriftenreihe der Hochschule Speyer, Band 39 (1968), S. $92 \mathrm{ff}$.

schaeder, Reinhard, Vergleich der Gesamtsysteme von Wirt- 
schafts- und Staatsordnung, Jahrbuch für Sozialwissenschaft 19 (1968), S. $287 \mathrm{ff}$.

schäfer, Max, Die logische struktur des Idealtypus bei Max Weber, Walter Eucken und Wilhelm Vershofen, Diss. Nürnberg 1951.

8cheuner, Ulrich, Einführung, in: Die staatlichen Einwirkungen auf die Wirtschaft. Wirtschaftsrechtliche Aufsätze 19461970, hrsg. und eingeleitet von Ulrich Scheuner, Frankfurt/M. 1971, s. $9 \mathrm{ff}$.

schiller, Karl, Neuere Entwicklungen in der Theorie der Wirtschaftspolitik, Tübingen 1958.

schluep, walter R., Was ist Wirtschaftsrecht, in: Festschrift für Walther Hug, Professor Dr. jur., S.J.D. Harvard, zum 70. Geburtstag, hrsg. von Riccardo L. Jagmetti und Walter R. Schluep, Bern 1968, S. $25 \mathrm{ff}$.

schmidt, walter, Die Entscheidungsfreiheit des einzelnen zwischen staatlicher Herrschaft und gesellschaftlicher Macht, Archiv des öffentlichen Rechts 101 (1976), S. $24 \mathrm{ff}$.

schmitt, Carl, Der Begriff des Politischen, Text von 1932 mit einem Vorwort und drei Corollarien, Berlin 1963.

schmitt, carl, Gesunde wirtschaft im starken staat, in: Mitteilungen des Vereins zur Wahrung der gemeinsamen wirtschaftlichen Interessen im Rheinland und Westfalen, $\mathrm{Nr}$. $1 / 1932$, S. $13 \mathrm{ff}$.

schmitt, carl, Der Hüter der Verfassung, Tübingen 1931.

schmitt, Carl, Politische Theologie. Vier Kapitel von der Souveränität, 2. Auflage, München/Leipzig 1934 (Politische Theologie).

8chmitt, carl, Die Tyrannei der Werte, in: Säkularisation und Utopie, Ebracher studien, Ernst Forsthoff zum 65. Geburtstag, stuttgart/Berlin/Köln/Mainz 1967, s. $37 \mathrm{ff}$.

schmitt, Carl, Über die drei Arten des rechtswissenschaftlichen Denkens, Hamburg 1934.

schmitt, Carl, Verfassungslehre, 5. unveränderte Auflage, Berlin 1970 .

8chmölders, Günter, Einleitung, in: Das Selbstverständnis der Verbände, Schriften des Vereins für Socialpolitik, hrsg. von Andreas Predöhl und Georg Weippert, N.F. Band 38 (1965), S. 1ff. 
schmölders, Günter, Die Weiterbildung des Wirtschaftsrechts. Das Wirtschaftsrecht als angewandte wirtschaftswissenschaft, Zeitschrift für die gesamte staatswissenschaft, Band 101 (1941), S. $64 \mathrm{ff}$.

schneider, Peter, Ausnahmezustand und Norm. Eine studie zur Rechtslehre von Carl Schmitt, stuttgart 1957 (Ausnahmezustand und Norm).

8cholz, Rupert, Koalitionsfreiheit als Verfassungsproblem, Münchner Universitätsschriften Band 18, Berlin 1971.

8chütz, Alfred, Der sinnhafte Aufbau der sozialen Welt. Eine Einleitung in die verstehende Soziologie, 2. Auflage, Wien 1960.

8eidel, Bruno, Industrialismus und Kapitalismus. Sozialethische und institutionelle Wandlungen einer Wirtschaftsform, Meisenheim/Glan 1955 (Industrialismus und Kapitalismus).

simson, Werner v., Das demokratische Prinzip im Grundgesetz, Veröffentlichungen der Vereinigung der Deutschen Staatsrechtslehrer, Band 29 (1971), S. Iff.

simson, Werner v., Die Souveränität im rechtlichen Verständnis der Gegenwart, Berlin 1965.

simson, Werner V., Zu F.A. v. Hayeks verfassungsrechtlichen Ideen, Der Staat 18 (1979), S. $403 \mathrm{ff}$.

8mend, Rudolf, Verfassung und Verfassungsrecht (1928), in: Staatsrechtliche Abhandlungen und andere Aufsätze, 2. Auflage, Berlin 1968, S. $119 \mathrm{ff}$.

8piethoff, Arthur, Anschauliche und reine volkswirtschaftliche Theorie und ihr Verhältnis zueinander, in: Synopsis, Festgabe für Alfred Weber, hrsg. von Edgar Salin, Heidelberg 1948 , S. $567 \mathrm{ff}$.

stackelberg, Heinrich Freiherr v., Die Grundlagen der Nationalökonomie. Bemerkungen zum gleichnamigen Buch von Walter Eucken, Weltwirtschaftliches Archiv, Band 51 (1940 I), S. $245 f f$.

stahlmann, Gerhard, Die Verwirklichung des sozialen Rechtsstaates als Voraussetzung der individuellen Freiheit, Diss. Göttingen 1973 .

stavenhagen, Gerhard, Geschichte der wirtschaftstheorie, 4. Auflage, Göttingen 1969.

8tern, Rlaus, Das Staatsrecht der Bundesrepublik Deutschland, Band 1, 2. Auflage, München 1984 (Staatsrecht I). 
stern, Klaus, Die Verbindung von Verfassungsidee und Grundrechtsidee zur modernen Verfassung, in: Staatsorganisation und staatsfunktionen im Wandel, Festschrift für Kurt Eichenberger zum 60. Geburtstag, hrsg. von Georg Müller u.a., Basel 1982, S. $197 \mathrm{ff}$.

strauss, Leo, Die Unterscheidung zwischen Tatsachen und Werten, aus: Naturrecht und Geschichte, stuttgart 1953, teilweise wieder abgedruckt und zitiert nach: Albert, Hans/ Topitsch, Ernst (Hrsg.), Werturteilsstreit, 2., um eine Bibliographie erweiterte Auflage, Darmstadt 1979, s. $73 \mathrm{ff}$. (Wege der Forschung Band 175).

streissler, Erich, Macht und Freiheit in der sicht des Neoliberalismus, in: Macht und ökonomisches Gesetz, Schriften des Vereins für Socialpolitik, hrsg. von Hans K. Schneider und Christian Watrin, N.F. Band 74/II (1973), S. $1391 \mathrm{ff}$.

strickrodt, Georg, Die Idee der Wirtschaftsverfassung als Gestaltungs- und Integrationsprinzip, Juristenzeitung 1957, S. $361 \mathrm{ff}$.

strubl, Gerhard, Die staatsauffassung des Neoliberalismus. Dargestellt am Staatsdenken von Walter Eucken, Wilhelm Röpke und Alexander Rüstow, Diss. Tübingen 1954 (Maschinenschrift).

Tettinger, Peter J., Neuer streit um die "Wirtschaftsverfassung"?, Der Betriebsberater 1977, S. $1617 \mathrm{ff}$.

Tichy, Geiserich E., Theoretische Grundlagen der politischen ökonomie. Beiträge zur ganzheitlichen Wirtschafts- und Gesellschaftslehre, Berlin 1970 .

Tinbergen, Jan, Wirtschaftspolitik, 2. unveränderte Auflage, Freiburg i.Br. 1972 .

Veit, otto, Geschichte und Erfahrungswissen. Aussprache zu "Wirtschaftsalltag und Wirtschaftsgeschichte" von Prof. Dr. Dr. Willy Hellpach, Heidelberg, in Tatwelt III 1940, Seite 109, Die Tatwelt, Jahrgang 16 (1940), S. 155ff. (Geschichte und Erfahrungswissen).

Veit, otto, ordo und ordnung. Versuch einer Synthese, ordo $\mathrm{V}$ (1953), S. 3ff.

vleugels, Wilhelm, Volkswirtschaftslehre als Lehre von der geschichtlichen wirklichkeit der wirtschaft. $\mathrm{zu}$ Walter Euckens neuem Werk "Die Grundlagen der Nationalökonomie", Jahrbücher für Nationalökonomie und statistik, Band 152 $(1940)$, S. $497 \mathrm{ff}$.

Weber, Max, Gesammelte Aufsätze zur Wissenschaftslehre, hrsg. von Johannes Winckelmann, 6., erneut durchgesehene Auflage, Tübingen 1985 (Wissenschaftslehre). 
Weber, Max, Die "Objektivität" sozialwissenschaftlicher und sozialpolitischer Erkenntnis, Archiv für Sozialwissenschaft und Sozialpolitik, Band XIX (1904), S. $22 \mathrm{ff}$.

Weber, Max, Die Produktivität der Volkswirtschaft, Debatte, in: Schriften des Vereins für Socialpolitik, Band 132 (1910), S. 580ff.

Weber, Wilhelm, Der ökonomische Begriff der Wirtschaftsverfassung, in: Wirtschaft und Verfassung in österreich, Dr. Franz Korinek zum 65. Geburtstag, Wien/Freiburg/Basel 1972, S. $11 \mathrm{ff}$.

Weber, Wilhelm/Topitsch, Ernst, Das Wertfreiheitsproblem seit Max Weber, in: Jochimsen, Reimut/Knobel, Helmut (Hrsg.), Gegenstand und Methoden der Nationalökonomie, Köln 1971 , S. $133 \mathrm{ff}$.

Weddigen, walter, Das Werturteil in der politischen Wirtschaftswissenschaft, Jahrbücher für Nationalökonomie und Statistik, Band 153 (1941), S. $263 \mathrm{ff}$.

weippert, Georg, Walter Euckens Grundlagen der Nationalökonomie, Zeitschrift für die gesamte Staatswissenschaft, Band 102 (1942), S. 1ff. und S. 271ff.

Weisser, Gerhard, Zur Erkenntniskritik der Urteile. Über den Wert sozialer Gebilde und Prozesse, Kölner Zeitschrift für Soziologie und Sozialpsychologie, Band 6 (1953), S. 16ff., wieder abgedruckt und zitiert nach: Albert, Hans/Topitsch, Ernst (Hrsg.), Werturteilsstreit, 2, um eine Bibliographie erweiterte Auflage, Darmstadt 1979, S. 125ff. (Wege der Forschung Band 175).

Welter, Erich, Walter Eucken (1891-1950), Geschichte der Volkswirtschaftslehre, hrsg. von Antonio Montaner, Köln/ Berlin 1967, S. $296 \mathrm{ff}$.

Werner, Josua, Die Verbände in Wirtschaft und Politik, Zürich/stuttgart 1959.

Werner, Josua, Die Wirtschaftsverbände in der Marktwirtschaft, Zürich/St. Gallen 1957.

Werner, Josua, Wohlstand, Freiheit und Gerechtigkeit: ihre Verwirklichung als Problem der Wirtschaftspolitik, Veröffentlichungen der Handels-Hochschule St. Gallen, Zürich/st. Gallen 1951 (Wohlstand).

willgerodt, Hans, Warum Staatsplanung in der Marktwirtschaft?, Ordo XVII (1966), S. $153 \mathrm{ff}$.

Woll, Arthur, Allgemeine Volkswirtschaftslehre, 8. Auflage, München 1984 . 
Wulff, Manfred, Die neoliberale Wirtschaftsordnung. Versuch einer dynamischen Analyse der Konzeption und der Realität, Tübingen 1976 (Die neoliberale Wirtschaftsordnung).

zacher, Hans F., Aufgaben einer Theorie der Wirtschaftsverfassung, in: Wirtschaftsordnung und Rechtsordnung, Festschrift zum 70. Geburtstag von Franz Böhm, Karlsruhe 1970, S. $63 \mathrm{ff}$.

ziegler, Heinz 0., Autoritärer oder totaler staat?, Tübingen 1932 .

zippelius, Reinhold, Allgemeine staatslehre, 9. Auflage, München 1985.

Zippelius, Reinhold, Machtkontrolle durch strukturelle vielfalt und Funktionsteilung, in: Staatsorganisation und staatsfunktionen, Festschrift für Kurt Eichenberger zum 60. Geburtstag, hrsg. von Georg Müller u.a., Basel 1982, S. $147 \mathrm{ff}$. 


\section{HOHENHEIMER VOLKSWIRTSCHAFTLICHE SCHRIFTEN}

Band 1 Walter Deffaa: Anonymisierte Befragungen mit zufallsverschlüsselten Antworten. Die Randomized-Response-Technik (RRT). Methodische Grundlagen, Modelle und Anwendungen. 1982.

Band 2 Thomas Michael Baum: Staatsverschuldung und Stabilisierungspolitik in der Demokratie. Zur neoinstitutionalistischen Kritik der keynesianischen Fiskalpolitik. 1982.

Band 3 Klaus Schröter: Die wettbewerbspolitische Behandlung der leitungsgebundenen Energiewirtschaft. Dargestellt am Beispiel der Fernwärmewirtschaft der Bundesrepublik Deutschland. 1986.

Band 4 Hugo Mann: Theorie und Politik der Steuerreform in der Demokratie. 1987.

Band 5 Max Christoph Wewel: Intervallarithmetische Dependenzanalyse in der Ökonometrie. Ein konjekturaler Ansatz. 1987.

Band 6 Heinrich Pascher: Die U.S.-amerikanische Deregulation Policy im Luftverkehrs- und Bankenbereich. 1987.

Band 7 Harald Lob: Die Entwicklung der französischen Wettbewerbspolitik bis zur Verordnung Nr. 86-1243 vom 01. Dezember 1986. Eine exemplarische Untersuchung der Erfassung der Behinderungsstrategie auf der Grundlage des Konzepts eines wirksamen Wettbewerbs. 1988.

Band 8 Ulrich Kirschner: Die Erfassung der Nachfragemacht von Handelsunternehmen. Eine Analyse der ökonomischen Beurteilungskriterien und der wettbewerbsrechtlichen Instrumente im Bereich der Verhaltenskontrolle.1988.

Band 9 Friedhelm Herb: Marktwirtschaftliche Innovationspolitik. 1988.

Band 10 Claus Schnabel: Zur ökonomischen Analyse der Gewerkschaften in der Bundesrepublik Deutschland. Theoretische und empirische Untersuchungen von Mitgliederentwicklung, Verhalten und Einfluß auf wirtschaftliche Größen. 1989.

Band 11 Jan B. Rittaler: Industrial Concentration and the Chicago School of Antitrust Analysis. A Critical Evaluation on the Basis of Effective Competition. 1989.

Band 12 Thomas Mărtz: Interessengruppen und Gruppeninteressen in der Demokratie. Zur Theorie des Rent-Seeking. 1990.

Band 13 Andreas Maurer: Statistische Verfahren zur Ermittlung von oligopolistischen Strukturen. 1990.

Band 14 Peter Mendler: Zur okonomischen und politisch-institutionellen Analyse öffentlicher Kredithilfen. 1992.

Band 15 Heinrich J. Engelke: Die Interpretation der Rundfunkfreiheit des Grundgesetzes: Eine Analyse aus okonomischer Sicht. 1992.

Band 16 Thomas Fischer: Staat, Recht und Verfassung im Denken von Walter Eucken. Zu den staats- und rechtstheoretischen Grundlagen einer wirtschaftsordnungspolitischen Konzeption. 1993. 